Welding of Vanadium, Tantalum, 304L and 21-6-9 Stainless Steels, and Titanium Alloys at Lawrence Livermore National Laboratory using a Fiber Delivered 2.2 kW Diode Pumped CW Nd:YAG Laser

T.A. Palmer, J.W. Elmer, R. Pong, M.D. Gauthier June 19, 2006 
This document was prepared as an account of work sponsored by an agency of the United States Government. Neither the United States Government nor the University of California nor any of their employees, makes any warranty, express or implied, or assumes any legal liability or responsibility for the accuracy, completeness, or usefulness of any information, apparatus, product, or process disclosed, or represents that its use would not infringe privately owned rights. Reference herein to any specific commercial product, process, or service by trade name, trademark, manufacturer, or otherwise, does not necessarily constitute or imply its endorsement, recommendation, or favoring by the United States Government or the University of California. The views and opinions of authors expressed herein do not necessarily state or reflect those of the United States Government or the University of California, and shall not be used for advertising or product endorsement purposes.

This work was performed under the auspices of the U.S. Department of Energy by University of California, Lawrence Livermore National Laboratory under Contract W-7405-Eng-48. 
UCRL-TR-222245

\title{
Welding of Vanadium, Tantalum, 304L and 21-6-9 Stainless Steels, and Titanium Alloys at Lawrence Livermore National Laboratory using a Fiber Delivered 2.2 kW Diode Pumped CW Nd:YAG Laser
}

\author{
T.A. Palmer, J.W. Elmer, R. Pong, and M.D. Gauthier
}

\section{Executive Summary}

This report summarizes the results of a series of laser welds made between 2003 and 2005 at Lawrence Livermore National Laboratory (LLNL). The results are a compilation of several, previously unpublished, internal LLNL reports covering the laser welding of vanadium, tantalum, 304L stainless steel, 21-6-9 (Nitronic 40) steel, and Ti-6Al-4V. All the welds were made using a Rofin Sinar DY-022 diode pumped continuous wave Nd:YAG laser. Welds are made at sharp focus on each material at various power levels and travel speeds in order to provide a baseline characterization of the performance of the laser welder. These power levels are based on measurements of the output power of the laser system, as measured by a power meter placed at the end of the optics train. Based on these measurements, it appears that the system displays a loss of approximately $10 \%$ as the beam passes through the fiber optic cable and laser optics. Since the beam is delivered to the fixed laser optics through a fiber optic cable, the effects of fiber diameter are also briefly investigated. Because the system utilizes 1:1 focusing optics, the laser spot size at sharp focus generally corresponds to the diameter of the fiber with which the laser is delivered. Differences in the resulting weld penetration in the different materials system are prevalent, with the welds produced on the Nitronic 40 material displaying the highest depths $(>5 \mathrm{~mm})$ and minimal porosity. A Primes focusing diagnostic has also been installed on this laser system and used to characterize the size and power density distribution of the beams as a function of both power and focus position. Further work is planned in which this focusing diagnostic will be used to better understand the effects of changes in beam properties on the resulting weld dimensions in these and other materials systems. 


\section{TABLE OF CONTENTS}

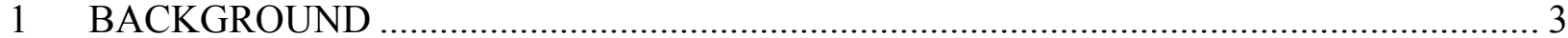

2 EXPERIMENTAL PROCEDURES OVERVIEW …...................................................... 3

$2.1 \quad$ Measurement of Laser Power Output ....................................................................... 3

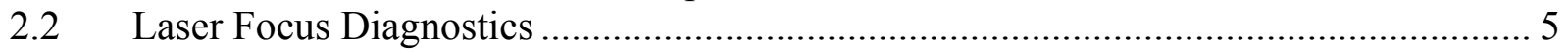

2.2.1 Description and Operation of Focus Monitor ............................................. 5

2.2.2 Characterization of Laser System ............................................................... 7

$2.3 \quad$ Laser Welding Experiments............................................................................... 10

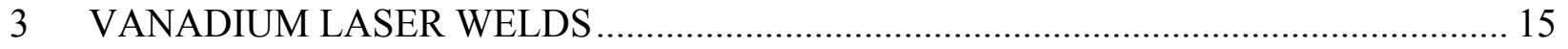

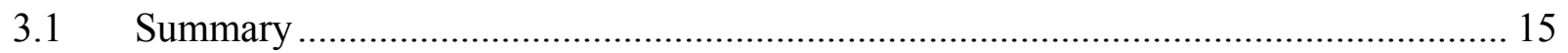

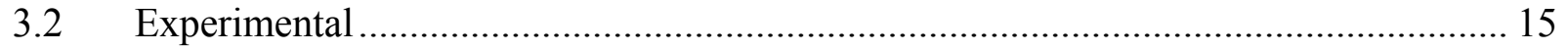

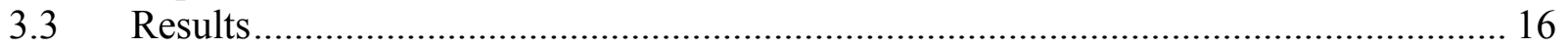

3.3.1 Effects of Variations in Power Input .............................................................. 16

3.3.2 Effects of Energy Input per Unit Length of Weld .......................................... 24

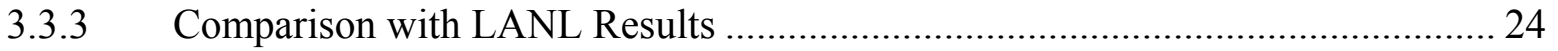

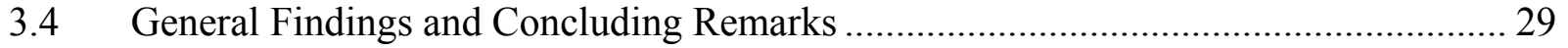

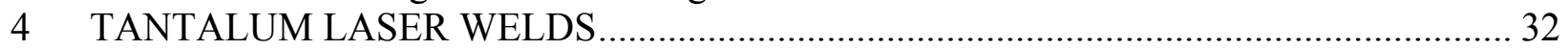

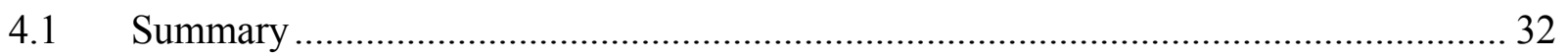

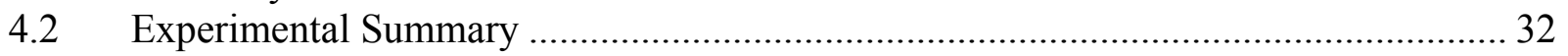

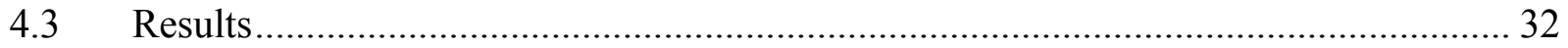

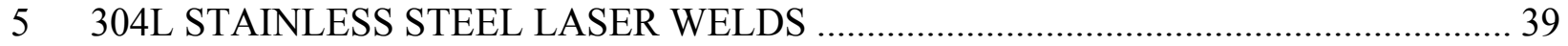

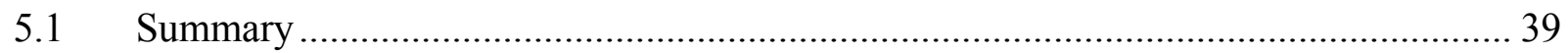

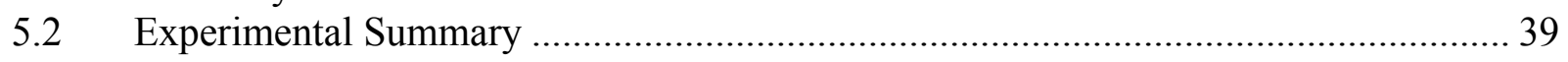

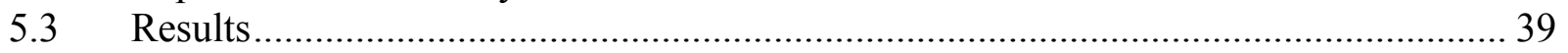

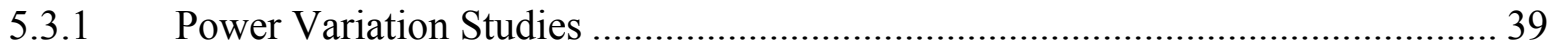

5.3.2 Travel Speed Variation Studies ..................................................................... 47

5.3.3 Effects of Energy Input per Unit Length of Weld ........................................ 52

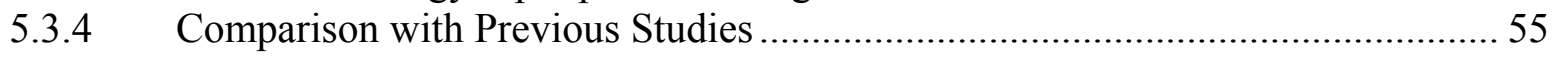

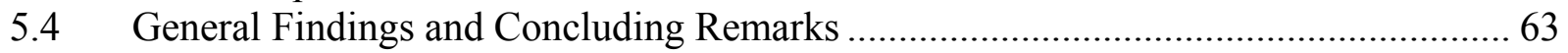

6 NITRONIC 40 (21-6-9) AUSTENITIC STAINLESS STEEL LASER WELDS ................ 65

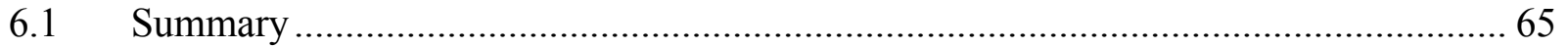

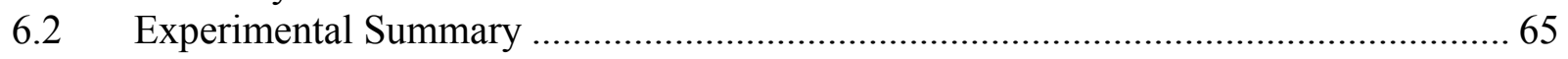

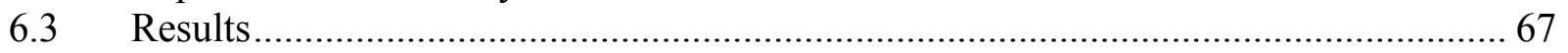

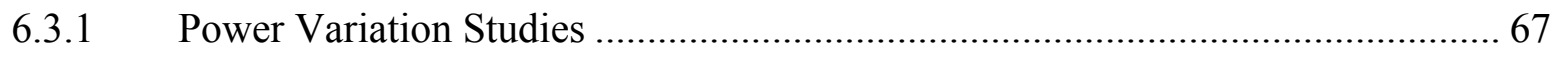

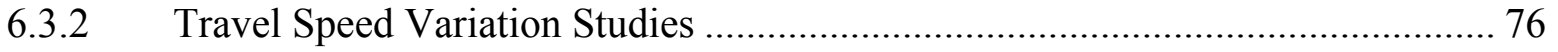

6.3.3 Effects of Energy Input per Unit Length of Weld ........................................ 76

6.3.4 Comparison with Previous Studies ............................................................ 82

6.4 General Findings and Concluding Remarks ..................................................... 93

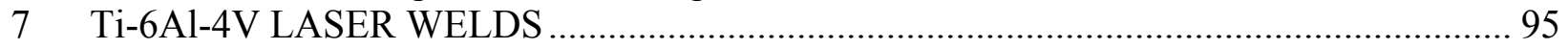

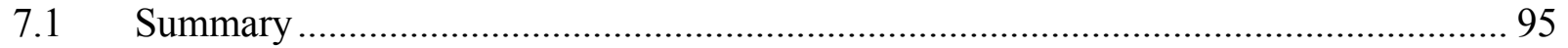

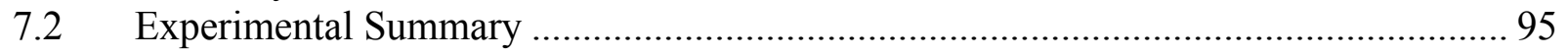

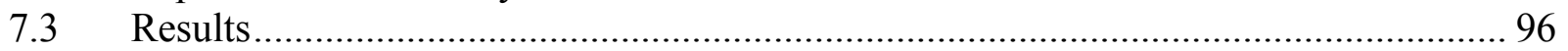

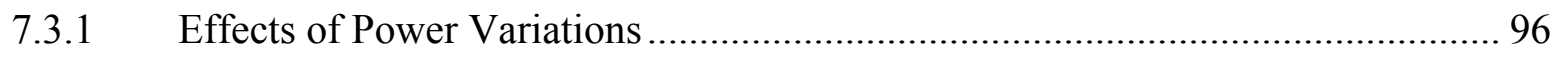

7.3.2 Effects of changes in Focus Position .............................................................. 101

7.3.3 Comparison between $300 \mu \mathrm{m}$ and $400 \mu \mathrm{m}$ diameter fiber optic cables............. 106

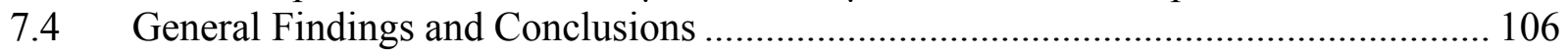

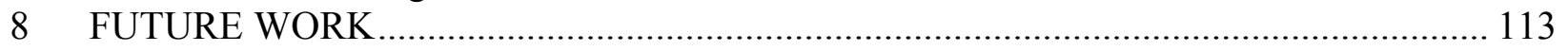




\section{BACKGROUND}

A Rofin-Sinar DY022 Continuous Wave (CW) Nd:YAG laser welding system has been recently purchased and installed at Lawrence Livermore National Laboratory. In order to evaluate the performance of this new system, a number of beam characterization tests have been performed using a laser power meter and a laser focusing diagnostic. Both items are commercially available and typically used as laser diagnostic and quality control tools. By characterizing the beams produced by this laser under a variety of different machine setting (i.e. power, focus position, and fiber optic cable diameter), its performance can be compared to that of other laser systems. In addition, it becomes possible to correlate the beam characteristics with the resulting weld dimensions formed using a given set of machine settings.

An additional series of preliminary welding tests have been performed on a range of materials systems, ranging from refractory metals (vanadium and tantalum) to austenitic stainless steels (304L and Nitronic 40) to a titanium alloy (Ti-6Al-4V). The different properties of each of these material systems allow the welding performance of this system to be evaluated for a range of materials. Particular attention is paid to the dimensions of the welds produced in each material system as well as the amount of porosity formed in each weld. Both characteristics are important considerations in the design and fabrication of suitable laser welds.

These initial tests provide a baseline evaluation of the performance of this laser system. With this information, weld development activities are undertaken using a more structured approach, in which the performance of the laser system under various experimental conditions can be accurately predicted. Future work will take advantage of the results of this work and allow more in-depth analyses of the effects of changes in beam parameters on weld dimensions. Additional work dealing with enhanced quality control techniques in laser welding will also be investigated.

The document which follows is divided into several sections. In the first section, the general performance of the laser is characterized through measurements of the output power. These measurements are then compared with the machine settings to determine the losses incurred by the beam as it passes from the power supply through the fiber optic cable to the laser optics. A summary of the results from the initial laser diagnostic tests follows, providing insight into the measured beam diameter over a range of focus positions and the characterization of the power density distribution in the beams. Several sections follow detailing the results of welding tests performed at different power levels and travel speeds for a range of materials, including vanadium, tantalum, 304L stainless steel, Nitronic 40 stainless steel, and Ti-6Al-4V.

\section{EXPERIMENTAL PROCEDURES OVERVIEW}

\subsection{Measurement of Laser Power Output}

The actual power output of the laser system at the exit of the optics assembly was measured using a water-cooled Coherent power meter over a range of machine power settings with both the $300 \mu \mathrm{m}$ and $400 \mu \mathrm{m}$ diameter fiber optic delivery cables. This power meter has a measurement accuracy of $\pm 1 \%$ and a calibration uncertainty of $\pm 2 \%$. Differences between the machine settings, which correspond with the beam power as it exits the power supply, and the actual power reaching the part to be welded are the result of losses incurred by the laser beam as it passes through the system optics. In Table 1, the power levels measured at the exit of the laser optics are listed over the range of machine settings for both the $300 \mu \mathrm{m}$ and $400 \mu \mathrm{m}$ diameter fiber optics. These values are also plotted in Figure 1, showing that the measured output powers 
UCRL-TR-222245

Table 1. Summary of power levels measured using the Coherent power meter over the range of machine power settings for both the $300 \mu \mathrm{m}$ and $400 \mu \mathrm{m}$ diameter fiber optics.

\begin{tabular}{|c|c|c|c|c|}
\hline \multirow{2}{*}{$\begin{array}{c}\text { Machine } \\
\text { Power } \\
\text { Setting (W) }\end{array}$} & \multicolumn{2}{|c|}{ 300 micron Fiber } & \multicolumn{2}{c|}{ 400 micron Fiber } \\
\cline { 2 - 5 } & $\begin{array}{c}\text { Measured } \\
\text { Output (W) }\end{array}$ & \% loss & $\begin{array}{c}\text { Measured } \\
\text { Output (W) }\end{array}$ & \% loss \\
\hline 220 & 202 & 8.2 & 202 & 8.2 \\
\hline 440 & 396 & 10.0 & 394 & 10.5 \\
\hline 660 & 588 & 10.9 & 587 & 11.1 \\
\hline 880 & 779 & 11.5 & 785 & 10.8 \\
\hline 1100 & 973 & 11.5 & 978 & 11.1 \\
\hline 1320 & 1160 & 12.1 & 1170 & 11.4 \\
\hline 1540 & 1340 & 13.0 & 1390 & 9.7 \\
\hline 1760 & 1550 & 11.9 & 1570 & 10.8 \\
\hline 1980 & 1770 & 10.6 & 1790 & 9.6 \\
\hline 2200 & 1980 & 10.0 & 1980 & 10.0 \\
\hline
\end{tabular}

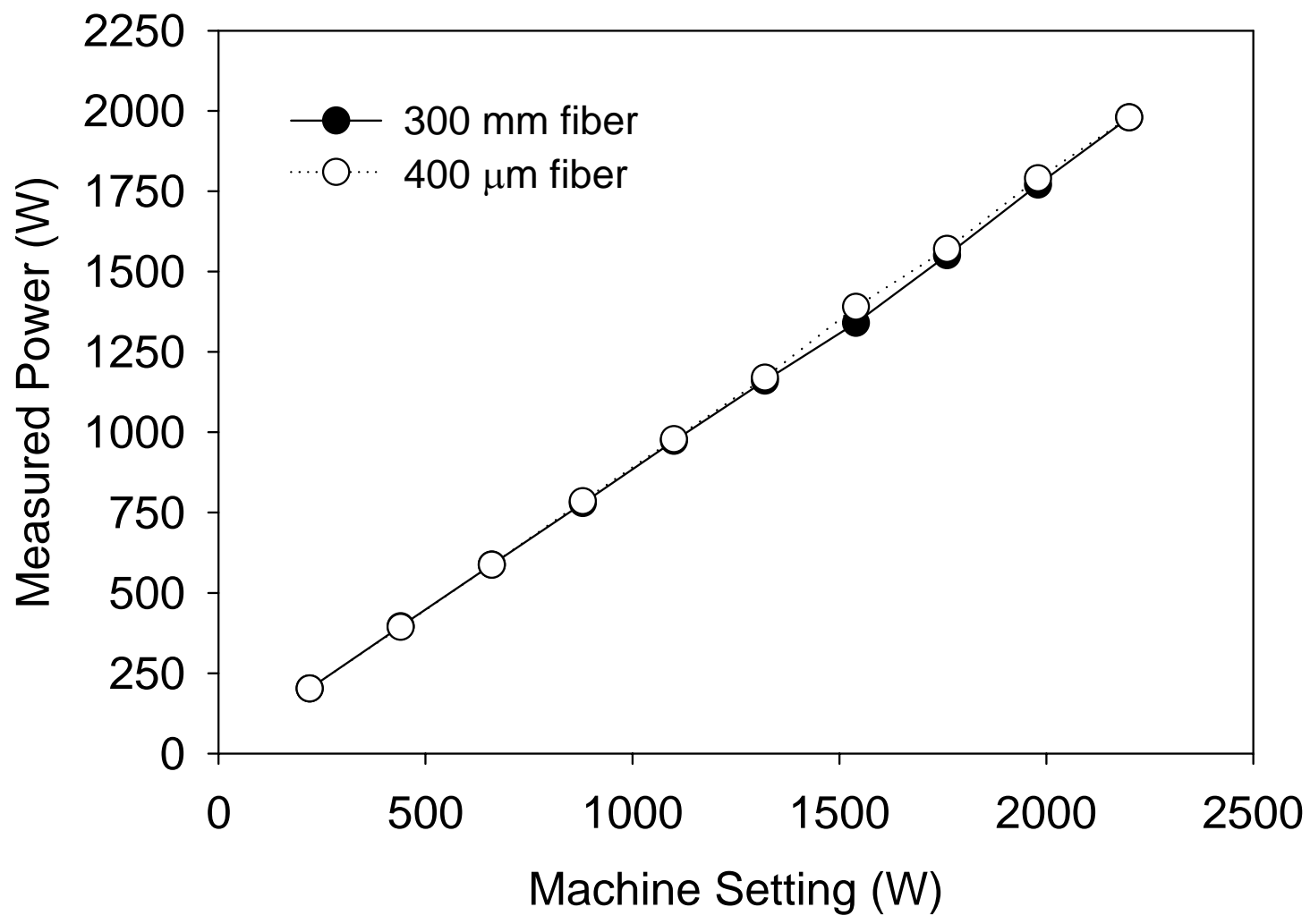

Figure 1. Plot comparing the machine power settings and the actual powers measured by the Coherent power meter after the laser passes through all of the focusing optics. The average loss for all data is $10.65 \%$ with a standard deviation of $1.19 \%$. 
UCRL-TR-222245

using both fibers are nearly identical across the range of machine settings. It is also evident from the results presented in Table 1 that the laser power measurements display losses of approximately $10 \%$ of the machine setting, and there appeared to be no significant difference with changes in the fiber diameter.

Unless otherwise stated, throughout the remainder of the report all references to power will use the measured values of laser power delivered to the part after the laser exits the final optics. This output power should be distinguished from machine setting, and is important to understand that the losses in different systems will be different. Therefore, when transferring laser welding parameters from LLNL to Los Alamos National Laboratory for example, the power delivered to the part, not the machine setting, must be used.

\subsection{Laser Focus Diagnostics}

\subsubsection{Description and Operation of Focus Monitor}

Laser beam diagnostics have also been installed into the laser workstation and used for the first time at LLNL to characterize the properties of these high power laser beams. This diagnostic system is manufactured by Primes and is designed as a focus monitor that measures the power distribution of the sharp focused beam. A photo of the diagnostic is shown in Figure 2 , with the general orientations of the $\mathrm{x}, \mathrm{y}$, and $\mathrm{z}$ axes and the locations of the sensor and Coherent power meter, which is used to capture the beam after it is analyzed by the diagnostic tool, are both indicated. The system is controlled by a software package installed on a common desktop computer. During operation, a small rapidly rotating probe with a pinhole aperture is passed through the laser beam to capture intensity information at selected locations along the length of the beam path. Because the speed of the rotating probe is so high, even a tightly focused high power laser beam will not damage the probe.

The plane on which the focus sensor resides is defined by the $\mathrm{x}$ and $\mathrm{y}$ axes, while the beam path from the final laser optics to the part is defined by the $\mathrm{z}$ axis. During operation, the sensor, which consists primarily of the rotating aperture described above and indicated in Figure 2, is moved into the beam path along the y axis. The probe is then rastered in a plane perpendicular to the beam path, as defined by the $\mathrm{x}$ axis, and the beam information is gathered. After completing the acquisition of data along this plane, the probe is then moved to another location in the beam path along the $\mathrm{z}$ axis in order to sample information along this next plane. Using the software control package, the number of planes and the overall distance to be analyzed by the focus monitor along the beam path are defined by the user.

In this study, seven focus measurements were automatically made over a z-axis range of up to $30 \mathrm{~mm}$ in order to determine the beam divergence and beam waist. Since it is not precisely known where the sharp focus location is located before running the diagnostic it would only be by chance that one of the seven measurements lied exactly on the sharp focus plane. Therefore, we run the diagnostic twice when precise measurements are required. The first run scans the beam, attempting to place plane number 3 at sharp focus. If plane 3 isn't exactly at sharp focus, then the laser head is moved up or down the required amount to bring plane 3 onto the sharp focus plane, and the scan is done again. This guarantees that a precise measurement of the beam will be made at its sharpest focus condition.

Based on these measurements, the focus diagnostics provides a physical location of sharp focus relative to the $x-y$ table that the focus monitor sits on. This location then needs to be related to a reference point on the laser head and eventually to the part being welded if the part 
UCRL-TR-222245

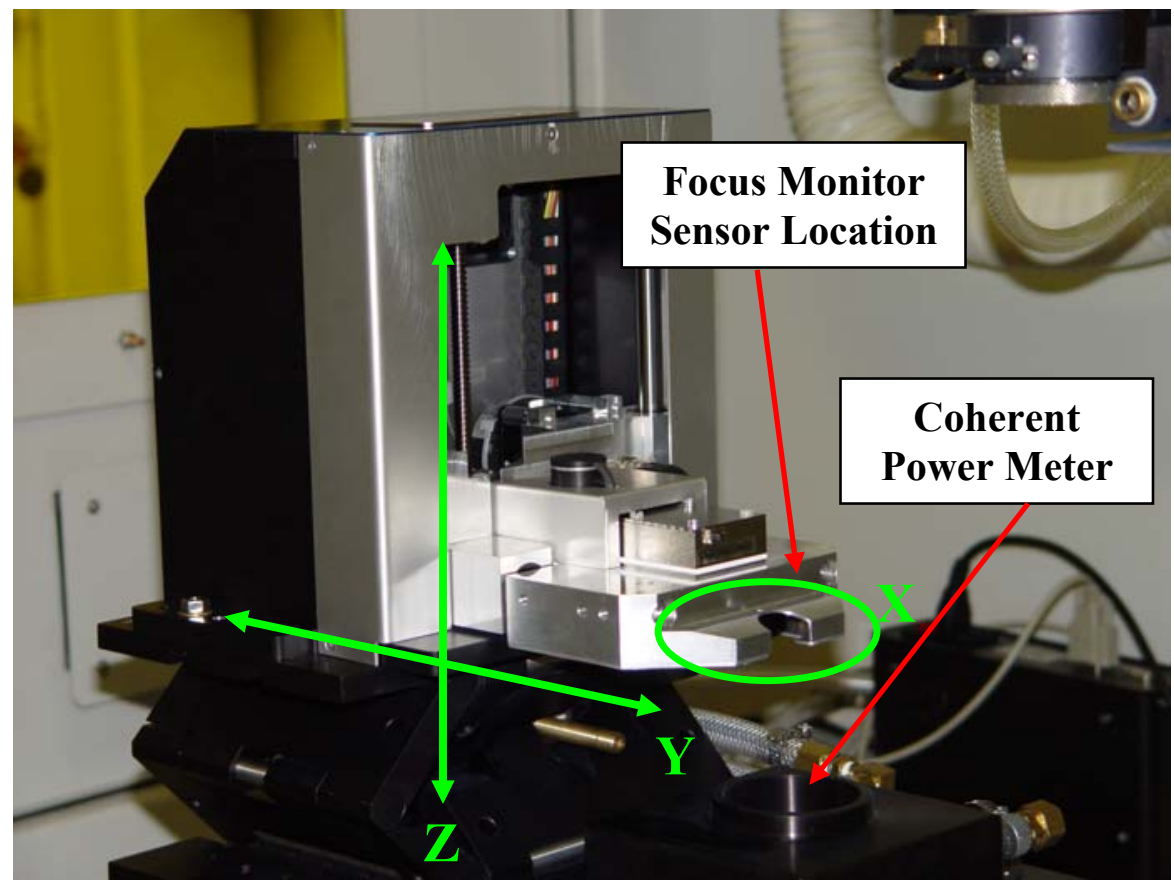

Figure 2. Primes Focus Monitor. Sensor is in parked position and has $152.4 \mathrm{~mm}$ of $Z$ travel. $X$, $\mathrm{Y} \& \mathrm{Z}$ motions are shown in green. 
UCRL-TR-222245

being welded is at a different level than the focus diagnostic. This distance is currently measured with a digital height gauge and is then transferred to the part to provide for the proper focus location. A laser micrometer range finder was recently procured in order to make a more accurate measurement and will be incorporated into the system.

After completion of the scan, the focus monitor software provides a summary of the beam properties. Images of the computer screens which detail typical output data obtained during an experimental run at a machine power setting of $2000 \mathrm{~W}$ using the $300 \mu \mathrm{m}$ diameter fiber optic cable are shown in Figures 3 and 4. A summary of the focus condition of the beam is provided in the primary output screen shown in Figure 3. There are several important features in this window which warrant further discussion. In the center of the screen a Rayleigh (beam divergence) plot, describing the depth of focus of the laser, is shown. With this plot, the location of sharp focus is defined by the narrowest beam width. A reconstruction of the power density distribution in the beam at the calculated sharp focus position (Plane 3) is also included, along with the calculated beam radius (Radius) and focus position (Position Z). A more in-depth tabulated summary of the beam properties along each of the seven planes analyzed in a typical experiment is also provided, as shown in screen shot provided in Figure 4. Note that the radius of this beam was measured at $150 \mu \mathrm{m}$ on plane 3 , which is exactly what we would expect for a $300 \mu \mathrm{m}$ diameter fiber focused with 1:1 optics (160mm collimator, $160 \mathrm{~mm}$ lens).

The laser focus monitor also provides pictorial representations of the power density distribution in the laser beam, primarily at the sharp focus condition. Figures 5(a) and 5(b) show the power density distribution for same beam in two formats. In the first format shown in Figure 5(a), the power density distribution is plotted in three dimensions, showing that this beam has a rough Gaussian shape. A two dimensional color plot of the power density distribution in the beam is shown in Figure 5(b). This plot provides a clear indication of the location of the hot spot near the center of the beam and the power density distribution across the width of the beam. The power density for this beam is shown to be near $2971\left(\mathrm{~kW} / \mathrm{cm}^{2}\right)$, which corresponds to 29.7 $\mathrm{kW} / \mathrm{mm}^{2}$.

\subsubsection{Characterization of Laser System}

Prior to welding, the performance of the laser system is characterized using the Primes focus monitor. Particular attention is paid in these tests to obtaining an accurate measurement of the sharp focus location and to test the repeatability of this measurement. The laser was run continuously, while the focus monitor made three independent measurements of the focus position. A summary of the results from these tests, including the focus position, beam radius, and power density, is given in Table 2 for machine power settings of $600 \mathrm{~W}, 900 \mathrm{~W}$, and 1200 $\mathrm{W}$. In this table, the focus position value corresponds to a location defined by the position of the focus monitor. These tests show that there is some variation in the repeatability of the measured focus position. For each power level, this variation is minimal, on the order of 0.1 to $0.4 \mathrm{~mm}$ in maximum variation, which corresponds to an accuracy of approximately $0.6 \%$. Variations in the measured beam radius are also rather minimal for these three power settings, reaching accuracies of approximately $0.8 \%$. 
UCRL-TR-222245

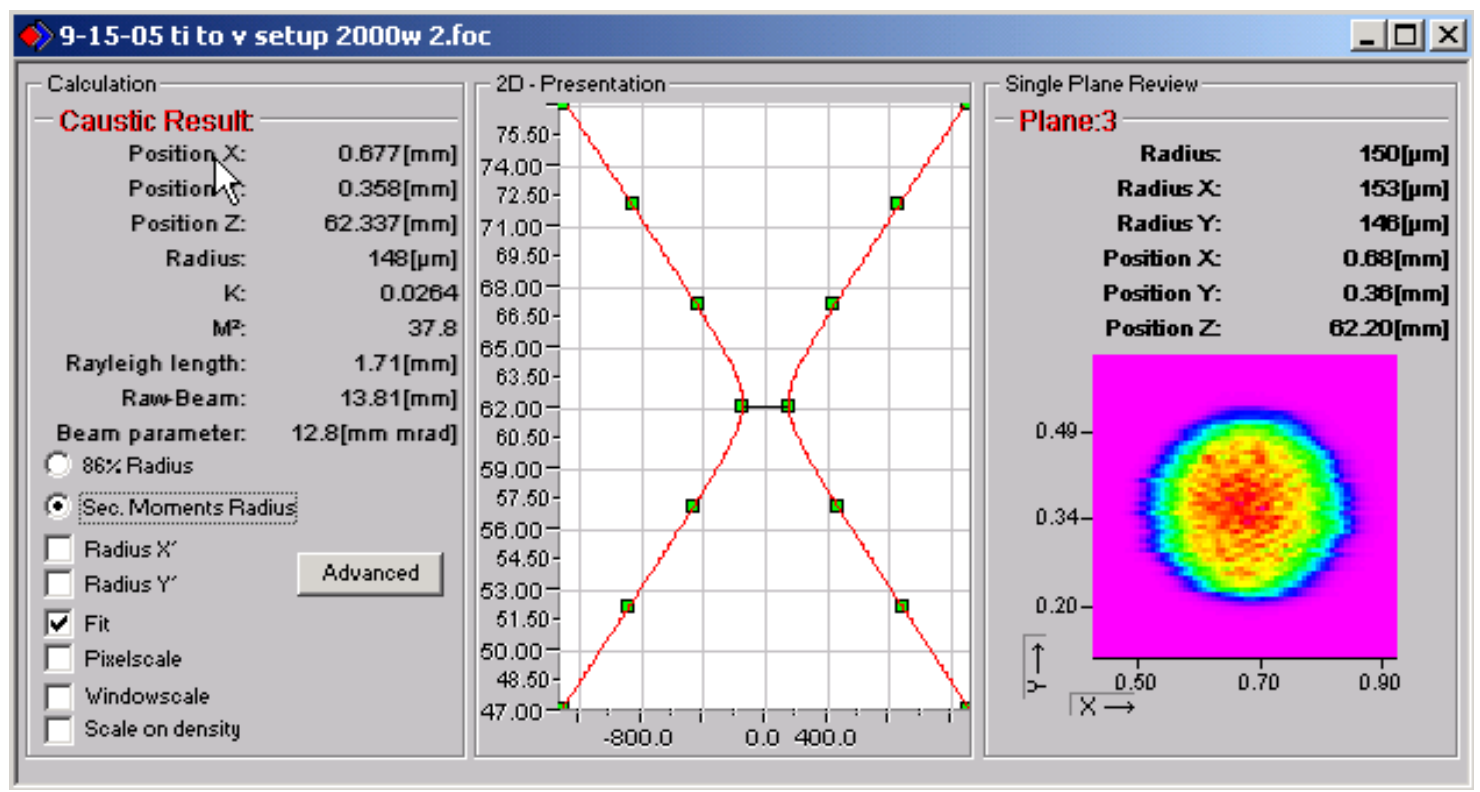

Figure 3. Focus monitor output measurement of the laser beam sliced in 7 planes over a 30mm range of focus for a beam produced at a machine setting of $2000 \mathrm{~W}$ and delivered to the laser optics using a $300 \mu \mathrm{m}$ diameter fiber optic.

\begin{tabular}{|c|c|c|c|c|c|c|c|c|}
\hline$\bigotimes 9-15-05$ ti to & $100 w 2$ & ment & & & & & -15 & $x$ \\
\hline Plane: & Plane 0 & Plane 1 & Plane 2 & Plane 3 & Plane 4 & Plane 5 & Plane 6 & 스 \\
\hline$\overline{\text { Radius [mm] }}$ & 1.311 & 0.887 & 0.470 & 0.150 & 0.440 & 0.860 & 1.298 & \\
\hline Radius X [mm] & 1.327 & 0.901 & 0.486 & 0.153 & 0.421 & 0.840 & 1.280 & \\
\hline Radius $Y^{\prime}[\mathrm{mm}]$ & 1.295 & 0.872 & 0.453 & 0.146 & 0.457 & 0.880 & 1.316 & \\
\hline Angle ["] & 2.1 & 7.2 & 3.3 & 5.2 & -9.3 & -7.0 & -7.5 & \\
\hline Position X [mm] & 0.613 & 0.625 & 0.661 & 0.676 & 0.661 & 0.633 & 0.596 & \\
\hline Position $Y[\mathrm{~mm}]$ & 0.194 & 0.216 & 0.290 & 0.359 & 0.403 & 0.432 & 0.481 & \\
\hline Position Z [mm] & 47.200 & 52.200 & 57.200 & 62.200 & 67.200 & 72.200 & 77.200 & \\
\hline Zero level [AD-Cnts] & 152.000 & 152.250 & 151.000 & 150.500 & 150.250 & 151.750 & 151.500 & \\
\hline Power [kiM] & 2.000 & 2.000 & 2.000 & 2.000 & 2.000 & 2.000 & 2.000 & \\
\hline Peak inten. [kiu/cm] & 70.568 & 155.859 & 545.798 & 3975.656 & 604.656 & 174.277 & 72.461 & \\
\hline Date: & 20.5 .5 & 20.5 .5 & 20.5 .5 & 20.5 .5 & 20.5 .5 & 20.5 .5 & 20.5 .5 & \\
\hline Time: & $6: 49: 40$ & $6: 49: 30$ & $6: 49: 3$ & $6: 48: 27$ & $6: 49: 59$ & $6: 50: 17$ & $6: 50: 27$ & \\
\hline Focal length $[\mathrm{mm}]$ & 160.000 & 160.000 & 160.000 & 160.000 & 160.000 & 160.000 & 160.000 & \\
\hline Z-axis-offset & 0.000 & 0.000 & 0.000 & 0.000 & 0.000 & 0.000 & 0.000 & \\
\hline X-axis-offset & 0.000 & 0.000 & 0.000 & 0.000 & 0.000 & 0.000 & 0.000 & \\
\hline$\gamma$-axis-offset & 0.000 & 0.000 & 0.000 & 0.000 & 0.000 & 0.000 & 0.000 & \\
\hline Coord.rotation [deg.] & 0.000 & 0.000 & 0.000 & 0.000 & 0.000 & 0.000 & 0.000 & \\
\hline Wavelength $[\mu \mathrm{m}]$ & 1.060 & 1.060 & 1.060 & 1.060 & 1.060 & 1.060 & 1.060 & \\
\hline $\begin{array}{l}\text { Lomment: } \\
\text { Radius } X[\mathrm{~mm}]\end{array}$ & 1.327 & 0.901 & 0.486 & 0.153 & 0.422 & 0.841 & 1.281 & \\
\hline Radius $\gamma^{\prime}[\mathrm{mm}]$ & 1.295 & 0.872 & 0.454 & 0.146 & 0.456 & 0.880 & 1.316 & - \\
\hline
\end{tabular}

Figure 4. Focus monitor output summary showing information on each of the 7 planes over a 30 $\mathrm{mm}$ range of focus. 
UCRL-TR-222245

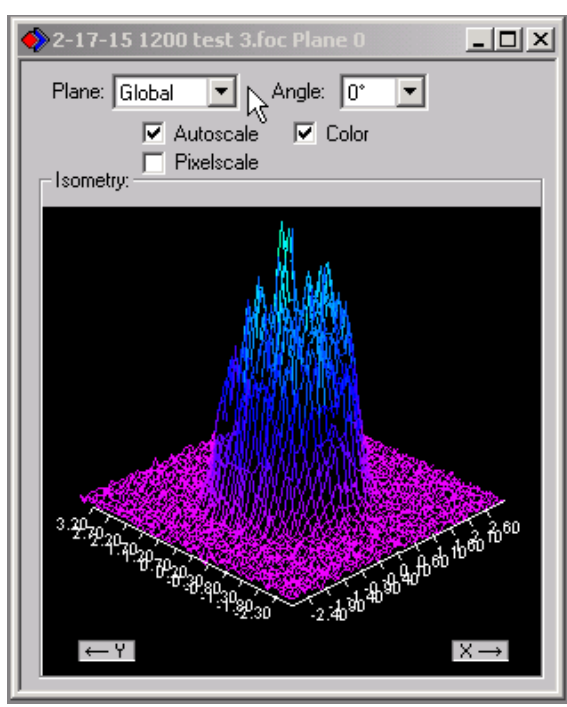

(a)

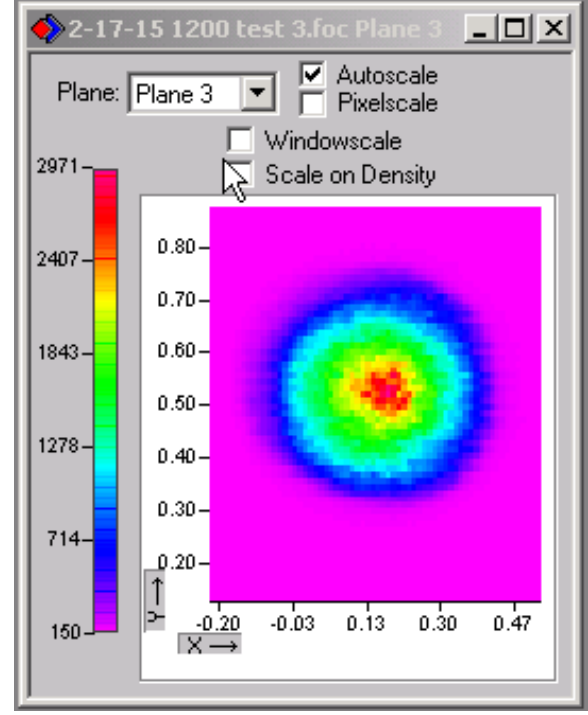

(b)

Figure 5(a\&b). (a) Three dimensional and (b) two dimensional pictorial with color beam intensity distribution representations of laser beam. In (b), the intensity shading of the power density is given in $\mathrm{kW} / \mathrm{cm}^{2}$.

Table 2. Focus position repeatability results for sharp focus beams measured at machine power settings of $600 \mathrm{~W}, 900 \mathrm{~W}$, and $1200 \mathrm{~W}$.

\begin{tabular}{|c|c|c|c|c|}
\hline & Test 1 & Test 2 & Test 3 & $\begin{array}{c}\text { Maximum } \\
\text { Variation }\end{array}$ \\
\hline \multicolumn{5}{|l|}{600 Watts } \\
\hline Focus Position (mm) & 60.457 & 60.496 & 60.383 & 0.113 \\
\hline Beam Radius (mm) & 0.143 & 0.141 & 0.147 & 0.006 \\
\hline Peak Power Density $\left(\mathrm{W} / \mathrm{mm}^{2}\right)$ & 8297 & 8528 & 7847 & 680 \\
\hline \multicolumn{5}{|l|}{900 Watts } \\
\hline Focus Position (mm) & 61.007 & 61.421 & 61.275 & 0.414 \\
\hline Beam Radius (mm) & 0.149 & 0.139 & 0.151 & 0.012 \\
\hline Peak Power Density $\left(\mathrm{W} / \mathrm{mm}^{2}\right)$ & 11456 & 13164 & 11154 & 2010 \\
\hline \multicolumn{5}{|l|}{1200 Watts } \\
\hline Focus Position (mm) & 61.506 & 61.634 & 61.704 & 0.198 \\
\hline Beam Radius (mm) & 0.155 & 0.158 & 0.155 & 0.003 \\
\hline Peak Power Density $\left(\mathrm{W} / \mathrm{mm}^{2}\right)$ & 14115 & 13584 & 14115 & 531 \\
\hline
\end{tabular}


UCRL-TR-222245

In addition to the repeatability of the focus position at a given power, variation in the position of sharp focus over the range of power settings was also analyzed using the focus monitor. It was found that the position of sharp focus varies with changes in the power setting, with the focus distance shortening by as much as $2.7 \mathrm{~mm}$ as the power setting is increased from $522 \mathrm{~W}$ to $1950 \mathrm{~W}$, as shown in Figure 6. It is therefore important to establish focus using the focus diagnostics at each power level.

The characteristics of these sharply focused beams over the range of power levels were measured using the focus diagnostic. Beams produced using both the $300 \mathrm{~mm}$ and $400 \mathrm{~mm}$ diameter fiber optic delivery cables were analyzed, and the peak power density and beam diameter values were measured. From these data, an average power density of the beam was calculated and is also summarized in Table 3. It is clear in this table that the beam diameters remain constant, matching the diameter of the fiber optic cable used to deliver the laser from the power supply to the workstation for this optical setup using 1:1 laser optics. Figure 7(a) plots the average power density for the two fiber diameters versus the power output delivered to the part, showing that the average power density of the $300 \mu \mathrm{m}$ fiber is approximately 1.8 times higher $\left(400^{2} / 300^{2}\right)$ than that of the $400 \mu \mathrm{m}$ fiber due to the difference in beam diameters and their affect on the beam area. Figure 7(b) plots the peak power densities as a function of laser power for both fiber optic cables. The peak power density increases nearly linearly with increasing power, nearly reaching $40 \mathrm{~kW} / \mathrm{mm}^{2}$ at the highest powers. Interestingly, both fibers produce similar peak power densities even though their average powers are different.

The focus diagnostics showed that the position of sharp focus moves closer to the system optics as the power level is increased, thus the parts being welded need height adjustments as the power level is changed. Peak power densities on the order of $20 \mathrm{~kW} / \mathrm{mm}^{2}$ were measured in sharply focused $1 \mathrm{KW}$ beams, which is similar to that of electron beams at the same power level. During welding, the weld size and shape was shown to change little with up to $1 \mathrm{~mm}$ changes in the focus position at high powers where the keyhole welding mode is dominant. However, at lower powers, near the transition from conduction to keyhole mode welding, such changes in focus position were observed to have a marked impact on the resulting weld shape and size. By using focus diagnostics, the data and information necessary to enable duplication and transferability of weld parameters between LLNL and LANL can be obtained. Further work will allow the standards and procedures necessary for these activities to be developed.

\subsection{Laser Welding Experiments}

The welds described in this report were made using a Rofin Sinar DY-022 diode pumped continuous wave Nd:YAG laser, located in the Laser Development Laboratory in B231, Room 1623 at Lawrence Livermore National Laboratory (LLNL). The maximum power output of the laser power supply is $2200 \mathrm{~W}$, which is delivered to a CNC Class 1 Laser Workstation using a 30 $\mathrm{m}$ long fiber optic cable. Fiber diameters of $300 \mu \mathrm{m}$ and $400 \mu \mathrm{m}$ are available for use. After the beam exits the fiber, it is collimated using a $160 \mathrm{~mm}$ focal length optic, passes through the optics assembly, and is focused onto the weld sample using a $160 \mathrm{~mm}$ focal length lens. A $4 \mathrm{~mm}$ diameter nozzle, placed approximately $25 \mathrm{~mm}$ from the laser beam impingement area, with a gas pressure of $80 \mathrm{psi}$, is used to deliver this shielding gas. The welding experiments performed on each materials system described in the following sections have utilized different ranges of welding parameters and sample thicknesses. Additional details, specific to the experiments performed on each material system, are provided in the appropriate sections. 
UCRL-TR-222245

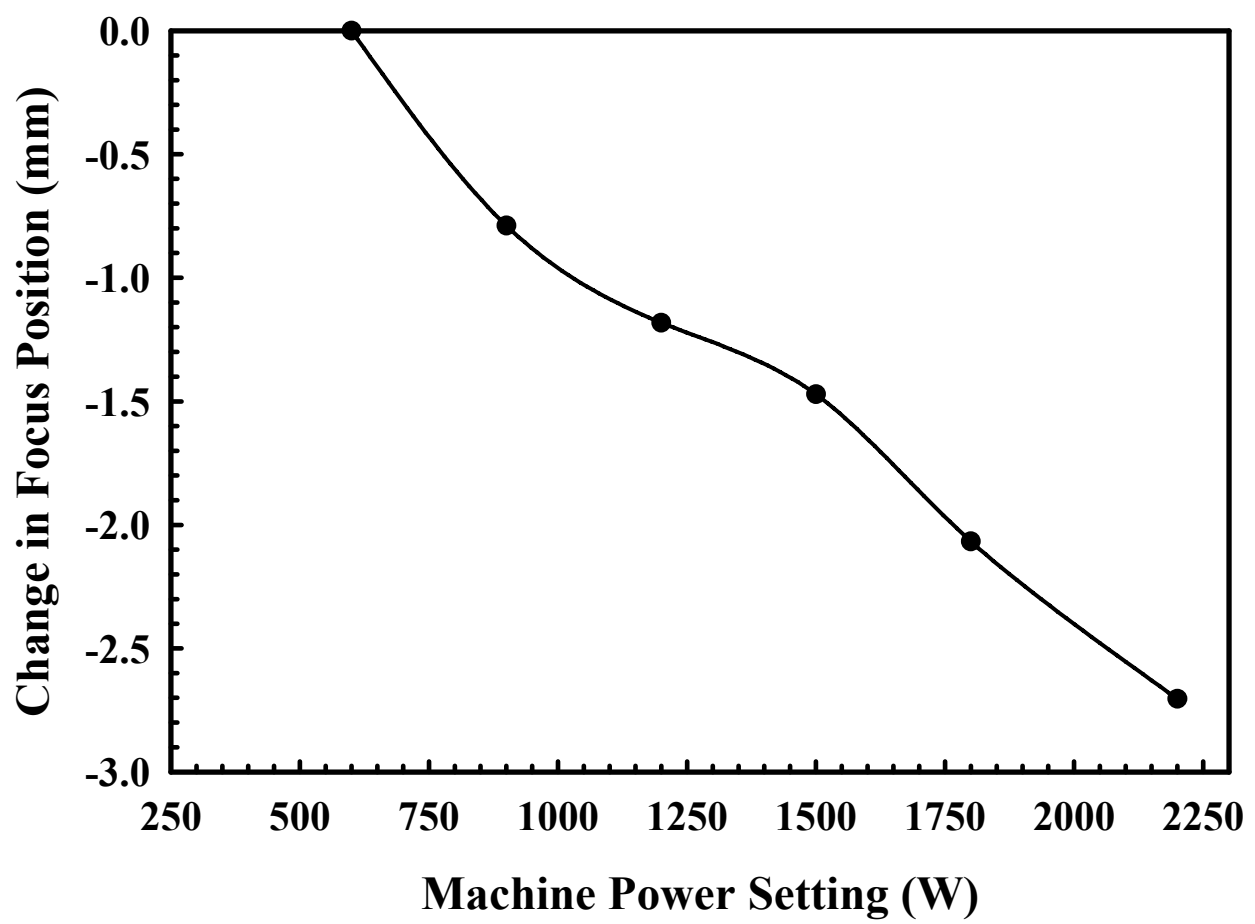

Figure 6. Plot showing effects of changes in output power on the position of sharp focus.

Table 3. Summary of diagnostic measurements made on sharply focused beams over a range of powers using the $300 \mu \mathrm{m}$ and $400 \mu \mathrm{m}$ fibers.

\begin{tabular}{|c|c|c|c|c|}
\hline $\begin{array}{c}\text { Machine } \\
\text { Setting } \\
\text { (W) }\end{array}$ & $\begin{array}{c}\text { Measured } \\
\text { Power } \\
\text { delivered to } \\
\text { part } \\
\text { (W) }\end{array}$ & $\begin{array}{c}\text { Measured } \\
\text { Peak Power } \\
\text { Density } \\
\left(\mathbf{W} / \mathbf{m m}^{2}\right)\end{array}$ & $\begin{array}{c}\text { Measured } \\
\text { Beam } \\
\text { Diameter } \\
(\mu \mathrm{m})\end{array}$ & $\begin{array}{c}\text { Average } \\
\text { Power } \\
\text { Density } \\
\left(\mathrm{W} / \mathrm{mm}^{2}\right)\end{array}$ \\
\hline \multicolumn{5}{|c|}{$300 \mu \mathrm{m}$ diameter fiber } \\
\hline 180 & 160 & 4595 & 300 & 2265 \\
\hline 500 & 450 & 9374 & 292 & 6723 \\
\hline 805 & 720 & 13703 & 290 & 10906 \\
\hline 1100 & 980 & 19173 & 294 & 14443 \\
\hline 1400 & 1230 & 31523 & 300 & 17410 \\
\hline 2000 & 1750 & 33105 & 304 & 24122 \\
\hline 2200 & 1950 & 36966 & 302 & 27236 \\
\hline \multicolumn{5}{|c|}{$400 \mu \mathrm{m}$ diameter fiber } \\
\hline 805 & 725 & 13320 & 396 & 5889 \\
\hline 1205 & 1090 & 20875 & 396 & 8855 \\
\hline 1600 & 1470 & 30040 & 392 & 12186 \\
\hline 2000 & 1830 & 31973 & 398 & 14717 \\
\hline
\end{tabular}


UCRL-TR-222245

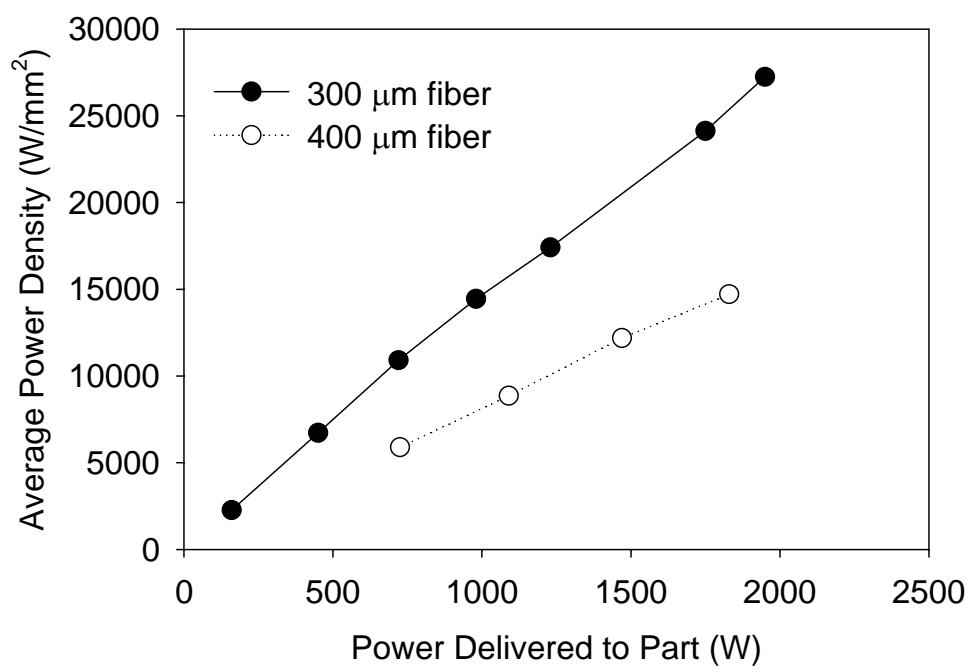

(a)

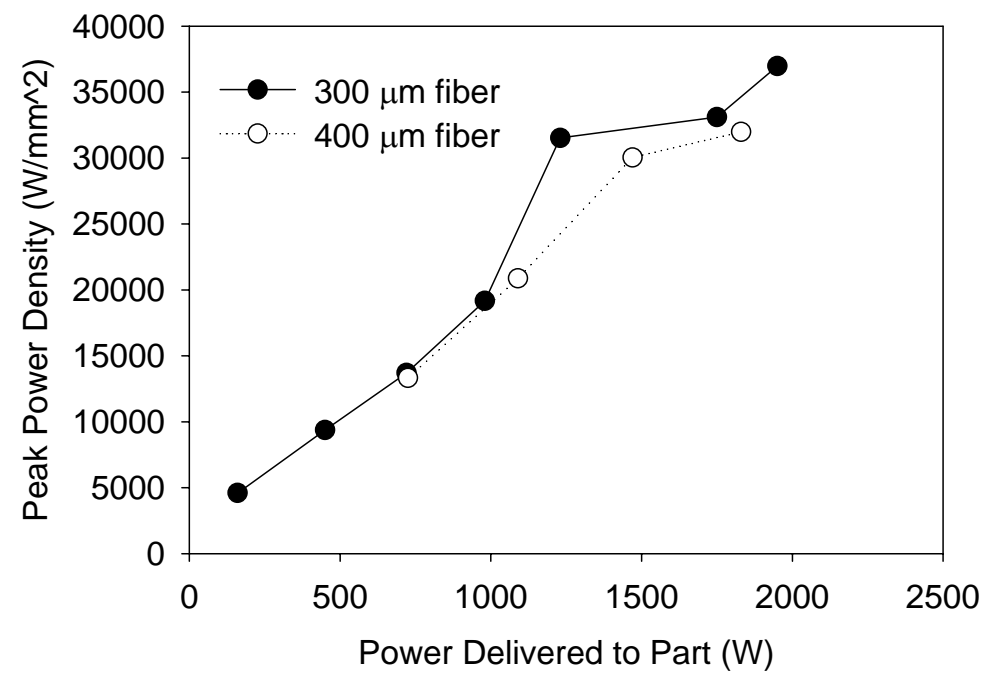

(b)

Figure 7(a\&b). (a) Plot comparing the average power density versus power delivered to the part for the $300 \mu \mathrm{m}$ and $400 \mu \mathrm{m}$ fibers, and b) measured peak power density values for both the 300 $\mu \mathrm{m}$ and $400 \mu \mathrm{m}$ diameter fibers. 
A representative cross section with the measurement locations and descriptions is shown in Figure 8. Four measurements are made on each weld cross section: (A) weld width at the top surface, (B) weld depth below the surface of the plate, (C) width of the keyhole, and (D) height of weld reinforcement. A fifth measurement, (E) weld underbead height, is made only on the full penetration welds. In addition to these measurements, the total melted area of each weld cross section is determined. All measurements are made from a digital image of each weld cross section using commercially available image analysis software (Adobe Photoshop 7.0 and Media Cybernetics Image Pro Plus V. 4.1). 
UCRL-TR-222245

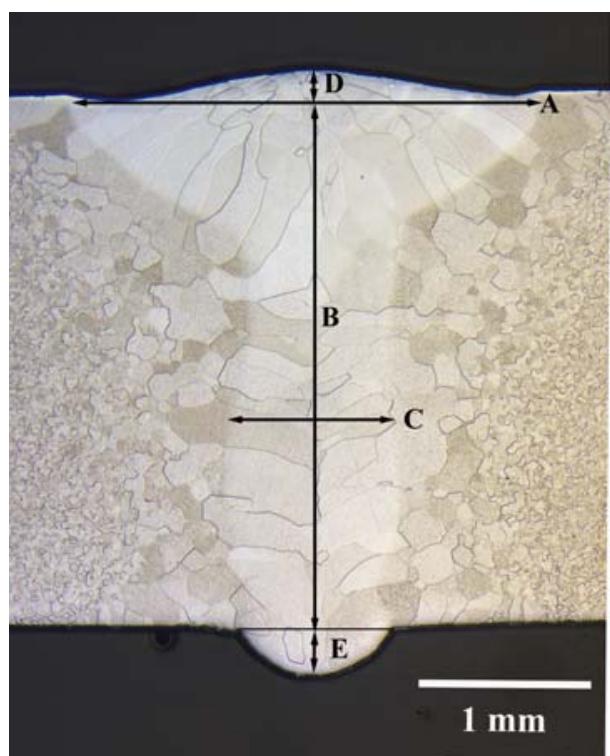

Figure 8. Sample weld cross-section macro showing general locations where weld measurements are made. A: Weld Width; B: Weld Depth; C: Keyhole Width; D: Weld Reinforcement Height; E: Underbead Height. 
UCRL-TR-222245

\section{VANADIUM LASER WELDS}

\subsection{Summary}

A series of autogenous bead on plate laser welds have been made on nominally pure vanadium plate using a Rofin Sinar DY-022 Continuous Wave (CW) Nd:YAG laser welder. In the vanadium weld tests, a keyhole welding mode is obtained at machine power settings greater than $500 \mathrm{~W}$ for travel speeds between $12.7 \mathrm{~mm} / \mathrm{sec}$ and $25.1 \mathrm{~mm} / \mathrm{sec}$. Full penetration welds were made on the $3.2 \mathrm{~mm}$ thick samples at machine power settings of $2000 \mathrm{~W}$ and above at a travel speed of $12.7 \mathrm{~mm} / \mathrm{sec}$. These results also compare favorably with welds made under similar conditions using another Rofin Sinar welding system. ${ }^{1}$ In many of the welds made at each travel speed using the LLNL system, porosity was observed to varying degrees of severity.

\subsection{Experimental}

A series of autogenous bead on plate laser welds have been made on nominally pure vanadium (0.034 wt.\% Si, 0.0052 wt.\% C, 0.0004 wt.\% H, 0.0170 wt. $\%$ N, and 0.0100 wt. \% O) samples $3.2 \mathrm{~mm}$ thick x $152.4 \mathrm{~mm}$ long x $25.4 \mathrm{~mm}$ wide using the LLNL laser system. Three welds, each $43.2 \mathrm{~mm}$ in length, are made on each sample. In this study, the effects of variations in machine power settings from $250 \mathrm{~W}$ to $2200 \mathrm{~W}$ are examined at three travel speeds (12.7 $\mathrm{mm} / \mathrm{sec}, 19.1 \mathrm{~mm} / \mathrm{sec}$, and $25.4 \mathrm{~mm} / \mathrm{sec}$ ). All welds are made with the laser focus set on the surface of the welding sample, resulting in a theoretical beam diameter of $300 \mu \mathrm{m}$. Argon gas is used to shield the welding area and to displace the laser plasma plume during welding. A $4 \mathrm{~mm}$ diameter nozzle, placed approximately $25 \mathrm{~mm}$ from the laser beam impingement area, with a gas pressure of $80 \mathrm{psi}$, is used to deliver this shielding gas. For all welds, the laser head is tilted at an offset angle of $5^{\circ}$ with respect to the direction normal to the sample surface towards the leading edge of the weld and along the direction of travel. This offset of the laser beam is used to avoid any potential back-reflection of laser light into the laser optics.

After welding, a sample is removed from a location near the middle of each welding line. This sample is mounted, polished, and etched to reveal both the microstructure and the resulting weld cross section shape and size. An etchant composed of $20 \mathrm{~mL}$ ethylene glycol, $10 \mathrm{~mL}$ $\mathrm{HNO}_{3}$, and $10 \mathrm{~mL} \mathrm{HF}$ is used to reveal the weldment microstructure and the fusion zone boundary. Because these welds are made on a nominally pure material, it can be difficult to discern the difference between fusion zone and HAZ microstructures. Therefore, care is taken in the metallographic preparation of each sample to ensure that a discernible boundary is present.

The welds made here have also been compared with those made on a similar laser system located at Los Alamos National Laboratory (LANL). The two laser systems operate on the same general principles, both being diode pumped and fiber optically delivered. The primary differences between the two systems reside in differences in the output power of the laser power supplies and in the laser optics used by each system. Even though the LANL system has a higher maximum output power ( $3300 \mathrm{~W}$ vs. $2200 \mathrm{~W}$ for the LLNL system), it exhibits a larger theoretical beam $(\sim 530 \mu \mathrm{m}$ vs $300 \mu \mathrm{m}$ for the LLNL system) when the laser is focused on the sample surface, due to the differences in the fiber diameter and focal length of the collimating lens. The welds from the LANL study are also made on $3.2 \mathrm{~mm}$ thick samples, but these

\footnotetext{
1 T.A. Palmer, B. Wood, J.W. Elmer, C. Westrich, J.O. Milewski, M. Piltch, M. Barbe, and R. Carpenter, "Characterization of Stainless Steel and Refractory Metal Welds Made Using a Diode-Pumped, Continuous Wave Nd:YAG Laser”, UCRL-ID-146005, 2001.
} 
UCRL-TR-222245

samples have a step joint machined into each abutting edge. A laser offset angle of $10^{\circ}$ with respect to the direction normal to the sample surface towards the leading edge of the weld and along the direction of travel is used rather than the $5^{\circ}$ offset used in the LLNL study. The vanadium used to fabricate these samples is taken from the same source as that described earlier and used in this study.

\subsection{Results}

\subsubsection{Effects of Variations in Power Input}

The three sets of weld experiments performed here examine the effects of variations in both power and travel speed on the resulting weld pool cross section size and shape. In these experiments, machine power settings range from $250 \mathrm{~W}$ to $2200 \mathrm{~W}$ at travel speeds of 12.7 $\mathrm{mm} / \mathrm{sec}, 19.1 \mathrm{~mm} / \mathrm{sec}$, and $25.4 \mathrm{~mm} / \mathrm{sec}$. These machine power settings translate into power inputs to the sample surface ranging from $220 \mathrm{~W}$ to $1980 \mathrm{~W}$, as documented in an earlier report. ${ }^{2}$ The same conditions of the laser optics system present during the measurement of these power outputs is assumed to exist during this series of welds. Micrographs showing the weld cross sections for machine power settings between $500 \mathrm{~W}$ and $2000 \mathrm{~W}$ are shown in Figures 9 through 11 at travel speeds of $12.7 \mathrm{~mm} / \mathrm{sec}, 19.1 \mathrm{~mm} / \mathrm{sec}$, and $25.4 \mathrm{~mm} / \mathrm{sec}$, respectively. All of the welds shown in these figures, with the exception of that performed at a machine power setting of $2000 \mathrm{~W}$ and a travel speed of $12.7 \mathrm{~mm} / \mathrm{sec}$ (Figure 11(d)), are partial penetration welds.

There are several features common to the weld pool cross sections shown in these figures. The first characteristic involves the general shape of the weld cross sections, which provides an indication of the prominent welding mode at each power setting. In laser welding, the conduction and keyhole modes are the two prominent welding modes. Conduction mode laser welding is typical at lower powers, where the heat transfer conditions between the laser beam and the sample surface result in a semi-hemispherical shaped weld pool. At higher powers, the power densities become high enough, usually on the order of $10^{6} \mathrm{~W} / \mathrm{cm}^{2}$ or higher, to produce strong evaporation on the weld pool surface. As a result, this energetic evaporation produces a recoil pressure, which is sufficient to produce a deep, narrow depression in the molten material, referred to as a keyhole, which is filled with a partially ionized plume of vapor and ambient gas. ${ }^{2}$ With the presence of a keyhole, the weld pool cross sections take on a shape, characterized by a semi-hemispherical top and a finger-like protrusion into the material being welded. At power settings above $500 \mathrm{~W}$, the observed weld cross sections exhibit a shape consistent with the keyhole welding mode.

The second characteristic involves the presence of porosity in the weld cross sections, in particular at the higher powers where the keyhole welding mode is observed. In high power continuous wave laser welds, which rely on a keyhole welding mode to achieve the desired penetration, porosity of this type is typically observed and is typically associated with the stability of the keyhole. ${ }^{3}$ The keyhole is constantly fluctuating and relies on a complex interaction of many factors, including evaporation recoil pressure, hydrodynamic pressures created by the melt and the laser plume, hydrostatic pressure, and surface tension, in order to

\footnotetext{
${ }^{2}$ J.Y. Lee, S.H. Ko, D.F. Farson, and C.D. Yoo, "Mechanism of Keyhole Formation and Stability in Stationary Laser Welding," J. Phys. D: Appl Phys. 35 (2002) 1570-1576.

${ }^{3}$ A. Matsunawa, "Problems and Solutions in Deep Penetration Laser Welding," Science and Technology of Welding and Joining, 6(6) (2001) 351-354.
} 
UCRL-TR-222245

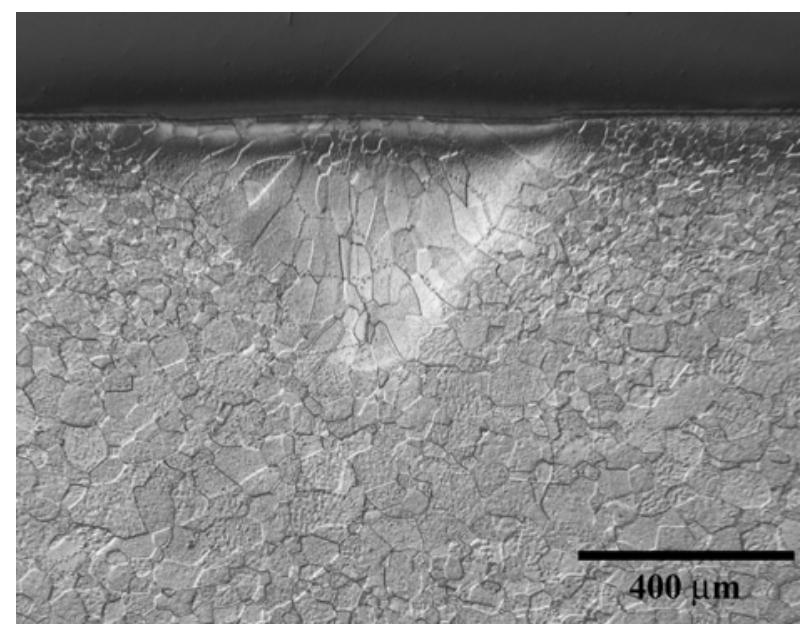

(a)

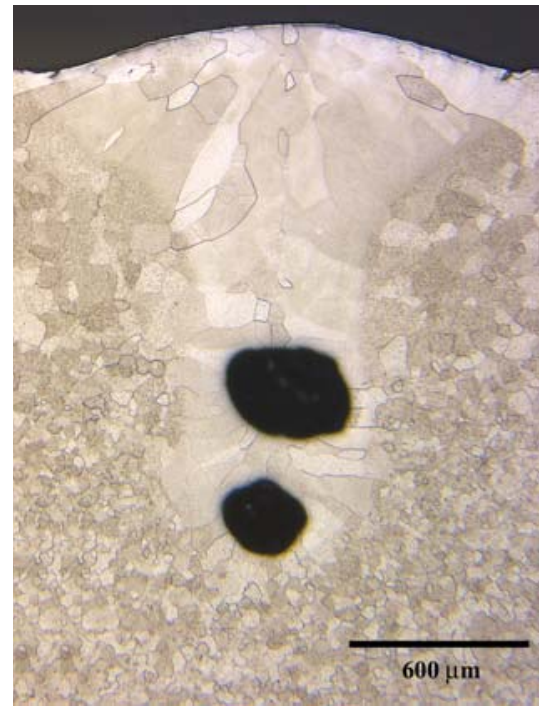

(c)

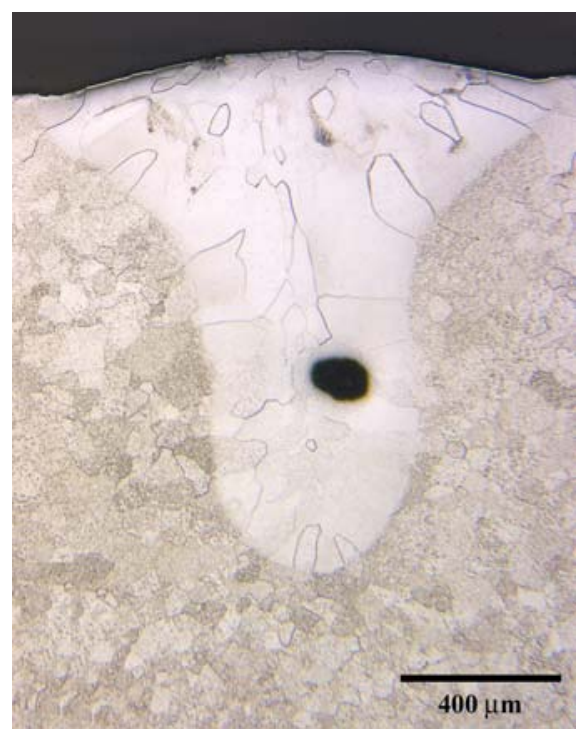

(b)

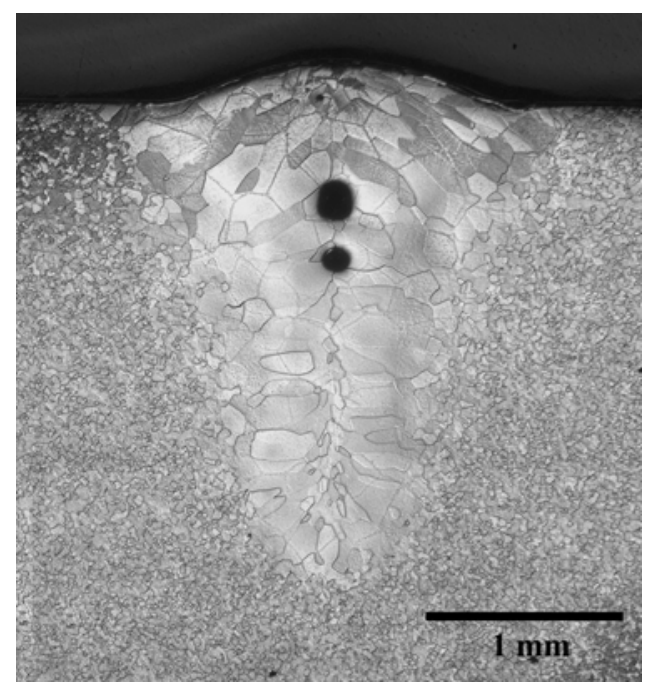

(d)

Figure 9(a-d). Micrographs of vanadium weld cross sections made on the LLNL welder at machine power settings of (a) $500 \mathrm{~W}$, (b) $1000 \mathrm{~W}$, (c) $1500 \mathrm{~W}$, and (d) $2000 \mathrm{~W}$ for a travel speed of $25.4 \mathrm{~mm} / \mathrm{sec}$. Note the variations of magnification in the micrographs. 
UCRL-TR-222245

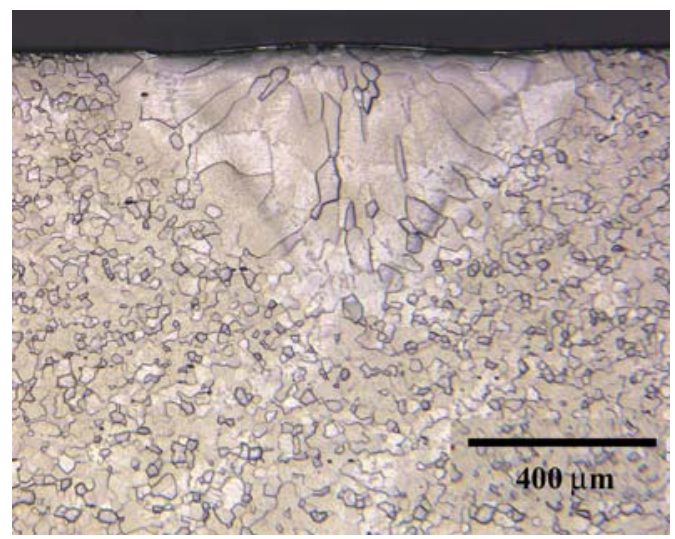

(a)

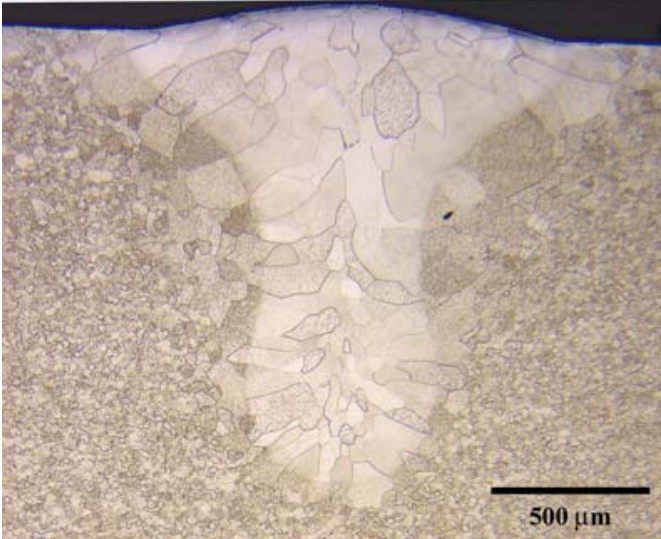

(b)

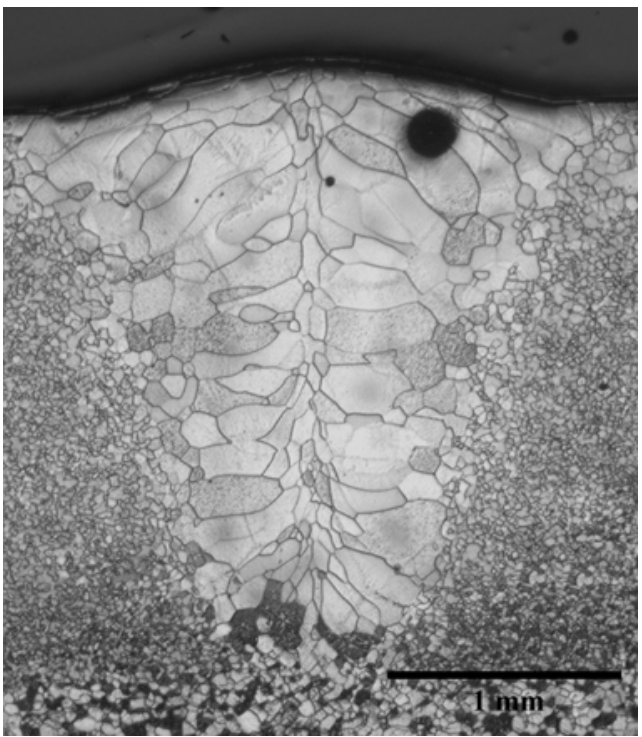

(d)

(c)

Figure 10(a-d). Micrographs of vanadium weld cross sections made on the LLNL welder at machine power settings of (a) $500 \mathrm{~W}$, (b) $1000 \mathrm{~W}$, (c) $1500 \mathrm{~W}$, and (d) $2000 \mathrm{~W}$ for a travel speed of $19.1 \mathrm{~mm} / \mathrm{sec}$. Note the variations of magnification in the micrographs. 
UCRL-TR-222245

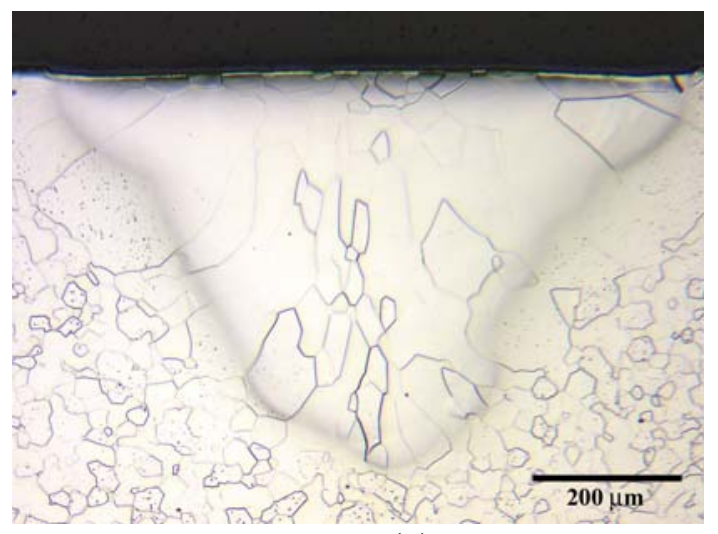

(a)

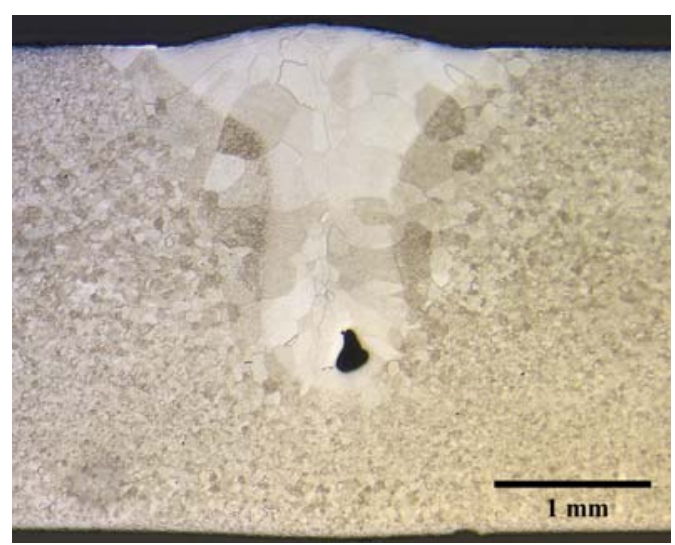

(c)

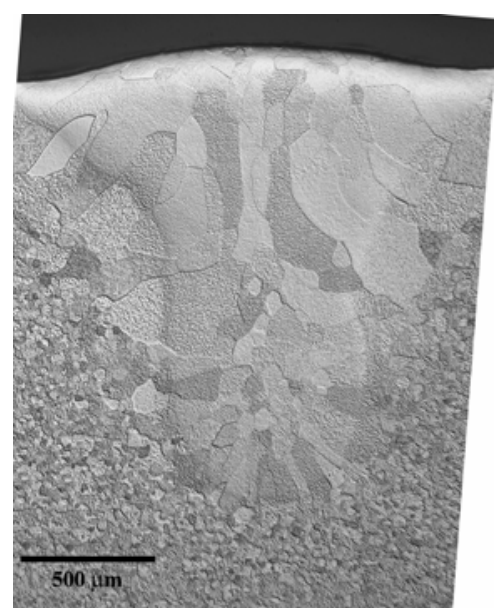

(b)

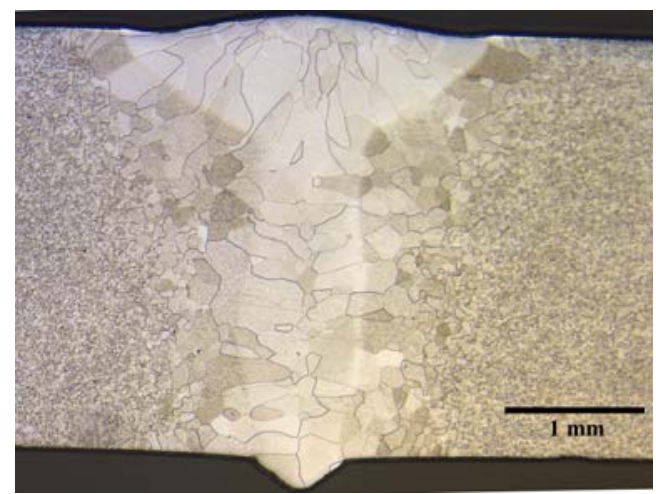

(d)

Figure 11(a-d). Micrographs of vanadium weld cross sections made on the LLNL welder at machine power settings of (a) $500 \mathrm{~W}$, (b) $1000 \mathrm{~W}$, (c) $1500 \mathrm{~W}$, and (d) $2000 \mathrm{~W}$ for a travel speed of $12.7 \mathrm{~mm} / \mathrm{sec}$. Note the variations of magnification in the micrographs. 
UCRL-TR-222245

remain stable. As a result, small fluctuations or variations in the keyhole result in the formation of small perturbations on the keyhole walls or its complete collapse. These instabilities thus result in the ejection of metal vapor and entrapped shielding gas from the keyhole column, leaving behind a non-continuous trail of pores along the longitudinal orientation of the weld.

A summary of the weld pool cross section measurements for each of the travel speeds is shown in Table 4. Along with measurements of the weld width, depth, keyhole width, reinforcement height, and melted area, the energy input and aspect ratio for each weld are included. The value for the energy input is based on the measured power input to the sample, which is shown in the first column of the table and the weld travel speed. The aspect ratio is defined as the depth-to-width ratio of the welds and provides a measure of the general shape of the fusion zone not possible through simple measures of the width or depth. Full penetration welds are also observed at the two highest power inputs $(1777 \mathrm{~W}$ and $1980 \mathrm{~W})$ at the lowest travel speed $(12.7 \mathrm{~mm} / \mathrm{sec})$. In each of these welds, an additional weld underbead appears on the back side of the weld sample, measuring approximately $0.21 \mathrm{~mm}$ and $0.27 \mathrm{~mm}$, respectively, for these two power inputs.

Plots comparing the primary weld measurements (width, depth, aspect ratio, and melted area) as a function of the power input for each travel speed are shown in Figures 12(a-d). With increasing power input, the weld width and depth increase. Of the three travel speeds, the highest widths and depths are observed at the lowest travel speed $(12.7 \mathrm{~mm} / \mathrm{sec})$. On the other hand, there appears to be little difference in the measured widths and depths for welds made at the two higher travel speeds $(19.1$ and $25.4 \mathrm{~mm} / \mathrm{sec})$. Similar trends are observed when the melted areas of the weld cross section are plotted as a function of the input power. These measurements can then be combined into the aspect ratio, which is plotted as a function of input power in Figure 12(c). In this case, the differences between the three travel speeds are minimized, and the aspect ratios for each travel speed show a general increase as the power input is increased up to power inputs of approximately $1250 \mathrm{~W}$, above which the values reach a constant level. The aspect ratios in the vanadium welds display a maximum value of approximately 1.2 .

Two other measurements of interest are made on each weld pool cross section. These measurements, which include the keyhole width and the reinforcement height, provide measures of the general properties of the keyhole and of the amount of weld porosity in partial penetration welds, respectively. Plots of the keyhole width and reinforcement height are shown in Figures 13(a\&b), respectively, as a function of the power input. The keyhole width values, shown in Figure 13(a), display similar trends as those for the other weld cross section measurements, i.e. a general increase with increasing power input, albeit with more scatter in the data. The reinforcement height values also increase with increasing power input, but no distinct trend arises for the individual travel speeds. This increasing trend appears to follow the same general trend observed in the micrographs, where porosity appears in the keyhole mode welds made at higher powers. 
Table 4. Summary of measurements made on vanadium weld samples made on the LLNL welder.

\begin{tabular}{|c|c|c|c|c|c|c|c|}
\hline$\frac{\text { Power }}{\frac{\text { to part }}{\text { (Watts) }}}$ & Speed & $\frac{\text { Weld Width }}{\underline{(\mathrm{mm})}}$ & $\frac{\text { Weld Depth }}{\underline{(\mathrm{mm})}}$ & $\frac{\text { Aspect Ratio }}{\text { (Depth/Width) }}$ & $\frac{\text { Keyhole Width }}{\underline{(\mathrm{mm})}}$ & $\frac{\text { Reinforcement }}{\underline{\text { Height }(\mathrm{mm})}}$ & $\frac{\text { Melted Area }}{\left(\mathrm{mm}^{2}\right)}$ \\
\hline 220 & $25.4 \mathrm{~mm} / \mathrm{sec}$ & 0.35 & 0.07 & 0.19 & ---- & ---- & 0.02 \\
\hline 442 & & 0.74 & 0.14 & 0.19 & $\begin{array}{l}--- \\
--\end{array}$ & $\begin{array}{l}--- \\
--\end{array}$ & 0.13 \\
\hline 664 & & 1.12 & 0.91 & 0.81 & 0.45 & 0.05 & 0.55 \\
\hline 887 & & 1.32 & 1.22 & 0.92 & 0.51 & 0.09 & 0.89 \\
\hline 1109 & & 1.52 & 1.51 & 1.00 & 0.55 & 0.12 & 1.24 \\
\hline 1332 & & 1.65 & 1.66 & 1.00 & 0.62 & 0.15 & 1.49 \\
\hline 1554 & & 2.21 & 2.50 & 1.13 & 0.74 & 0.17 & 2.71 \\
\hline 1777 & & 1.90 & 2.18 & 1.15 & 0.63 & 0.17 & 2.08 \\
\hline 1980 & & 2.13 & 2.28 & 1.07 & 0.92 & 0.22 & 2.31 \\
\hline 220 & $19.1 \mathrm{~mm} / \mathrm{sec}$ & 0.34 & 0.08 & 0.23 & --- & --- & 0.02 \\
\hline 442 & & 0.78 & 0.49 & 0.63 & 0.33 & 0.03 & 0.24 \\
\hline 664 & & 1.32 & 0.93 & 0.70 & 0.51 & 0.06 & 0.73 \\
\hline 887 & & 1.43 & 1.43 & 1.00 & 0.55 & 0.09 & 1.09 \\
\hline 1109 & & 1.56 & 1.35 & 0.87 & 0.38 & 0.09 & 1.15 \\
\hline 1332 & & 1.65 & 1.55 & 0.94 & 0.64 & 0.12 & 1.36 \\
\hline 1554 & & 1.65 & 1.64 & 0.99 & 0.56 & 0.11 & 1.47 \\
\hline 1777 & & 2.12 & 2.24 & 1.06 & 0.71 & 0.20 & 2.47 \\
\hline 1980 & & 2.12 & 2.45 & 1.16 & 0.76 & 0.18 & 2.69 \\
\hline 220 & $12.7 \mathrm{~mm} / \mathrm{sec}$ & 0.35 & 0.08 & 0.23 & ---- & ---- & 0.02 \\
\hline 442 & & 0.85 & 0.53 & 0.62 & 0.35 & ---- & 0.27 \\
\hline 664 & & 1.45 & 1.03 & 0.71 & 0.55 & 0.07 & 0.83 \\
\hline 887 & & 1.86 & 1.58 & 0.85 & 0.88 & 0.13 & 1.55 \\
\hline 1109 & & 1.95 & 1.87 & 0.96 & 0.68 & 0.13 & 1.75 \\
\hline 1332 & & 2.13 & 2.19 & 1.03 & 0.92 & 0.15 & 2.50 \\
\hline 1554 & & 2.38 & 2.64 & 1.11 & 0.84 & 0.16 & 3.04 \\
\hline $1777^{*}$ & & 2.65 & 3.05 & 1.15 & 0.87 & 0.13 & 3.72 \\
\hline 1980* & & 2.78 & 3.14 & 1.13 & 1.01 & 0.13 & 4.24 \\
\hline
\end{tabular}

* Full Penetration Welds. 


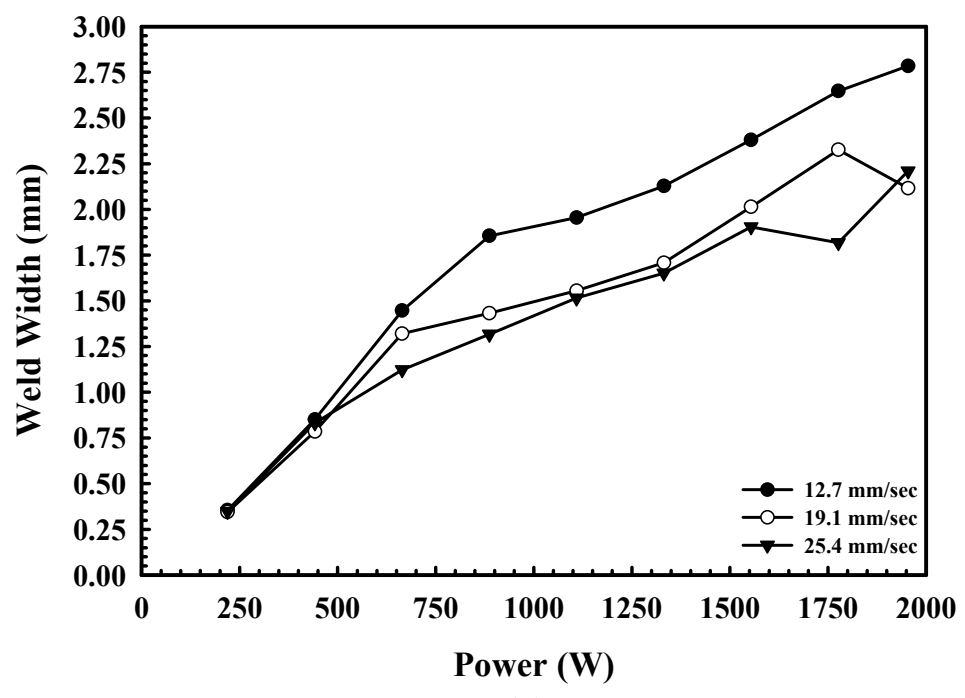

(a)

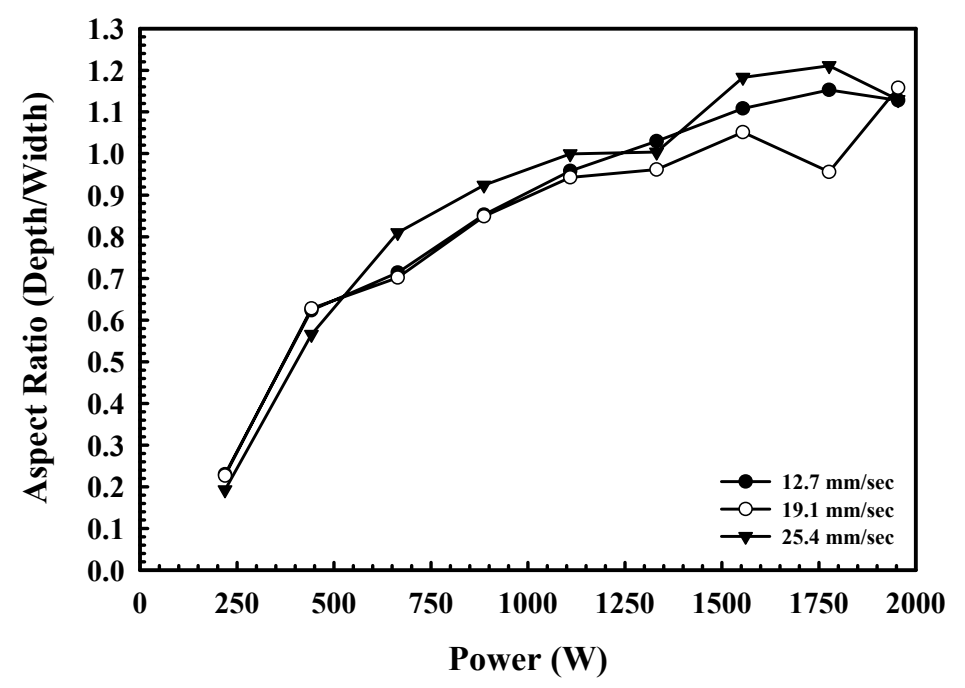

(c)

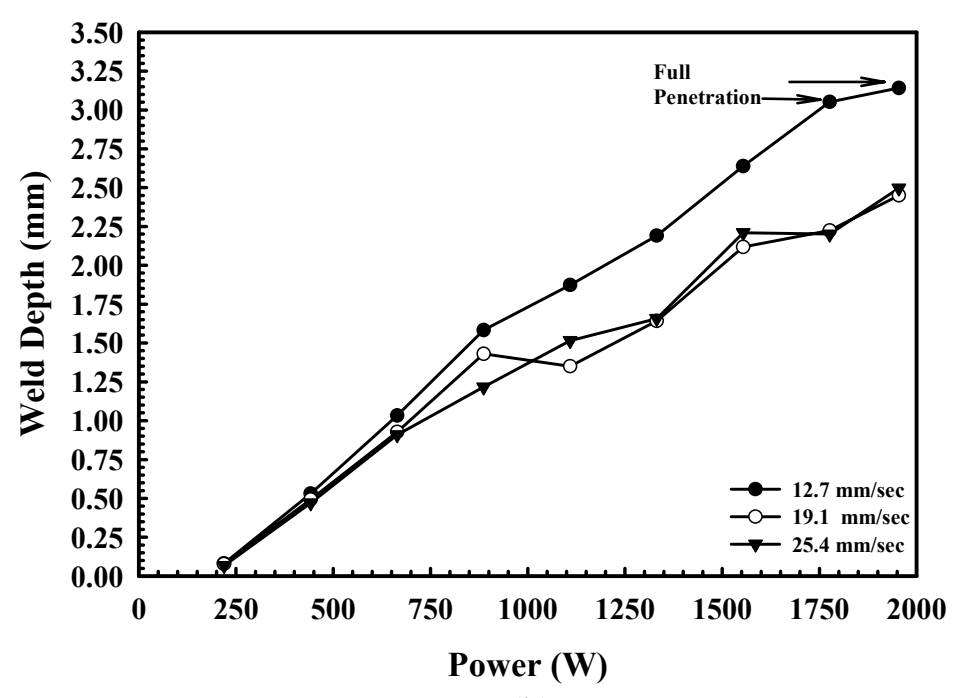

(b)

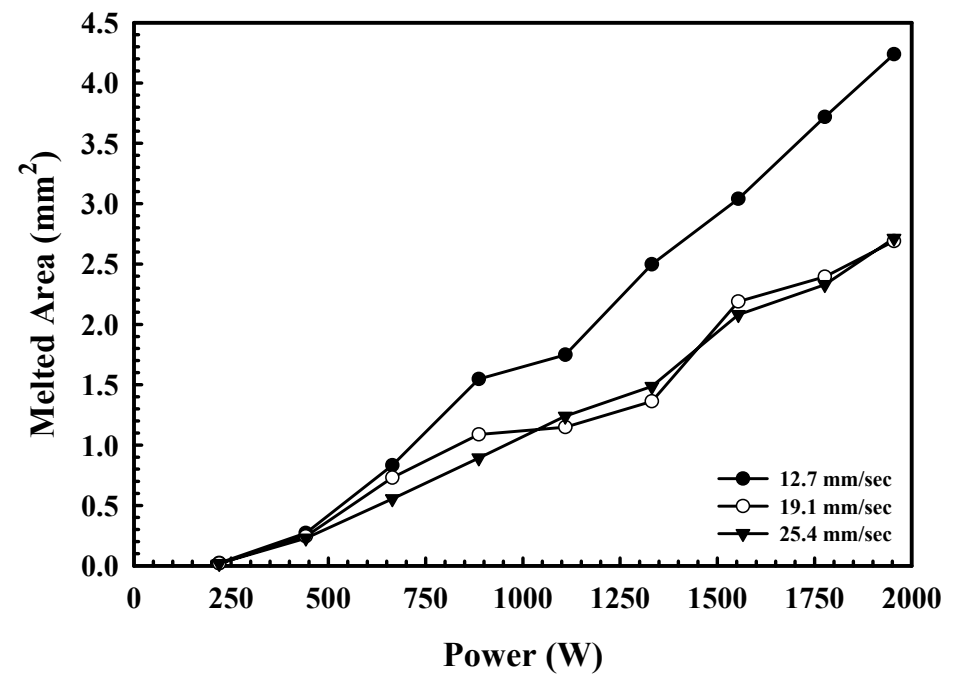

(d)

Figure 12(a-d). Plots showing variations in the (a) weld width, (b) weld depth, (c) aspect ratio (depth/width), and (d) melted area with changes in the machine output power or travel speeds of $25.4 \mathrm{~mm} / \mathrm{sec}, 19.1 \mathrm{~mm} / \mathrm{sec}$ and $12.7 \mathrm{~mm} / \mathrm{sec}$ for vanadium welds made on the LLNL welder. 


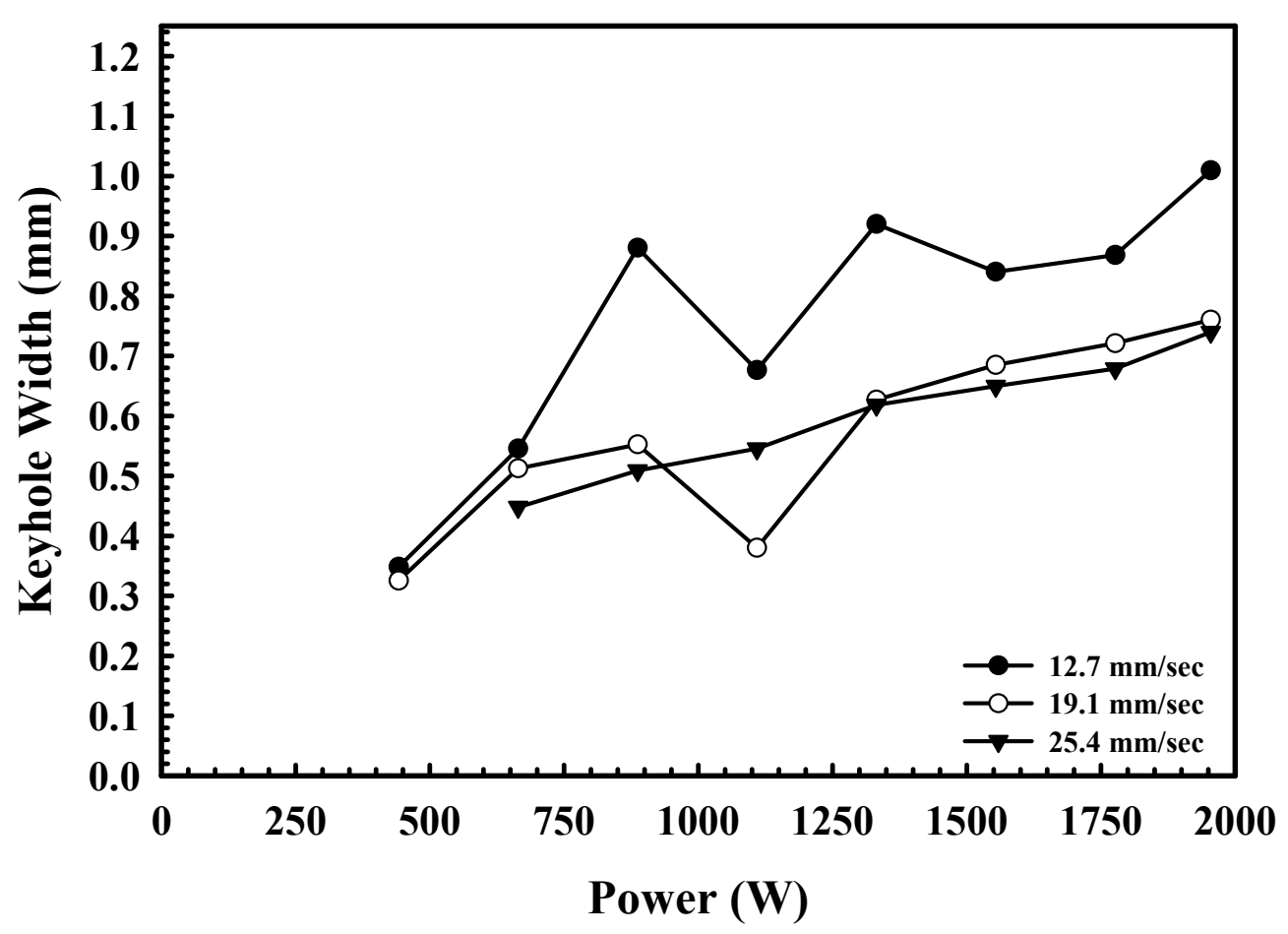

(a)

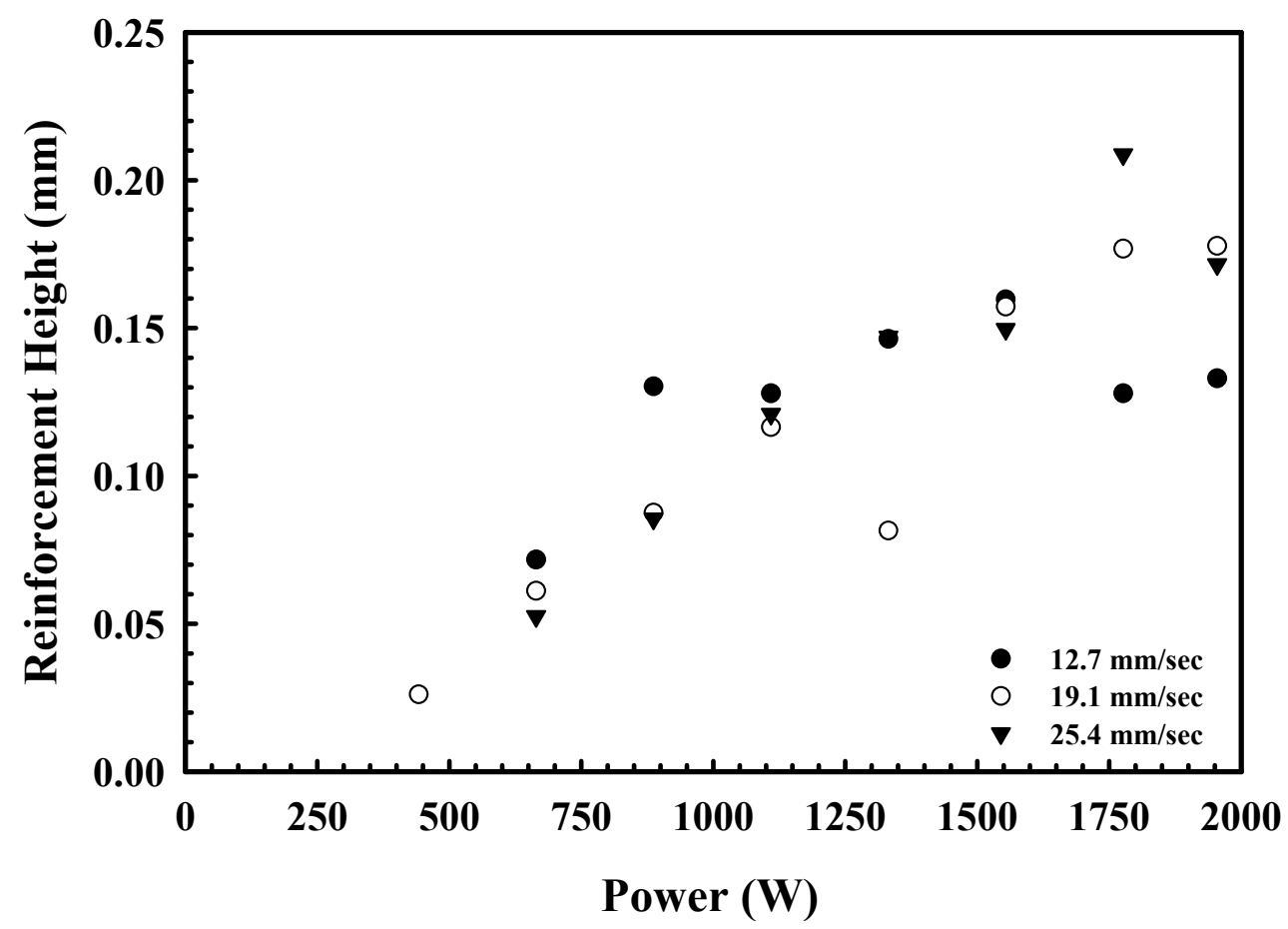

(b)

Figure 13(a\&b). Plots showing variations in the (a) keyhole width and (b) overfill height with changes in the machine output power setting for travel speeds at $25.4 \mathrm{~mm} / \mathrm{sec}, 19.1 \mathrm{~mm} / \mathrm{sec}$ and $12.7 \mathrm{~mm} / \mathrm{sec}$ for vanadium welds made on the LLNL welder. 


\subsubsection{Effects of Energy Input per Unit Length of Weld}

In addition to plotting the weld pool measurements as a function of the power input, the trends in these measurements can be examined as a function of the energy input per unit length. The use of this parameter, defined as the input power divided by the travel speed, is a more general description of the energy or power imparted on the workpiece. Unlike the previous comparisons, in which the effects of travel speed and power input are separate, the results of the power variation and travel speed variation studies can be directly compared. The energy inputs for each weld are included in Table 4 along with the measured weld dimensions.

The weld width, depth, aspect ratio, and total melted area are plotted as a function of the energy input per unit length in Figures 14(a-d). Whereas similar trends as those in Figures 12(ad) are observed in these figures, there is one major difference: the more rapid travel speeds appear to produce both wider and deeper weld pools than the lower travel speeds for a given energy input. This trend is related to the higher power density required at the higher travel speeds in order to reach an equivalent energy input per unit length. For example, in order for an energy input per unit length of $50 \mathrm{~J} / \mathrm{mm}$ to be attained at travel speeds of 25.4 and $12.7 \mathrm{~mm} / \mathrm{sec}$, power inputs of $1270 \mathrm{~W}$ and $635 \mathrm{~W}$, respectively, are required.

In Figures 15(a\&b), the effects of changes in the energy input per unit length on the keyhole width and reinforcement height, respectively, are shown. Both parameters show increasing trends with increases in the energy input, as expected. The same trends noted in Figures 14(a-d), in which the higher travel speed produces larger weld dimensions at equivalent energy inputs, are also present here, especially with the reinforcement height measurements shown in Figure 15(b). The trend is not as evident in the keyhole width measurements, shown in Figure 15(a), where the measurements from the three travel speeds fall within a close proximity of each other at comparable energy inputs.

\subsubsection{Comparison with LANL Results}

Comparisons can be made between the results from the LLNL laser system and those from the LANL system, described in an earlier section. A summary of the measurements made on the weld cross sections produced by the LANL system is shown in Table 5. Even though the systems are comparable and the welds are made on material taken from a common source, there are other differences worth noting. First, the LANL welding experiments have been performed with both helium and argon shielding gases, whereas only argon has been used in the LLNL experiments. There is also a difference in the laser offset angle used in the two experiments. The LLNL results are based on an offset angle of $5^{\circ}$, while the LANL results are based on an offset angle of $10^{\circ}$ towards the leading edge of the weld pool. Therefore, the effects of not only changes in power input on the resulting weld pool cross section dimensions can be compared, but also the basic effects of shielding gases and offset angle can be analyzed.

Figures 16(a-d) show comparisons between the measured weld depth, width, aspect ratio, and total melted area, respectively, for measurements made on both systems at a travel speed of 19.1 $\mathrm{mm} / \mathrm{sec}$. These values are plotted in each figure as a function of the machine power setting, which is used because comparable measurements of the power input at the sample surface have not been performed on the LANL system. Without these measurements, the power loss from the laser optics between the laser power supply and the sample surface can not be determined, making the machine power setting the only common value with which to compare the results from the different systems. 


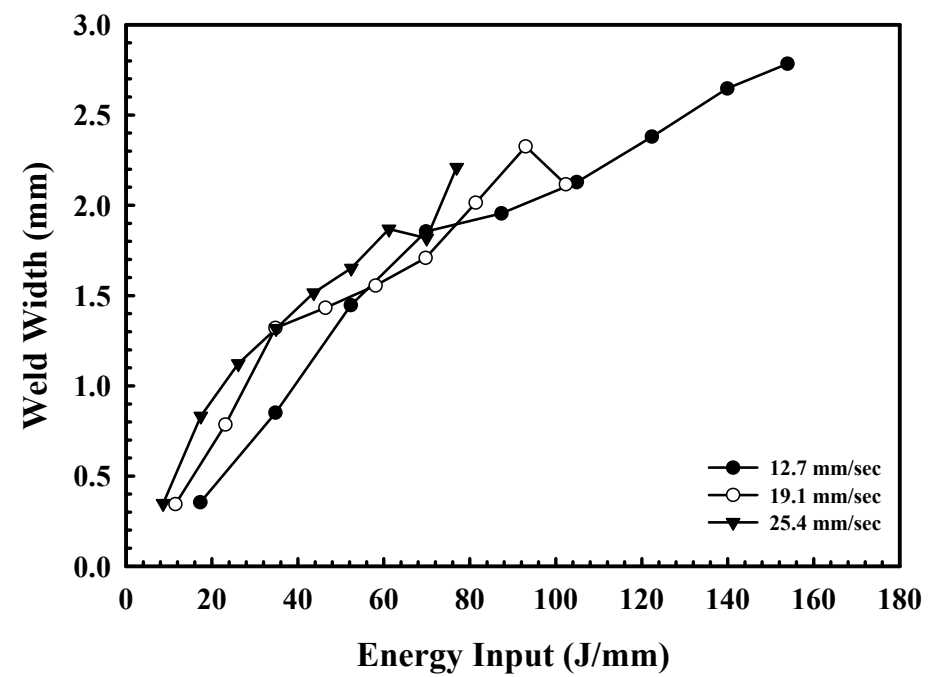

(a)

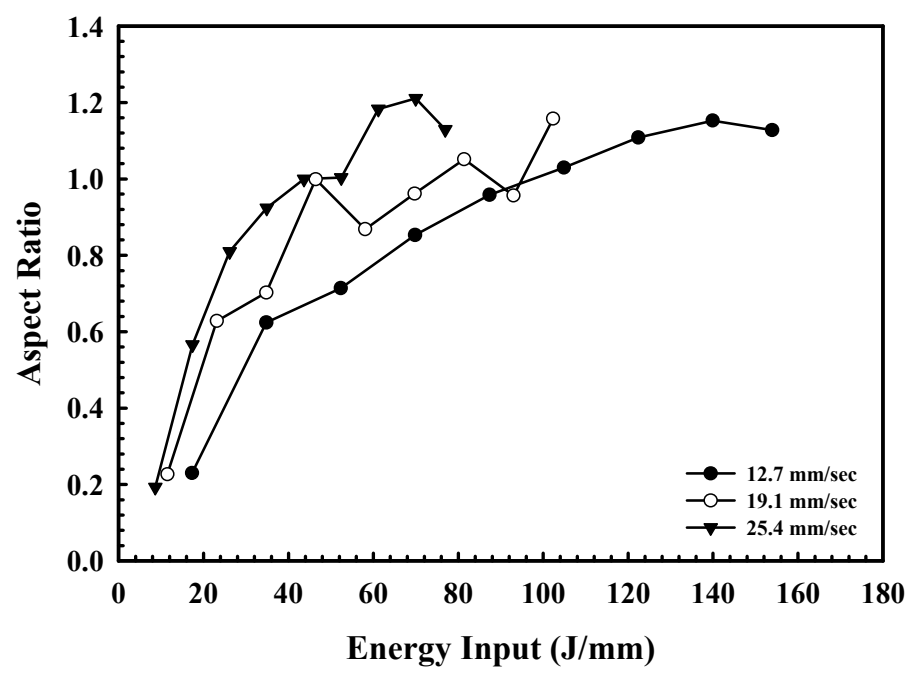

(c)

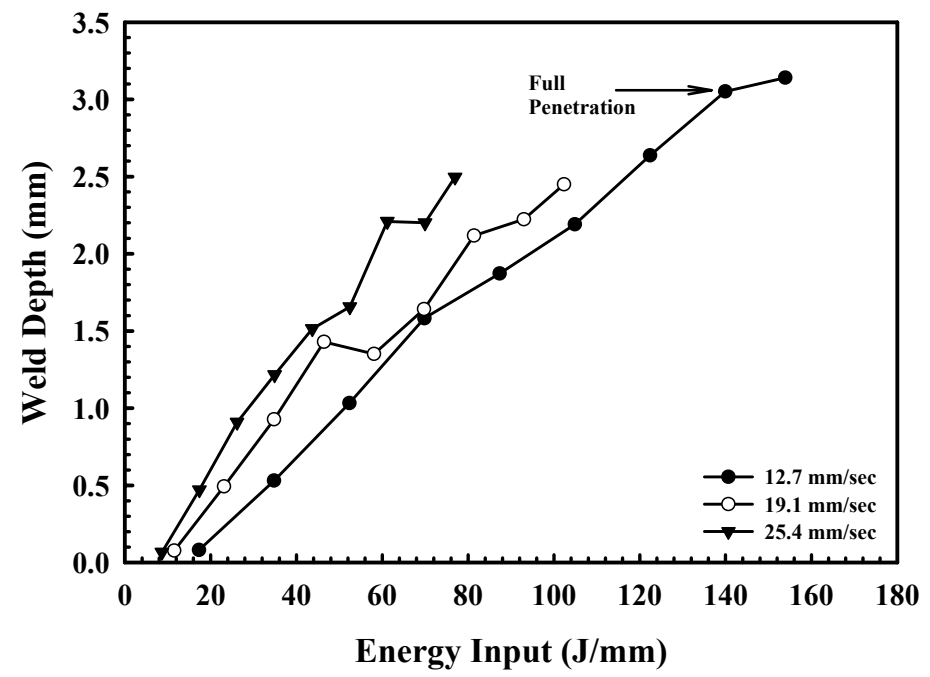

(b)

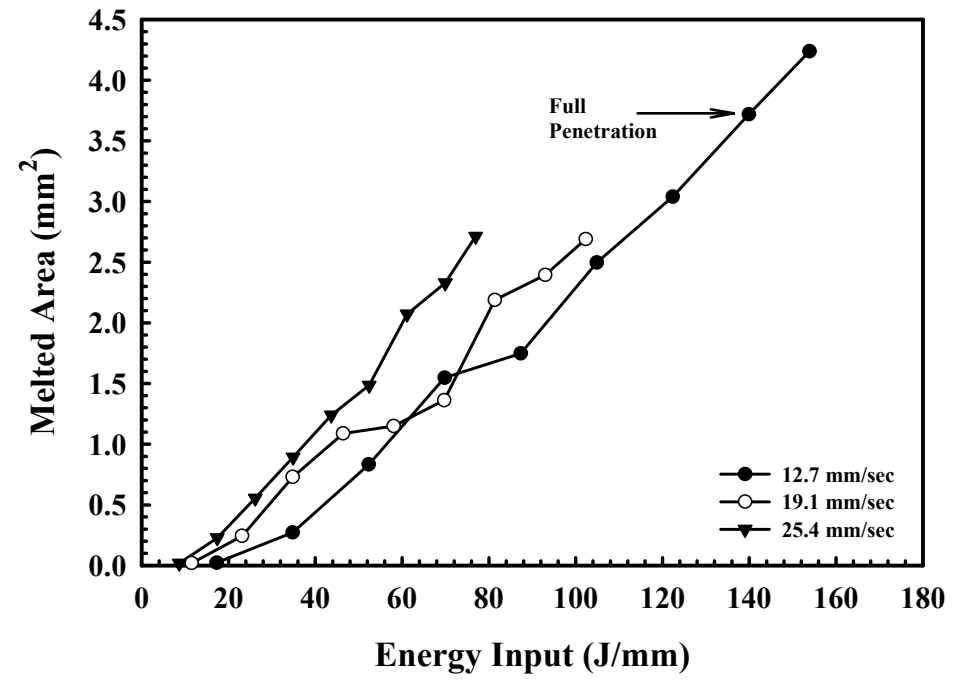

(d)

Figure 14(a-d). Plots showing variations in the (a) weld width, (b) weld depth, (c) aspect ratio (depth/width), and (d) melted area with changes in the energy input at travel speeds of $25.4 \mathrm{~mm} / \mathrm{sec}, 19.1 \mathrm{~mm} / \mathrm{sec}$ and $12.7 \mathrm{~mm} / \mathrm{sec}$ for vanadium welds made on the LLNL welder.. 


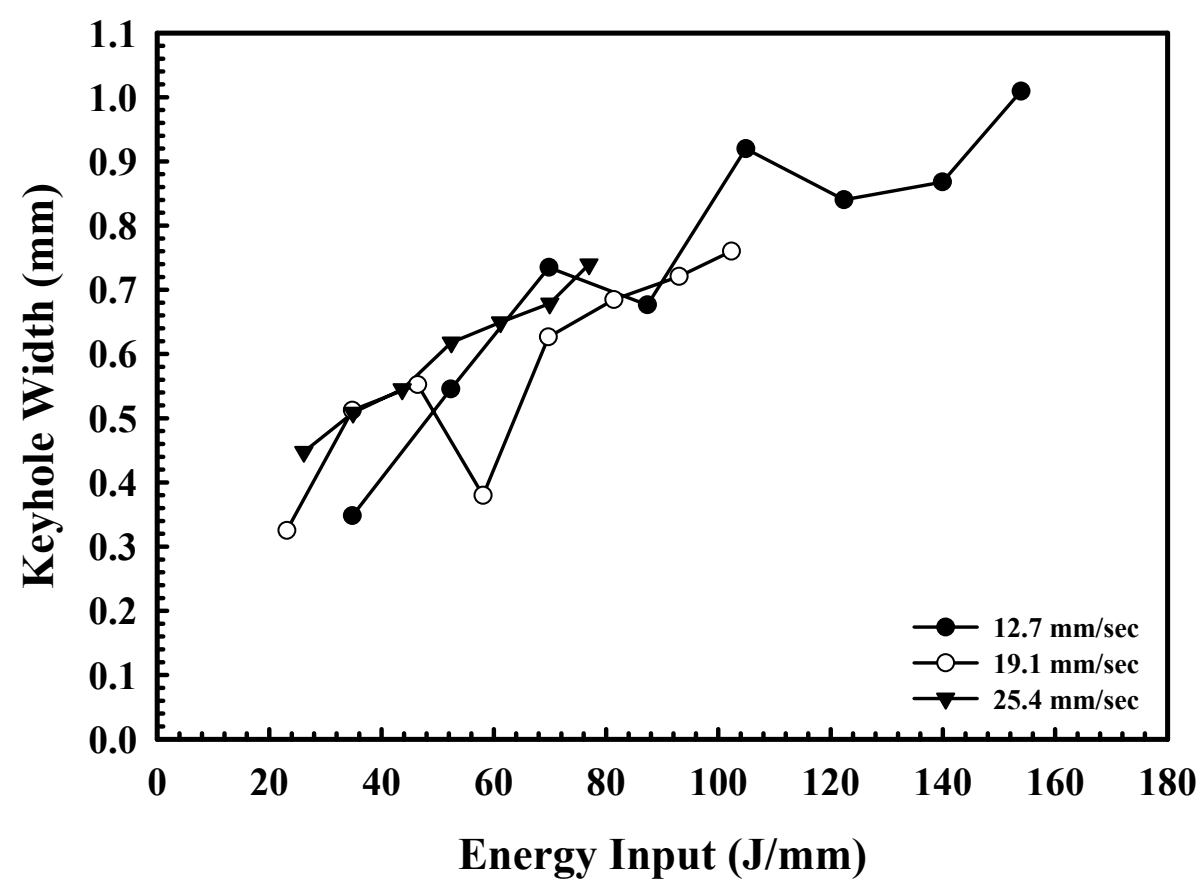

(a)

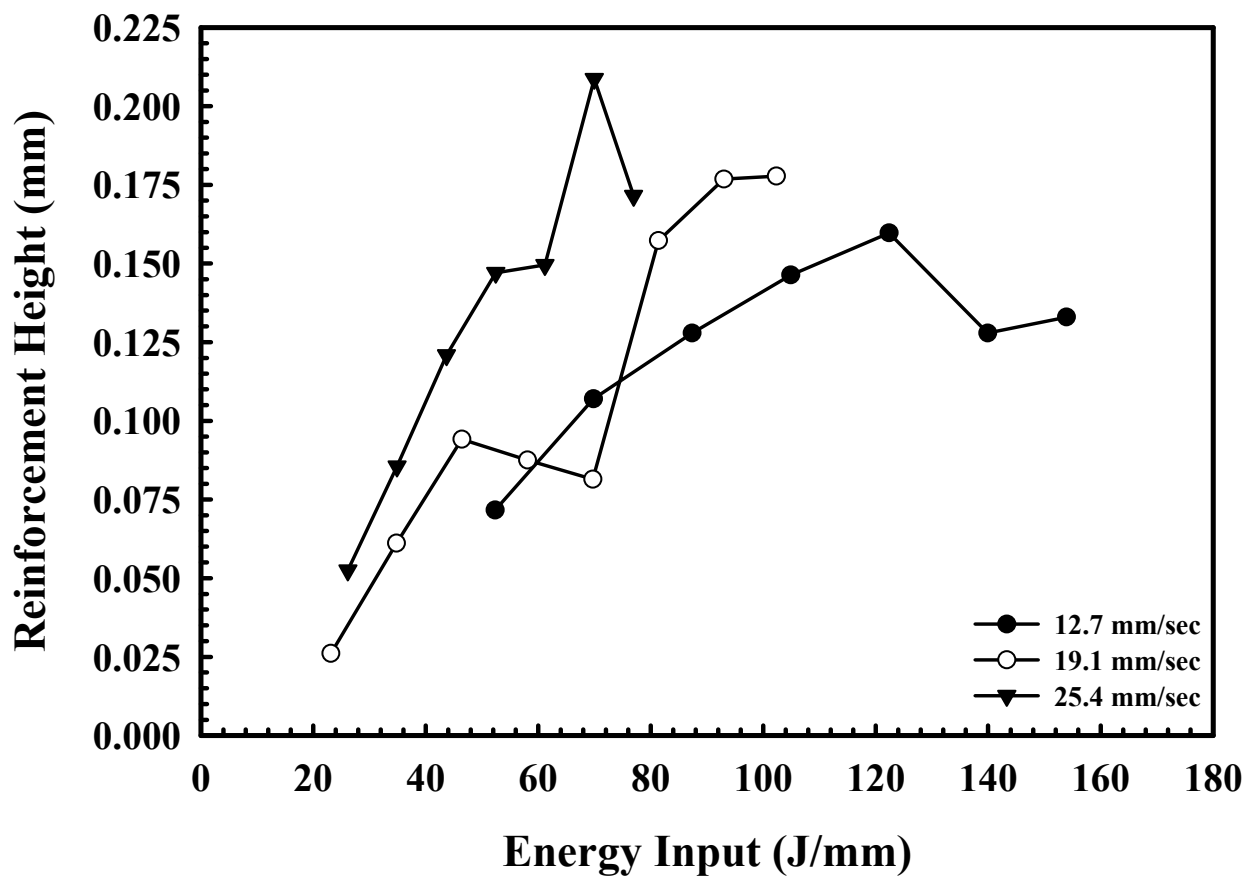

(b)

Figure 15(a\&b). Plots showing variations in the (a) keyhole width and (b) overfill height with changes in the energy input per unit length at travel speeds at $25.4 \mathrm{~mm} / \mathrm{sec}, 19.1 \mathrm{~mm} / \mathrm{sec}$ and $12.7 \mathrm{~mm} / \mathrm{sec}$ for vanadium welds made on the LLNL welder.. 
Table 5. Summary of measurements made on vanadium weld samples under similar experimental conditions using the LANL Laser Welder and a travel speed of $19.7 \mathrm{~mm} / \mathrm{sec}$.

\begin{tabular}{|c|c|c|c|c|c|c|c|}
\hline$\frac{\text { Machine }}{\frac{\text { Power }}{\text { (Watts) }}}$ & $\underline{\text { Shielding Gas }}$ & $\frac{\text { Weld Width }}{\underline{(\mathrm{mm})}}$ & Weld Depth (mm) & $\frac{\text { Aspect Ratio }}{\text { (Depth/Width) }}$ & $\frac{\text { Keyhole Width }}{\underline{(\mathrm{mm})}}$ & $\frac{\frac{\text { Reinforcement }}{\text { Height (mm) }}}{\underline{\text { (mm }}}$ & $\frac{\text { Melted Area }}{\left(\mathrm{mm}^{2}\right)}$ \\
\hline 250 & Helium & ---- & --- & --- & --- & ---- & ---- \\
\hline 500 & Helium & 0.598 & 0.213 & 0.357 & $\begin{array}{ll}--- \\
\end{array}$ & $\begin{array}{ll}--- \\
\end{array}$ & 0.095 \\
\hline 750 & Helium & 1.170 & 0.853 & 0.729 & ---- & --- & 0.681 \\
\hline 1000 & Helium & 1.378 & 1.170 & 0.849 & 0.7925 & 0.0792 & 1.002 \\
\hline 1250 & Helium & 1.671 & 1.469 & 0.808 & 1.1765 & 0.0977 & 1.669 \\
\hline 1500 & Helium & 1.902 & 1.865 & 0.981 & 1.2070 & 0.1097 & 2.295 \\
\hline 1750 & Helium & 2.232 & 2.207 & 0.989 & 1.3777 & 0.1341 & 3.162 \\
\hline 2000 & Helium & 2.384 & 2.481 & 1.041 & 1.6947 & 0.1402 & 4.181 \\
\hline 2250 & Helium & 2.542 & 3.005 & 1.182 & 1.5302 & 0.1646 & 5.149 \\
\hline 750 & Argon & 0.906 & 0.206 & 0.227 & --- & 0.1341 & 0.123 \\
\hline 1000 & Argon & 1.171 & 0.412 & 0.352 & ---- & 0.1402 & 0.356 \\
\hline 1250 & Argon & 1.594 & 1.288 & 0.808 & 1.2706 & 0.1646 & 1.567 \\
\hline
\end{tabular}




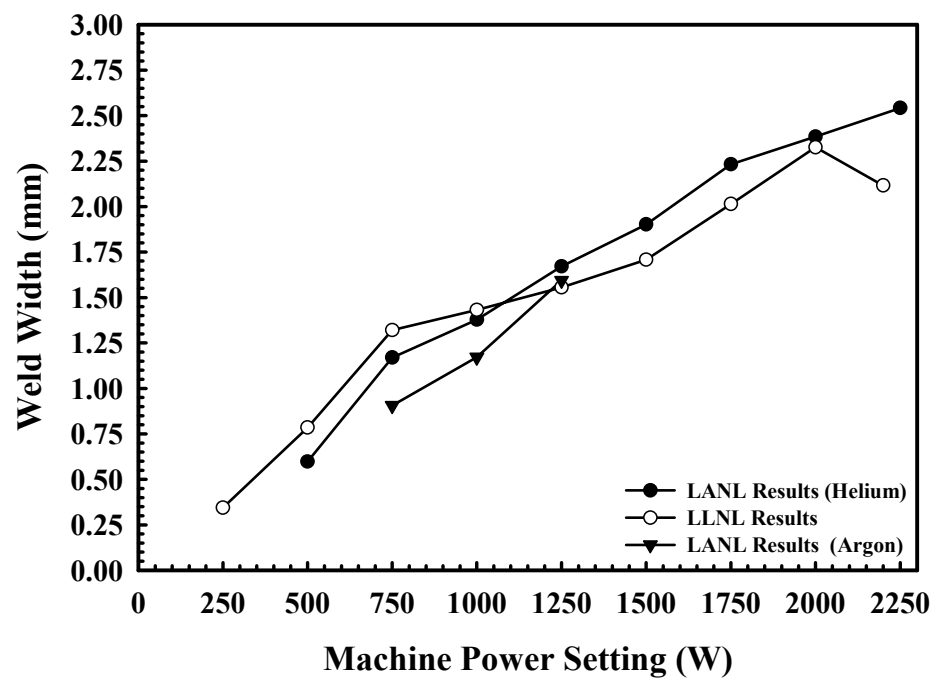

(a)

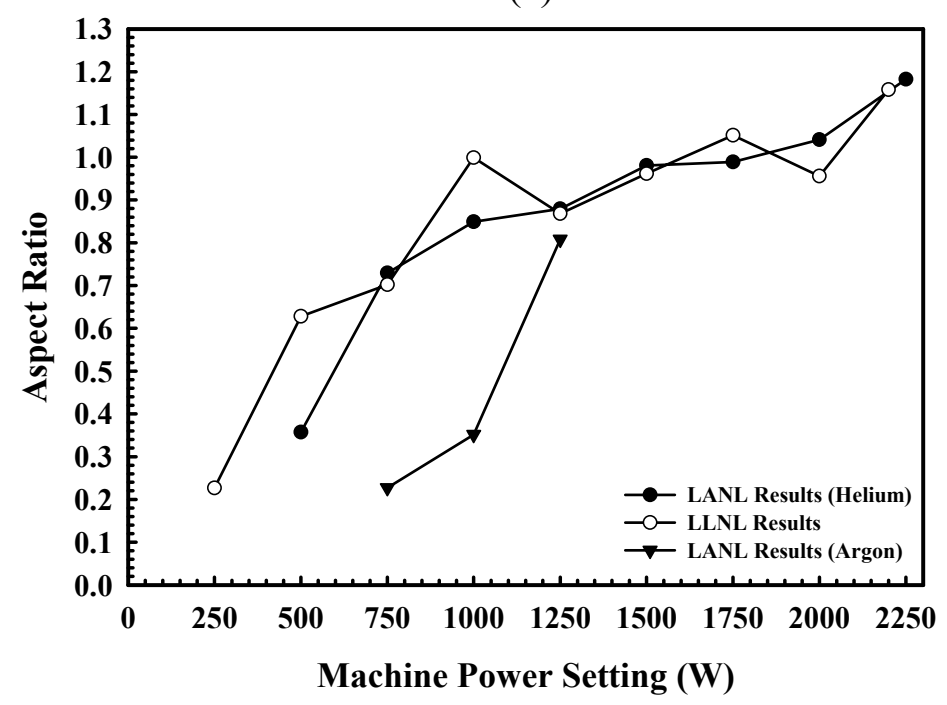

(c)

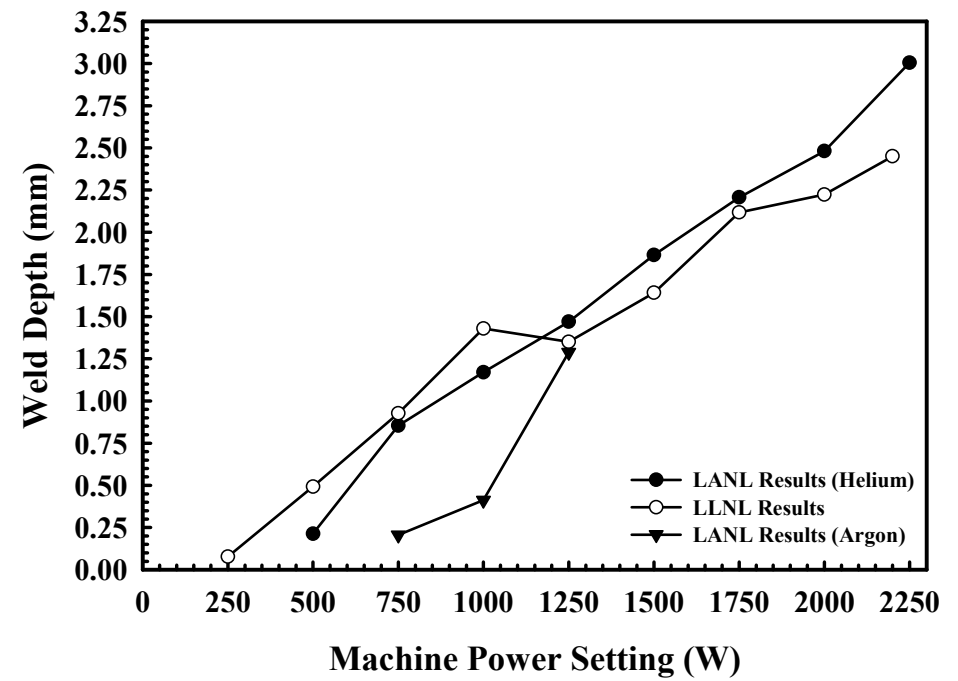

(b)

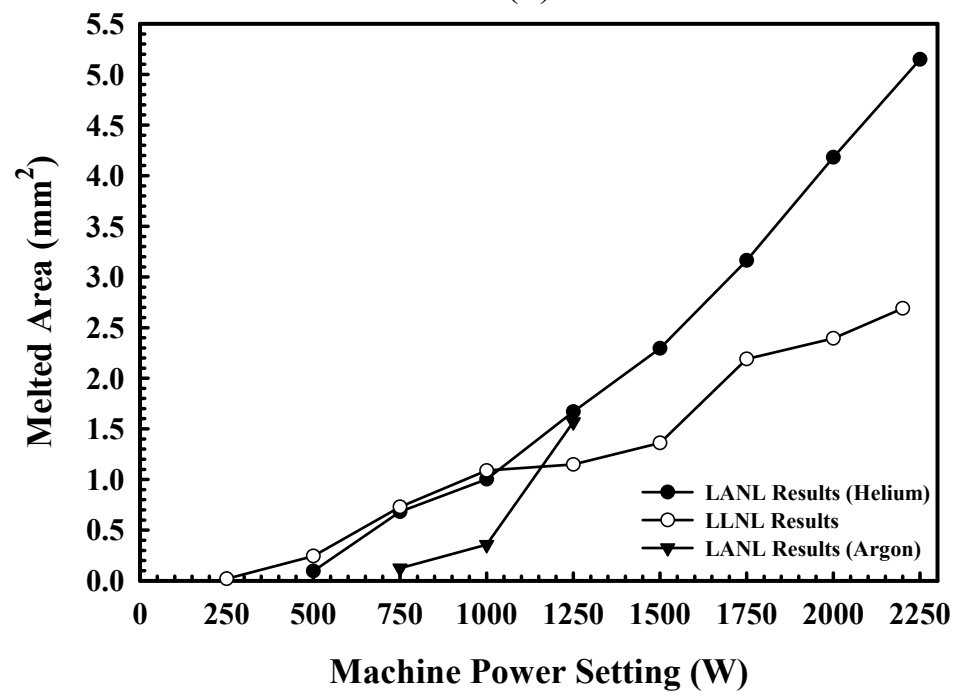

(d)

Figure 16(a-d). Comparison between (a) weld width, (b) depth, (c) aspect ratio, and (d) melted area with changes in weld power at a travel speed of $19.1 \mathrm{~mm} / \mathrm{sec}$ for LLNL and LANL vanadium weld measurements. 
UCRL-TR-222245

As shown in Figures 16(a-d), the results from the two comparable laser welding systems follow the same general trends. Overall, the results from the LLNL system compare most favorably with the LANL results using helium as a shielding gas at machine power settings up to approximately $1000 \mathrm{~W}$. Additional comparisons between these two welding systems have also been performed on measurements of the keyhole width and weld reinforcement height in Figures 17(a\&b), respectively. In these plots, the variations between the LANL and LLNL results are similar to those observed with other weld pool measurements. In terms of the keyhole width, the LANL system produces welds with much wider keyholes than the LLNL system. This increased keyhole width can be attributed, in part, to the wider laser beam spot size characteristic of the LANL system.

A comparison between the LANL results using an argon shielding gas and the LLNL results reveals a different relationship. Whereas the weld widths are comparable, as shown in Figure 17(a), the LANL results using argon as a shielding gas tend to display lower weld depths, aspect ratios, and total melted areas than both the LLNL results and the LANL results using helium. Overall, the use of helium as a shielding gas with the LANL laser produces a larger weld, particularly in terms of the melted area. This effect is most pronounced at higher power settings, where the LANL system produces a much larger weld than the LLNL system. The use of helium shielding gas with the LANL welding system is the most likely cause for this enhanced performance. Further investigation of the effects of the choice in shielding gases on the weld pool size and shape is required in order to determine if this effect can be transferred to the LLNL system.

\subsection{General Findings and Concluding Remarks}

A series of autogenous bead-on-plate laser welds have been made on $3.2 \mathrm{~mm}$ thick nominally pure vanadium samples using a Rofin Sinar DY-022 diode pumped CW Nd:YAG laser welder. The effects of variations in the machine power setting at three travel speeds on the size and shape of the resulting weld pool cross sections have been examined. Measurements of the weld width, depth, melted area, keyhole width, and weld reinforcement height have been made on each weld cross section. Comparisons with results from an equivalent laser system located at Los Alamos National Laboratory have also been made. A summary of the general findings of this study are given below:

- In the weld cross sections studied here, a keyhole welding mode is observed at machine power settings above $500 \mathrm{~W}$ for the three travel speeds considered. The conversion from conduction mode to keyhole mode welding occurs at higher levels with more rapid travel speeds.

- Porosity is observed in weld cross sections at machine power settings beginning at $500 \mathrm{~W}$ and up at each travel speed. The observed porosity is believed to originate from the collapse of the keyhole during welding.

- Increases in the laser power and decreases in travel speed result in increasing weld widths, depths, and melted areas of the weld cross sections. Full penetration welds are obtained at the highest machine power settings (2000 and $2200 \mathrm{~W}$ ) at a travel speed of $12.7 \mathrm{~mm} / \mathrm{sec}$. 
UCRL-TR-222245

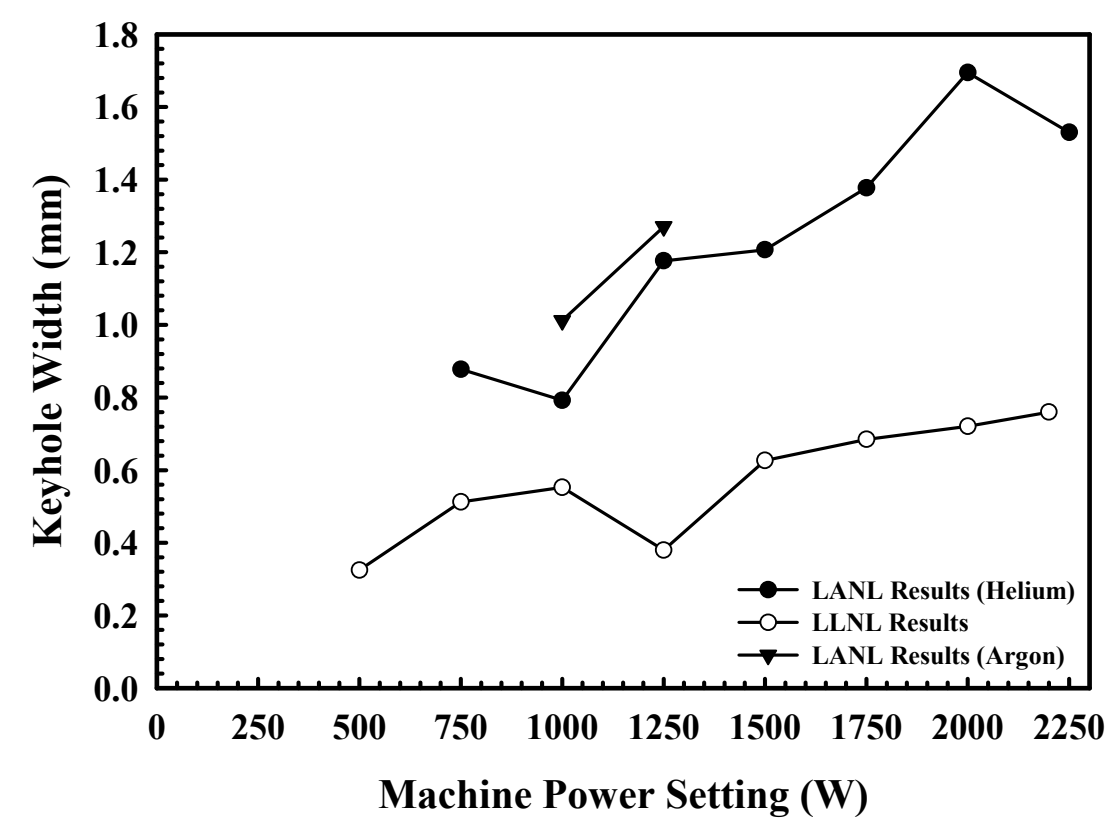

(a)

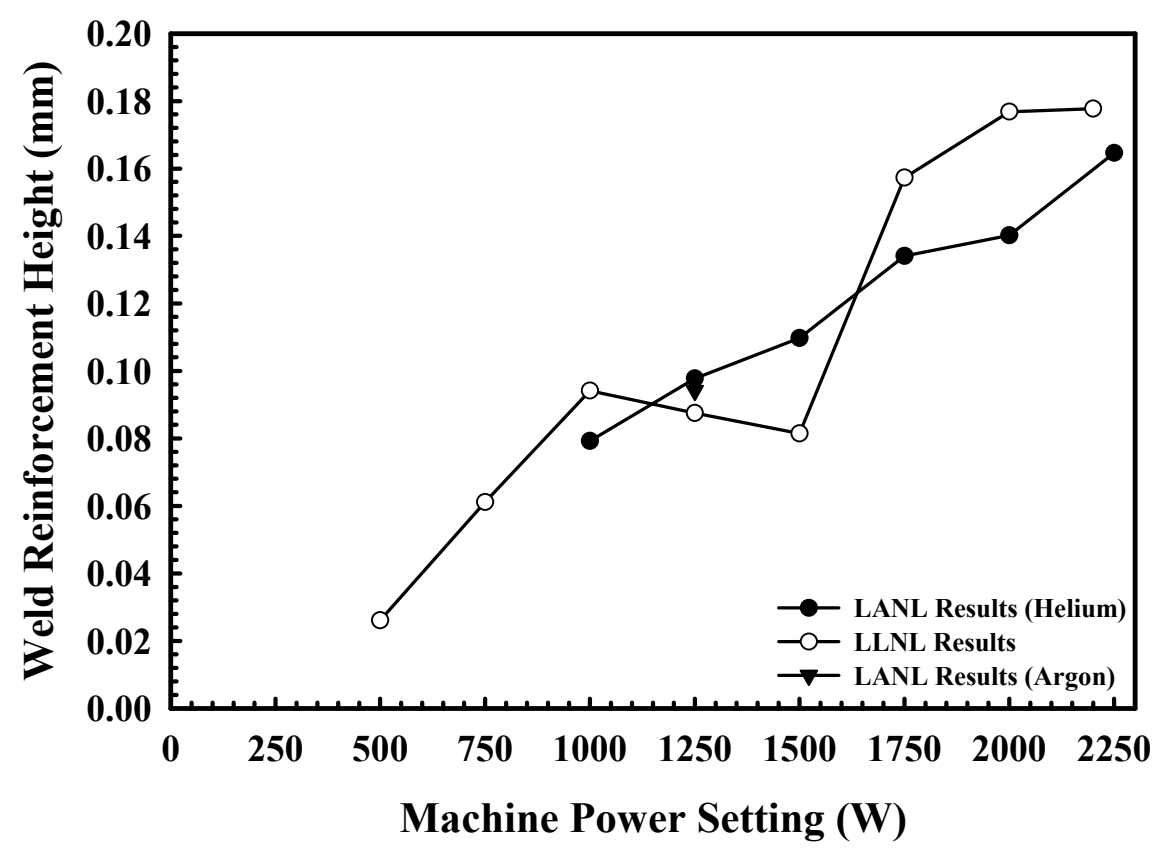

(b)

Figure 17(a\&b). Comparisons between the (a) keyhole width and (b) overfill height with changes in weld power at a travel speed of $19.1 \mathrm{~mm} / \mathrm{sec}$ for LLNL and LANL vanadium weld measurements. 
UCRL-TR-222245

- Weld aspect ratios show little variation with changes in the travel speed and do not rise to levels higher than 1.2 at the highest machine power settings. These maximum values are lower than those attained for 304L stainless steel, ${ }^{2}$ which displayed maximum aspect ratios of approximately 1.7 .

- Comparisons between the weld measurements and the energy input per unit length show that the higher travel speeds produce the larger weld pools at an equivalent energy input. This effect is due in large part to the higher power input required at the more rapid travel speeds to produce an equivalent energy input per unit length. 
UCRL-TR-222245

\section{TANTALUM LASER WELDS}

\subsection{Summary}

Laser welds were made on commercially pure tantalum to determine the geometric shape of the fusion zone for a range of weld heat inputs from $0.15 \mathrm{~kJ} / \mathrm{mm}$ to $2.2 \mathrm{~kJ} / \mathrm{mm}$. Different welding speeds were used to produce different energy inputs, all at the maximum available laser power of $2.2 \mathrm{~kW}$, to determine the maximum possible penetration that could be achieved. Results show that weld penetrations up to $2.9 \mathrm{~mm}$ can be produced in tantalum with this laser, however, weld quality degraded for penetrations greater than $2.3 \mathrm{~mm}$. By increasing the laser power to the current commercially available state-of-the art level of $4.4 \mathrm{~kW}$, weld depths approaching $5 \mathrm{~mm}$ with good weld quality should be possible using this technology.

\subsection{Experimental Summary}

A total of six welds were made, all at the maximum laser power but with different weld travel speeds to deposit different amounts of energy per unit length of weld. These welds were made on coupons measuring $150 \mathrm{~mm} \times 25 \mathrm{~mm} \times 6 \mathrm{~mm}$ thick, fabricated with a step joint $75 \%$ of the way through the thickness (see Figure 18). The laser welding parameters are summarized in Table 6 , and consist of travel speeds that vary from $0.85 \mathrm{~mm} / \mathrm{s}(2 \mathrm{ipm})$ to $12.7 \mathrm{~mm} / \mathrm{s}(30 \mathrm{ipm})$, with all other variables held constant. Each weld segment measured $43 \mathrm{~mm}$ long, and was metallographically cross sectioned near the end of each weld to determine the weld depth and width. An aqueous chemical etch consisting of 30 grams of Ammonium Bifluoride, $20 \mathrm{ml}$ water, and $50 \mathrm{ml}$ Nitric Acid was used to reveal the weld microstructure.

\section{3 $\quad$ Results}

The cross sections of the welds are shown in Figure 19, indicating that all were produced in a keyhole mode. Substantial grain growth occurred in the heat affected zone (HAZ) of the welds, particularly at the lower travel speeds. Grain growth in the HAZ and large fusion zone grains are typical of welds in high purity tantalum. Porosity was observed in several of the welds, and tended to be more prevalent as the travel speed decreased. The surface of the welds showed only small amounts of undercutting at the higher speeds, but increased significantly as the weld speed decreased. No cracking was observed in any of the welds.

The measured depths and widths of each of the welds are summarized in Table 6, showing that the maximum penetration achieved was $2.9 \mathrm{~mm}$ below the original surface of the coupon. The widths, as measured at the top surface of the coupon, were larger than the depths in all cases. The measured depth-to-width ratios decreased from 0.91 to 0.66 as the weld speed decreased.

These welds represent the first CW Nd:YAG laser welds made on tantalum at LLNL, and extend a study performed jointly by LLNL and LANL using a similar laser located in the Sigma facility at Los Alamos National Laboratory. This previous study was performed at a constant weld speed equal to the highest speed used at LLNL $(12.7 \mathrm{~mm} / \mathrm{min})$, but varied the laser power level from $0.5 \mathrm{~kW}$ to $2.0 \mathrm{~kW}$. The results of the previous study for tantalum are summarized in Table 7 for lower heat inputs than those made at LLNL. Although the fiber diameter and optics of the LANL welder is different than those used at LLNL, the weld penetration is similar at the $0.15 \mathrm{~kJ} / \mathrm{mm}$ level at approximately $2 \mathrm{~mm}$ in both cases.

The data from both studies are plotted in Fig. 3, showing the depth and width versus weld 
UCRL-TR-222245

energy input per unit length. Figure 20(a) compares the weld depths for the two studies, and reveals notably different trends for each. The open triangles represent the results for the welds that were all made at a fast travel speed of $12.7 \mathrm{~mm} / \mathrm{s}$, at power levels from $0.5 \mathrm{~kW}$ to $2.0 \mathrm{~kW}$. The trend is nearly linear over this range, showing approximately $1.1 \mathrm{~mm}$ of weld depth per 1.0 $\mathrm{kW}$ of weld power. The solid circles represent the results for the welds made at the maximum laser power of $2.2 . \mathrm{kW}$ for travel speeds that varied from $12.7 \mathrm{~mm} / \mathrm{s}$ to $0.85 \mathrm{~mm} / \mathrm{s}$. This trend shows much less increase in penetration as the energy input is increased, where the weld depth only increases $50 \%$ for a $15 \mathrm{x}$ increase in energy input. The marginal increase in penetration with energy input is common in slow speed laser welds, and results from the interaction time of the heat source with the base metal. Since the heat has more time to diffuse away from the liquid weld pool at low speeds, wider welds relative to their depths are produced. This behavior is apparent in the weld width results presented in Fig. 3b, and the aspect ratio of the welds presented in Fig. 3c, showing that the depth-to-width ratio of the welds decreases as the travel speed decreases.

Figure 21 shows the microstructure of the weld made at $2.54 \mathrm{~mm} / \mathrm{s}$ which was metallographically sectioned through a plane along the centerline of the weld and parallel to the welding direction. The longitudinal section of the weld in Figure 21(b) shows the consistency of the weld penetration and the columnar nature of the grains in the fusion zone. Porosity is present near the root of the weld, but would be expected to be less in the welds made at higher travel speeds.

In summary, weld depths up to $2.9 \mathrm{~mm}$ were produced in tantalum using a $2.2 \mathrm{~kW} \mathrm{CW} \mathrm{NdYG}$ laser. However, the practical limit for weld penetration is approximately $2.3 \mathrm{~mm}$, due to weld defects that occurred at lower travel speeds. Deeper penetrations could be accomplished using a higher power laser. The current state-of-the-art in this field is a $4.4 \mathrm{~kW}$ diode pumped CW NdYAG laser made by Rofin Sinar, which will produce an estimated weld penetration approaching $5 \mathrm{~mm}$ in tantalum at a travel speed of $12.7 \mathrm{~mm} / \mathrm{s}$ by extrapolating the data (open triangles) presented in Figure 20(a). Demonstrations of the performance of a $4.4 \mathrm{~kW}$ laser welder could be performed using the Rofin Sinar applications laboratory in Detroit Michigan. 
UCRL-TR-222245

Table 6. Summary of laser welds made in tantalum at LLNL on June 17, 2003

\begin{tabular}{|c|c|c|c|c|c|c|c|}
\hline $\begin{array}{c}\text { Power } \\
\text { on Part } \\
(\mathrm{W})\end{array}$ & $\begin{array}{c}\text { Travel } \\
\text { Speed } \\
(\mathrm{mm} / \mathrm{s})\end{array}$ & $\begin{array}{c}\text { Energy/Length } \\
\text { of weld } \\
(\mathrm{kJ} / \mathrm{mm})\end{array}$ & $\begin{array}{c}\text { Shielding } \\
\text { Gas } \\
(80 \mathrm{psi})\end{array}$ & $\begin{array}{c}\text { *Incident } \\
\text { Angle } \\
(\mathrm{deg})\end{array}$ & $\begin{array}{c}\text { Weld } \\
\text { Depth } \\
(\mathrm{mm})\end{array}$ & $\begin{array}{c}* * \text { Weld } \\
\text { Width } \\
(\mathrm{mm})\end{array}$ & $\begin{array}{c}\text { Depth/ } \\
\text { Width } \\
\text { ratio }\end{array}$ \\
\hline 1900 & 12.7 & 0.15 & Argon & 5 & 2.0 & 2.2 & 0.91 \\
\hline 1900 & 6.40 & 0.30 & Argon & 5 & 2.2 & 2.6 & 0.85 \\
\hline 1900 & 3.81 & 0.50 & Argon & 5 & 2.3 & 3.1 & 0.74 \\
\hline 1900 & 2.54 & 0.74 & Argon & 5 & 2.5 & 3.7 & 0.68 \\
\hline 1900 & 1.70 & 1.18 & Argon & 5 & 2.7 & 3.5 & 0.77 \\
\hline 1900 & 0.85 & 2.23 & Argon & 5 & 2.9 & 4.4 & 0.66 \\
\hline
\end{tabular}

* beam angled toward front keyhole wall

** width at top surface

$300 \mu \mathrm{m}$ diameter fiber

$160 \mathrm{~mm}$ lens, $160 \mathrm{~mm}$ collimator

Sharp focus on plate surface, beam diameter $\sim 300 \mu \mathrm{m}$

Table 7. Summary of laser welds made in tantalum at LANL, 2001

\begin{tabular}{|c|c|c|c|c|c|c|c|}
\hline $\begin{array}{c}\text { Power } \\
\text { Setting } \\
(\mathrm{W})\end{array}$ & $\begin{array}{c}\text { Travel } \\
\text { Speed } \\
(\mathrm{mm} / \mathrm{s})\end{array}$ & $\begin{array}{c}\text { Energy/Length } \\
\text { of weld } \\
(\mathrm{kJ} / \mathrm{mm})\end{array}$ & $\begin{array}{c}\text { Shielding } \\
\text { Gas }\end{array}$ & $\begin{array}{c}\text { Incident } \\
\text { Angle } \\
(\mathrm{deg})\end{array}$ & $\begin{array}{c}\text { Weld } \\
\text { Depth } \\
(\mathrm{mm})\end{array}$ & $\begin{array}{c}\text { **Weld } \\
\text { Width } \\
(\mathrm{mm})\end{array}$ & $\begin{array}{c}\text { Depth/ } \\
\text { Width } \\
\text { ratio }\end{array}$ \\
\hline 500 & 12.7 & 0.039 & Helium & 10 & 0.100 & 0.336 & 0.298 \\
\hline 1000 & 12.7 & 0.079 & Helium & 10 & 0.471 & 0.471 & 1.000 \\
\hline 1500 & 12.7 & 0.118 & Helium & 10 & 1.576 & 1.612 & 0.978 \\
\hline 1750 & 12.7 & 0.138 & Helium & 10 & 1.776 & 1.777 & 0.999 \\
\hline 2000 & 12.7 & 0.157 & Helium & 10 & 2.200 & 2.436 & 0.903 \\
\hline
\end{tabular}

* beam angled toward front keyhole wall

**width at top surface

$400 \mu \mathrm{m}$ diameter fiber

$160 \mathrm{~mm}$ lens, $120 \mathrm{~mm}$ collimator

Sharp focus on plate surface, beam diameter $\sim 540 \mu \mathrm{m}$ 
UCRL-TR-222245

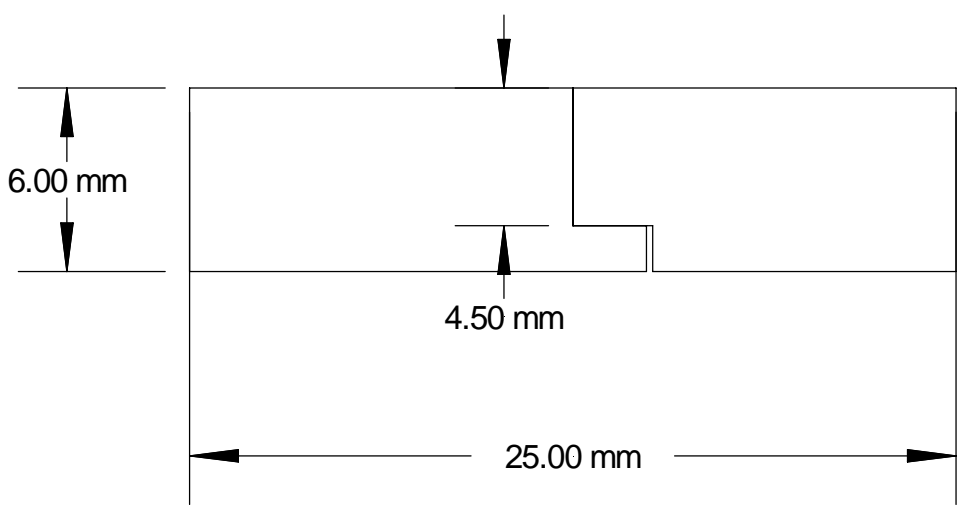

Figure 18. Cross section of the weld coupon showing the step joint configuration. The laser impinges on the top surface, and a small gap is left on the bottom side of the coupon to insure zero gap along the weld seam. 

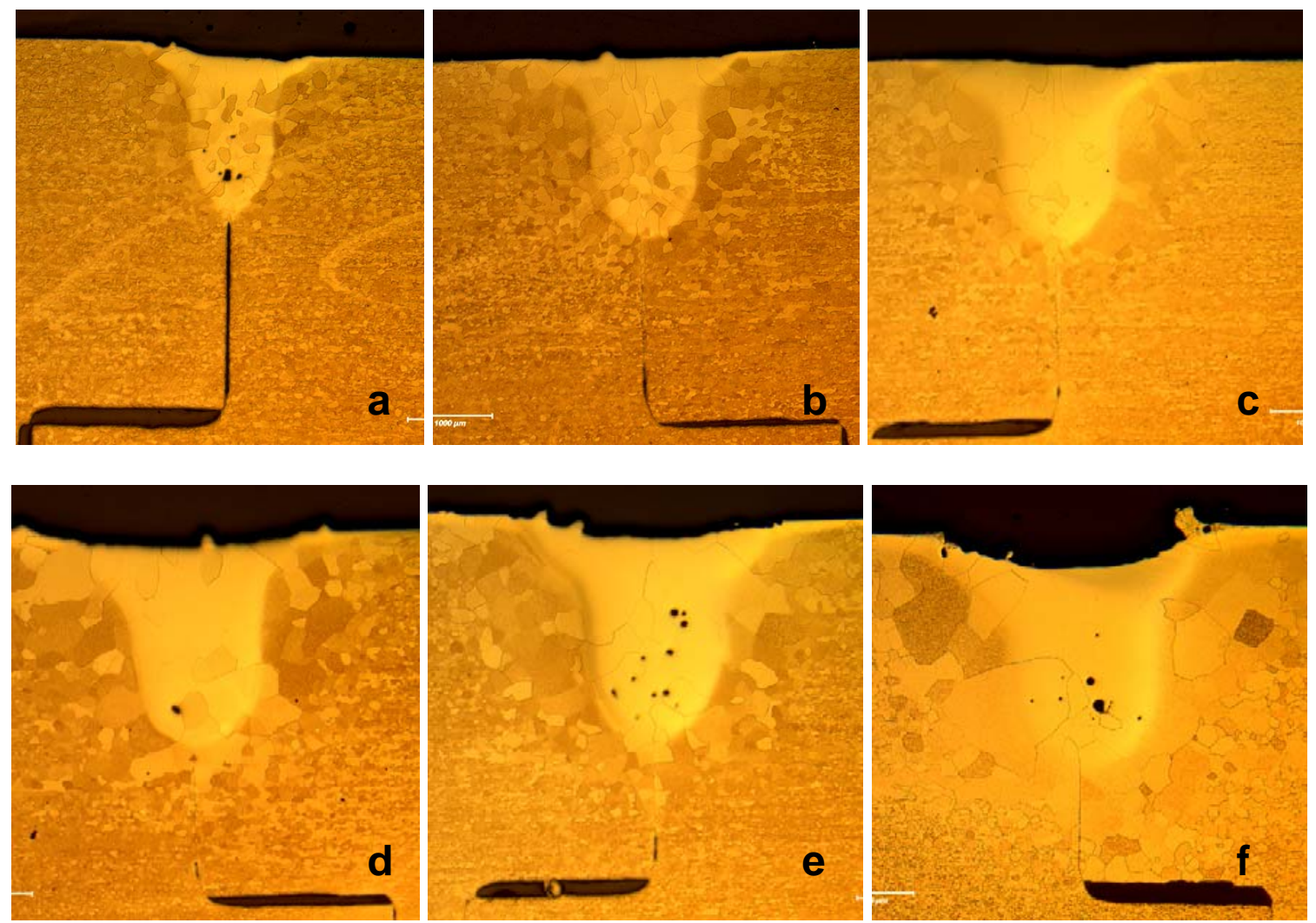

Figure 19: Metallographic cross sections of the six welds made at a delivered power of $1.9 \mathrm{~kW}$ on the surface of the tantalum coupons made at LLNL. a) $12.7 \mathrm{~mm} / \mathrm{s}$, b) $6.4 \mathrm{~mm} / \mathrm{s}$, c) $3.8 \mathrm{~mm} / \mathrm{s}$, d) $2.54 \mathrm{~mm} / \mathrm{s}$, e) $1.70 \mathrm{~mm} / \mathrm{s}$, f) $0.85 \mathrm{~mm} / \mathrm{s}$. 
UCRL-TR-222245
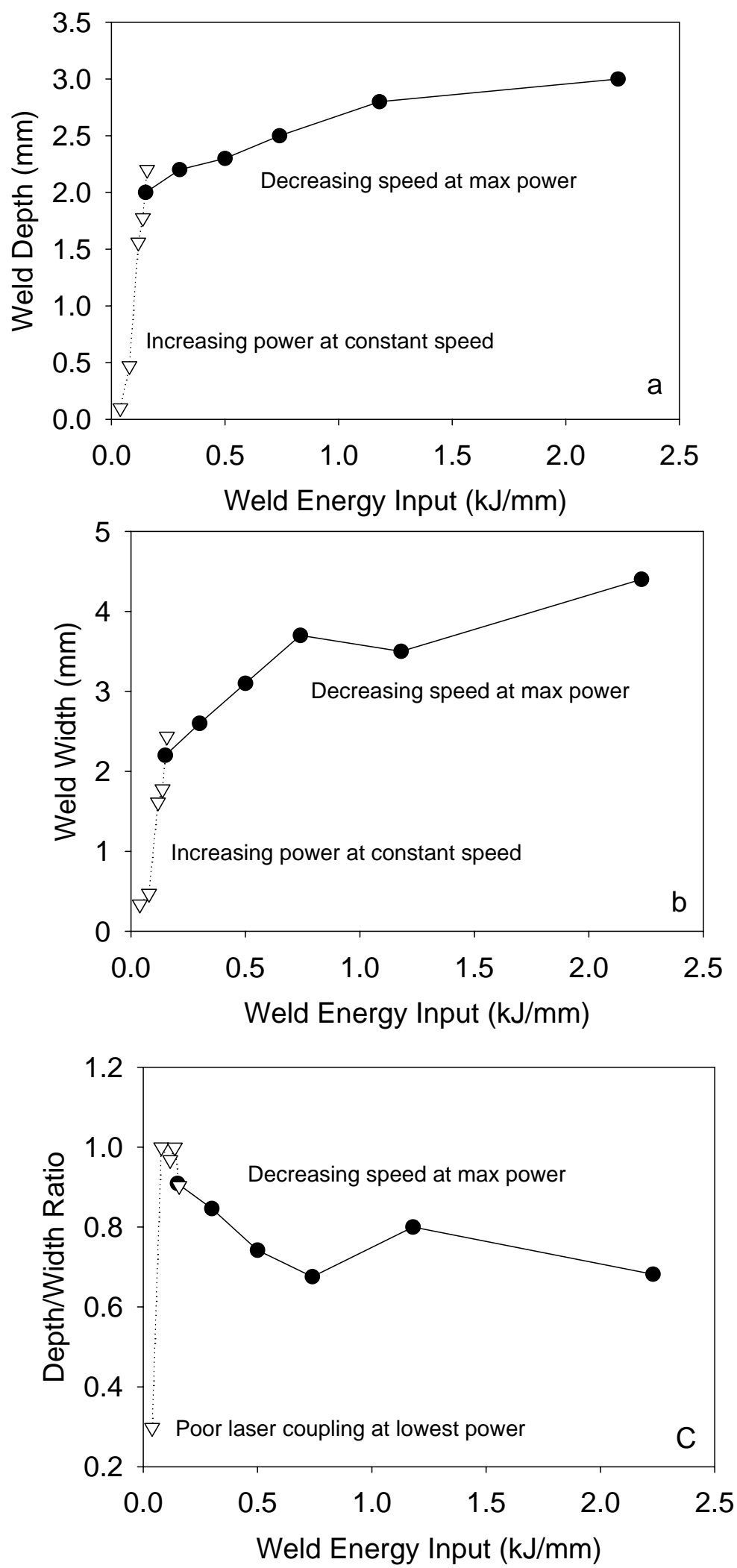

Figure 20(a-c). a) Weld depth, b) weld width, and c) weld aspect ratio, plotted versus energy input for tantalum welds made at LLNL. The open triangles give results of the laser power study at a constant weld speed of $12.7 \mathrm{~mm} / \mathrm{s}$, while the open circles give results of the weld speed study at the max laser power of $2.2 \mathrm{~kW}$. 

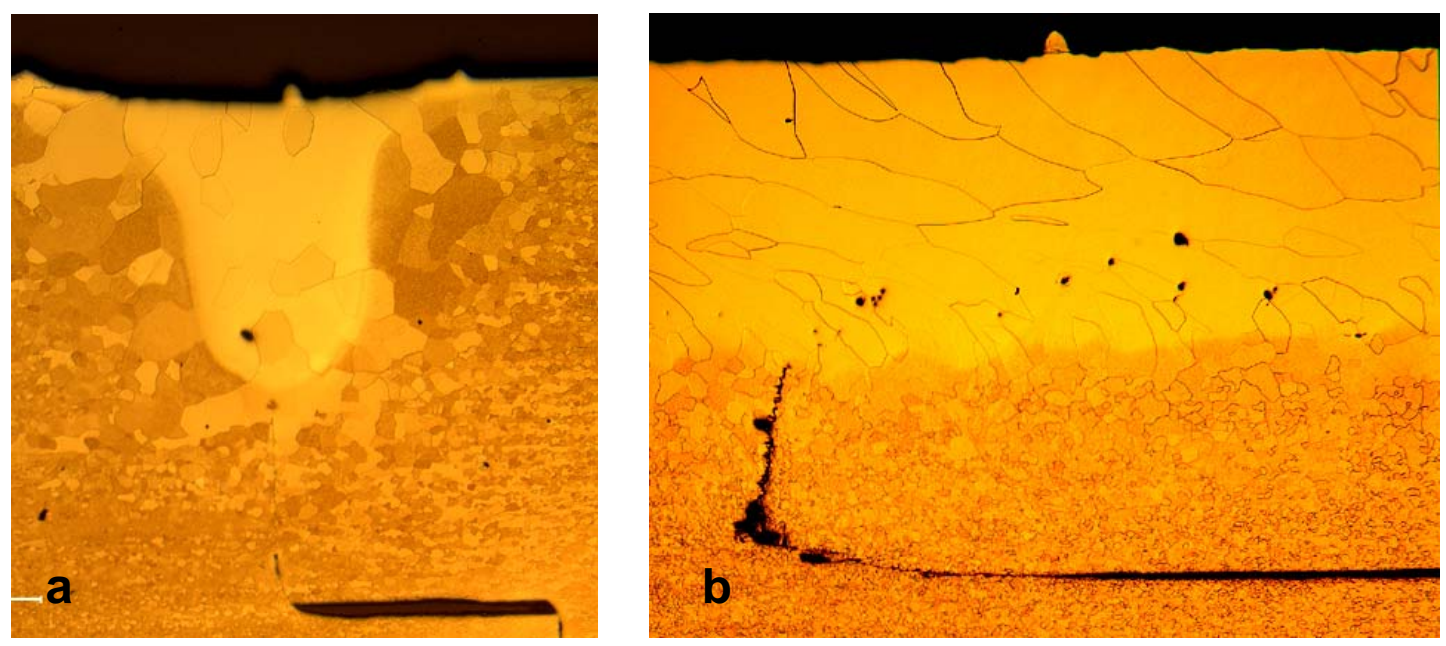

Figure 21(a\&b). a) Cross section of the $1.9 \mathrm{~kW}$ laser weld made at $2.54 \mathrm{~mm} / \mathrm{s}$ on tantalum at LLNL, and b) longitudinal section through the centerline of this same weld. Note the presence of porosity in the lower portion of the weld, and reasonably consistent weld penetration. The weld direction was from right to left in (b). 
UCRL-TR-222245

\section{304L STAINLESS STEEL LASER WELDS}

\subsection{Summary}

A series of autogenous partial-penetration bead on plate laser welds were made on 304L stainless steel plate using a Rofin Sinar DY-022 Continuous Wave (CW) Nd:YAG welder at Lawrence Livermore National Laboratory (LLNL). The goal of these experiments was to examine the performance of this newly installed laser system and to determine the weld fusion zone geometry as a function of laser welding parameters. High depth-to-width ratio welds were produced with weld penetrations up to $5 \mathrm{~mm}$. The results were compared with those taken under similar experimental conditions on equivalent laser systems, showing that the LLNL system produces equivalent or slightly deeper welds. Porosity, which is attributed to the collapse of the keyhole during welding, was also observed in many of the welds.

\subsection{Experimental Summary}

Autogenous bead-on-plate laser welds have been made using the LLNL laser system on 9.5 mm thick x $152.4 \mathrm{~mm}$ long x $25.4 \mathrm{~mm}$ wide 304L stainless steel weld samples. In addition to the LLNL system, welds are made on two comparable systems, located at Los Alamos National Laboratory (LANL) and the Rofin Sinar Development Labs in Detroit, MI, under similar welding conditions. A summary of the general characteristics of the three laser systems used in this study is given in Table 8. Generally, the LLNL and Rofin Sinar systems display similar properties, primarily because the same optics system is used for the results reported on the two systems. Power is delivered from the laser power supply to the workpiece using the $300 \mu \mathrm{m}$ diameter fiber. Three welds, $43.2 \mathrm{~mm}$ in length, are made on each of these stainless steel samples. All of the samples used in the LLNL and Rofin Sinar studies originate from the same heat of material. The welds from the LANL study are made on $3.2 \mathrm{~mm}$ thick samples with a step joint machined into each abutting edge. ${ }^{2}$ A summary of the chemical compositions of the 304L stainless steel used in each study is given in Table 9.

Three primary studies have been performed on the 304L stainless steel samples using the LLNL laser system. These studies include two power variation studies using machine power settings ranging from $250 \mathrm{~W}$ to $2200 \mathrm{~W}$ at travel speeds of 12.7 and $19.1 \mathrm{~mm} / \mathrm{sec}$ and a travel speed variation study at travel speeds ranging from $4.2 \mathrm{~mm} / \mathrm{sec}$ to $16.9 \mathrm{~mm} / \mathrm{sec}$ at the maximum machine output power setting of $2200 \mathrm{~W}$. All welds reported here are made with the laser focus set on the surface of the welding sample. In this sharp focus condition, the theoretical beam diameter is $300 \mu \mathrm{m}$. Argon gas is used to shield the welding area and to displace the laser plasma plume during welding. The laser optics assembly is set at an angle normal to the sample surface, since no back reflection is expected because of the superior coupling between the $\mathrm{Nd}$ :YAG laser wavelength light and the stainless steel surface.

\section{$5.3 \quad \underline{\text { Results }}$}

\subsubsection{Power Variation Studies}

The first series of weld experiments discussed here examines the effects of changes in power on the resulting weld pool cross-section shape and size. Two sets of experiments, with machine power settings ranging from $250 \mathrm{~W}$ to $2200 \mathrm{~W}$, which translate into powers of $220 \mathrm{~W}$ to $1955 \mathrm{~W}$ impinging on the surface of the weld sample, are performed at travel speeds of $12.7 \mathrm{~mm} / \mathrm{sec}$ and $19.1 \mathrm{~mm} / \mathrm{sec}$. Micrographs showing the weld cross sections for four power settings 
UCRL-TR-222245

Table 8. Comparison of laser welding systems used in this study.

\begin{tabular}{|c|c|c|c|c|c|c|}
\hline & $\frac{\text { Model }}{\text { Number }}$ & $\frac{\frac{\text { Peak }}{\text { Output }}}{\frac{\text { Power }}{(W)}}$ & $\frac{\frac{\text { Fiber }}{\text { Diameter }}}{(\mu \mathrm{m})}$ & $\frac{\text { Collimating }}{\frac{\text { Lens Focal }}{\frac{\text { Length }}{(\mathrm{mm})}}}$ & 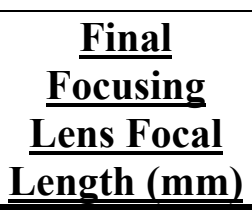 & $\frac{\frac{\text { Calculated }}{\text { Beam Size }}}{(\mu \mathrm{m})}$ \\
\hline LLNL* & DY -022 & 2200 & 300 & 160 & 160 & $\sim 300$ \\
\hline Rofin-Sinar* & DY-044 & 4400 & 300 & 160 & 160 & $\sim 300$ \\
\hline LANL & DY-033 & 3300 & 400 & 120 & 160 & $\sim 530$ \\
\hline
\end{tabular}

* Welds made on these two systems utilize the same optics.

Table 9. Chemical compositions of 304L stainless steel autogenous welding samples used here. (All values are in wt.\%.)

\begin{tabular}{|c|c|c|}
\hline & $\frac{\text { LLNL and Rofin Sinar }}{\text { Welds }}$ & $\underline{\text { LANL Welds }}$ \\
\hline $\mathrm{Fe}$ & Balance & Balance \\
\hline $\mathrm{Cr}$ & 18.20 & 18.3 \\
\hline $\mathrm{Ni}$ & 8.16 & 8.7 \\
\hline $\mathrm{Mn}$ & 1.71 & 1.9 \\
\hline $\mathrm{Mo}$ & 0.47 & 0.256 \\
\hline $\mathrm{Co}$ & 0.14 & 0.094 \\
\hline $\mathrm{Cu}$ & 0.35 & 0.277 \\
\hline $\mathrm{Si}$ & 0.44 & 0.478 \\
\hline $\mathrm{C}$ & 0.020 & 0.0218 \\
\hline $\mathrm{N}$ & 0.082 & 0.076 \\
\hline $\mathrm{P}$ & 0.03 & 0.020 \\
\hline $\mathrm{S}$ & 0.0004 & ---- \\
\hline
\end{tabular}


between 500 and $2000 \mathrm{~W}$ are shown in Figures 22 and 23 for travel speeds of $19.1 \mathrm{~mm} / \mathrm{sec}$ and $12.7 \mathrm{~mm} / \mathrm{sec}$, respectively. There are two characteristics common to the micrographs in each of these figures. The first characteristic involves the general shape of the weld cross sections, which provides an indication of the prominent welding mode at that power setting. The second characteristic involves the presence of porosity in the weld cross section.

In laser welding, the conduction and keyhole modes are the two prominent welding modes. Conduction mode laser welding is typical at lower powers, where the heat transfer conditions between the laser beam and the sample surface result in a semi-hemispherical shaped weld pool, such as that observed at a machine setting of $250 \mathrm{~W}$ and a travel speed of $19.1 \mathrm{~mm} / \mathrm{sec}$ and shown in Figure 24. At higher powers, though, the power densities become high enough, usually on the order of $10^{6} \mathrm{~W} / \mathrm{cm}^{2}$ or higher, to produce strong evaporation on the weld pool surface. As a result, this energetic evaporation produces a recoil pressure, which is sufficient to produce a deep, narrow depression in the molten material. This depression is referred to as a keyhole, and is filled with a partially ionized plume of vapor and ambient gas. ${ }^{2}$ With the presence of a keyhole, the weld pool cross sections take on a much different shape, characterized by a semihemispherical top and a finger-like protrusion into the material being welded. It is apparent that in the welds produced here a keyhole welding mode is achieved at a machine setting of $500 \mathrm{~W}$, corresponding to a power density of $7 \times 10^{5} \mathrm{~W} / \mathrm{cm}^{2}$, and maintained at higher powers. Under these conditions, porosity appeared in the welds.

Both minor and gross porosity present in the weld cross sections are shown in Figures 22(ad). Since each cross section represents only a single location along the length of each weld, porosity is therefore assumed to be present in all the welds. In other fusion welding processes, such as arc welding, porosity is typically associated with the gas absorption, typically involving hydrogen, oxygen, or nitrogen. In high power continuous wave laser welds, which rely on a keyhole welding mode to achieve the desired penetration, porosity of this type is typically observed and is typically associated with the stability of the keyhole. ${ }^{3}$ It is important to understand that the keyhole formed during laser welding is constantly fluctuating and relies on a complex interaction of many factors, including evaporation recoil pressure, hydrodynamic pressures created by the melt and the laser plume, hydrostatic pressure, and surface tension, in order to remain stable. As a result, small fluctuations or variations in the keyhole result in the formation of small perturbations on the keyhole walls or its complete collapse. These instabilities thus result in the ejection of metal vapor and entrapped shielding gas from the keyhole column, leaving behind a non-continuous trail of pores along the longitudinal orientation of the weld.

A summary of the weld measurements taken on each weld is given in Table 10. The values for the power used on each weld correspond with the values measured by a power meter in the workstation chamber. In addition to these measurements, the aspect ratio of each weld, which is defined as the depth to width ratio, is also listed. This value provides a measure of the general shape of the weld fusion zone not available with simple width and depth measurements alone. For example, a typical keyhole weld, which displays a larger depth than width, will have an aspect ratio greater than unity. Plots comparing each of these measurements with the power impinging on the sample surface are shown in Figures 25(a-d) for each travel speed. With increasing power, both the weld width and depth increase, albeit at different rates. For the two travel speeds investigated, the speed has a minimal effect on the weld depth, a decrease in the travel speed produces a significantly wider weld, as is shown in Figure 25(a). 


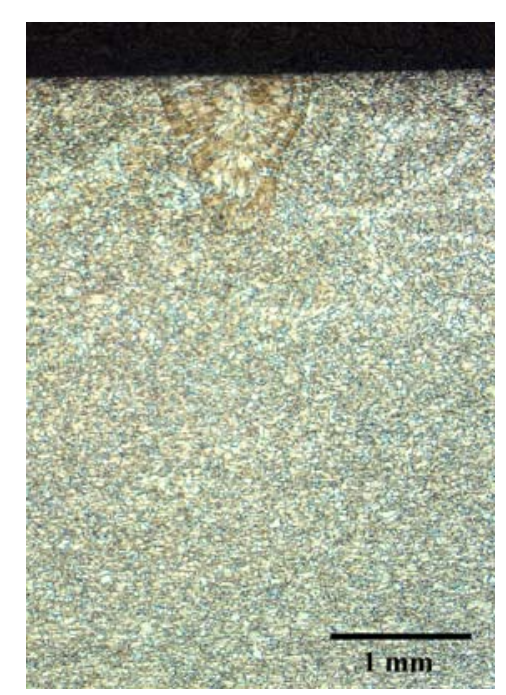

(a)

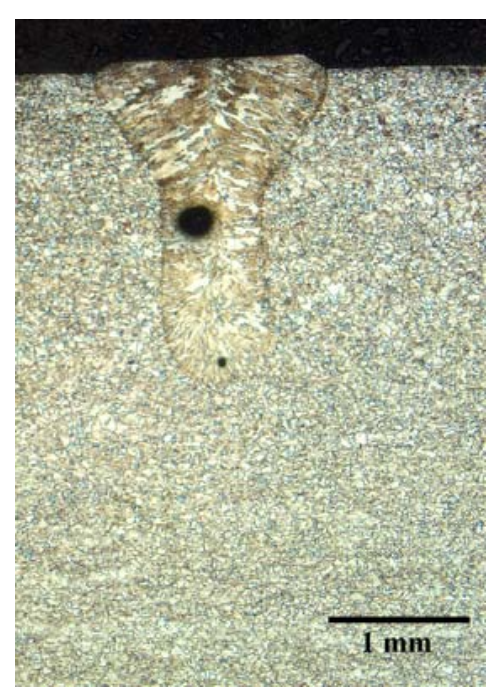

(b)

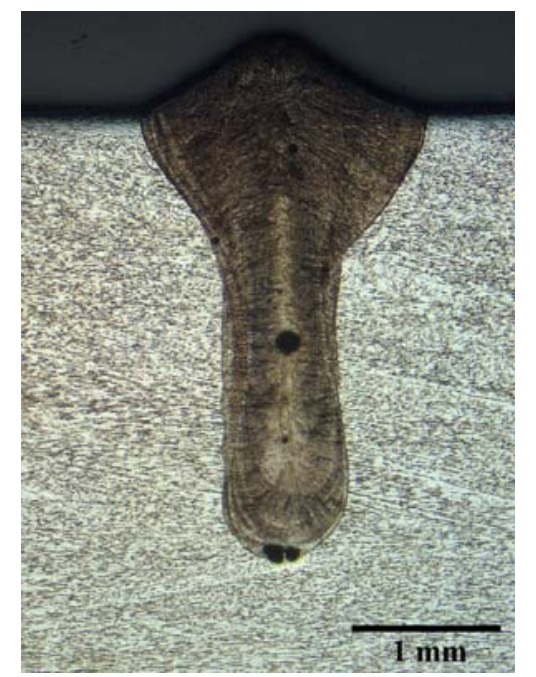

(c)

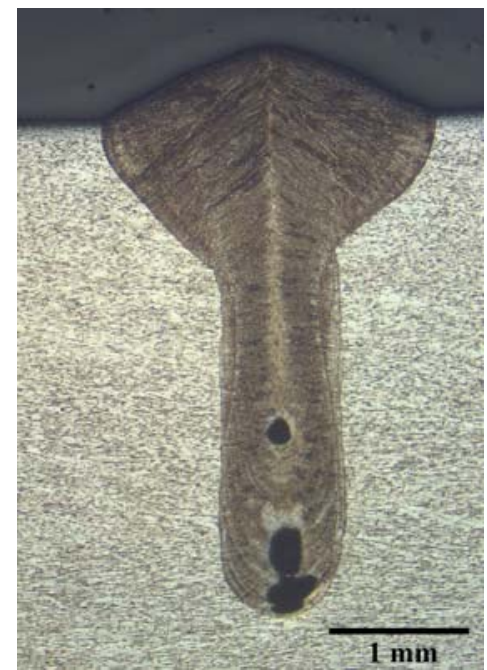

(d)

Figure 22(a-d). Micrographs of 304L stainless steel weld cross sections for machine power settings of (a) $500 \mathrm{~W}$, (b) $1000 \mathrm{~W}$, (c) 1500 $\mathrm{W}$, and (d) $2000 \mathrm{~W}$ at a travel speed of $19.1 \mathrm{~mm} / \mathrm{sec}$. These welds have been made on the LLNL laser system. 


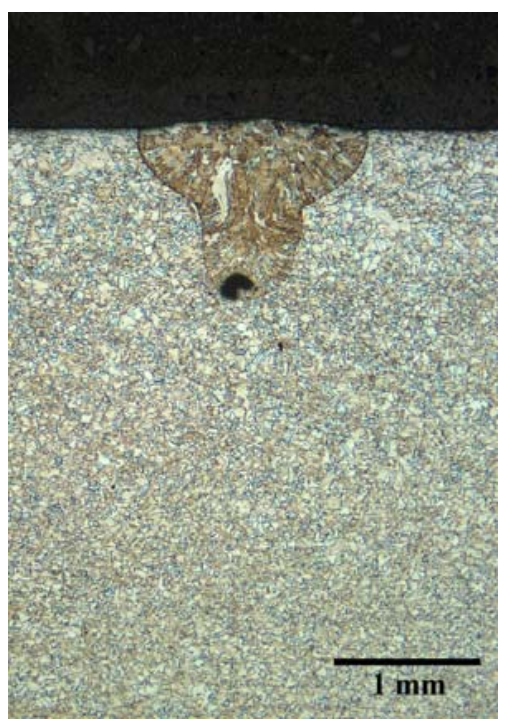

(a)

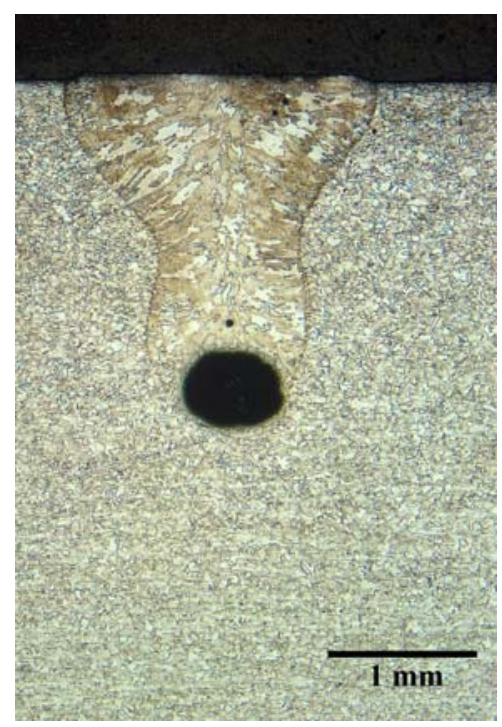

(b)

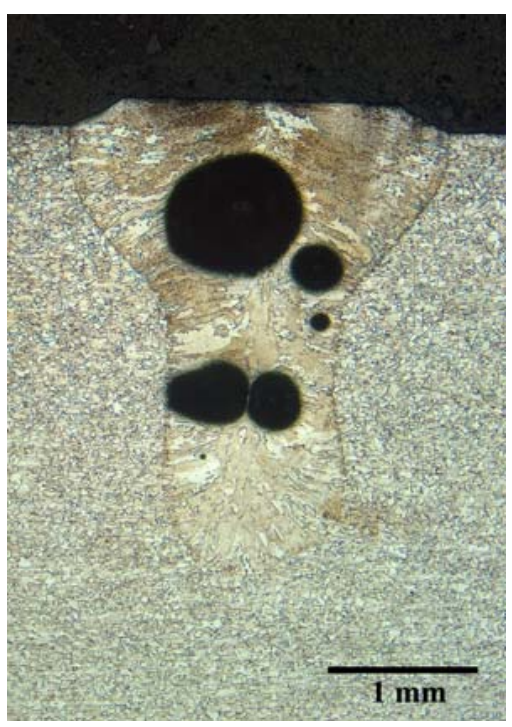

(c)

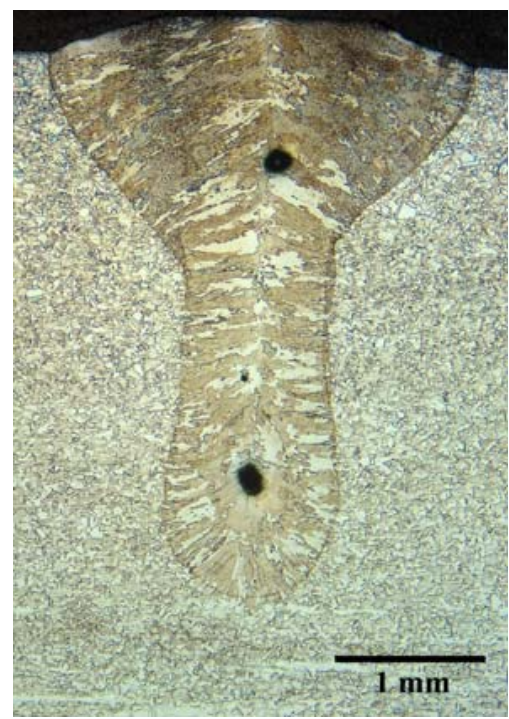

(d)

Figure 23(a-d). Micrographs of 304L stainless steel weld cross sections for machine power settings of (a) $500 \mathrm{~W}$, (b) $1000 \mathrm{~W}$, (c) 1500 $\mathrm{W}$, and (d) $2000 \mathrm{~W}$ at a travel speed of $12.7 \mathrm{~mm} / \mathrm{sec}$. These welds have been made on the LLNL laser system. 
UCRL-TR-222245

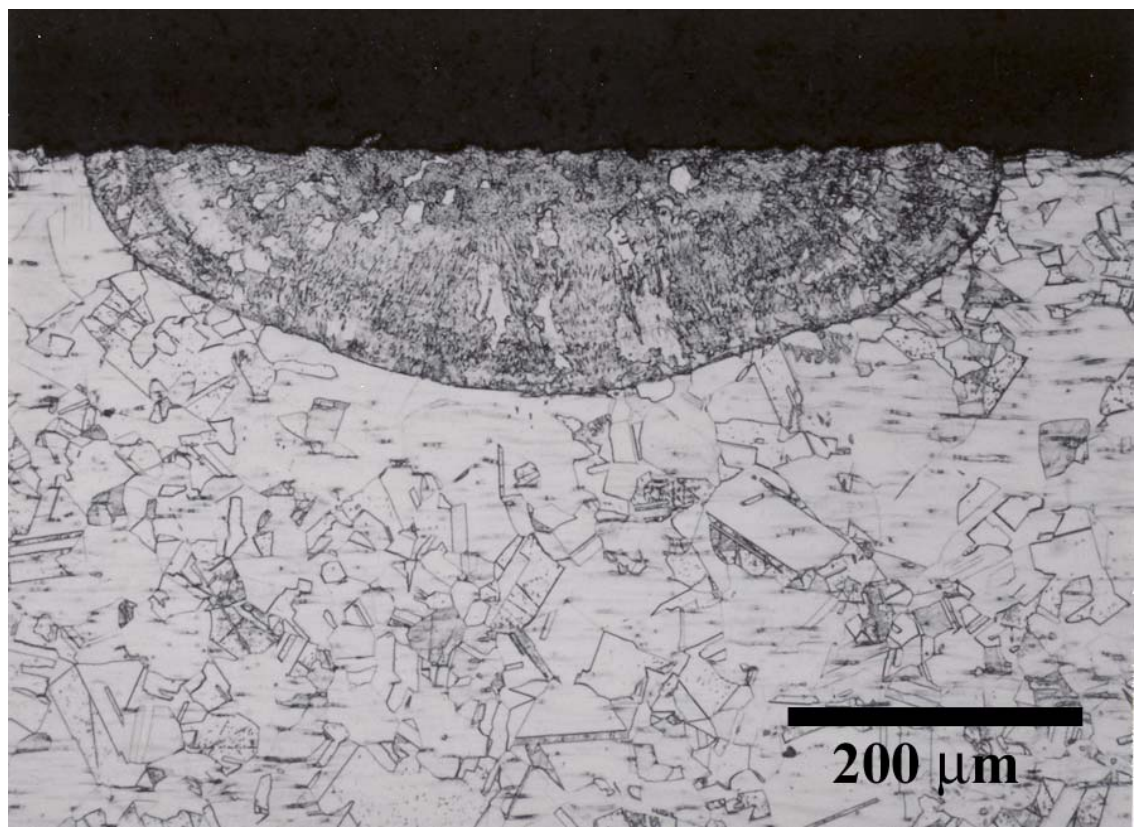

Figure 24. Micrograph showing a conduction mode laser weld on 304L stainless steel made at a machine power setting of $250 \mathrm{~W}$ and a travel speed of $19.1 \mathrm{~mm} / \mathrm{sec}$ on the LLNL welder. No porosity is observed in this conduction mode weld. 
Table 10. Summary of weld measurements taken during power variation studies on 304L stainless steel on the LLNL welder.

\begin{tabular}{|c|c|c|c|c|c|c|c|}
\hline$\frac{\text { Power }}{\frac{\text { to Part }}{\text { (Watts) }}}$ & Speed & $\frac{\underline{\text { Weld }}}{\frac{\text { Width }}{(\mathrm{mm})}}$ & $\frac{\text { Weld Depth }}{\underline{(\mathrm{mm})}}$ & $\frac{\text { Aspect Ratio }}{\text { (Depth/Width) }}$ & $\frac{\text { Keyhole }}{\frac{\text { Width }}{\text { (mm) }}}$ & $\frac{\stackrel{\text { Weld }}{\text { Reinforcement }}}{\text { Height }(\mathrm{mm})}$ & $\frac{\text { Melted }}{\frac{\text { Area }}{\left(\mathrm{mm}^{2}\right)}}$ \\
\hline 219 & $19.1 \mathrm{~mm} / \mathrm{sec}$ & 0.53 & 0.17 & 0.33 & $\mathrm{~N} / \mathrm{A}$ & 0 & 0.07 \\
\hline 442 & & 1.11 & 1.10 & 0.99 & 0.54 & 0 & 0.76 \\
\hline 664 & & 1.30 & 1.65 & 1.27 & 0.63 & 0.05 & 1.40 \\
\hline 887 & & 1.66 & 2.22 & 1.34 & 0.78 & 0.12 & 1.92 \\
\hline 1109 & & 1.79 & 2.50 & 1.40 & 0.85 & 0.17 & 2.77 \\
\hline 1332 & & 1.79 & 2.79 & 1.56 & 0.76 & 0.49 & 2.96 \\
\hline 1554 & & 1.93 & 3.21 & 1.67 & 0.77 & 0.53 & 3.77 \\
\hline 1777 & & 2.22 & 3.32 & 1.50 & 0.79 & 0.49 & 4.23 \\
\hline 1980 & & 2.19 & 3.33 & 1.52 & 0.34 & 0.74 & 4.15 \\
\hline 219 & $12.7 \mathrm{~mm} / \mathrm{sec}$ & 0.62 & 0.16 & 0.27 & $\mathrm{~N} / \mathrm{A}$ & 0 & 0.09 \\
\hline 442 & & 1.57 & 1.17 & 0.74 & 0.65 & 0.08 & 1.18 \\
\hline 664 & & 1.98 & 1.69 & 0.85 & 0.89 & 0 & 2.03 \\
\hline 887 & & 2.10 & 2.33 & 1.11 & 1.08 & 0.06 & 2.92 \\
\hline 1109 & & 2.10 & 2.59 & 1.23 & 1.10 & 0.15 & 4.10 \\
\hline 1332 & & 2.53 & 2.93 & 1.16 & 1.20 & 0.20 & 4.49 \\
\hline 1554 & & 2.99 & 3.23 & 1.08 & 1.30 & 0.07 & 5.01 \\
\hline 1777 & & 2.87 & 3.63 & 1.27 & 1.15 & 0.30 & 5.45 \\
\hline 1980 & & 3.30 & 3.65 & 1.11 & 1.43 & 0.47 & 6.95 \\
\hline
\end{tabular}




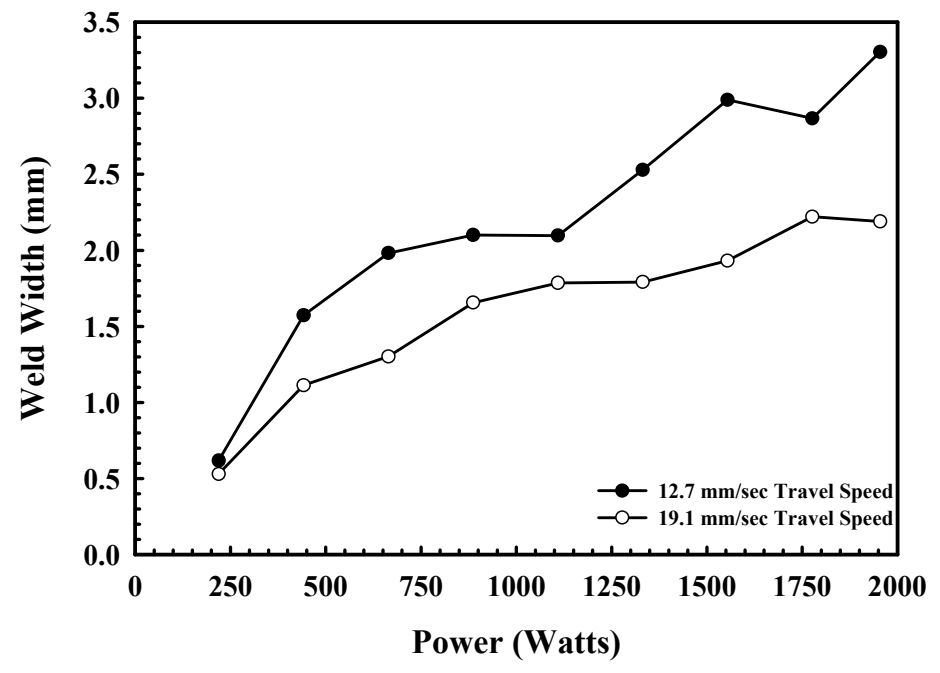

(a)

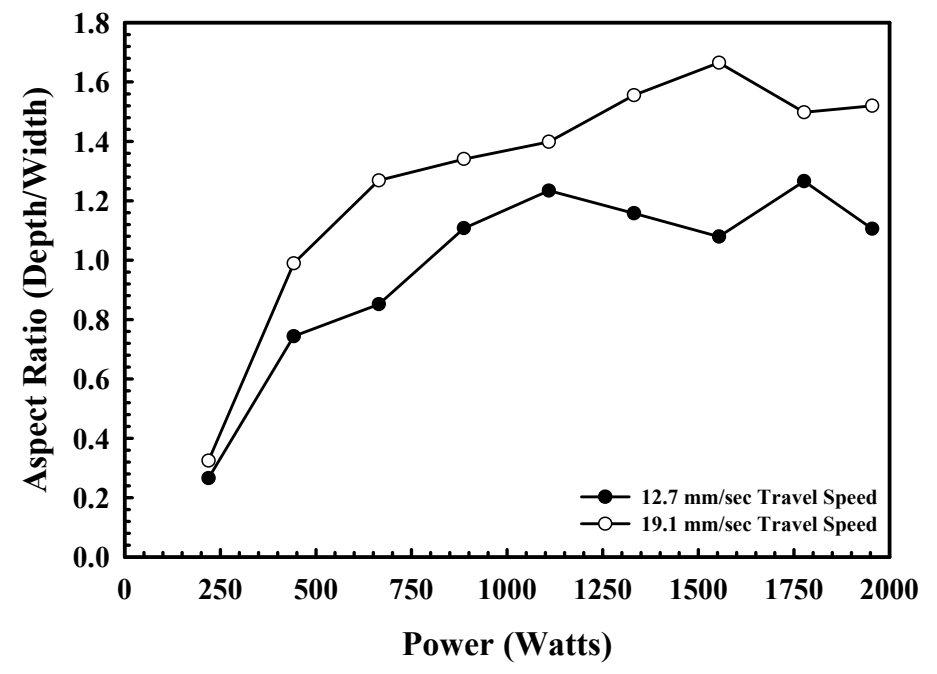

(c)

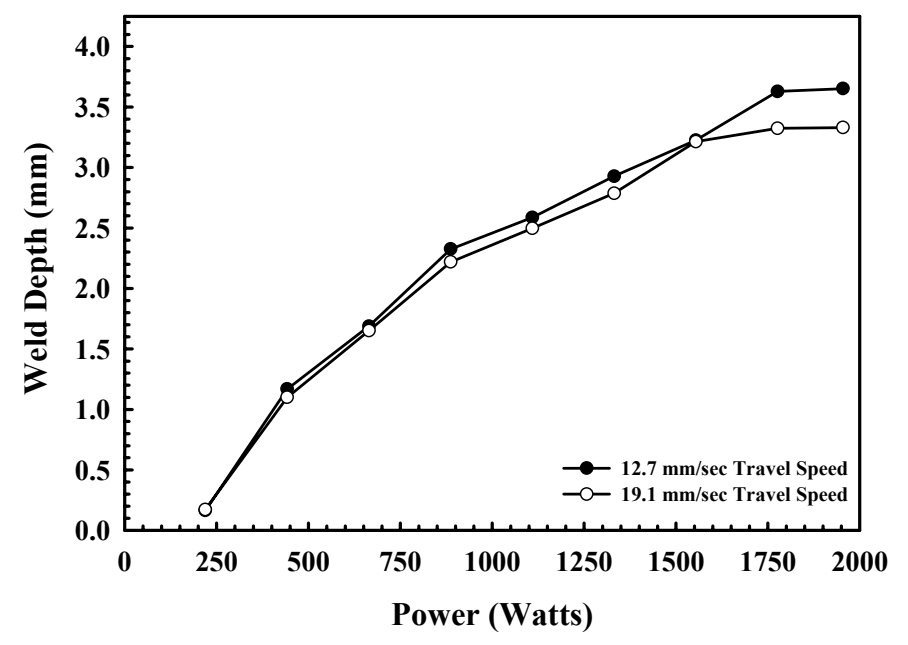

(b)

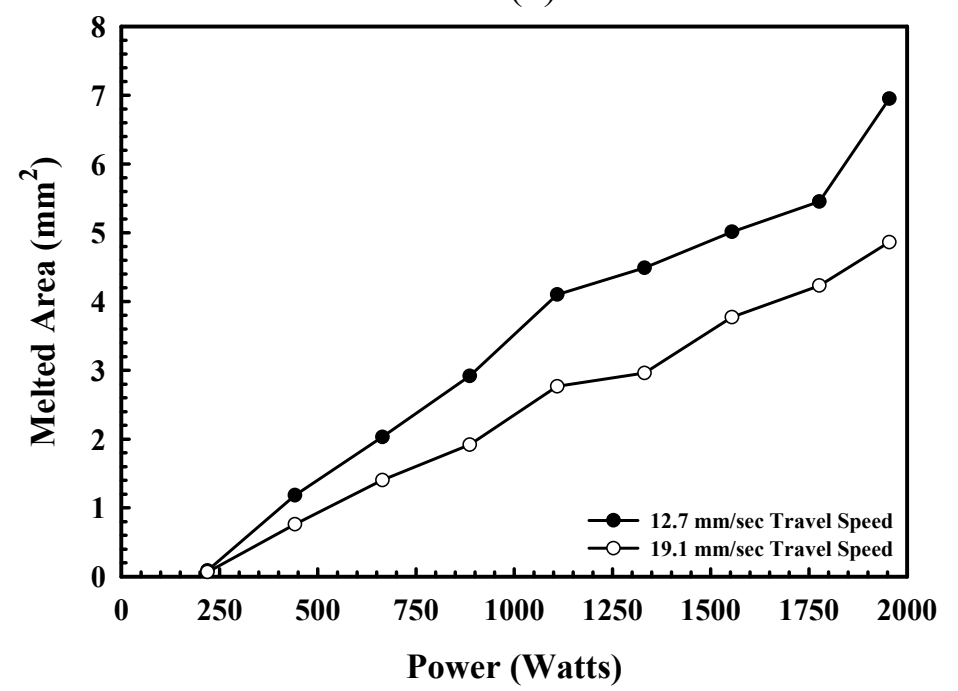

(d)

Figure 25(a-d). Plots showing variations in the (a) weld width, (b) weld depth, (c) aspect ratio (depth/width), and (d) melted area with changes in the machine output power setting for travel speeds of $19.1 \mathrm{~mm} / \mathrm{sec}$ and $12.7 \mathrm{~mm} / \mathrm{sec}$ on 304L stainless steel using the LLNL welder. 
The effects of changes in the machine power setting on the weld aspect (depth/width) ratio are shown in Figure 25(c). With increasing power, the aspect ratio increases as the weld cross section is becoming deeper and narrower, thus indicating that the weld is taking on a more typical keyhole shape. At the higher travel speed $(19.1 \mathrm{~mm} / \mathrm{sec})$, the aspect ratio continues to increase as the machine power setting is increased, resulting in a deep and narrow weld at a power setting of $2200 \mathrm{~W}$. On the other hand, the measured aspect ratios at the slower travel speed $(12.7 \mathrm{~mm} / \mathrm{sec})$ fall well below those measured at the faster travel speed and maintain a constant value or even decrease at power levels above approximately $900 \mathrm{~W}$. Measurements of the melted area of each weld pool cross section are plotted in Figure 25(d) as a function of power. In this plot, the cross sectional area measured at each travel speed increases in a generally linear manner with increasing power.

Two additional measurements have also been made on each weld cross section. These measurements, which include the keyhole width and reinforcement height, provide a measure of other weld characteristics, rather than just the general weld shape and size. For example, the weld keyhole width provides a general measure of the keyhole width and additional knowledge of the general characteristics of the keyhole under these welding conditions. In addition, measurements of the reinforcement height can provide a general indicator of porosity in the weld cross section. Since all of the welds discussed here are partial penetration welds in a relatively thick plate, there is a conservation of volume, with the reinforcement being caused by the volume of porosity present in the weld. The effects of changes in power on the keyhole width and the reinforcement height are shown in Figures 26(a\&b). Whereas the keyhole width displays a definite increasing trend with increasing power, the reinforcement height shows increasing values with increasing power, which generally corresponds with the observation of increasing porosity with increasing power, but no trend emerges.

\subsubsection{Travel Speed Variation Studies}

As discussed in the power variation studies, changes in the weld travel speed result in changes in the weld characteristics. In order to better define the effects of travel speed, another set of experiments, in which the weld travel speed has been varied at a constant power, has been performed. Travel speeds between 6.4 and $16.9 \mathrm{~mm} / \mathrm{sec}$ have been examined at a constant power $(1980 \mathrm{~W})$. This power corresponds with the maximum power delivered to the sample by the LLNL laser system, thus providing the best indication of the maximum depth possible for this laser system. Micrographs of weld cross sections taken at travel speeds of 16.9, 10.6, 8.5 and 4.2 $\mathrm{mm} / \mathrm{sec}$ are shown in Figures 27(a-d), respectively. As shown in Figures 22 and 23, there are a number of common characteristics in the weld cross sections shown here. For example, each cross section micrograph displays a shape consistent with a keyhole mode of welding, along with significant porosity. In addition, with the decrease in travel speed in each micrograph, the size and shape of the weld pool change, especially the keyhole width values.

The results of this study on the LLNL laser system are summarized in Table 11. The values listed in this table, including the weld width, depth, aspect ratio, and total melted area, are plotted in Figures 28(a-d), respectively, as a function of power. In general, the weld width decreases with increasing travel speed from 6.4 to $16.9 \mathrm{~mm} / \mathrm{sec}$, as shown in Figures 28(a) and 28(b). In both cases, though, the largest weld width $(4.79 \mathrm{~mm})$ and depth $(5.13 \mathrm{~mm})$ are observed at the lowest travel speed $(6.4 \mathrm{~mm} / \mathrm{sec})$. These changing dimensions result in a nearly constant aspect ratio, in the vicinity of 1.0, across the range of travel speeds (Figure 28(c)). The effect of changes in travel speed on the melted area of each weld shows a consistent trend. As shown in 


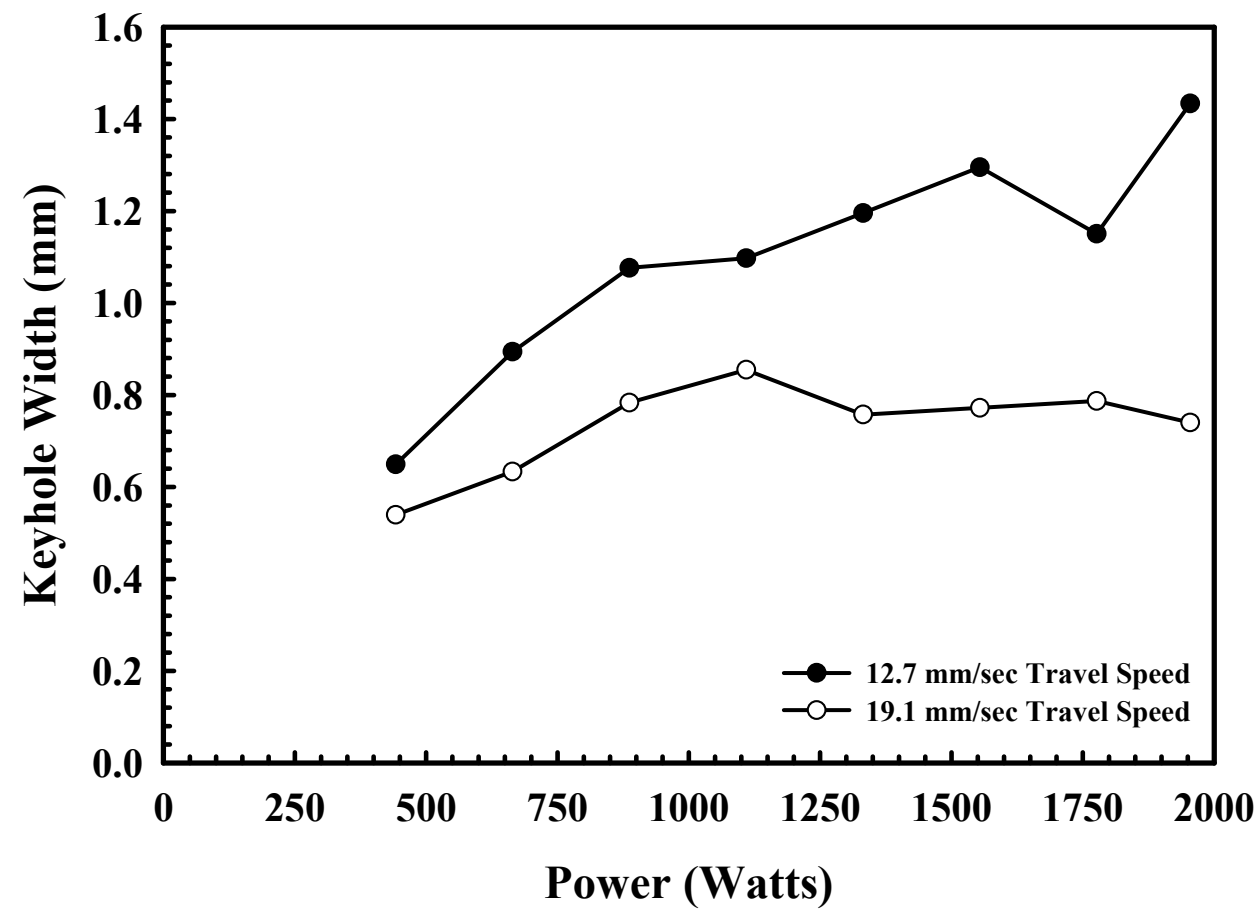

(a)

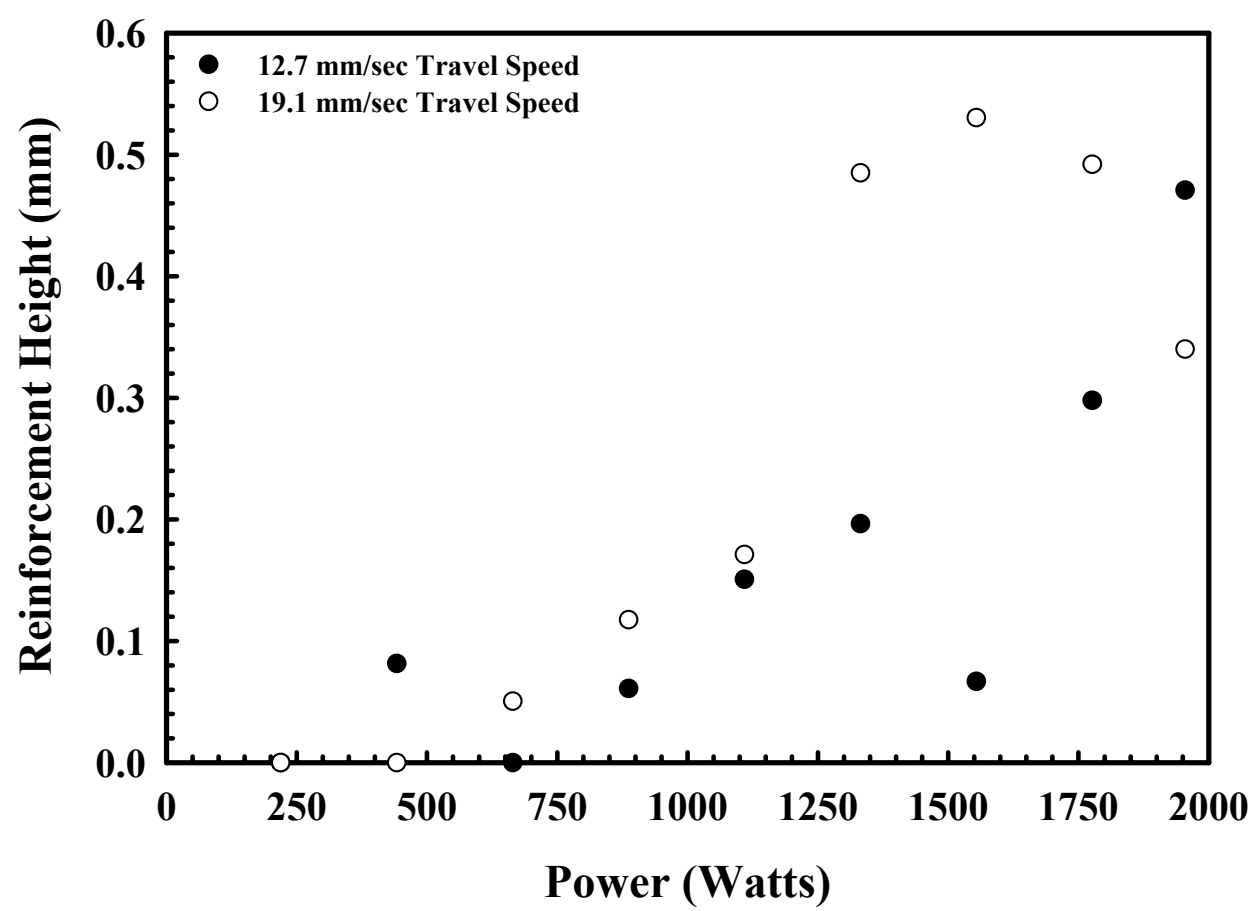

(b)

Figure 26(a\&b). Plots showing variations in the (a) keyhole width and (b) overfill height with changes in the machine output power setting for travel speeds of $19.1 \mathrm{~mm} / \mathrm{sec}$ and $12.7 \mathrm{~mm} / \mathrm{sec}$ on 304L stainless steel using the LLNL welder. 


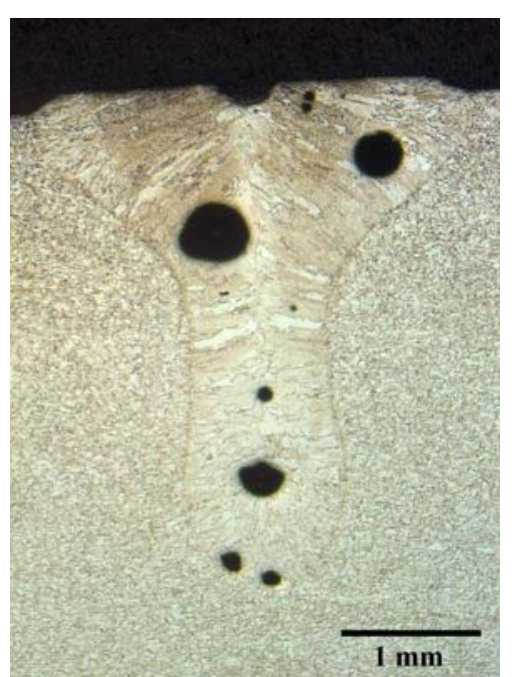

(a)

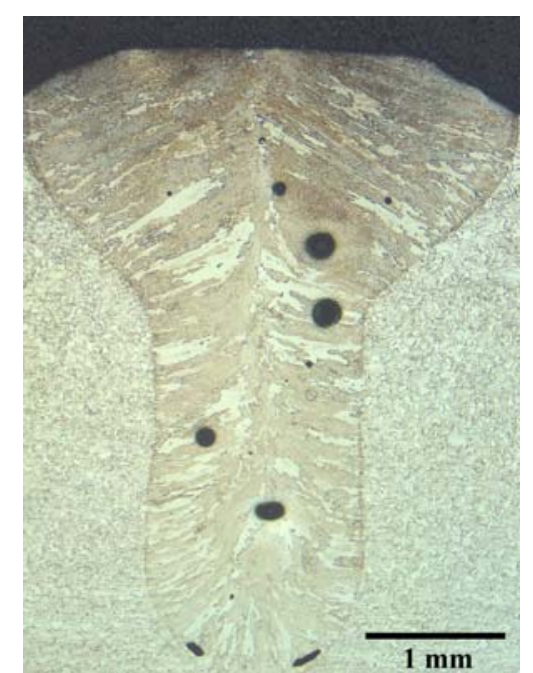

(b)

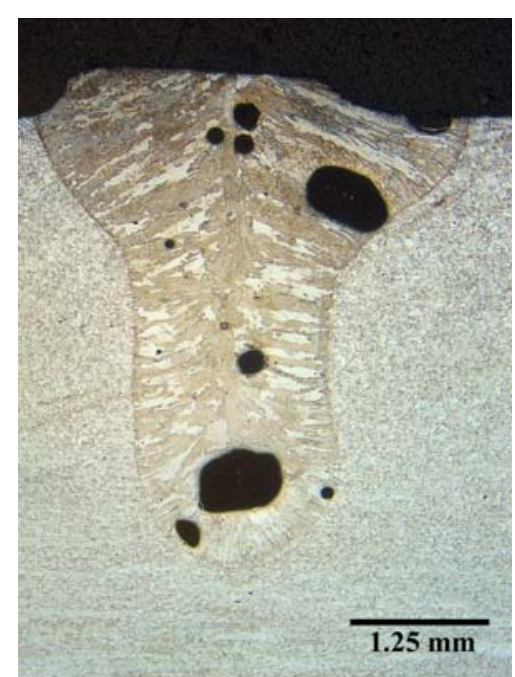

(c)

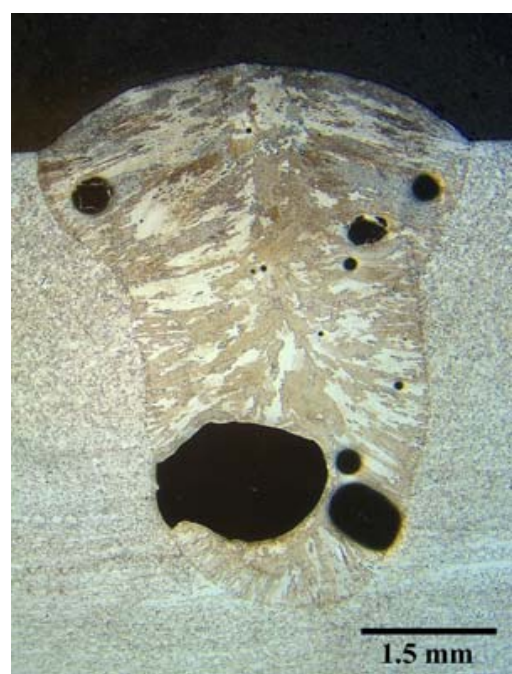

(d)

Figure 27(a-d). Micrographs of weld cross sections for travel speeds of (a) $16.9 \mathrm{~mm} / \mathrm{sec}$, (b) $10.6 \mathrm{~mm} / \mathrm{sec}$, (c) $8.5 \mathrm{~mm} / \mathrm{sec}$, and (d) 4.2 $\mathrm{mm} / \mathrm{sec}$ at a constant machine power setting of $2200 \mathrm{~W}$. Note changes in magnifications of micrographs in (c) and (d). These $304 \mathrm{~L}$ stainless steel welds have been made on the LLNL laser system. 
UCRL-TR-222245

Table 11. Summary of 304L weld measurements taken during travel speed variation studies made at the maximum power output setting (1980 W delivered to the part) on the LLNL welder.

\begin{tabular}{|c|c|c|c|c|c|c|c|}
\hline$\frac{\text { Travel }}{\underline{\text { Speed }}}$ & $\frac{\text { Energy }}{\underline{\text { Input }}}$ & $\frac{\text { Weld }}{\text { Width }}$ & $\frac{\text { Weld }}{\frac{\text { Depth }}{(\mathrm{mm})}}$ & $\frac{\text { Aspect Ratio }}{\text { (Depth/Width) }}$ & $\frac{\text { Keyhole }}{\frac{\text { Width }}{(\mathrm{mm})}}$ & $\frac{\stackrel{\text { Weld }}{\text { Reinforcement }}}{\text { Height }(\mathrm{mm})}$ & $\frac{\text { Melted }}{\frac{\text { Area }}{\left(\mathrm{mm}^{2}\right)}}$ \\
\hline $\begin{array}{c}19.1 \\
(45 \mathrm{in} / \mathrm{min})\end{array}$ & 102 & 2.19 & 3.33 & 1.52 & 0.34 & 0.74 & 4.15 \\
\hline $\begin{array}{c}16.9 \\
(40 \mathrm{in} / \mathrm{min})\end{array}$ & 116 & 3.10 & 3.41 & 1.10 & 1.05 & 0.15 & 5.26 \\
\hline $\begin{array}{c}14.8 \\
(35 \mathrm{in} / \mathrm{min})\end{array}$ & 132 & 3.23 & 3.51 & 1.09 & 1.16 & 0.34 & 6.25 \\
\hline $\begin{array}{c}12.7 \\
(30 \mathrm{in} / \mathrm{min})\end{array}$ & 154 & 3.30 & 3.65 & 1.11 & 1.43 & 0.47 & 6.95 \\
\hline $\begin{array}{c}10.6 \\
(25 \mathrm{in} / \mathrm{min})\end{array}$ & 184 & 3.61 & 4.06 & 1.12 & 1.53 & 0.45 & 9.15 \\
\hline $\begin{array}{c}8.5 \\
(20 \mathrm{in} / \mathrm{min}) \\
\end{array}$ & 230 & 4.08 & 4.16 & 1.02 & 1.88 & 0.41 & 10.74 \\
\hline $\begin{array}{c}6.4 \\
(15 \mathrm{in} / \mathrm{min})\end{array}$ & 306 & 4.48 & 4.48 & 1.00 & 2.28 & 0.45 & 13.56 \\
\hline $\begin{array}{c}4.2 \\
(10 \mathrm{in} / \mathrm{min})\end{array}$ & 466 & 4.79 & 5.13 & 1.07 & 3.11 & 0.92 & 20.96 \\
\hline
\end{tabular}




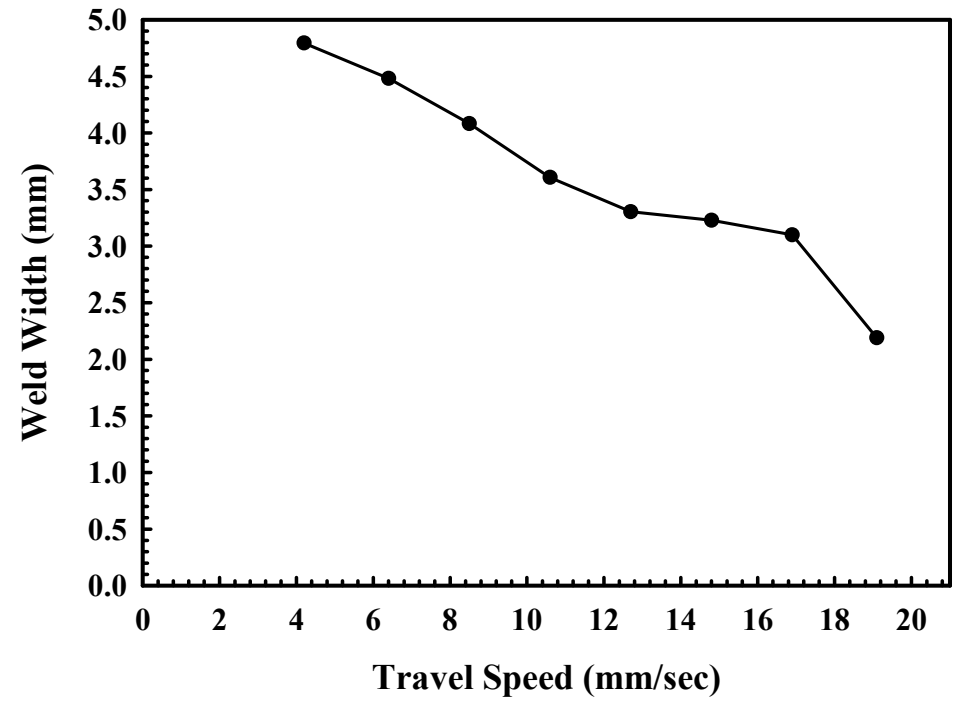

(a)

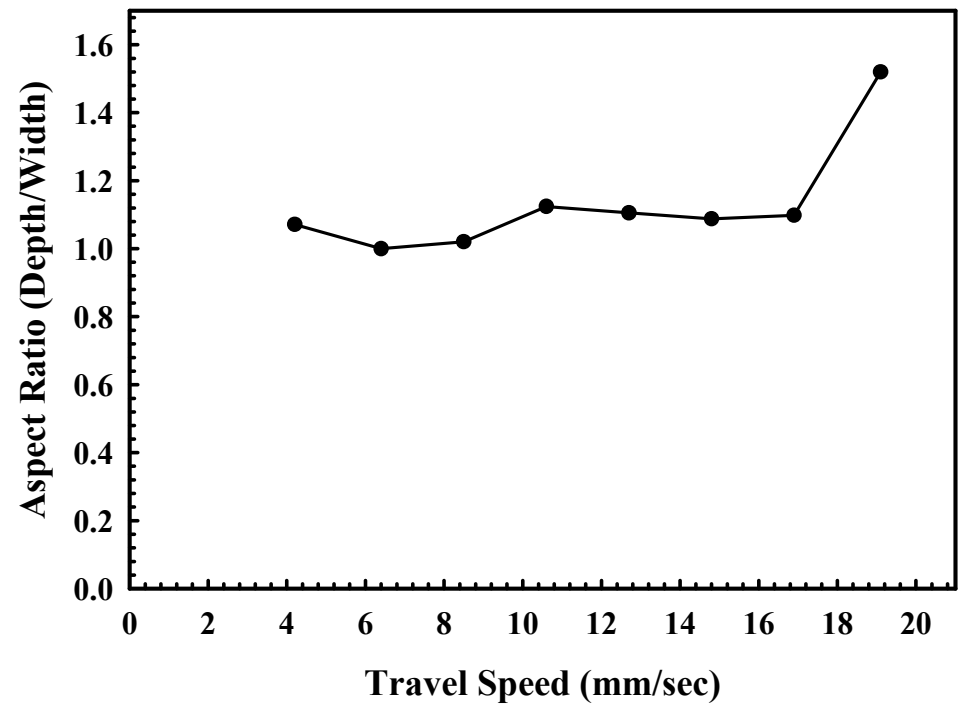

(c)

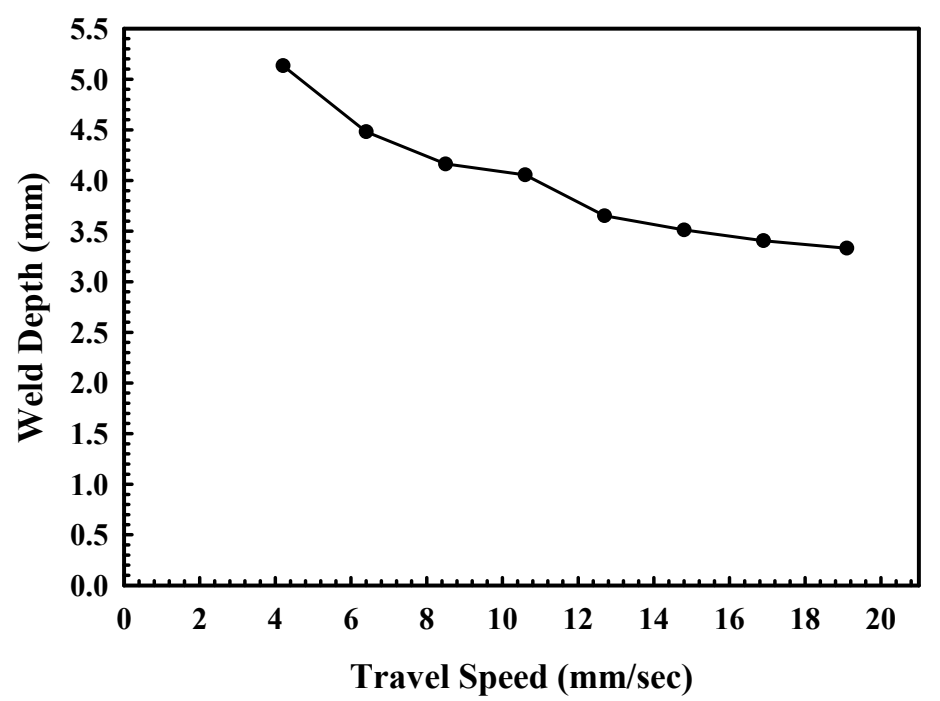

(b)

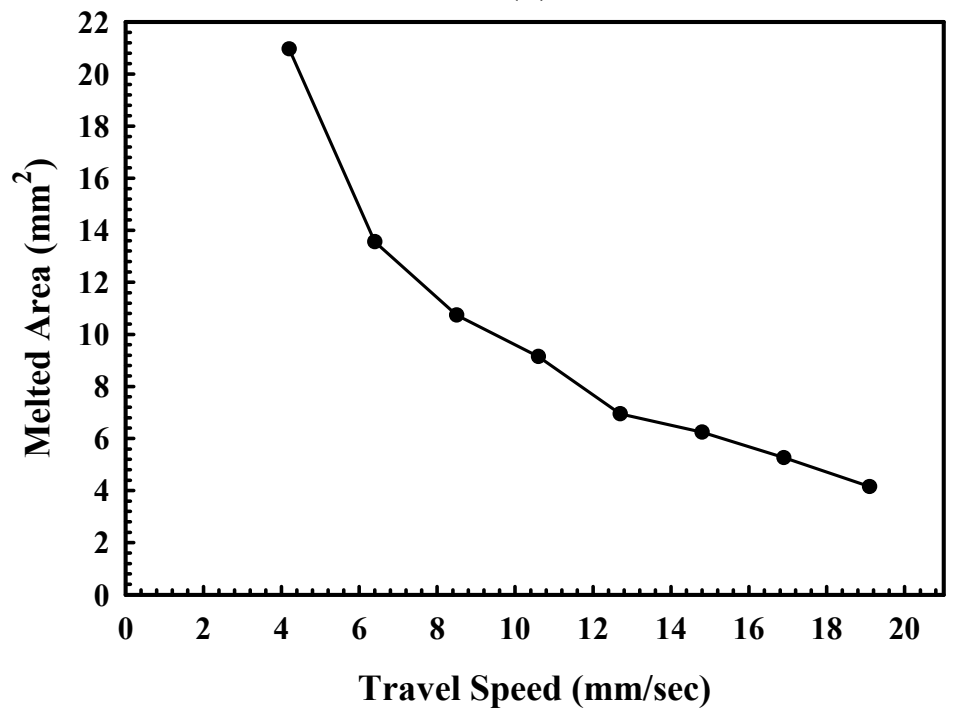

(d)

Figure 28(a-d). Plots showing variations in the (a) weld width, (b) weld depth, (c) aspect ratio, and (d) melted area with changes in the travel speed for a maximum power of $1980 \mathrm{~W}$ on $304 \mathrm{~L}$ stainless steel using the LLNL welder. 
UCRL-TR-222245

Figure 28(d), the melted area consistently decreases with an increase in travel speed. Such behavior is expected since the melted area provides a more general description of the weld pool than the weld width and depth, which are both affected by changes in the characteristics of the keyhole with changing weld parameters. The rate of change in the melted area is greatest at the lower travel speeds and becomes more constant at the higher travel speeds analyzed here.

The effects of changing travel speed on the keyhole width and reinforcement height are shown in Figures 29(a\&b), respectively. In these figures, the keyhole width and reinforcement height decrease with increasing travel speeds, albeit with differing trends. This behavior is expected, given the general connection between increasing keyhole width and decreasing travel speed observed in the power variation studies and the rather significant porosity observed in the weld cross sections produced at the lower travel speeds.

\subsubsection{Effects of Energy Input per Unit Length of Weld}

The use of the parameter energy input per unit length of weld, defined as the input power divided by the travel speed, is a more general description of the energy or power imparted on the workpiece than used in the previous sections. Unlike the previous comparisons, in which the effects of travel speed and power input are separate, the results of the power variation and travel speed variation studies can be directly compared. The energy inputs for each weld are included in Tables 9 and 10 along with the measured weld dimensions. Comparisons between the measured weld width, depth, aspect ratio, and melted area for all of the results shown above are plotted in Figures 30(a-d) as a function of energy input per unit length of weld.

When comparing the weld widths with the energy inputs for the three studies described here, it is difficult to discern any difference in the measurements from the different studies. For example, the two power variation studies produce similar energy inputs, which in the plot in Figure 30(a), show little difference and fall along the same trend line. This trend line continues at the higher energy inputs corresponding with the results from the travel speed variation study. Taken together, the three studies produce a single trend in weld width, which is defined by a general increase in value with increasing energy input. In the case of the weld depth, which is shown in Figure 30(b), differences in the power variation studies are observed at the lower energy inputs. The power variation study performed at a travel speed of $19.1 \mathrm{~mm} / \mathrm{sec}$ produces slightly higher weld depths than those measured at a travel speed of $12.7 \mathrm{~mm} / \mathrm{sec}$, for a given energy input. As the energy input per unit length of weld is increased, and the weld travel speed decreases, the weld depths continue to increase, albeit at a lower rate.

This difference in weld depth at lower energy inputs is translated into welds with higher aspect ratios as a function of energy input, as shown in Figure 30(c). In fact, the aspect ratios for the higher travel speed power variation study are significantly higher than all of those at the lower travel speeds. As shown in the plot, there appears to be a spike in the depth/width ratio at energy inputs of approximately $85 \mathrm{~J} / \mathrm{mm}$. This spike in values indicates that there is possibly a change in the keyhole characteristics or mode of welding at this energy input.

The comparison between the melted area and the energy input, shown in Figure 30(d), displays little to no difference in the behaviors of the various weld studies. As a result, the melted areas show a consistent trend over the range of energy inputs. Unlike the other weld measurements, the melted areas display a consistent linear trend over the entire range of energy inputs. A linear regression analysis of the data in Figure 30(d) shows a slope of 0.056, which corresponds with the rate of change of the melted area as a function of the energy input per unit 


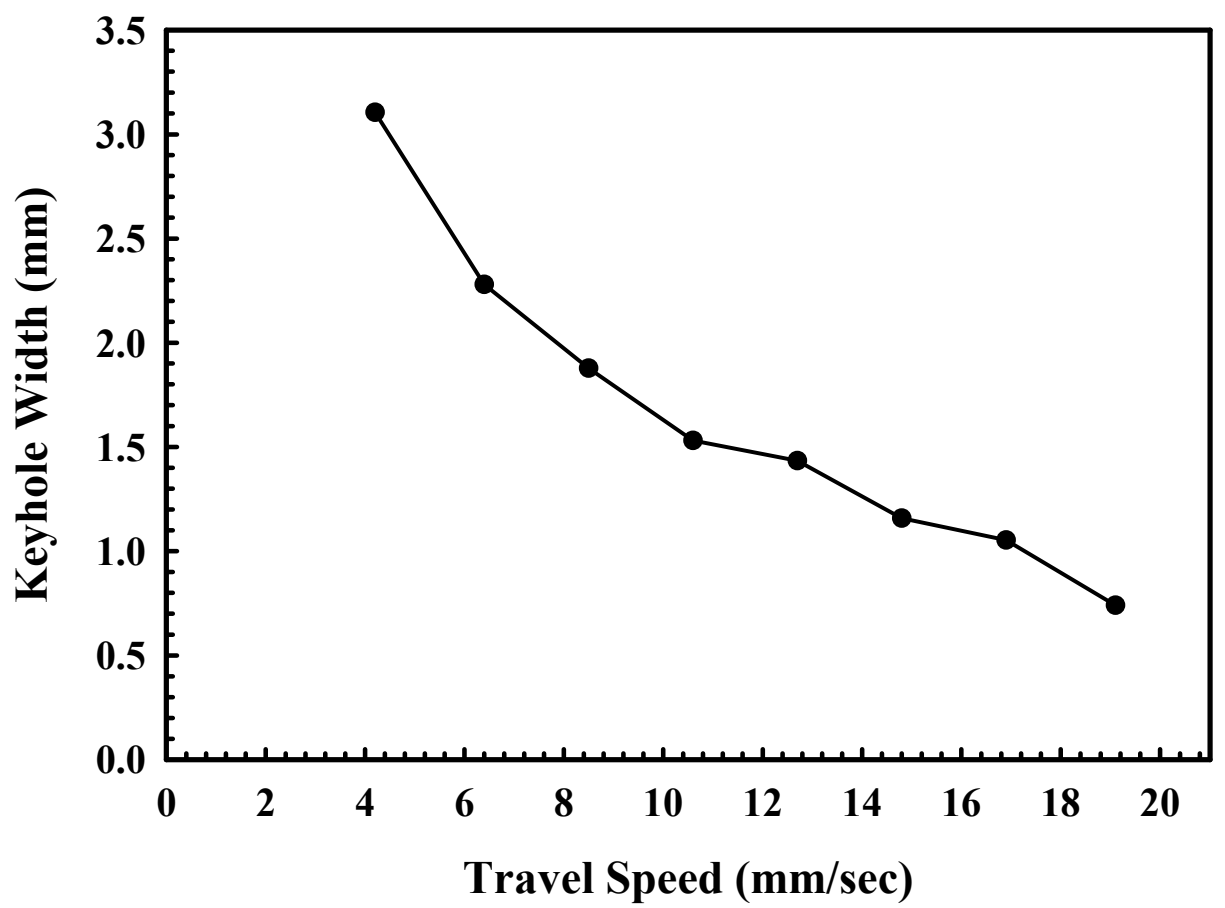

(a)

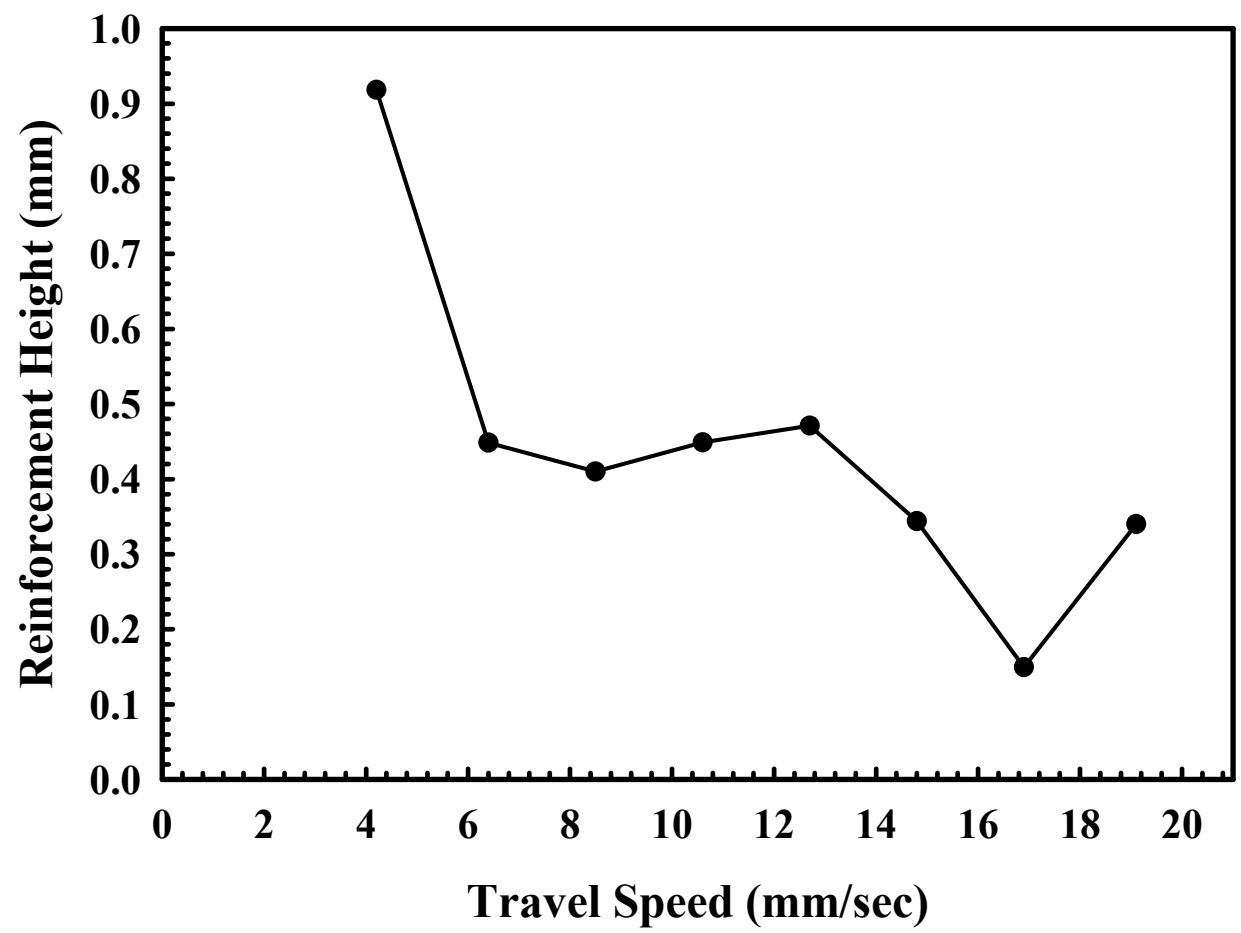

(b)

Figure 29(a\&b). Plots showing variations in the (a) keyhole width and (b) overfill height with changes in travel speed at a machine output power setting of $2200 \mathrm{~W}$ on 304L stainless steel using the LLNL welder. 


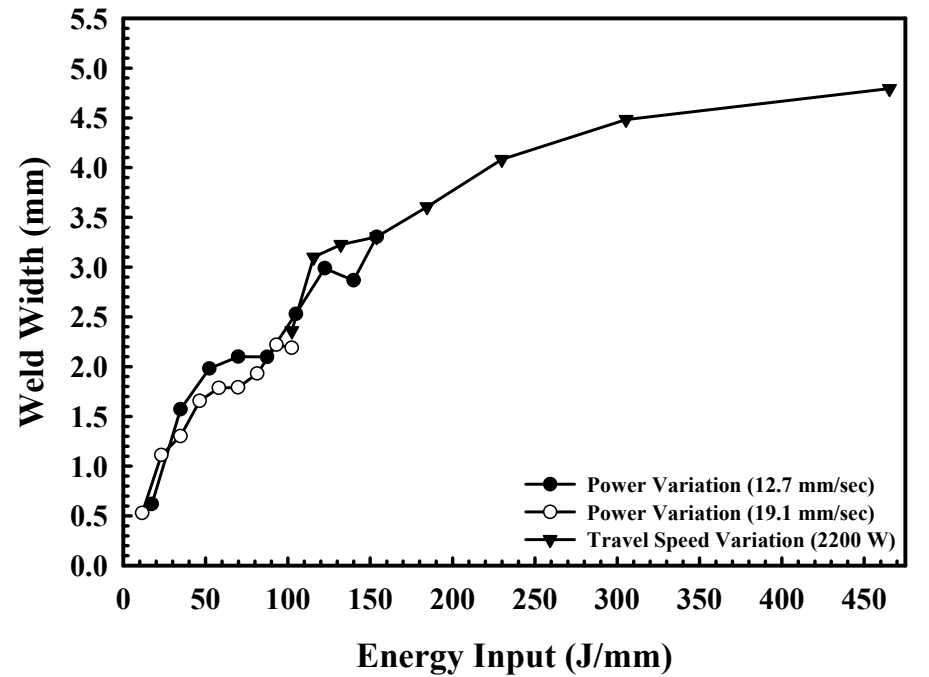

(a)

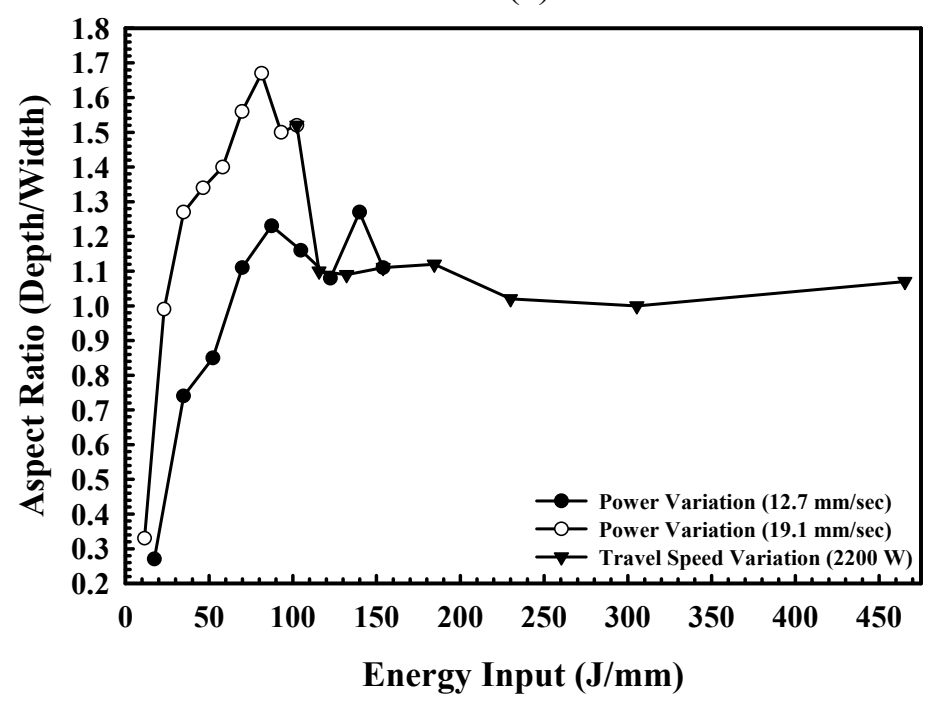

(c)

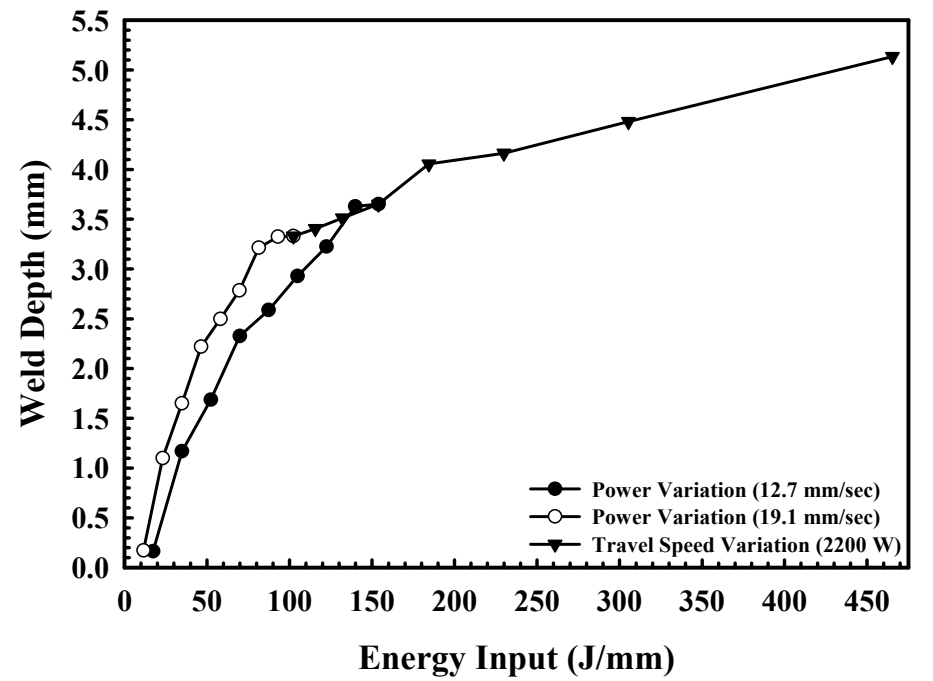

(b)

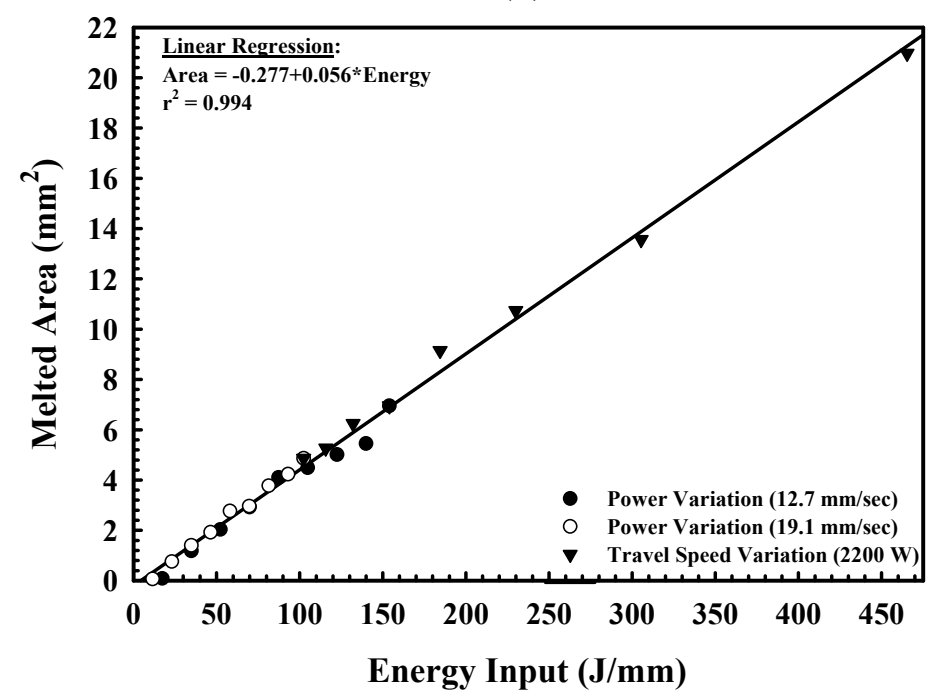

(d)

Figure 30(a-d). Plots showing variations in the (a) weld width, (b) weld depth, (c) aspect ratio, and (d) melted area of each weld cross section as a function of the energy input for the two power variation studies and the travel speed variation study on 304L stainless steel using the LLNL welder. 
UCRL-TR-222245

length of weld. This behavior is the result of the melted area not being affected by the mode of laser welding but being strictly a function of the amount of power from the laser beam interacting with the sample surface.

\subsubsection{Comparison with Previous Studies}

Results from both the power variation and travel speed studies performed on the LLNL laser system are also compared with results from other comparable systems under similar welding conditions. Of the two systems, the results from the Rofin Sinar Development Lab ${ }^{*}$ provide the closest comparison, since they were made on the same material as the LLNL results and even used the same optics system as that used in the LLNL tests. Several micrographs showing weld cross sections made using the Rofin Sinar laser welder are shown in Figures 31(a-d) and 32(a-c). In Figures 31(a-d), several weld cross sections, taken from welds made at machine power settings ranging from $500 \mathrm{~W}$ to $2000 \mathrm{~W}$ at a travel speed of $19.1 \mathrm{~mm} / \mathrm{sec}$, are shown. Figures 32 (a-c) show weld cross sections taken at a constant machine power setting of $2200 \mathrm{~W}$ and at travel speeds ranging from 4.2 to $16.9 \mathrm{~mm} / \mathrm{sec}$. The weld cross sections shown in these two figures are produced using nominally the same welding conditions as those used to produce the weld cross sections in Figures 22 and 27, respectively. A comparison of the two sets of micrographs indicates that the resulting weld pool cross sections for each system are very similar in appearance. For example, both sets of weld cross sections display a keyhole appearance, and porosity is present in both sets of micrographs.

Table 12 lists the results from the power variation study performed at the Rofin Sinar Developmental Lab at a travel speed of $19.1 \mathrm{~mm} / \mathrm{sec}$. Results from the LANL tests are not tabulated here, but applicable results from these tests are plotted in the appropriate figures. The measured weld widths, depths, aspect ratios, and melted areas for these three systems are plotted as a function of the machine power setting in Figures 33(a-d), respectively. Even though different laser power supplies are used, the measured weld widths, depths, and melted areas follow the same general trends and display similar values across the range of machine power settings studied. A closer examination of the plots shows that the LLNL results typically display a slightly smaller width and a larger depth and melted area than the results from the other systems. As a result, the aspect ratios of the LLNL welds display higher values than the Rofin Sinar and LANL results. Comparisons of the measured keyhole width and reinforcement height for the LLNL and Rofin Sinar welds are shown in Figures 34(a\&b), respectively. Overall, the measured keyhole widths and reinforcement heights follow the same general trends, with both values increasing with increasing machine power setting. Unlike the results summarized in Figures 33(a-d), though, neither set of results shows a consistently higher set of values than the other.

Table 13 lists the results of the travel speed variation study performed at the Rofin Sinar Development Lab. In this study, travel speeds between 6.4 and $19.1 \mathrm{~mm} / \mathrm{sec}$ have been analyzed. Figures 35(a-d) show comparisons between the measured weld widths, depths, aspect ratios, and melted areas, respectively, for the Rofin Sinar and LLNL welding systems. As in the case of the power variation study discussed above, the results from both the Rofin Sinar and the LLNL weld studies display similar trends across the range of travel speeds considered here. In this study, though, the widths, depths, and aspect ratios of the LLNL studies are not consistently

\footnotetext{
* This study was performed as part of the laser workstation procurement acceptance on August 21, 2002 in Detroit Michigan.
} 


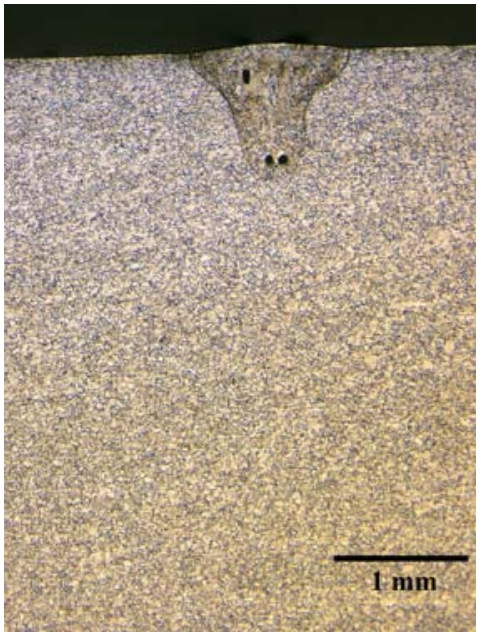

(a)

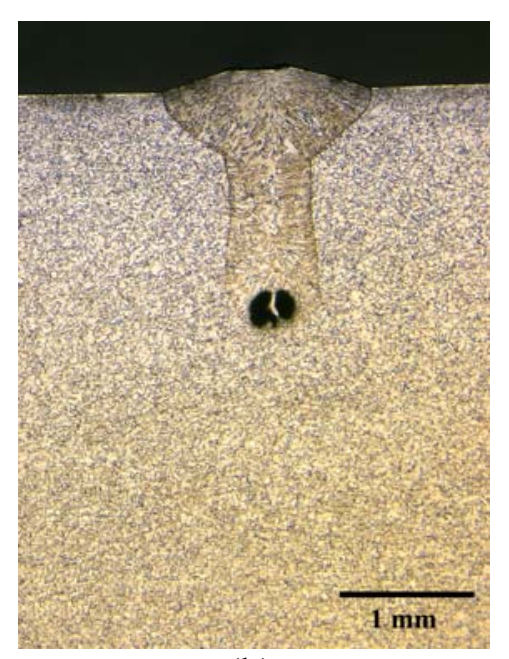

(b)

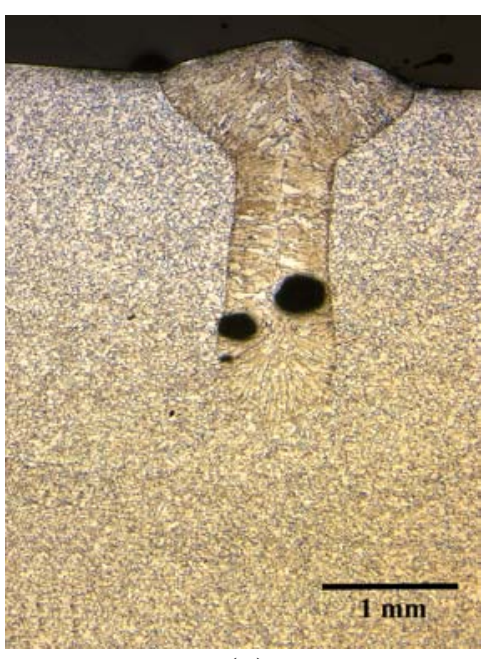

(c)

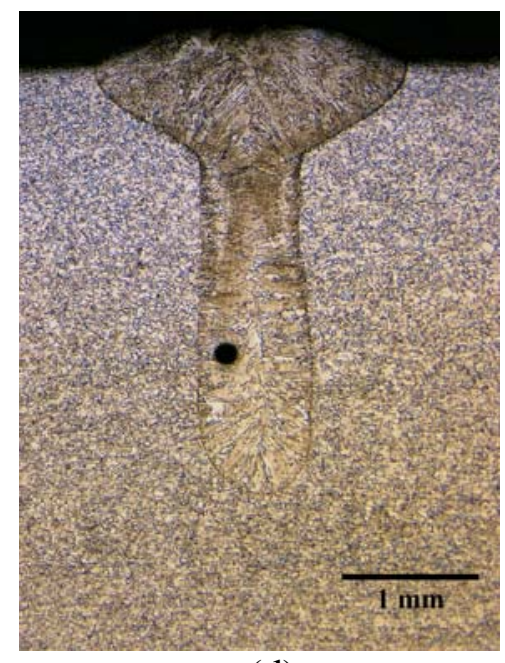

(d)

Figure 31(a-d). Micrographs of weld cross sections for machine power settings of (a) $500 \mathrm{~W}$, (b) $1000 \mathrm{~W}$, (c) $1500 \mathrm{~W}$, and (d) $2000 \mathrm{~W}$ at a travel speed of $19.1 \mathrm{~mm} / \mathrm{sec}$ made at the Rofin Sinar Development Labs on 304L stainless steel. 


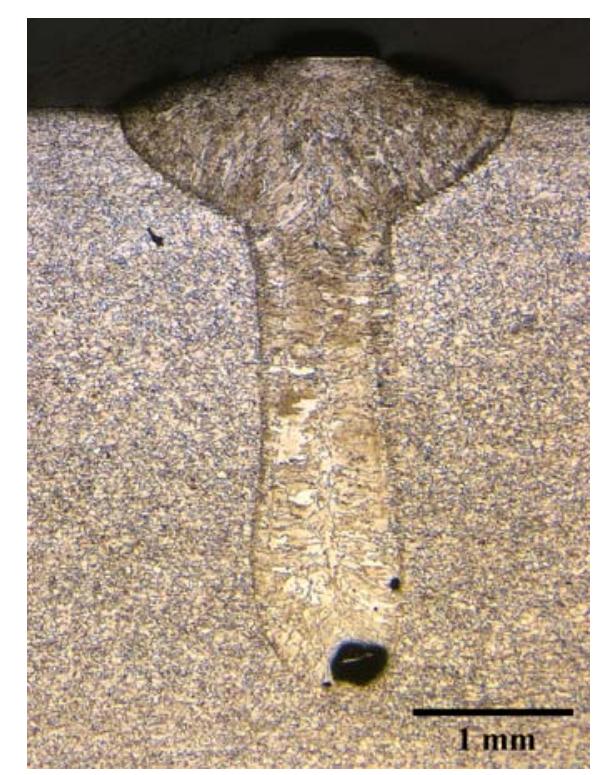

(a)

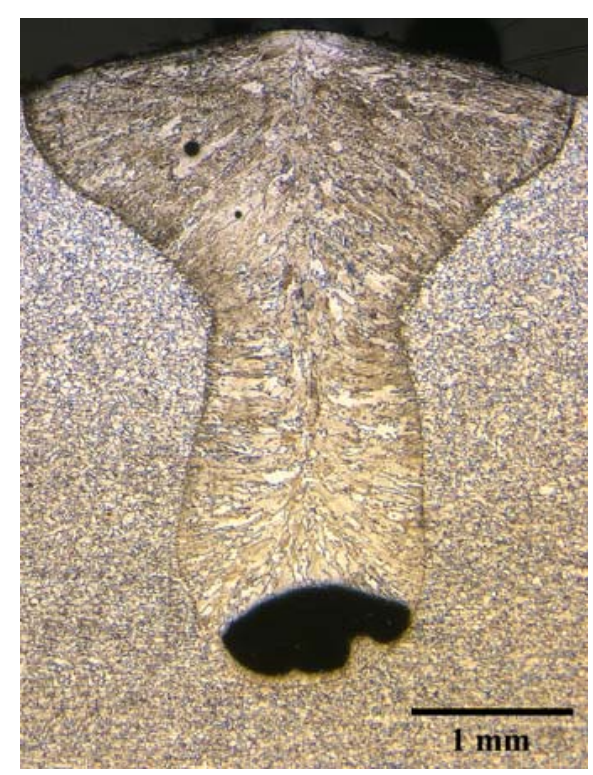

(b)

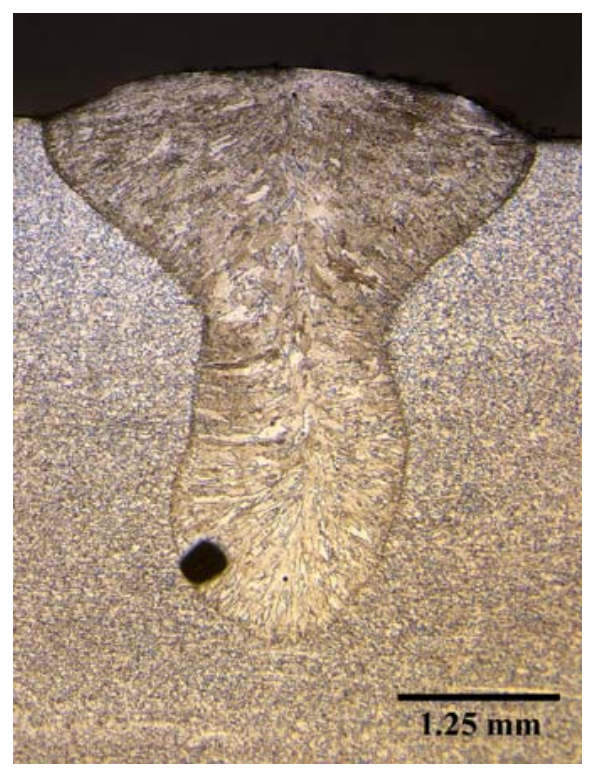

(c)

Figure 32(a-d). Micrographs of weld cross sections for travel speeds of (a) $16.9 \mathrm{~mm} / \mathrm{sec}$, (b) $10.6 \mathrm{~mm} / \mathrm{sec}$, and (c) $8.5 \mathrm{~mm} / \mathrm{sec}$ at a constant machine power setting of $2200 \mathrm{~W}$ made at the Rofin Sinar Development Labs on 304L stainless steel. Note change in magnification of micrograph in (c). 
UCRL-TR-222245

Table 12. Summary of 304L stainless steel weld measurements taken with varying machine power settings on welds made at the Rofin Sinar Developmental Lab using a DY-044 laser welder on the LLNL work station.

\begin{tabular}{|c|c|c|c|c|c|c|}
\hline$\frac{\text { Machine }}{\frac{\text { Power }}{\text { Setting }}}$ & $\frac{\underline{\text { Weld }}}{\underline{\text { Width }}}$ & $\frac{\frac{\text { Weld }}{\text { Depth }}}{\underline{\text { (mm) }}}$ & $\frac{\text { Aspect Ratio }}{\text { (Depth/Width) }}$ & $\frac{\text { Keyhole }}{\frac{\text { Width }}{\underline{\text { (mm) }}}}$ & $\frac{\stackrel{\text { Weld }}{\text { Reinforcement }}}{\underline{\text { Height }(\mathrm{mm})}}$ & $\frac{\text { Melted }}{\underline{\text { Area }}} \frac{\left(\mathrm{mm}^{2}\right)}{}$ \\
\hline 250 & 0.54 & 0.18 & 0.33 & $\mathrm{~N} / \mathrm{A}$ & $\mathrm{N} / \mathrm{A}$ & 0.06 \\
\hline 500 & 1.21 & 0.98 & 0.81 & 0.06 & 0.50 & 0.70 \\
\hline 750 & 1.44 & 1.45 & 1.01 & 0.12 & 0.62 & 1.26 \\
\hline 1000 & 1.56 & 1.91 & 1.22 & 0.16 & 0.65 & 1.75 \\
\hline 1250 & 1.84 & 2.08 & 1.13 & 0.21 & 0.76 & 2.14 \\
\hline 1500 & 1.91 & 2.56 & 1.34 & 0.29 & 0.74 & 2.80 \\
\hline 1750 & 2.06 & 2.82 & 1.37 & 0.24 & 0.81 & 3.24 \\
\hline 2000 & 2.30 & 3.21 & 1.39 & 0.28 & 0.80 & 3.70 \\
\hline 2200 & 2.41 & 3.43 & 1.43 & 0.35 & 0.76 & 4.15 \\
\hline
\end{tabular}




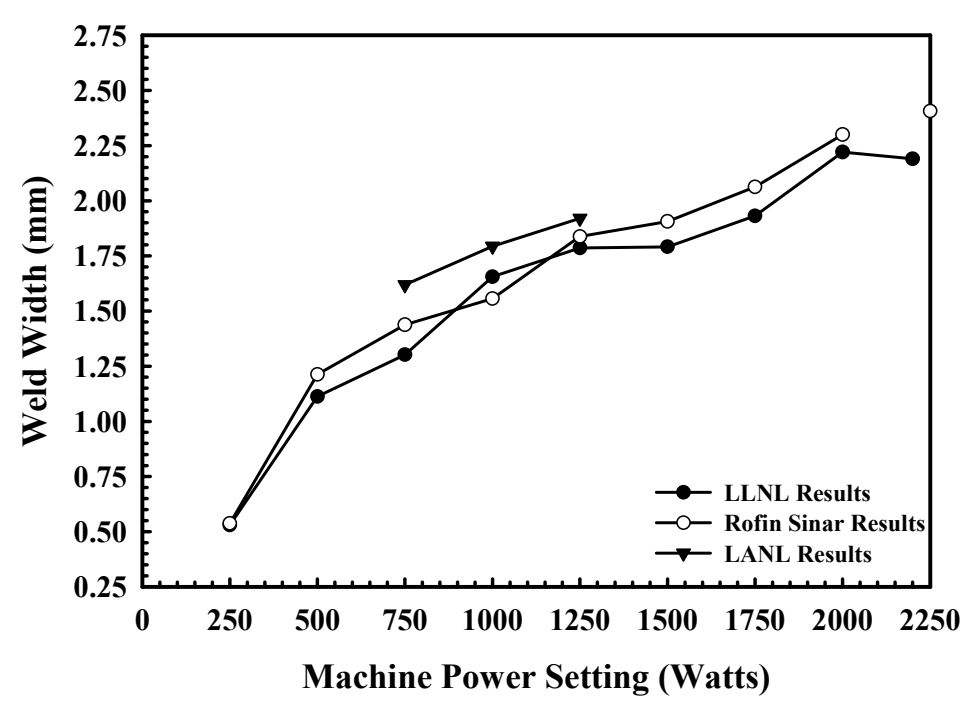

(a)

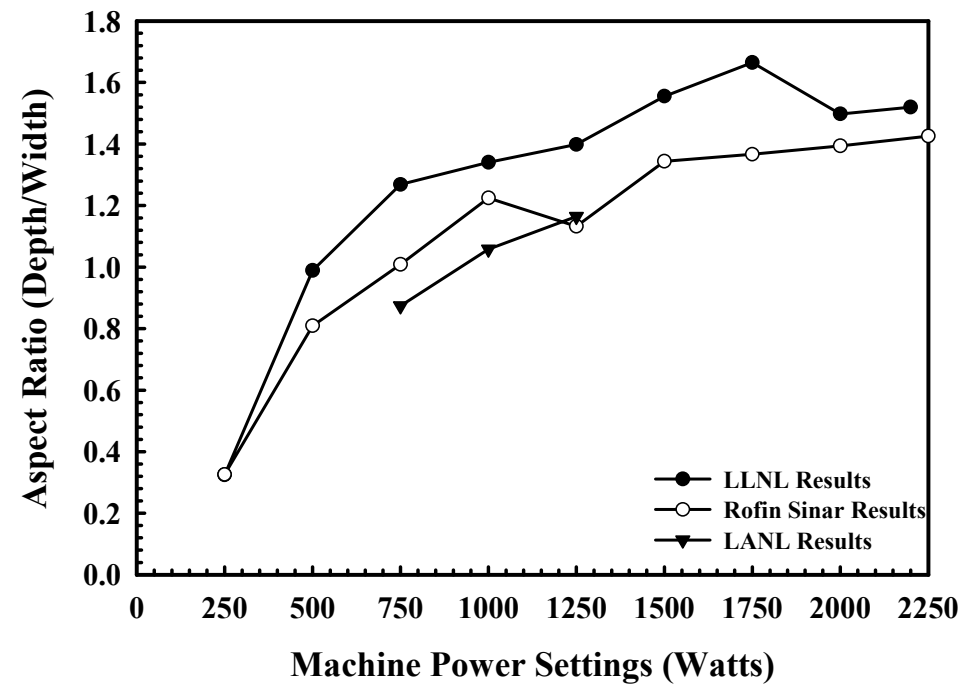

(c)

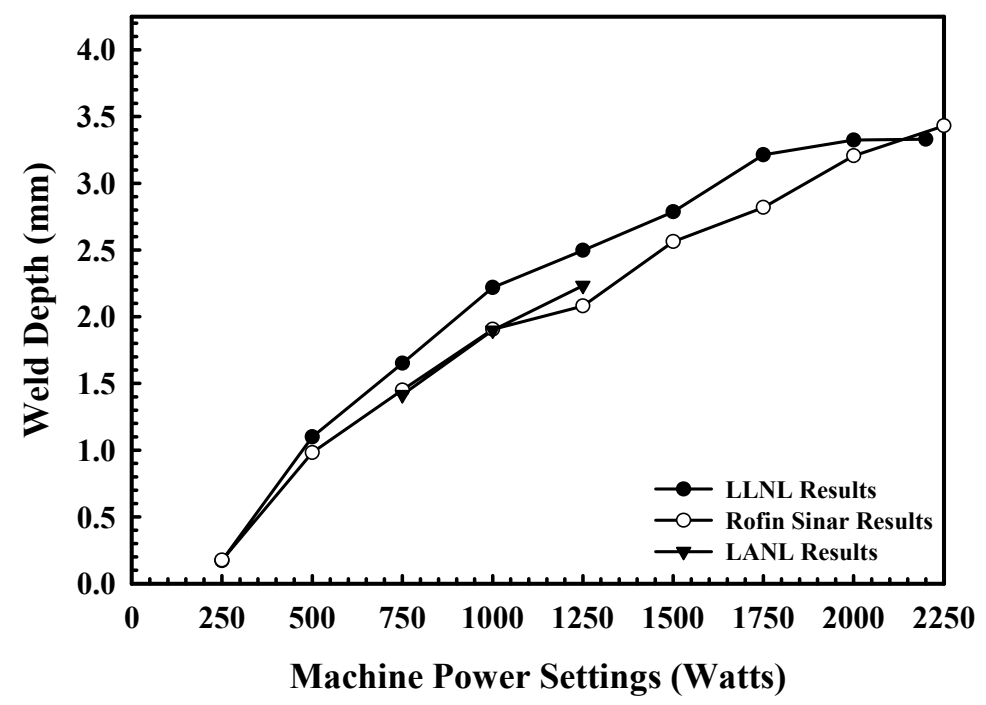

(b)

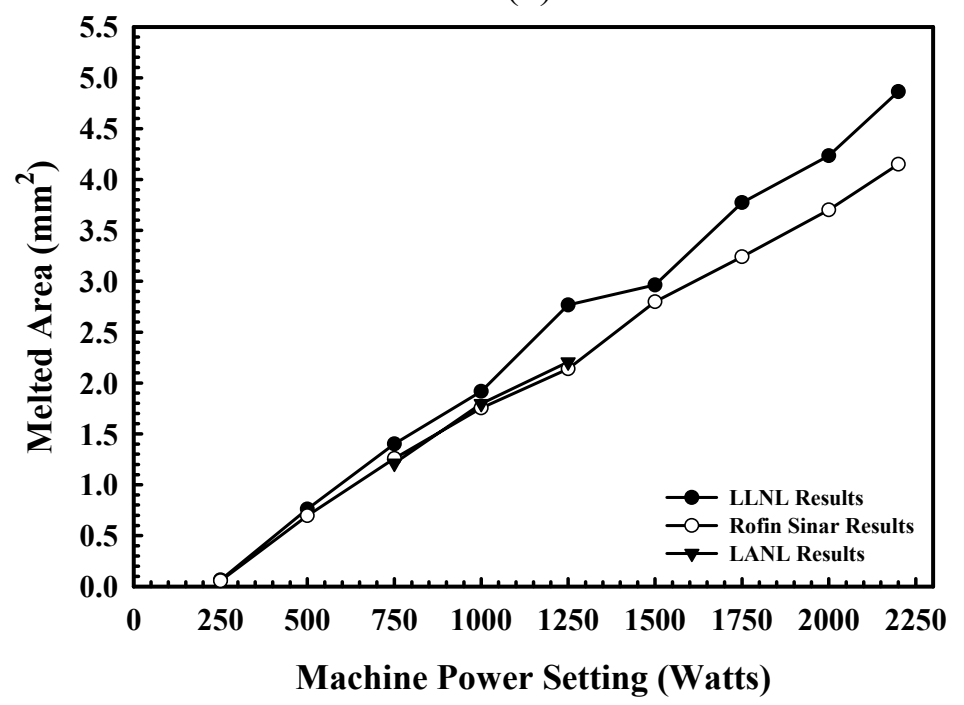

(d)

Figure 33(a-d). Comparison between (a) weld width, (b) depth, (c) aspect ratio, and (d) melted area with changes in weld power at a travel speed of $19.1 \mathrm{~mm} / \mathrm{sec}$ for LLNL, Rofin Sinar, and LANL 304L stainless steel weld measurements. 
UCRL-TR-222245

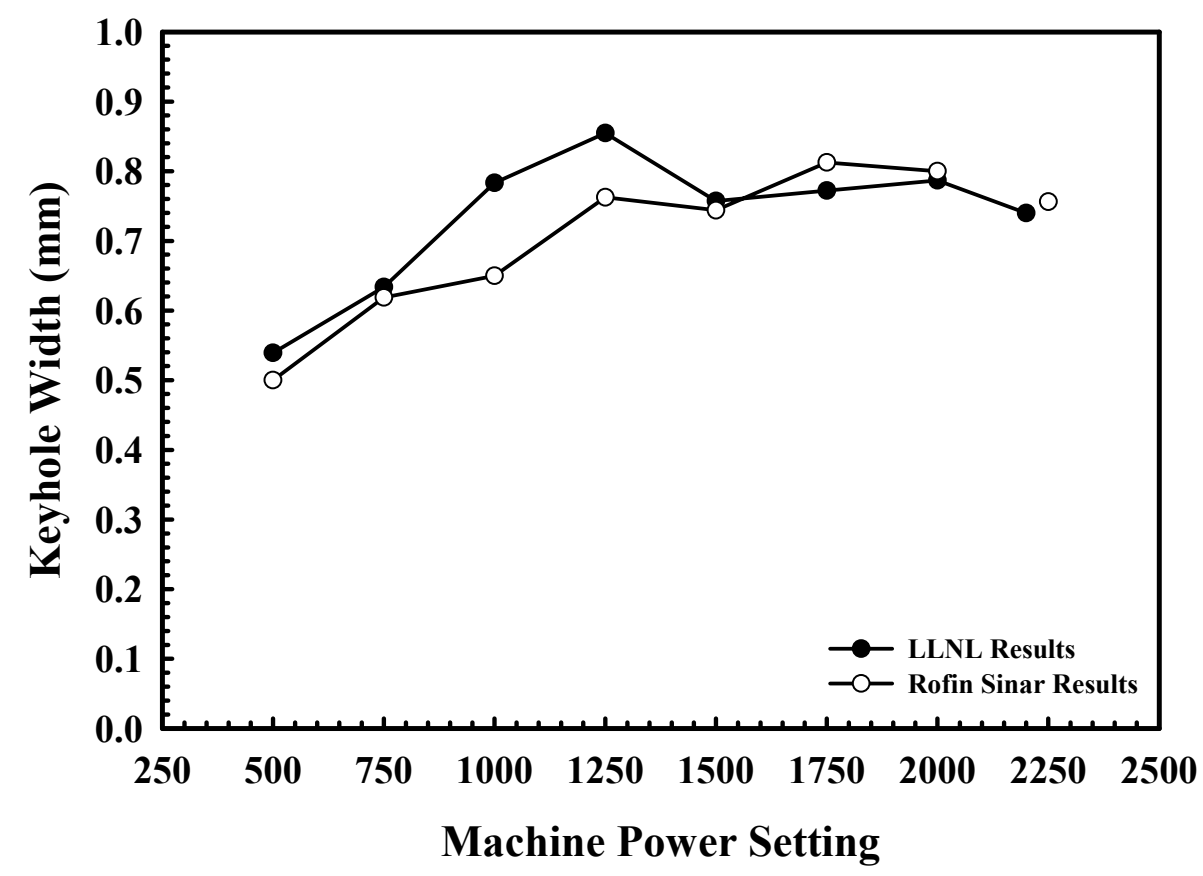

(a)

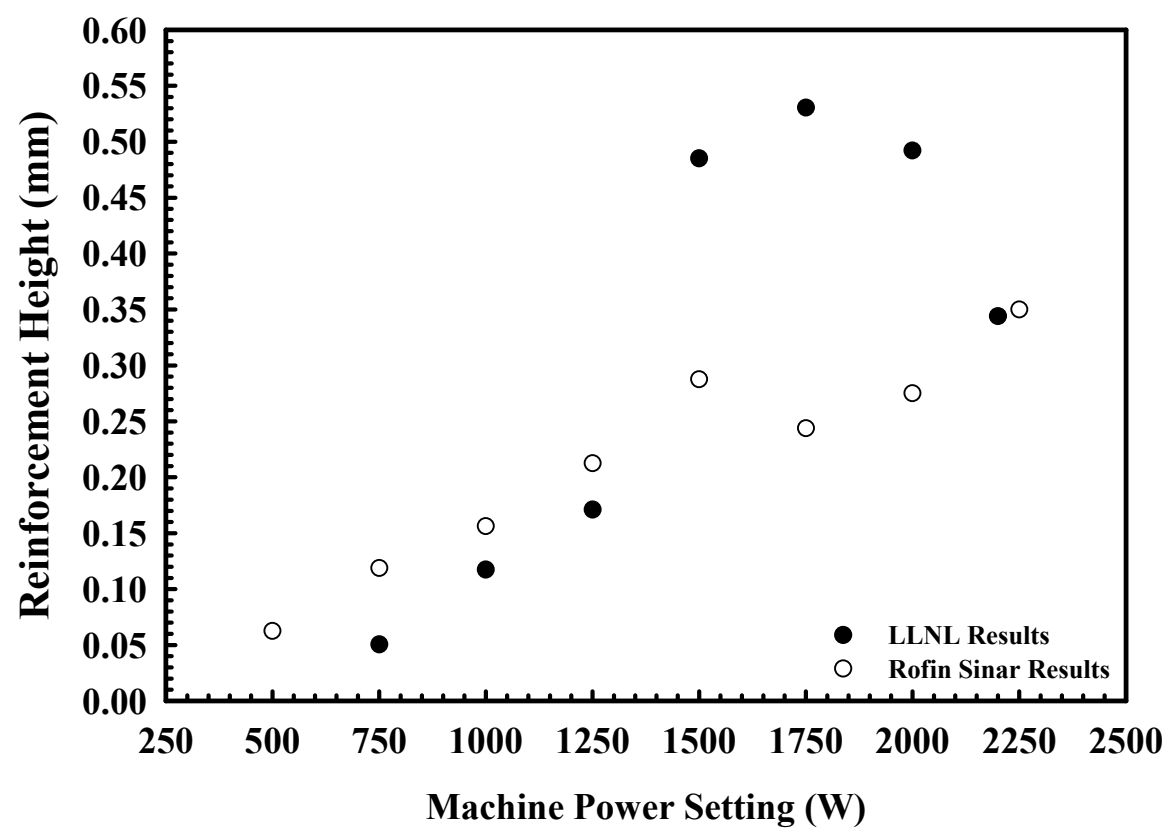

(b)

Figure 34(a\&b). Plots showing variations in the (a) keyhole width and (b) overfill height with changes in weld power at a travel speed of $19.1 \mathrm{~mm} / \mathrm{sec}$ for $304 \mathrm{~L}$ stainless steel welds using the LLNL and Rofin Sinar lasers. 
UCRL-TR-222245

Table 13. Summary of weld measurements taken with varying travel speeds on welds made at the Rofin Sinar Developmental Lab using a DY-044 laser welder and LLNL work station at a constant machine power setting $(2200 \mathrm{~W})$ on 304L stainless steel.

\begin{tabular}{|c|c|c|c|c|c|c|}
\hline$\frac{\text { Travel Speed }}{\underline{(\mathrm{mm} / \mathrm{sec})}}$ & $\frac{\text { Weld }}{\text { Width }}$ & $\frac{\text { Weld }}{\text { Depth }}$ & $\frac{\text { Aspect Ratio }}{\text { (Depth/Width) }}$ & $\frac{\text { Keyhole }}{\frac{\text { Width }}{(\mathrm{mm})}}$ & $\frac{\stackrel{\text { Weld }}{\text { Reinforcement }}}{\underline{\text { Height }(\mathrm{mm})}}$ & $\frac{\text { Melted }}{\frac{\text { Area }}{\left(\mathrm{mm}^{2}\right)}}$ \\
\hline $19.1(45 \mathrm{in} / \mathrm{min})$ & 2.41 & 3.43 & 1.43 & 0.76 & 0.35 & 4.15 \\
\hline $16.9(40 \mathrm{in} / \mathrm{min})$ & 2.48 & 3.68 & 1.49 & 0.84 & 0.32 & 5.58 \\
\hline $14.8(35 \mathrm{in} / \mathrm{min})$ & 2.77 & 3.54 & 1.28 & 1.04 & 0.36 & 5.16 \\
\hline $12.7(30 \mathrm{in} / \mathrm{min})$ & 3.26 & 3.61 & 1.11 & 1.16 & 0.45 & 6.42 \\
\hline $10.6(25 \mathrm{in} / \mathrm{min})$ & 3.44 & 3.78 & 1.10 & 1.47 & 0.40 & 7.57 \\
\hline $8.5(20 \mathrm{in} / \mathrm{min})$ & 3.87 & 4.04 & 1.05 & 1.73 & 0.48 & 9.69 \\
\hline $6.4(15 \mathrm{in} / \mathrm{min})$ & 4.60 & 3.86 & 0.84 & 1.99 & 0.59 & 11.62 \\
\hline
\end{tabular}



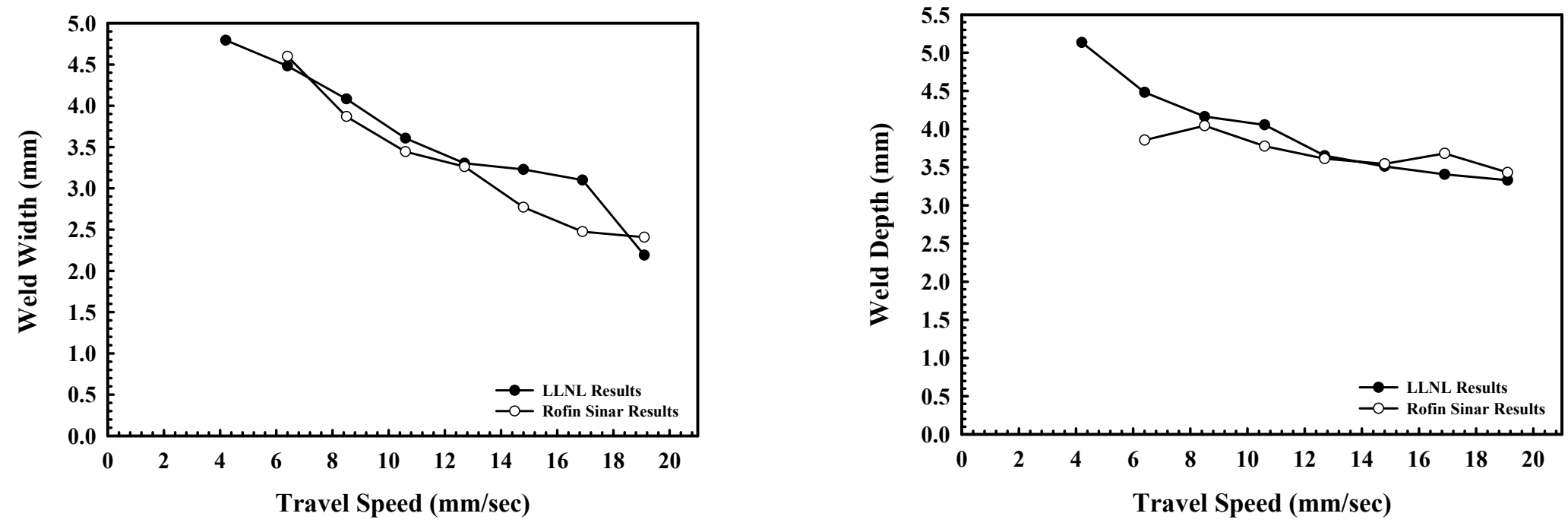

(a)

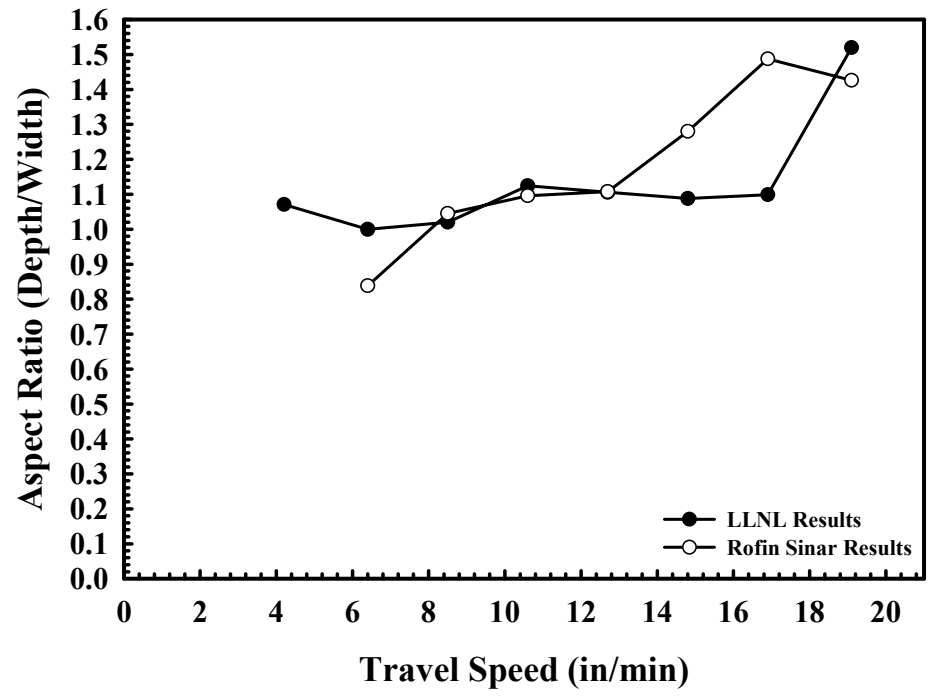

(c)

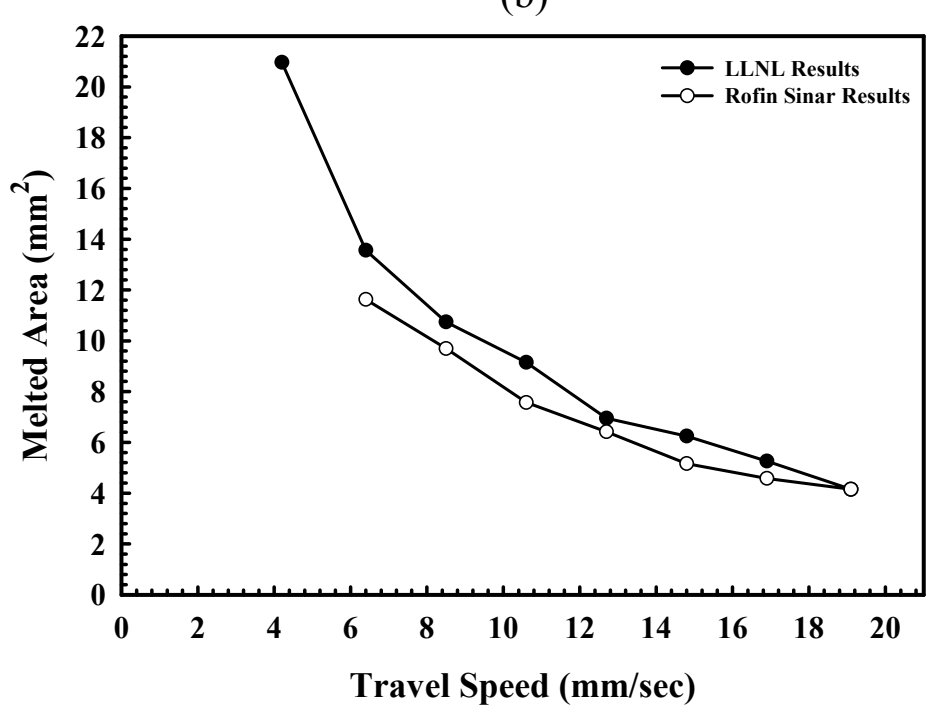

(d)

Figure 35(a-d). Comparison between (a) weld width, (b) depth, (c) aspect ratio, and (d) melted area with changes in travel speed for LLNL and Rofin Sinar weld measurements at a constant machine power setting of $2200 \mathrm{~W}$ on $304 \mathrm{~L}$ stainless steel. 
UCRL-TR-222245

more optimal (smaller width, larger depth) than the Rofin Sinar results. On the other hand, the melted area of the LLNL welds consistently show a higher melted area than the Rofin Sinar results across the range of travel speeds considered. Figures $36(\mathrm{a} \& \mathrm{~b})$ display the comparisons between the keyhole widths and reinforcement heights, respectively. Both sets of results display the expected trends, with an increasing keyhole width and reinforcement height with decreasing travel speed. In the case of the keyhole widths, the LLNL results are consistently higher than the Rofin Sinar results, while neither set of results shows a consistent trend in the case of the reinforcement heights.

\subsection{General Findings and Concluding Remarks}

A series of autogenous bead-on-plate laser welds have been made on $9.5 \mathrm{~mm}$ thick 304L stainless steel samples using a Rofin Sinar DY-022 CW Nd:YAG laser welder. The effects of variations in the machine power setting and travel speed on the resulting weld pool cross sections have been examined. Measurements of the weld width, depth, and melted area have been made on each weld cross section. Comparisons with results taken from other equivalent laser systems have also been made. A summary of the general findings of this study are given below:

- In the weld cross sections studied here, a keyhole welding mode is observed at machine power settings from $500 \mathrm{~W}$ and up for all of the travel speeds considered. Porosity is observed in weld cross sections at machine power settings beginning at $500 \mathrm{~W}$ and up. The observed porosity is believed to originate from the collapse of the keyhole during welding.

- Increases in the laser power and decreases in travel speed result in increasing weld widths, depths, and melted areas of the weld cross sections for all travel speeds studies. A maximum weld depth of penetration of slightly more than $5 \mathrm{~mm}$ is obtained at the slowest travel speed and highest machine power setting. However, severe porosity is present in the weld cross sections from the lower travel speed welds.

- Weld aspect ratios greater than unity are obtained at the highest power settings and fastest travel speeds. Decreasing travel speeds result in aspect ratios approaching unity because of rapidly increasing weld widths. These decreasing travel speeds also cause an expansion in the weld keyhole width.

- Direct comparison of the results from the power variation and travel speed variation studies can be made by using energy input per unit length (Power/Travel Speed) as a measure of the input power. These comparisons show that a maximum weld aspect ratio is obtained at energy inputs of approximately $85 \mathrm{~J} / \mathrm{mm}$. At higher energy inputs, which are obtained in this study by slowing the travel speed, the aspect ratios decrease and approach unity.

- Comparisons between the LLNL results and results obtained using other equivalent laser systems at the Rofin Sinar Development Laboratory and Los Alamos National Laboratory have been made. The welds made using each system are comparable in size and shape and display similar trends with changes in the machine power setting and travel speed. Although, welds made using the LLNL system tend to display slightly greater weld depths and melted areas than those made using the other systems with similar welding parameters. 
UCRL-TR-222245

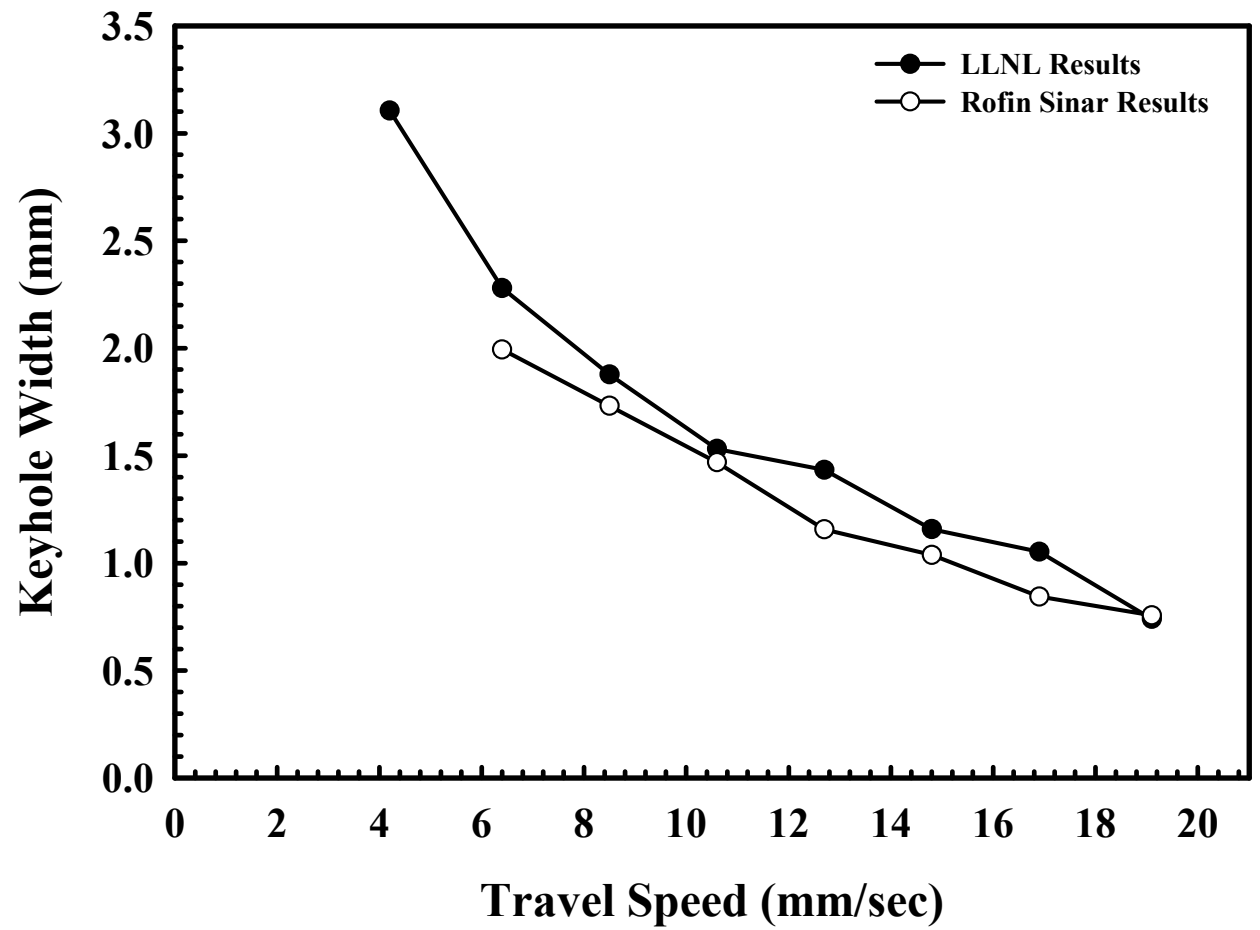

(a)

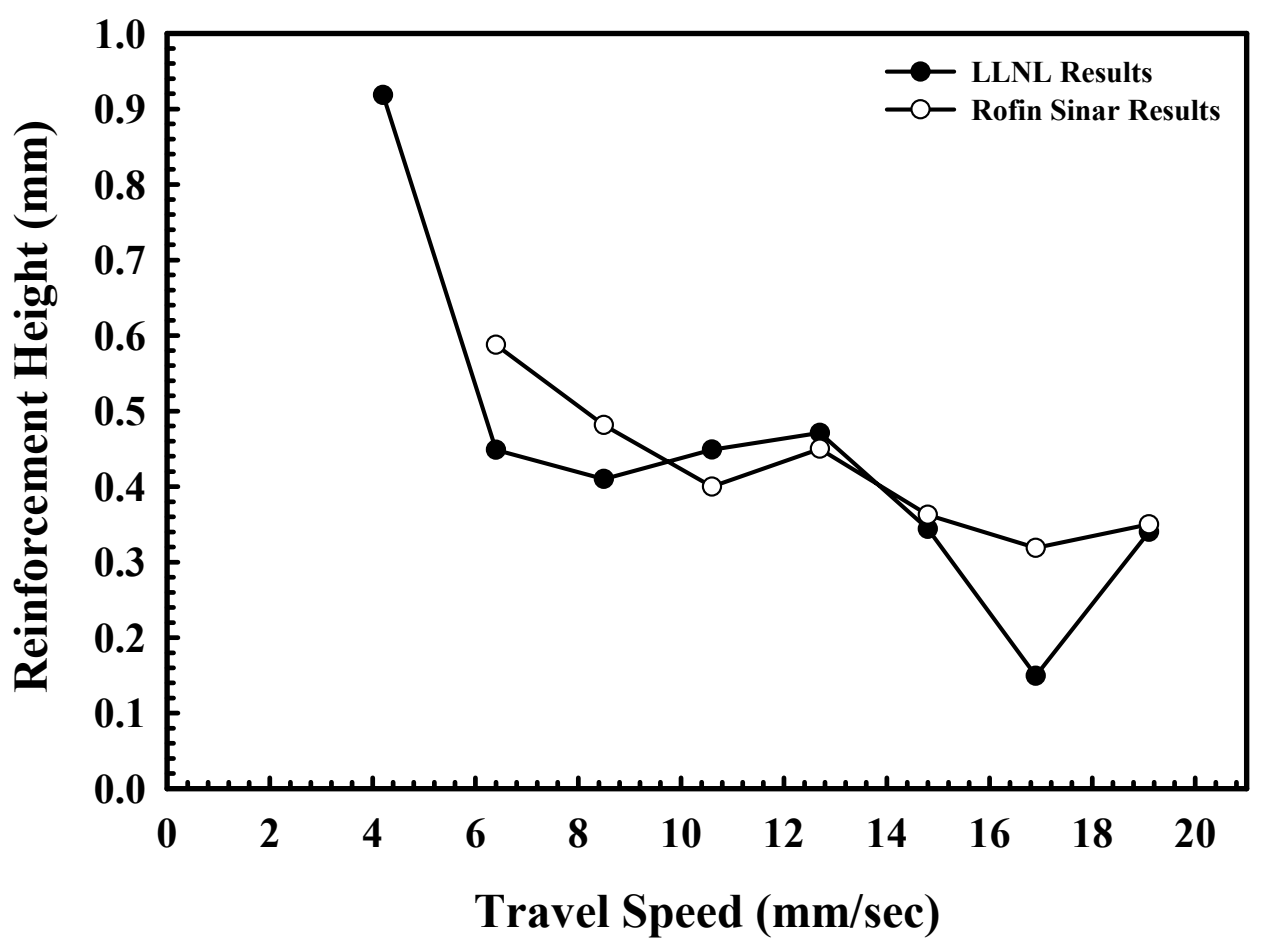

(b)

Figure 36(a\&b). Plots showing variations in the (a) keyhole width and (b) overfill height with changes in travel speed for LLNL and Rofin Sinar weld measurements at a constant machine power setting of $2200 \mathrm{~W}$ on 304L stainless steel. 
UCRL-TR-222245

\section{NITRONIC 40 (21-6-9) AUSTENITIC STAINLESS STEEL LASER WELDS}

\subsection{Summary}

A series of autogenous partial-penetration bead on plate laser welds were made on Nitronic 40 (21-6-9) austenitic stainless steel plate using a Rofin Sinar DY-022 Continuous Wave (CW) Nd:YAG welder at Lawrence Livermore National Laboratory (LLNL). In these experiments, measurements of the weld width, depth, and melted area are made under conditions of changing power input and travel speed. High depth-to-width ratio welds were produced with weld penetrations up to nearly $5.5 \mathrm{~mm}$ observed at the highest power and slowest travel speed. Unlike other materials systems examined using this welding system, the laser welds produced on the Nitronic 40 stainless steel exhibited little to no porosity. This lack of porosity in the weld cross sections is attributed to the stabilizing effect of manganese additions in the Nitronic 40 on the laser keyhole. These results were then compared with those taken under similar experimental conditions on equivalent laser systems, showing that the LLNL system produces equivalent or slightly deeper welds. Additional comparisons have also been made with laser welds made on 304L stainless steel using the LLNL laser system under similar welding conditions. In this comparison, the Nitronic 40 welds exhibited deeper penetration and a much higher depth-towidth ratio than the 304L laser welds. At the same time, though, the two sets of welds exhibited similar melted areas under equivalent welding conditions.

\subsection{Experimental Summary}

Autogenous bead-on-plate laser welds have been made using the LLNL laser system on 12.7 mm thick x $152.4 \mathrm{~mm}$ long x $25.4 \mathrm{~mm}$ wide Nitronic $40^{*}$ stainless steel weld samples. Three welds, $43.2 \mathrm{~mm}$ in length, are made on each sample. This material is a nitrogen-strengthened austenitic stainless steel, which provides a higher-performance alternative to more typical 300 series austenitic stainless steels. It is typically referred to as a 21-6-9 stainless steel, based on the nominal amounts of chromium, nickel, and manganese, respectively, present in the alloy. A summary of the chemical compositions of the material used in this study is given in Table 14. In addition to the composition of the material used in this study, the typical composition range for this alloy and a desired composition range are included in this table. The material used in this welding study falls within the desired composition ranges for all the alloying elements except for silicon.

Several studies have been performed on the Nitronic 40 stainless steel samples using the LLNL laser system and the $300 \mu \mathrm{m}$ diameter fiber. These studies include three power variation studies using machine power settings ranging from $250 \mathrm{~W}$ to $2200 \mathrm{~W}$ at travel speeds of 12.7, 19.1, and $25.4 \mathrm{~mm} / \mathrm{sec}$ and a travel speed variation study at travel speeds ranging from 6.4 $\mathrm{mm} / \mathrm{sec}$ to $25.4 \mathrm{~mm} / \mathrm{sec}$ at the maximum machine power setting of $2200 \mathrm{~W}$. All welds reported here are made with the laser focus set on the surface of the welding sample, and the laser optics assembly is set at an angle normal to the sample surface. Argon gas is used to shield the welding area and to displace the laser plasma plume during welding.

\footnotetext{
${ }^{*}$ Nitronic is a registered trademark of AK Steel Nitronics ${ }^{\circledR}$, formerly Armco Advanced Materials Company.
} 
UCRL-TR-222245

Table 14. Summary of alloying element compositions in Nitronic 40 alloys used here. (All values are in wt.\%.)

\begin{tabular}{|c|c|c|c|c|c|}
\hline & $\underline{\underline{\text { LLNL }}} \underline{\text { Welding }}$ & $\frac{\text { LANL }}{\text { Welding }}$ & $\stackrel{\text { Typical }}{\text { Composition }}^{4}$ & $\frac{\text { Desired }}{\text { Composition }}$ & $\underline{304 L}$ \\
\hline Carbon & 0.02 & 0.0342 & $0.08 \mathrm{Max}$ & $0.02-0.04$ & 0.020 \\
\hline Chromium & 19.96 & 18.9 & $19.0-21.5$ & $19.0-21.5$ & 18.20 \\
\hline Nickel & 7.02 & 7.4 & $5.5-7.5$ & $5.5-7.5$ & 8.16 \\
\hline Manganese & 9.14 & 8.8 & $8.0-10.0$ & $8.0-10.0$ & 1.71 \\
\hline Silicon & 0.05 & 0.47 & 1.0 Max & $0.3-0.7$ & 0.44 \\
\hline Nitrogen & 0.23 & 0.26 & $0.15-0.40$ & $0.20-0.30$ & 0.082 \\
\hline Phosphorous & 0.014 & $<0.01$ & $0.06 \mathrm{Max}$ & $0.020 \mathrm{Max}$ & 0.03 \\
\hline Sulfur & $<0.005$ & ---- & $0.03 \mathrm{Max}$ & $0.02 \mathrm{Max}$ & 0.0004 \\
\hline Oxygen & $<0.001$ & $<0.005$ & $\begin{array}{ll}--- \\
--\end{array}$ & $0.007 \mathrm{Max}$ & $\begin{array}{ll}--- \\
--\end{array}$ \\
\hline Aluminum & 0.04 & 0.014 & ---- & ---- & ---- \\
\hline Iron & Balance & Balance & Balance & Balance & Balance \\
\hline
\end{tabular}

\footnotetext{
${ }^{4}$ Alloy Digest, Filing Code SS-327, May 1976, Revised August 1990.
} 
UCRL-TR-222245

\section{3 $\quad$ Results}

\subsubsection{Power Variation Studies}

The first series of weld experiments discussed here examines the effects of changes in power on the resulting weld pool cross-section shape and size. Three sets of experiments are performed over a range of machine power settings from $250 \mathrm{~W}$ to $2200 \mathrm{~W}$ at travel speeds of $12.7 \mathrm{~mm} / \mathrm{sec}$, $19.1 \mathrm{~mm} / \mathrm{sec}$, and $25.4 \mathrm{~mm} / \mathrm{sec}$. These machine power settings translate into powers ranging from $220 \mathrm{~W}$ to $1955 \mathrm{~W}$ impinging on the surface of the weld sample. Micrographs showing the weld cross sections for machine power settings between 500 and $2000 \mathrm{~W}$ for each travel speed are shown in Figures 37 through 39. Each of the weld cross sections shown in these figures displays a shape typical of keyhole mode laser welding. On the other hand, at a machine power setting of $250 \mathrm{~W}$ at each travel speed, as shown in Figures 40(a-c), the resulting weld pool cross sections display a shape more typical of conduction mode laser welding.

In laser welding, the conduction and keyhole modes are the two prominent welding modes. Conduction mode laser welding is typical at lower powers, where the heat transfer conditions between the laser beam and the sample surface result in a semi-hemispherical shaped weld pool. When the power densities become high enough, usually on the order of $10^{6} \mathrm{~W} / \mathrm{cm}^{2}$ or higher, a strong evaporation of the weld pool surface is produced. The resulting energetic evaporation of the weld pool surface produces a recoil pressure, which is sufficient to produce a deep, narrow depression in the molten material. This depression is referred to as a keyhole, and is filled with a partially ionized plume of vapor and ambient gas. ${ }^{2}$ With the presence of a keyhole, the weld pool cross sections take on a much different shape, characterized by a semi-hemispherical top and a finger-like protrusion into the material being welded. It is apparent that in the welds produced here a keyhole welding mode is achieved at a machine setting of $500 \mathrm{~W}$, corresponding to a power density of $7 \times 10^{5} \mathrm{~W} / \mathrm{cm}^{2}$, and maintained at higher powers. Under these conditions, porosity appeared in the welds.

In addition to the weld keyhole shape common to the weld cross sections at machine power settings above $500 \mathrm{~W}$, these Nitronic 40 welds display little to no porosity. This behavior is the opposite of that previously observed in the 304L laser welds made on this laser welding system, where significant porosity is present in all of the weld pool cross sections. In these high power continuous wave laser welds on 304L stainless steel, the porosity is associated with instabilities in the keyhole. ${ }^{3}$ It is important to understand that the keyhole formed during laser welding is constantly fluctuating and relies on a complex interaction of many factors, including evaporation recoil pressure, hydrodynamic pressures created by the melt and the laser plume, hydrostatic pressure, and surface tension, in order to remain stable. As a result, small fluctuations or variations in the keyhole result in the formation of small perturbations on the keyhole walls or its complete collapse. Ejection of metal vapor and entrapped shielding gas from the keyhole column occurs as a result of the keyhole collapse, leaving behind a non-continuous trail of pores along the longitudinal orientation of the weld.

These conditions are mitigated in the Nitronic 40 by the presence of one of its primary alloying constituents, manganese. Unlike the 304L stainless steel, which contains only 1.71 wt.\% Mn, the Nitronic 40 stainless steel used in this study contains 9.14 wt.\%. Manganese plays 


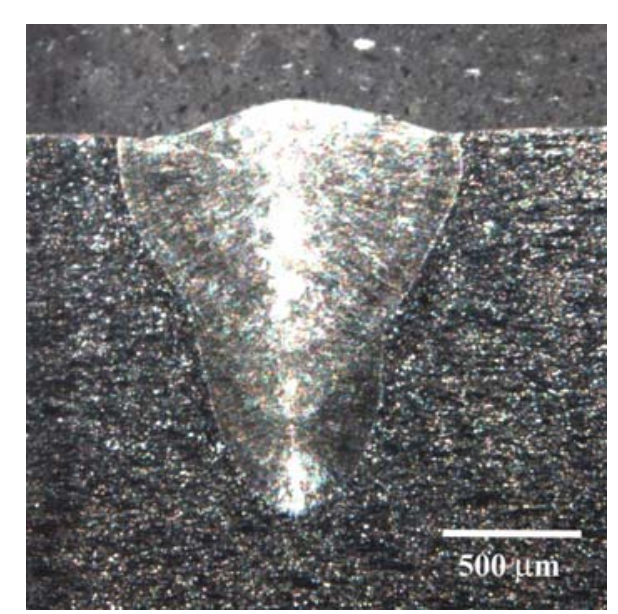

(a)

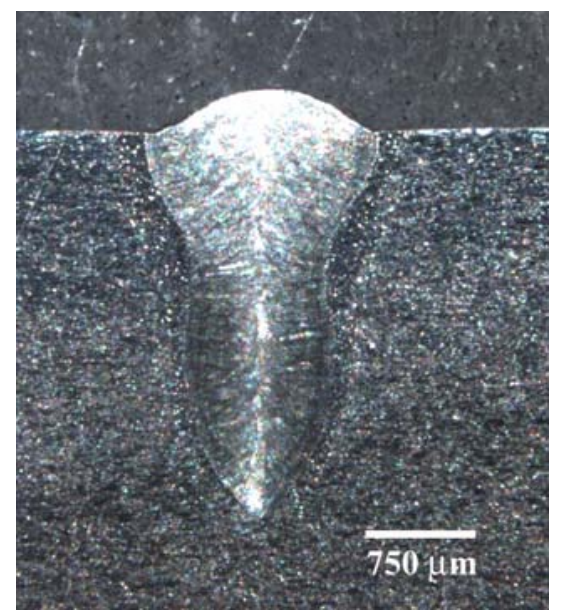

(b)

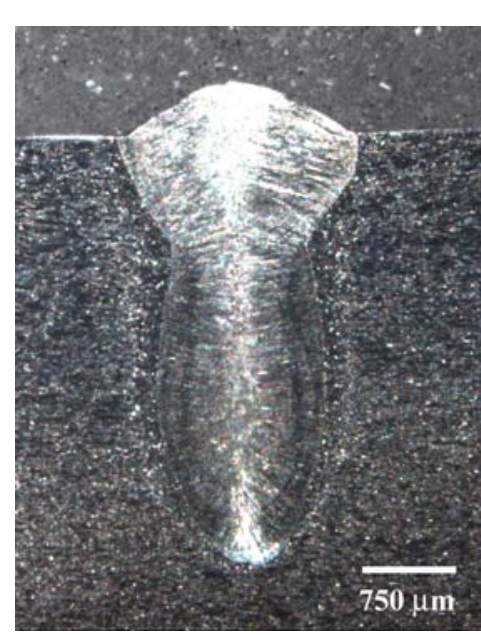

(c)

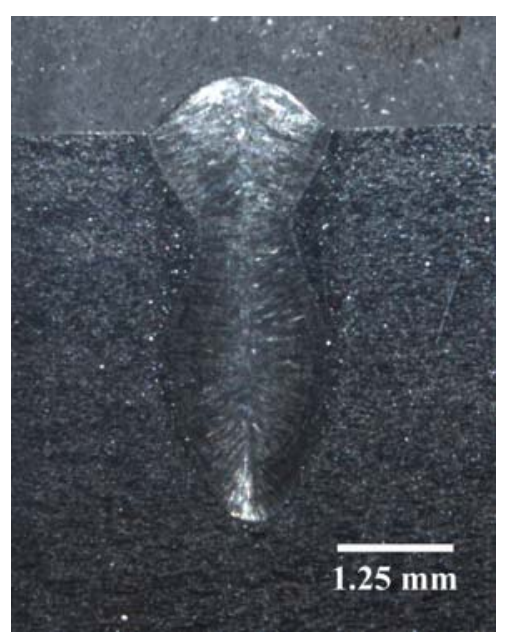

(d)

Figure 37(a-d). Micrographs of Nitronic 40 weld cross sections made using the LLNL welder at machine power settings of (a) $500 \mathrm{~W}$, (b) $1000 \mathrm{~W}$, (c) $1500 \mathrm{~W}$, and (d) $2000 \mathrm{~W}$ at a travel speed of $12.7 \mathrm{~mm} / \mathrm{sec}$. 


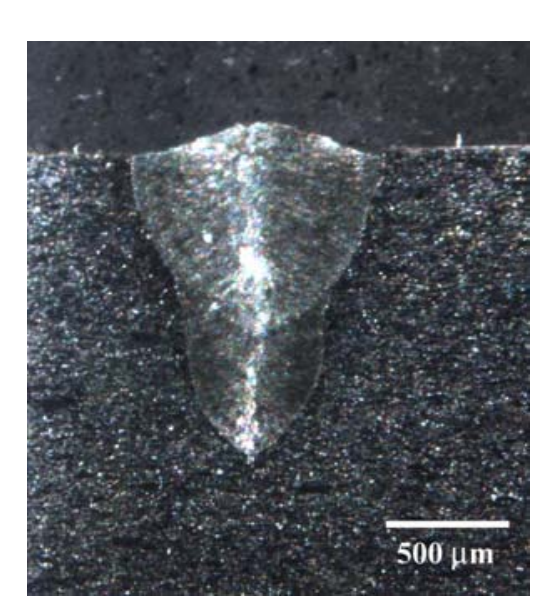

(a)

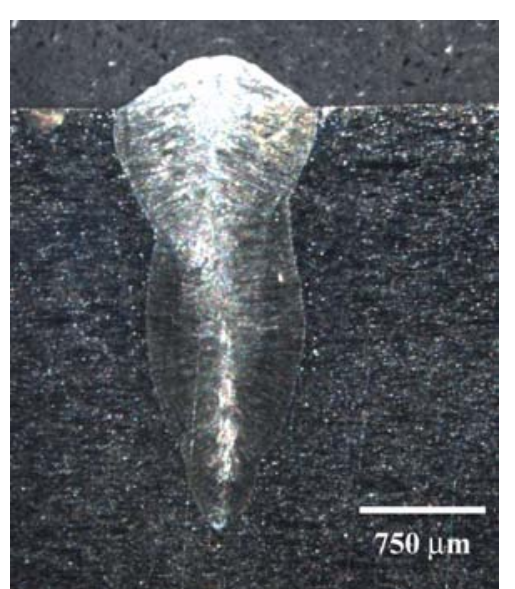

(b)

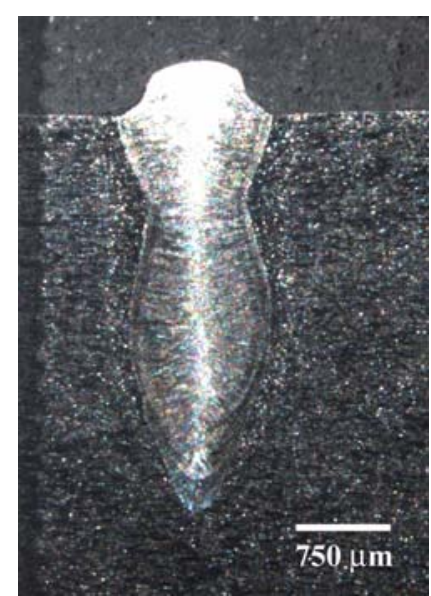

(c)

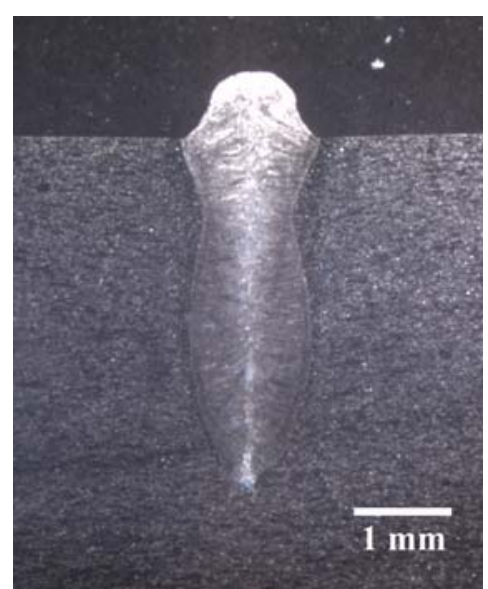

(d)

Figure 38(a-d). Micrographs of Nitronic 40 weld cross sections made using the LLNL welder at machine power settings of (a) $500 \mathrm{~W}$, (b) $1000 \mathrm{~W}$, (c) $1500 \mathrm{~W}$, and (d) $2000 \mathrm{~W}$ at a travel speed of $19.7 \mathrm{~mm} / \mathrm{sec}$. 


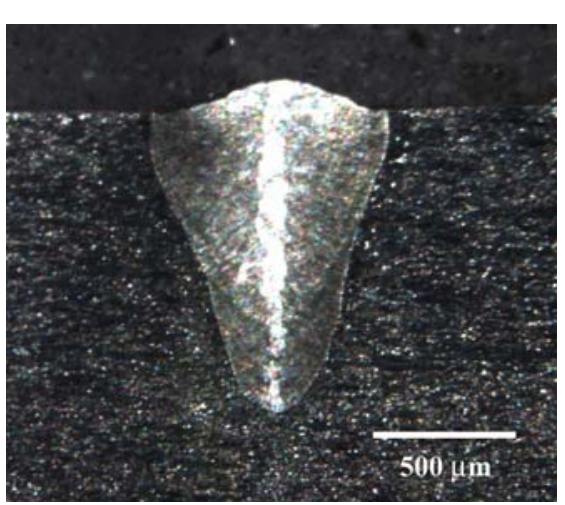

(a)

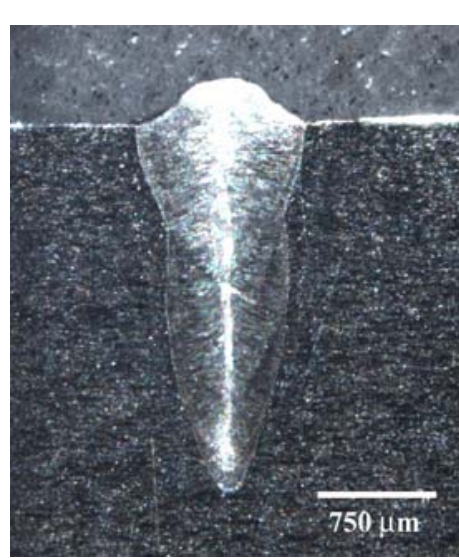

(b)

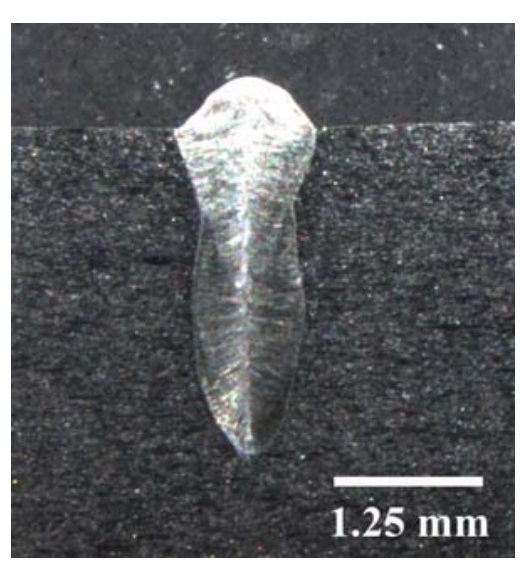

(c)

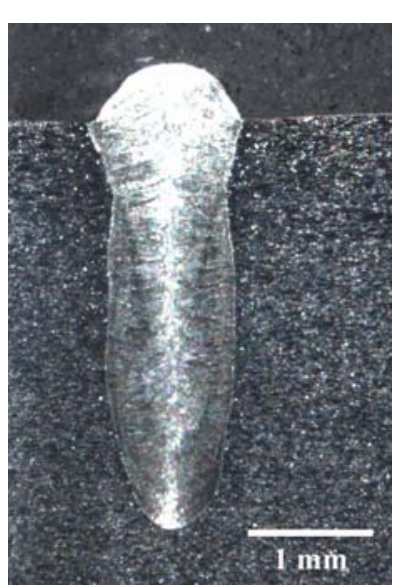

(d)

Figure 39(a-d). Micrographs of Nitronic 40 weld cross sections made using the LLNL welder at machine power settings of (a) $500 \mathrm{~W}$, (b) $1000 \mathrm{~W}$, (c) $1500 \mathrm{~W}$, and (d) $2000 \mathrm{~W}$ at a travel speed of $25.4 \mathrm{~mm} / \mathrm{sec}$. 


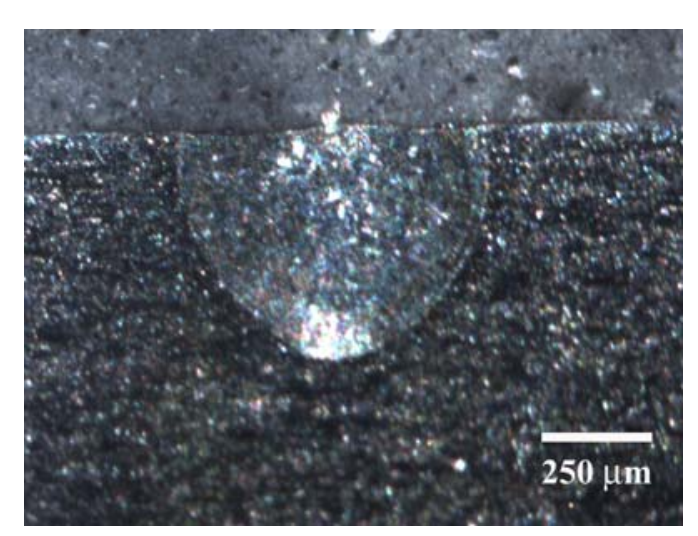

(a)

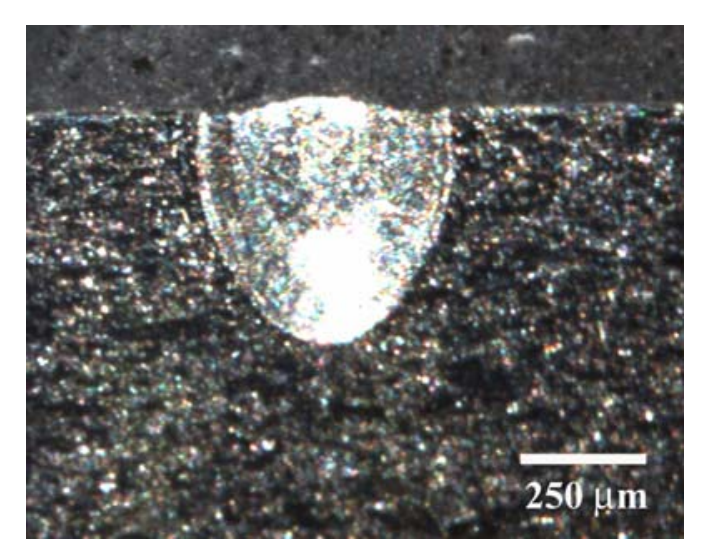

(b)

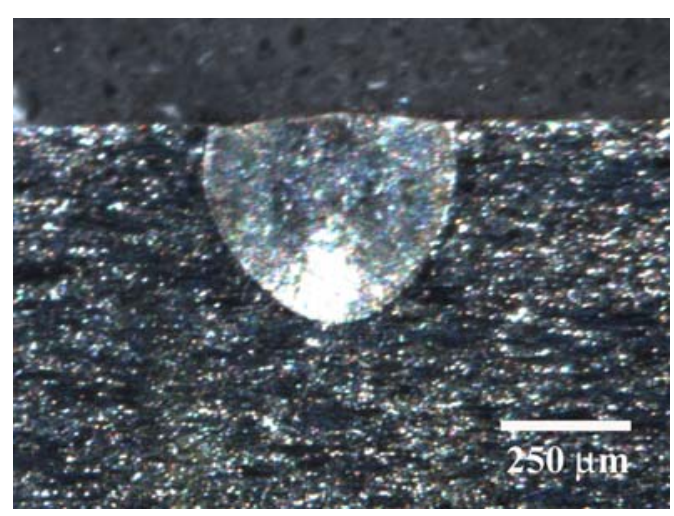

(c)

Figure 40(a-c). Micrographs of Nitronic 40 weld cross sections made using the LLNL welder at machine power settings of $250 \mathrm{~W}$ at travel speeds of (a) $12.7 \mathrm{~mm} / \mathrm{sec}$, (b) $19.1 \mathrm{~mm} / \mathrm{sec}$, and (c) $25.4 \mathrm{~mm} / \mathrm{sec}$. Note the differing magnifications of each micrograph. 
an important role in stabilizing the keyhole because of its high vapor pressure in comparison with the other alloying elements(165.1 $\mathrm{Pa}$ vs. $2.3 \mathrm{~Pa}$ for pure iron at their respective melting points, $1236^{\circ} \mathrm{C}$ for $\mathrm{Mn}$ and $1536^{\circ} \mathrm{C}$ for $\left.\mathrm{Fe}\right){ }^{5}$ Even though this value is for a pure metal, the effects in this alloy system, where manganese is bonding with other alloying elements, are similar. With such a high vapor pressure, manganese evaporates very easily, making it much easier for the keyhole to form and, in turn, be sustained during welding. As a result, the deep penetrating and porosity-free welds observed in Figures 37 through 39 are produced.

A summary of the weld measurements taken on each weld is given in Table 15. The values for the power used on each weld correspond with the power input measured at the sample surface. In addition to the width, depth, and area measurements, the aspect ratio of each weld, which is defined as the depth to width ratio, is also listed. This value provides a measure of the general shape of the weld fusion zone not available with simple width and depth measurements alone. For example, a typical keyhole weld, which displays a larger depth than width, will have an aspect ratio greater than unity.

Plots comparing each of these primary measurements with the power impinging on the sample surface are shown in Figures 41(a-d) for each travel speed. With increasing power, both the weld width and depth increase, albeit at different rates. For the travel speeds investigated, the slowest travel speed $(12.7 \mathrm{~mm} / \mathrm{sec})$ produces both the widest and deepest weld pools with the highest melted areas. This characteristic is consistent across all of the power inputs, from $220 \mathrm{~W}$ to $1980 \mathrm{~W}$. Even though the travel speed has this marked effect in the primary weld pool measurements, the decreasing travel speed has no effect on the weld aspect ratio. As shown in Figure 41(c), the weld aspect ratios for each travel speed increase with increasing power. When the results from the three travel speeds are compared, the slowest travel speed displays the smallest aspect ratio, while the two more rapid travel speeds show little difference in values. Overall, the aspect ratios for all three sets of welds are much higher than any seen in previous welding experiments using this laser system. For example, the aspect ratios measured at each of the three travel speeds at the highest power input level display values greater than 2.0. An aspect ratio of this magnitude represents a deep weld with narrow width.

Two additional measurements have also been made on each weld cross section. These measurements, which include the keyhole width and reinforcement height, provide a measure of other weld characteristics, rather than just the general weld shape and size. For example, the weld keyhole width provides a general measure of the keyhole width and additional knowledge of the general characteristics of the keyhole under these welding conditions. In addition, measurements of the reinforcement height can provide a general indicator of porosity in the weld cross section. Since all of the welds discussed here are partial penetration welds in a relatively thick plate, there is a conservation of volume, and the reinforcement height is assumed to offset the volume of porosity present in the weld. The effects of changes in power on the keyhole width and the reinforcement height are shown in Figures $42(\mathrm{a} \& \mathrm{~b})$ for the three travel speeds investigated here. In general, both values increase with increasing power input. Whereas the keyhole width shows a distinct relation with travel speed, in which the slower travel speeds produce wider keyholes, the weld reinforcement heights are similar for each travel speed.

\footnotetext{
${ }_{5}^{5}$ Smithells Metals Reference Book, Seventh Edition, ed. by E.A. Brandes and G.B. Brook, (Butterworth Heinemann, Oxford, 1998)
} 
Table 15. Summary of measurements made on Nitronic 40 weld samples using the LLNL welding system during the power variation studies.

\begin{tabular}{|c|c|c|c|c|c|c|c|}
\hline$\frac{\text { Power }}{\frac{\text { to Part }}{\text { (Watts) }}}$ & Speed & $\frac{\text { Weld Width }}{\underline{(\mathrm{mm})}}$ & $\frac{\text { Weld Depth }}{\underline{(\mathrm{mm})}}$ & $\frac{\text { Aspect Ratio }}{\text { (Depth/Width) }}$ & $\frac{\text { Keyhole Width }}{\underline{(\mathrm{mm})}}$ & $\frac{\text { Reinforcement }}{\underline{\text { Height }(\mathrm{mm})}}$ & $\frac{\text { Melted Area }}{\left(\mathbf{m m}^{2}\right)}$ \\
\hline 220 & $25.4 \mathrm{~mm} / \mathrm{sec}$ & 0.488 & 0.387 & 0.794 & $\begin{array}{ll}--- \\
\end{array}$ & ---- & 0.164 \\
\hline 442 & & 0.858 & 1.093 & 1.274 & 0.508 & 0.125 & 0.684 \\
\hline 664 & & 1.008 & 1.707 & 1.693 & 0.590 & 0.212 & 1.195 \\
\hline 887 & & 1.094 & 2.360 & 2.157 & 0.770 & 0.313 & 1.873 \\
\hline 1109 & & 1.204 & 2.335 & 1.940 & 0.897 & 0.347 & 2.181 \\
\hline 1332 & & 1.220 & 2.806 & 2.301 & 0.970 & 0.461 & 2.974 \\
\hline 1554 & & 1.244 & 2.966 & 2.385 & 1.047 & 0.416 & 3.178 \\
\hline 1777 & & 1.243 & 3.236 & 2.604 & 1.010 & 0.459 & 3.526 \\
\hline 1980 & & 1.226 & 3.361 & 2.740 & 1.100 & 0.592 & 4.032 \\
\hline 220 & $19.1 \mathrm{~mm} / \mathrm{sec}$ & 0.486 & 0.444 & 0.913 & ---- & 0.033 & 0.189 \\
\hline 442 & & 1.003 & 1.210 & 1.206 & 0.539 & 0.109 & 0.884 \\
\hline 664 & & 1.282 & 1.997 & 1.558 & 0.698 & 0.161 & 1.588 \\
\hline 887 & & 1.225 & 2.496 & 2.038 & 0.924 & 0.321 & 2.259 \\
\hline 1109 & & 1.252 & 2.699 & 2.156 & 1.022 & 0.424 & 2.796 \\
\hline 1332 & & 1.253 & 3.135 & 2.502 & 1.131 & 0.447 & 3.127 \\
\hline 1554 & & 1.319 & 3.478 & 2.637 & 1.164 & 0.485 & 3.905 \\
\hline 1777 & & 1.496 & 3.665 & 2.450 & 1.293 & 0.698 & 4.827 \\
\hline 1980 & & 1.509 & 3.982 & 2.639 & 1.337 & 0.650 & 5.562 \\
\hline 220 & $12.7 \mathrm{~mm} / \mathrm{sec}$ & 0.673 & 0.498 & 0.740 & ---- & ---- & 0.281 \\
\hline 442 & & 1.311 & 1.453 & 1.109 & 0.680 & 0.136 & 1.300 \\
\hline 664 & & 1.734 & 2.178 & 1.256 & 0.822 & 0.184 & 2.274 \\
\hline 887 & & 1.662 & 2.782 & 1.674 & 1.096 & 0.314 & 3.225 \\
\hline 1109 & & 1.833 & 3.187 & 1.739 & 1.143 & 0.400 & 4.126 \\
\hline 1332 & & 1.987 & 3.532 & 1.778 & 1.398 & 0.424 & 5.162 \\
\hline 1554 & & 1.964 & 4.386 & 2.234 & 1.536 & 0.472 & 6.520 \\
\hline 1777 & & 1.965 & 4.182 & 2.128 & 1.713 & 0.579 & 6.709 \\
\hline 1980 & & 1.975 & 4.720 & 2.391 & 1.617 & 0.561 & 7.379 \\
\hline
\end{tabular}




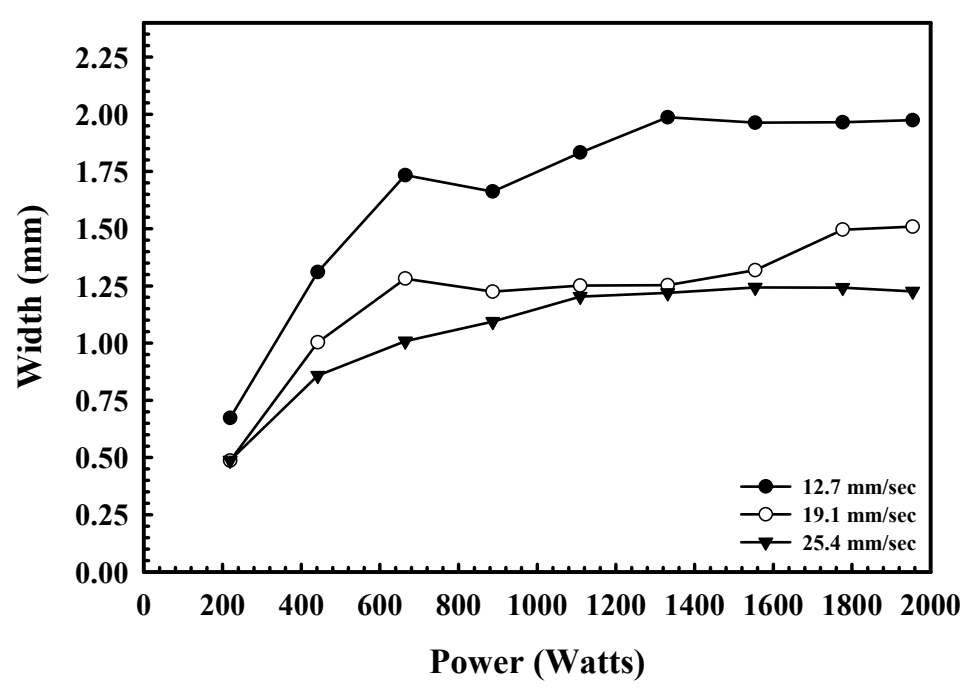

(a)

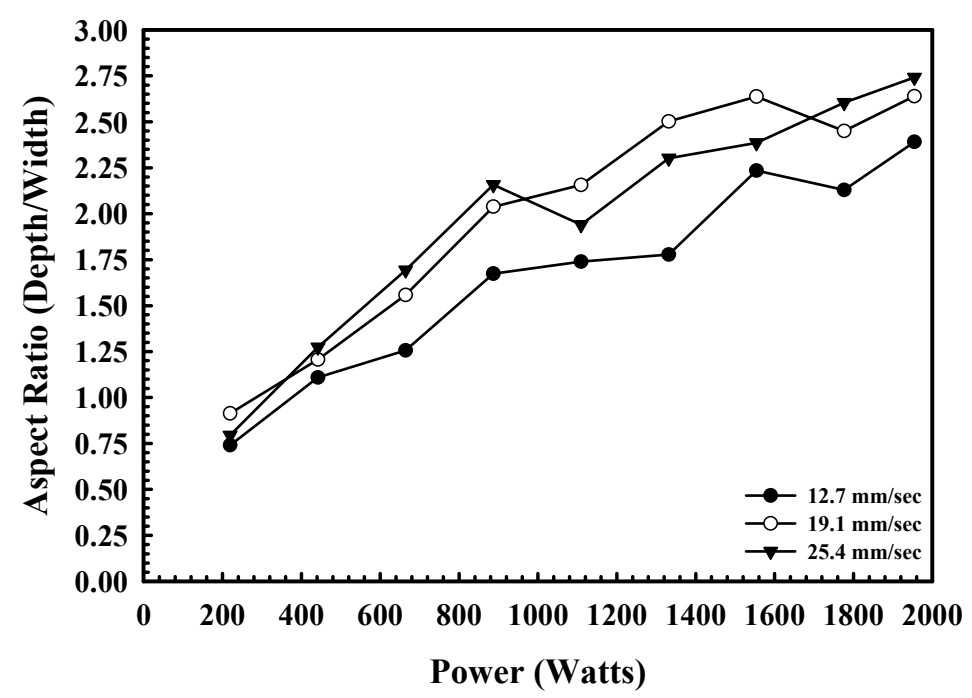

(c)

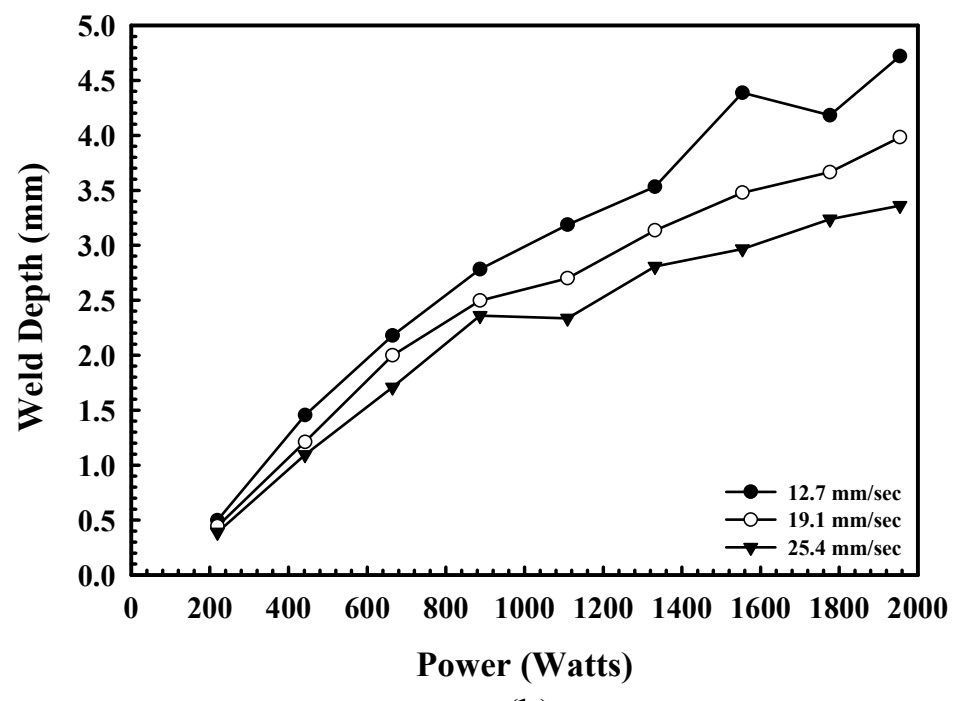

(b)

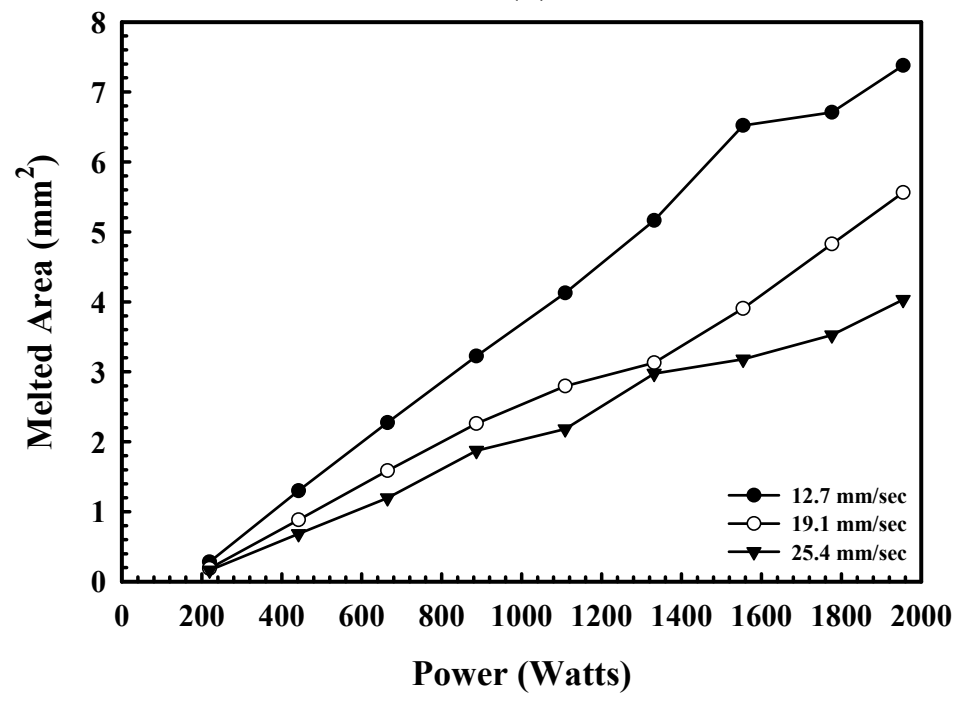

(d)

Figure 41(a-d). Plots showing variations in the (a) weld width, (b) weld depth, (c) aspect ratio (depth/width), and (d) melted area of Nitronic 40 welds made using the LLNL machine with changes in the power input for travel speeds of $12.7 \mathrm{~mm} / \mathrm{sec}, 19.1 \mathrm{~mm} / \mathrm{sec}$, and $25.4 \mathrm{~mm} / \mathrm{sec}$. 
UCRL-TR-222245

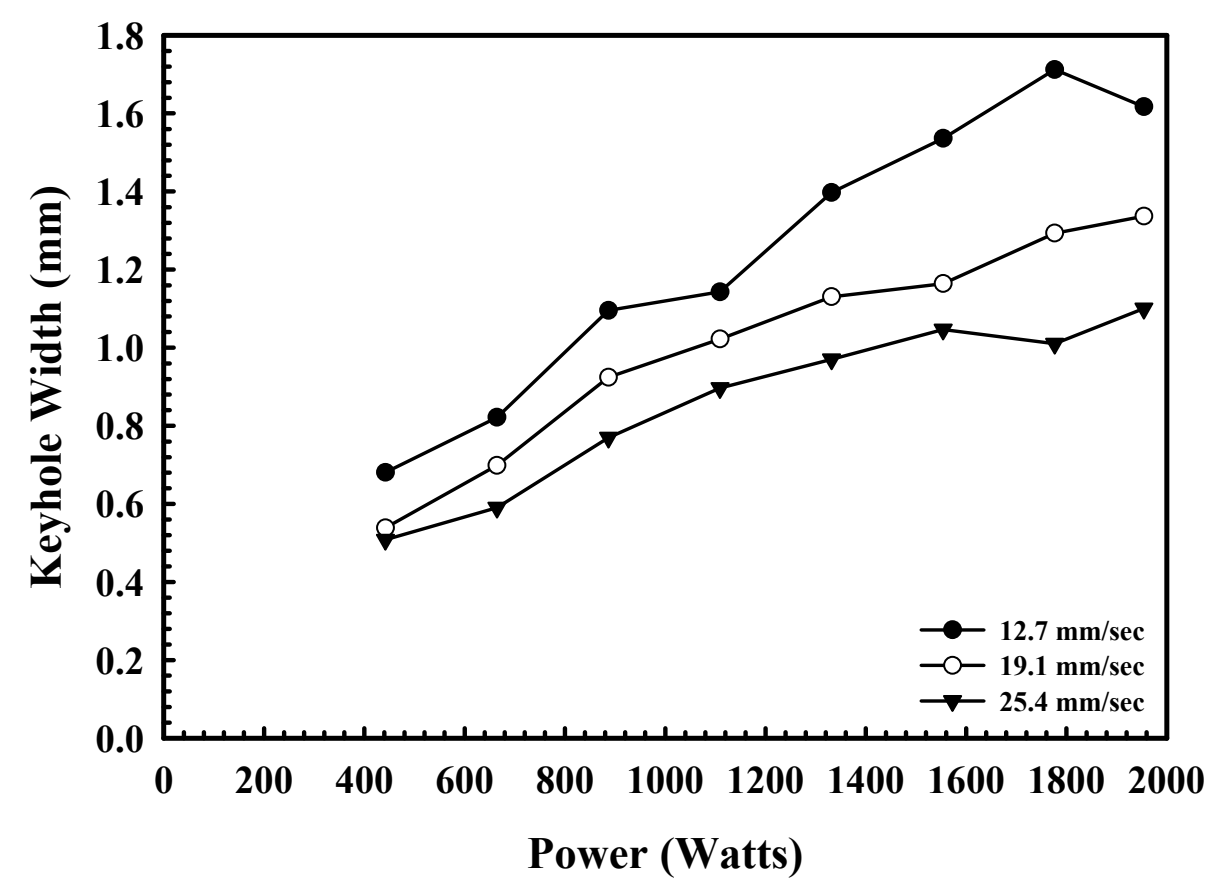

(a)

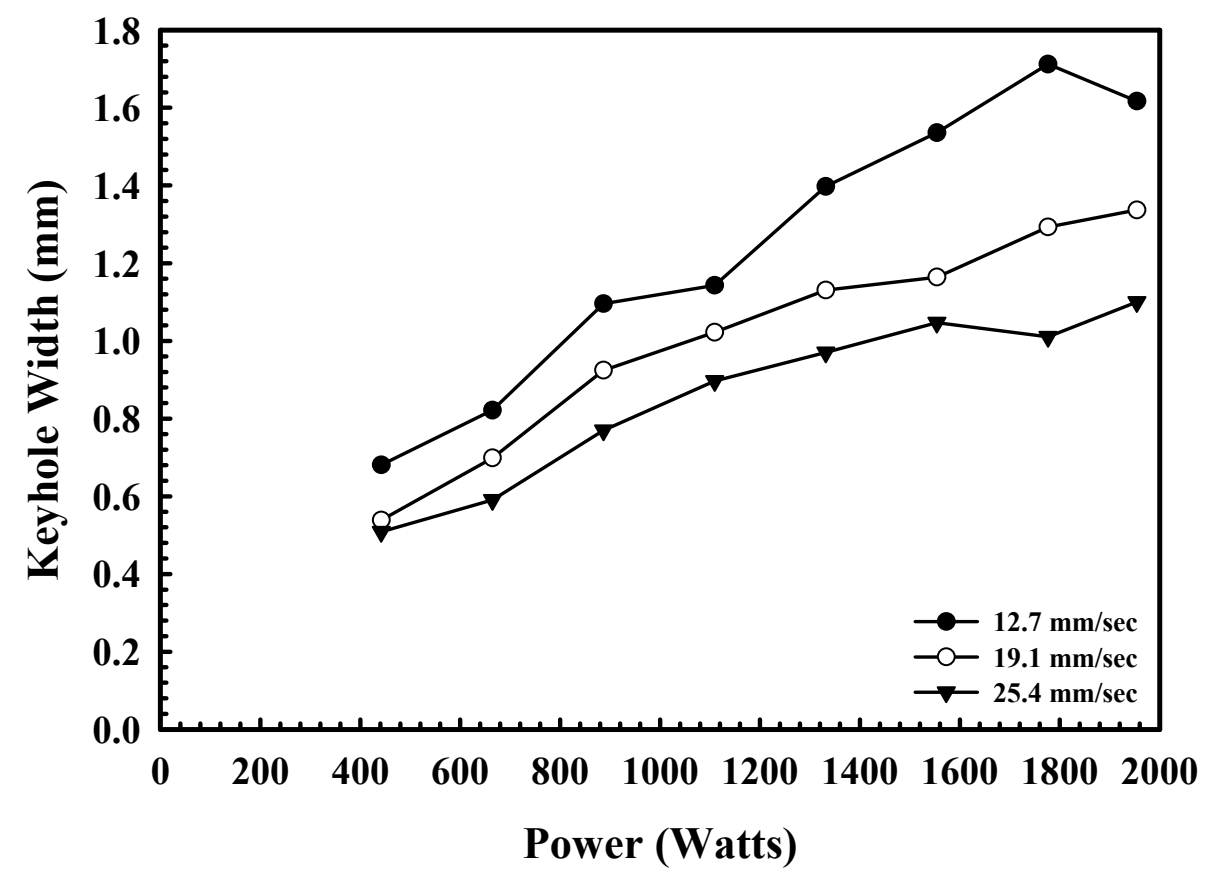

(b)

Figure 42(a\&b). Plots showing variations in the (a) keyhole width and (b) weld reinforcement height with changes in the machine output power setting for Nitronic 40 welds made using the LLNL machine at travel speeds of $12.7 \mathrm{~mm} / \mathrm{sec}, 19.1 \mathrm{~mm} / \mathrm{sec}$, and $25.4 \mathrm{~mm} / \mathrm{sec}$. 
UCRL-TR-222245

\subsubsection{Travel Speed Variation Studies}

As discussed in the power variation studies, changes in the weld travel speed result in changes in the weld characteristics. In order to better define the effects of travel speed, another set of experiments, in which the weld travel speed has been varied at a constant power, has been performed. Travel speeds between 6.4 and $25.4 \mathrm{~mm} / \mathrm{sec}$ have been examined at a constant power $(1980 \mathrm{~W})$. This power corresponds with the maximum power delivered to the sample by the LLNL laser system, thus providing the best indication of the maximum depth possible for this laser system. Micrographs of weld cross sections taken at travel speeds of 21.2, 14.8, 8.5 and 6.4 $\mathrm{mm} / \mathrm{sec}$ are shown in Figures 43(a-d), respectively. Like the weld cross sections shown previously, each cross section micrograph in Figures 43(a-d) displays a shape consistent with a keyhole mode of welding. In addition, with the decrease in travel speed in each micrograph, the size and shape of the weld pool, especially the keyhole width values, change.

The measurements made on the weld cross sections in the travel speed variation study are summarized in Table 16, while the weld width, depth, aspect ratio, and total melted area are plotted in Figures 44(a-d), respectively, as a function of the travel speed. In general, the weld width, depth, and melted area decrease, albeit at different rates, with increasing travel speed, as shown in Figures 44(a), 44(b), and 44(d). In each case, the largest weld width (3.26 mm), depth $(5.42 \mathrm{~mm})$, and melted area $\left(12.71 \mathrm{~mm}^{2}\right)$ are observed at the lowest travel speed $(6.4 \mathrm{~mm} / \mathrm{sec})$. On the other hand, the aspect ratios display the highest values at the highest travel speeds. For example, a comparison between the highest and lowest travel speeds studied here shows that an aspect ratio of approximately 2.8 is achieved at a travel speed of $25.4 \mathrm{~mm} / \mathrm{sec}$, while one of only 1.7 is achieved at a travel speed of $6.4 \mathrm{~mm} / \mathrm{sec}$.

The effects of changing travel speed on the keyhole width and reinforcement height are shown in Figures 45(a\&b), respectively. In these figures, the keyhole width and reinforcement height show differing trends. For example, the keyhole width, shown in Figure 45(a) decreases with increasing travel speed. This behavior is consistent with that observed in the power variation studies, where the keyhole widths produced at the slower travel speeds are the largest. On the other hand, the reinforcement height remains constant over all of the travel speeds investigated here, matching that behavior observed in the power variation studies, where the different travel speeds displayed a uniform increase in weld reinforcement height with increasing power.

\subsubsection{Effects of Energy Input per Unit Length of Weld}

The use of the parameter energy input per unit length of weld, defined as the input power divided by the travel speed, is a more general description of the energy or power imparted on the workpiece than the input power alone. Unlike the previous comparisons, in which the effects of travel speed and power input are separate, the results of the power variation and travel speed variation studies can be directly compared. The energy inputs for each weld are included in Tables 15 and 16 along with the measured weld dimensions. Comparisons between the measured weld width, depth, aspect ratio, and melted area for the results from both the power variation and travel speed studies are plotted in Figures 46(a-d) as a function of energy input per unit length of weld.

In general, these four sets of measurements show increasing values with increasing energy inputs, albeit at different rates. The trends in the weld width as a function of energy input shown in Figure 46(a) display this behavior, except in a range of energy inputs between approximately 


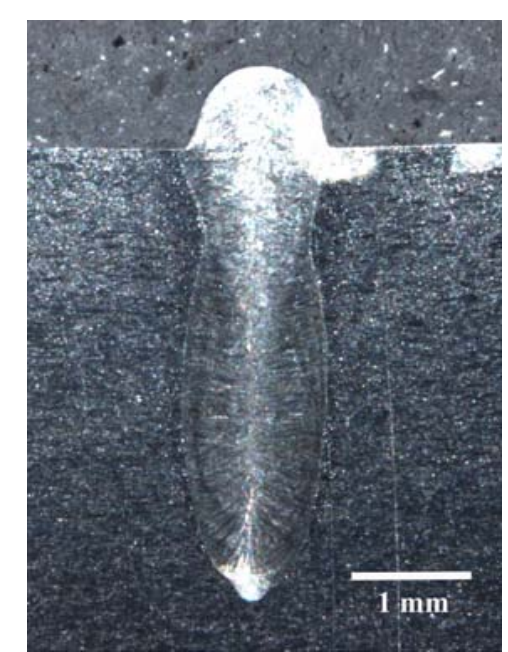

(a)

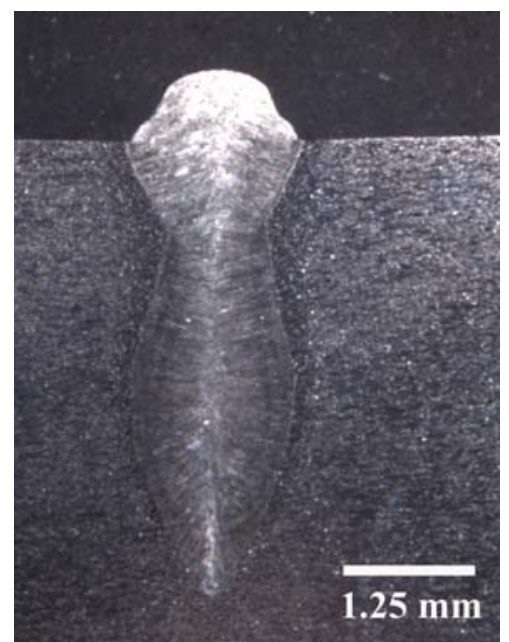

(b)

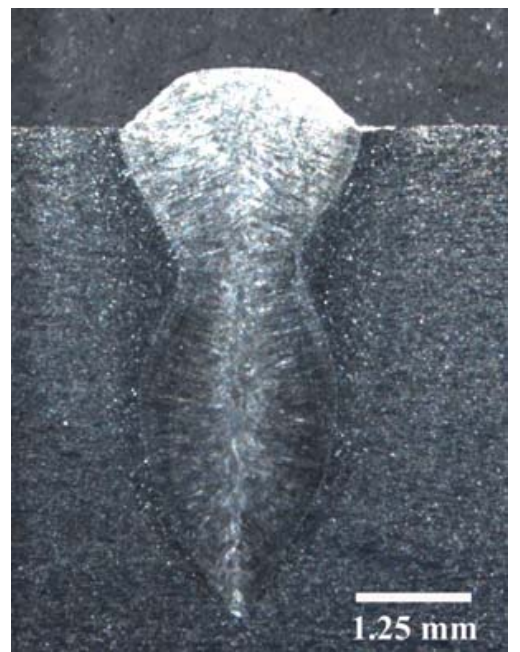

(c)

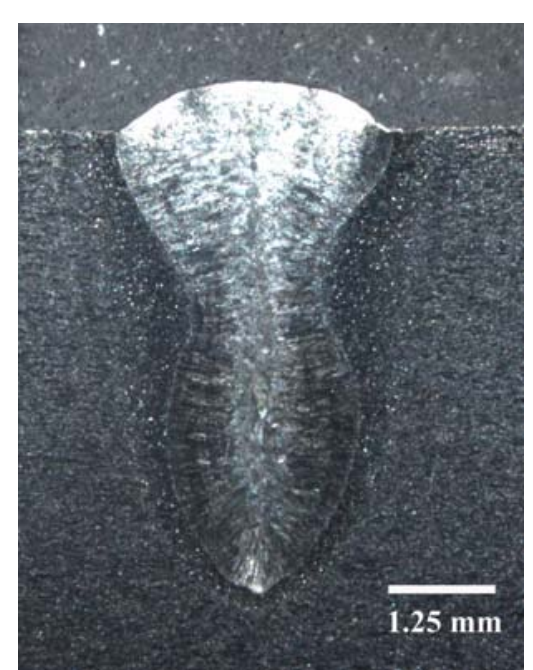

(d)

Figure 43(a-d). Micrographs of Nitronic 40 weld cross sections made using the LLNL welder at travel speeds of (a) $21.2 \mathrm{~mm} / \mathrm{sec}$, (b) $14.8 \mathrm{~mm} / \mathrm{sec}$, (c) $8.5 \mathrm{~mm} / \mathrm{sec}$, and (d) $6.4 \mathrm{~mm} / \mathrm{sec}$ at a maximum power of $1955 \mathrm{~W}$. 
UCRL-TR-222245

Table 16. Summary of Nitronic 40 weld measurements made using the LLNL welder during travel speed variation studies made at the maximum power output setting ( $1980 \mathrm{~W}$ delivered to the part).

\begin{tabular}{|c|c|c|c|c|c|c|}
\hline$\frac{\text { Travel }}{\underline{\text { Speed }}}$ & $\frac{\text { Weld }}{\frac{\text { Width }}{\text { (mm) }}}$ & $\frac{\frac{\text { Weld }}{\text { Depth }}}{(\mathrm{mm})}$ & $\frac{\text { Aspect Ratio }}{\text { (Depth/Width) }}$ & $\frac{\text { Keyhole }}{\frac{\text { Width }}{(\mathrm{mm})}}$ & 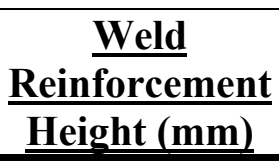 & $\frac{\text { Melted }}{\underline{\text { Area }}}$ \\
\hline $\begin{array}{c}25.4 \\
(60 \mathrm{in} / \mathrm{min})\end{array}$ & 1.226 & 3.361 & 2.740 & 1.100 & 0.592 & 4.032 \\
\hline $\begin{array}{c}21.2 \\
(50 \mathrm{in} / \mathrm{min})\end{array}$ & 1.330 & 3.810 & 2.864 & 1.219 & 0.718 & 4.662 \\
\hline $\begin{array}{c}19.1 \\
(45 \mathrm{in} / \mathrm{min})\end{array}$ & 1.408 & 3.982 & 2.639 & 1.337 & 0.650 & 5.562 \\
\hline $\begin{array}{c}16.9 \\
(40 \mathrm{in} / \mathrm{min})\end{array}$ & 1.472 & 4.348 & 2.954 & 1.445 & 0.657 & 5.950 \\
\hline $\begin{array}{c}14.8 \\
(35 \mathrm{in} / \mathrm{min})\end{array}$ & 1.713 & 4.368 & 2.551 & 1.570 & 0.718 & 6.659 \\
\hline $\begin{array}{c}12.7 \\
(30 \mathrm{in} / \mathrm{min})\end{array}$ & 1.975 & 4.720 & 2.391 & 1.617 & 0.561 & 7.379 \\
\hline $\begin{array}{c}10.6 \\
(25 \mathrm{in} / \mathrm{min})\end{array}$ & 2.250 & 4.837 & 2.150 & 1.787 & 0.599 & 8.818 \\
\hline $\begin{array}{c}8.5 \\
(20 \mathrm{in} / \mathrm{min})\end{array}$ & 2.690 & 5.302 & 1.971 & 2.145 & 0.674 & 10.405 \\
\hline $\begin{array}{c}6.4 \\
(15 \mathrm{in} / \mathrm{min}) \\
\end{array}$ & 3.257 & 5.419 & 1.664 & 2.293 & 0.603 & 12.713 \\
\hline
\end{tabular}




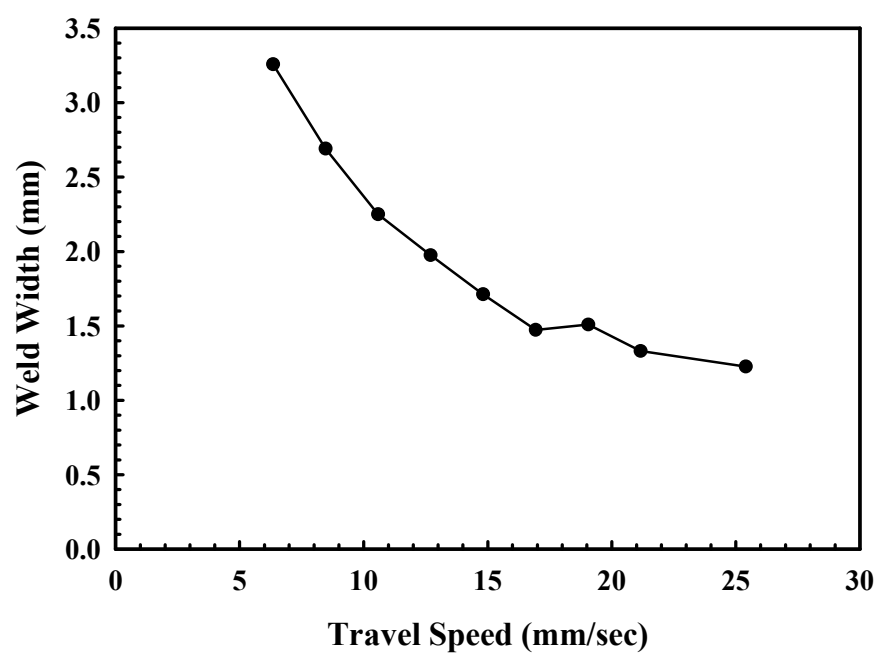

(a)

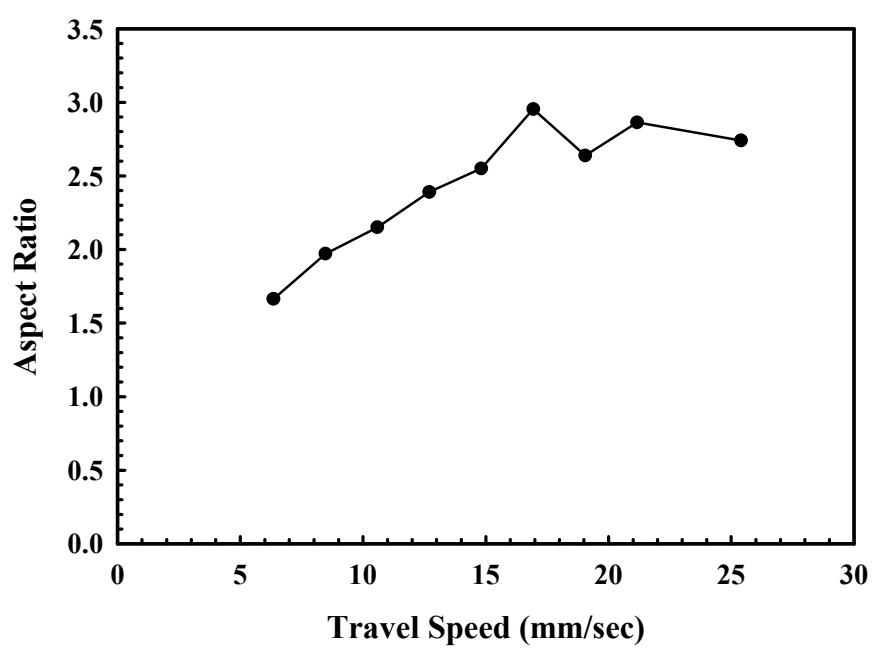

(c)

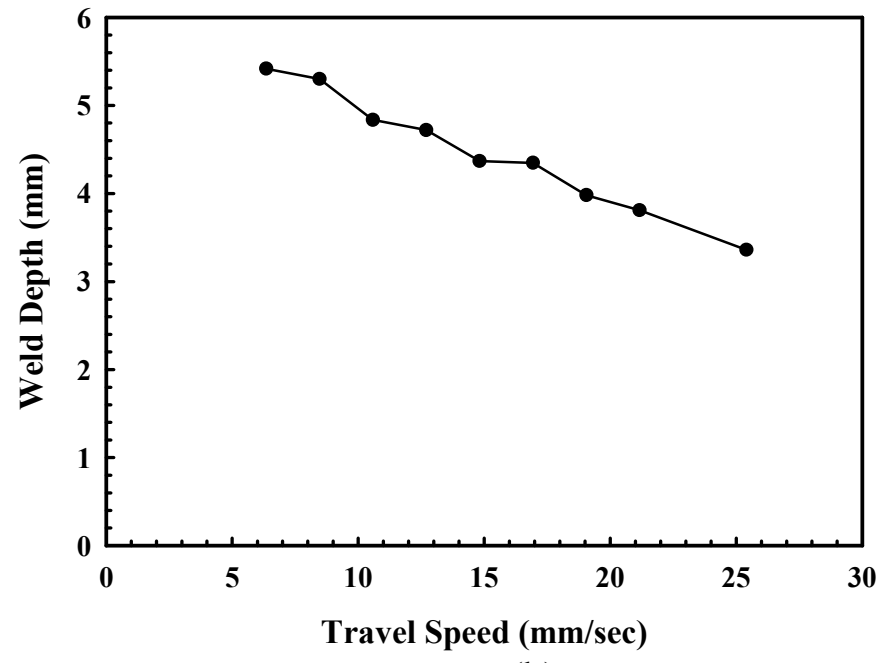

(b)

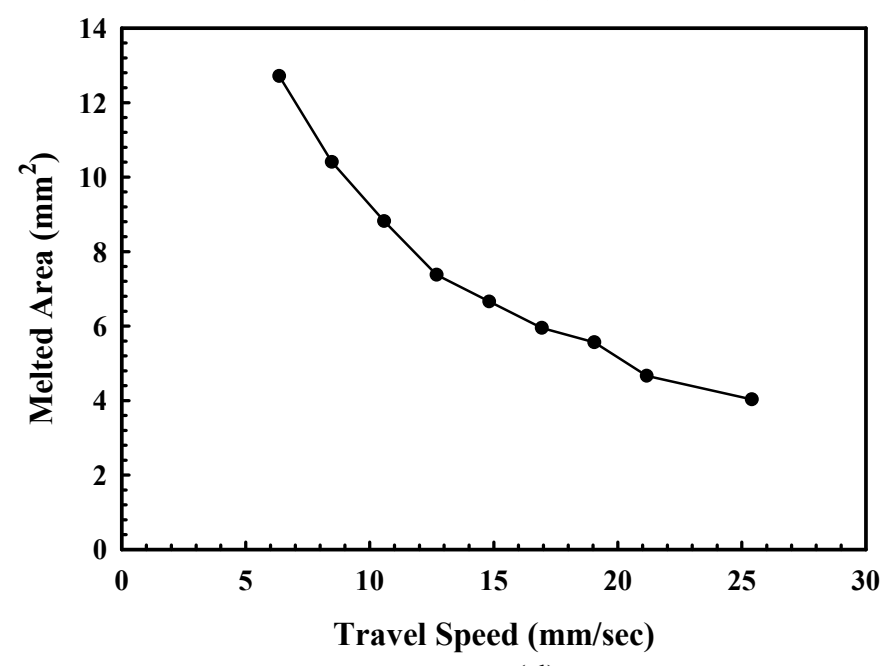

(d)

Figure 44(a-d). Plots showing variations in the (a) weld width, (b) weld depth, (c) aspect ratio, and (d) melted area for Nitronic 40 welds made using the LLNL welder with changes in the travel speed for a maximum power of $1980 \mathrm{~W}$. 
UCRL-TR-222245

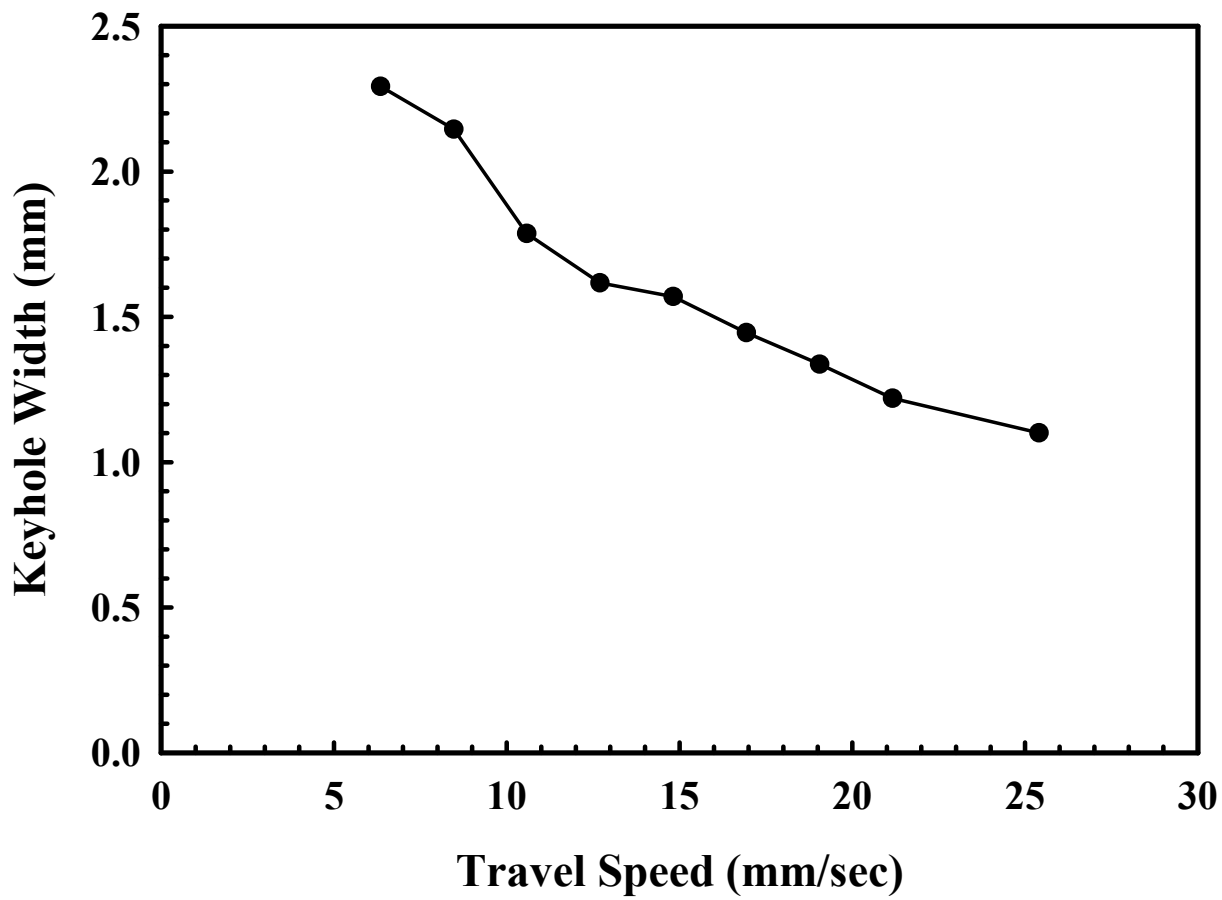

(a)

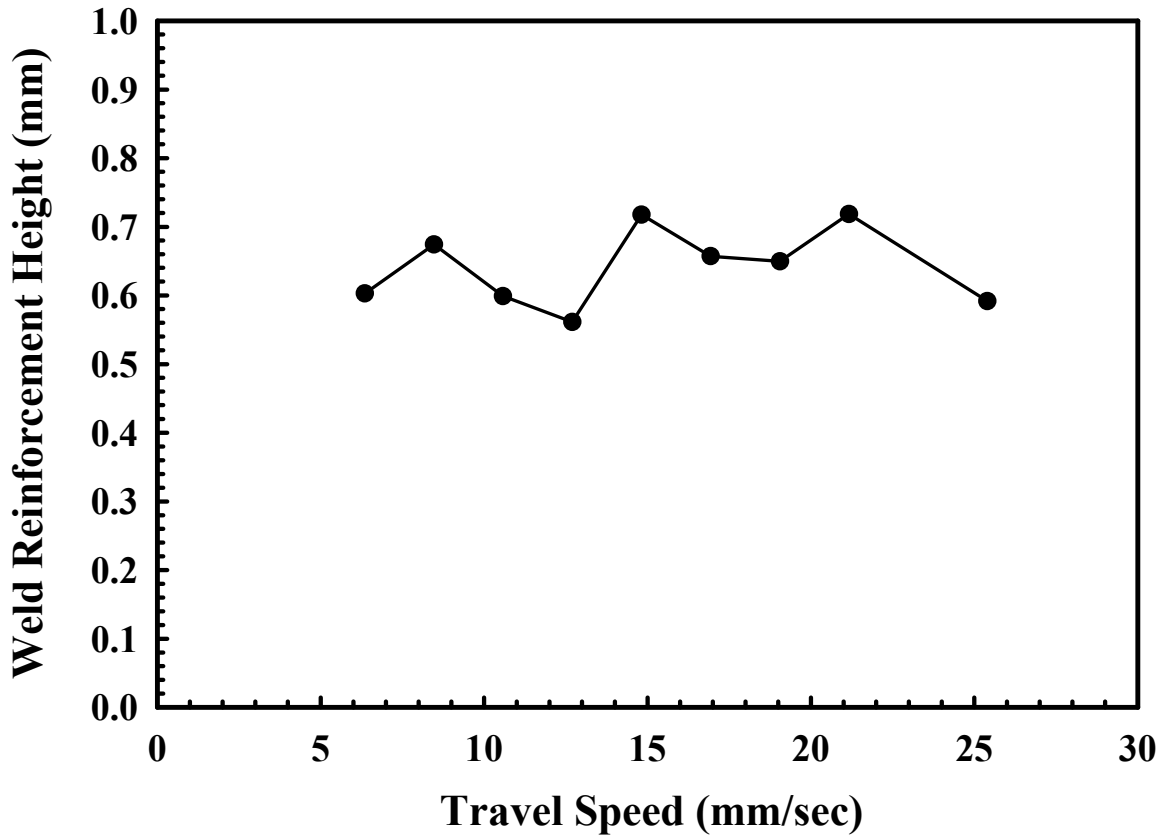

(b)

Figure 45(a\&b). Plots showing variations in the (a) keyhole width and (b) overfill height for Nitronic 40 welds made on the LLNL welder with changes in travel speed at a machine output power setting of $2200 \mathrm{~W}$. 


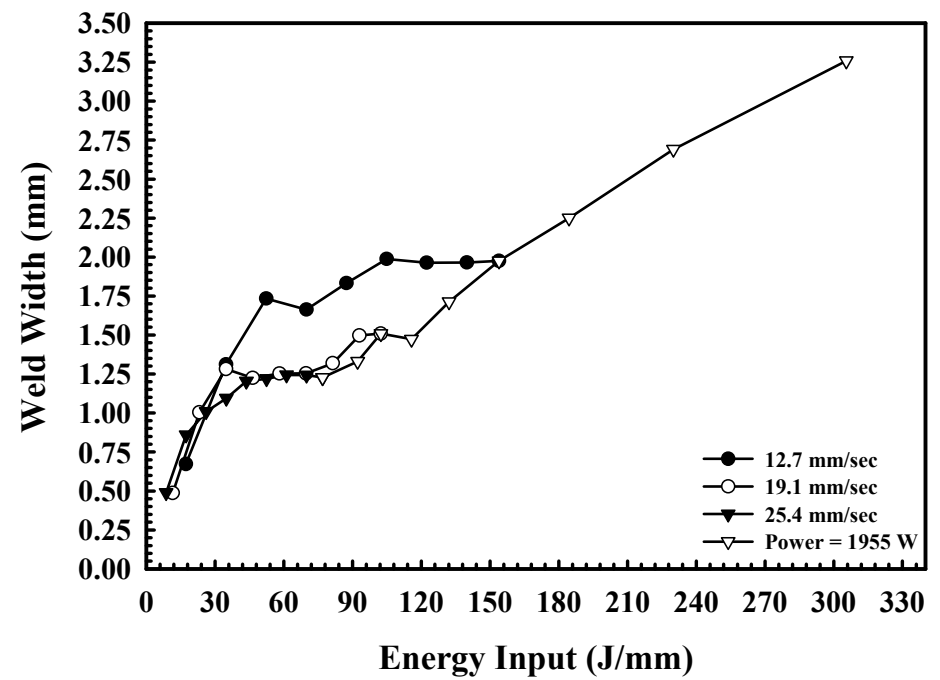

(a)

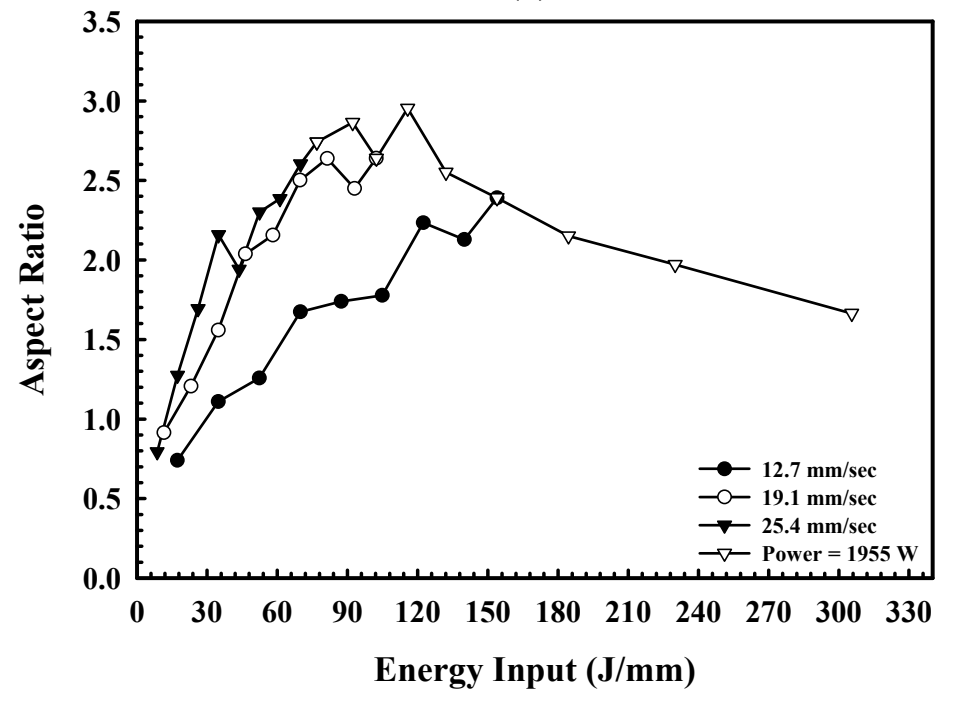

(c)

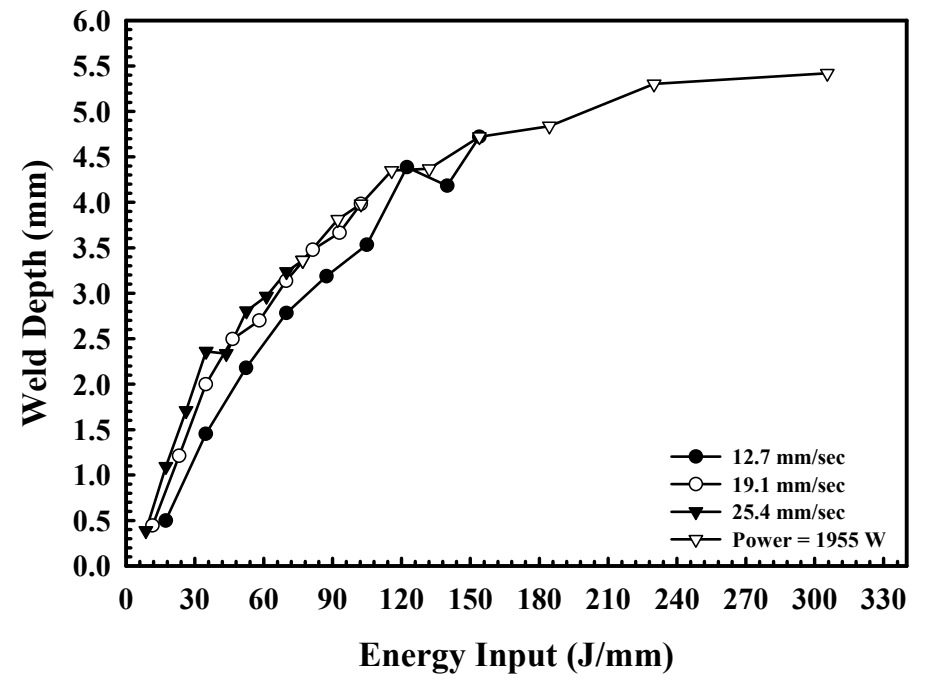

(b)

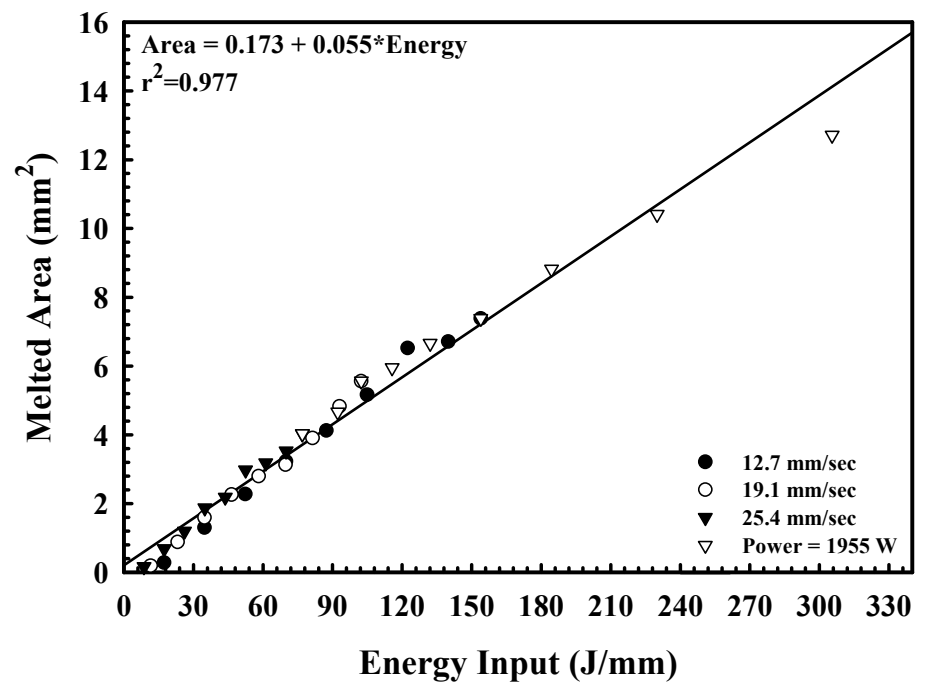

(d)

Figure 46(a-d). Plots showing variations in the (a) weld width, (b) weld depth, (c) aspect ratio, and (d) melted area of each Nitronic 40 weld cross section made using the LLNL welder as a function of the energy input for the two power variation studies and the travel speed variation study. 
UCRL-TR-222245

$50 \mathrm{~J} / \mathrm{mm}$ and $100 \mathrm{~J} / \mathrm{mm}$. Over this range of energy inputs, the weld widths taken from the power variation study at $12.7 \mathrm{~mm} / \mathrm{sec}$ are notably higher than those taken from the other studies. In the case of the weld depth, the three power variation studies and the travel speed variation study produce similar trends in weld depth as a function of energy input, as shown in Figure 46(b), show little difference and fall along the same trend line. Taken together, the three studies produce a single trend in weld depth, which is defined by a general increase in value with increasing energy input.

When comparing the weld aspect ratios with the energy input per unit length in Figure 46(c), a different trend from that observed in either the weld width or depth measurements becomes evident. At lower energy inputs, the aspect ratios tend to increase with increasing energy input, reaching peak values at approximately $100 \mathrm{~J} / \mathrm{mm}$. Unlike the trends observed in the weld width and depth plots in Figures 46(a) and 46(b), there are noticeable differences in the aspect ratios measured in each of the power variation studies, with the aspect ratios measured at a travel speed of $12.7 \mathrm{~mm} / \mathrm{sec}$ displaying values much lower than those measured at the other travel speeds. As the energy input per unit length is further increased above $100 \mathrm{~J} / \mathrm{mm}$, the aspect ratios start decreasing. This decrease results from the weld widths increasing faster than the weld depths at these higher energy input levels.

The comparison between the melted area and the energy input is shown in Figure 46(d). When comparing these more generalized parameters, the four studies are taken together to display a single trend line over the range of energy inputs considered here. A linear regression analysis of the data in Figure 46(d) shows a slope of 0.055, which corresponds with the rate of change of the melted area as a function of the energy input per unit length of weld. This behavior is the result of the melted area being strictly a function of the amount of power from the laser beam interacting with the sample surface.

Plots showing the relationships between the keyhole width and energy input per unit length and the reinforcement height and energy input per unit length are shown in Figures 47(a\&b), respectively. In the case of the keyhole width in Figure 47(a), the results from the four studies display a single trend, in which the keyhole widths increase with increasing energy input. Little to no difference in the keyhole widths measured in the different studies at equivalent energy inputs is observed. On the other hand, rather significant differences are observed in the reinforcement heights measured in each power variation study are taken as a function of the energy input. The reinforcement height values measured in the power variation study at a travel speed of $12.7 \mathrm{~mm} / \mathrm{sec}$ are the lowest observed in this energy input range. In general, though, the reinforcement heights increase with increasing energy input up to an energy input value of approximately $100 \mathrm{~J} / \mathrm{mm}$. Above this level, the measured reinforcement heights take on a constant value of slightly more than $0.50 \mathrm{~mm}$.

\subsubsection{Comparison with Previous Studies}

In addition to analyzing the results from the above studies, comparisons are made between these results and comparable results taken using another laser system. These additional results

are taken from a previous study performed on a comparable laser welding system at Los Alamos National Laboratory (LANL). The results of this study are summarized in a previous report. ${ }^{1}$ 


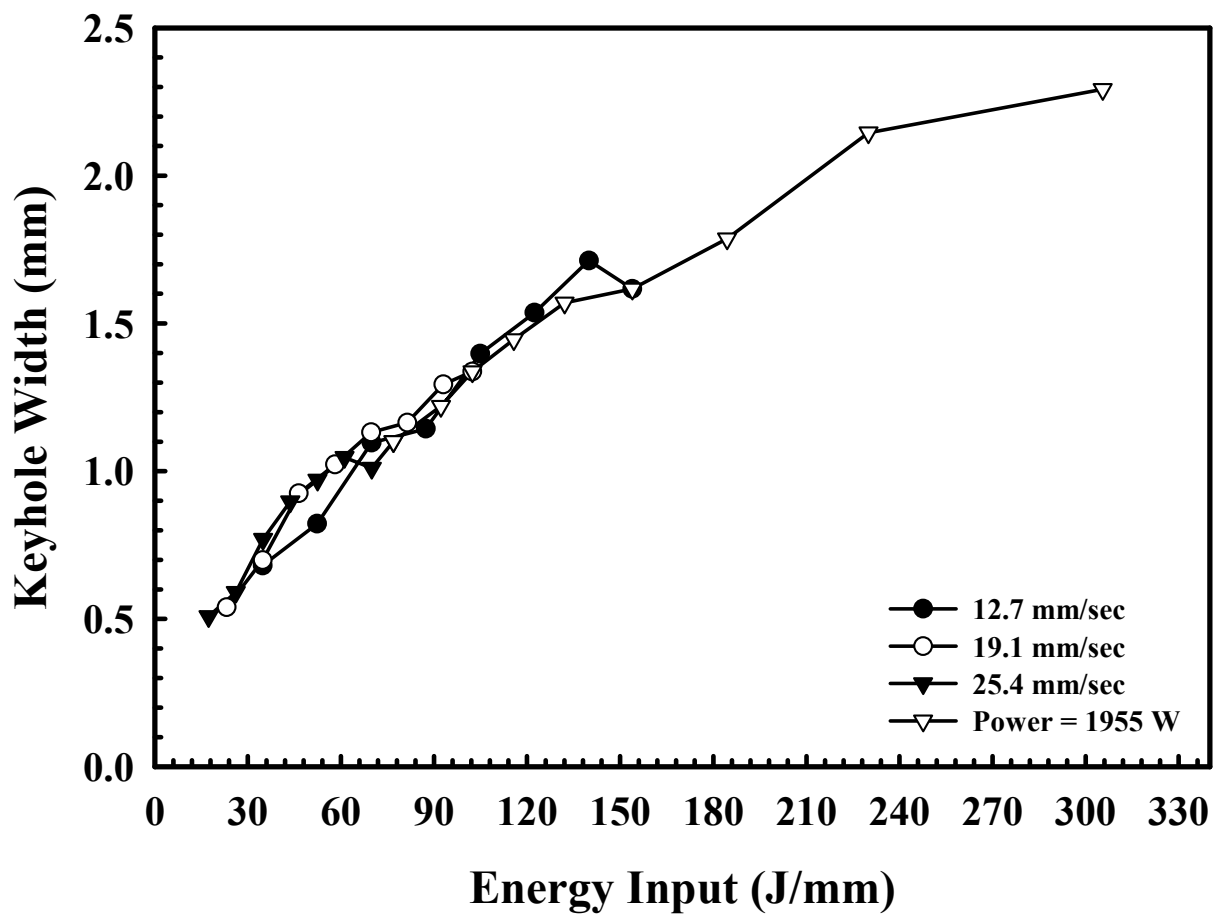

(a)

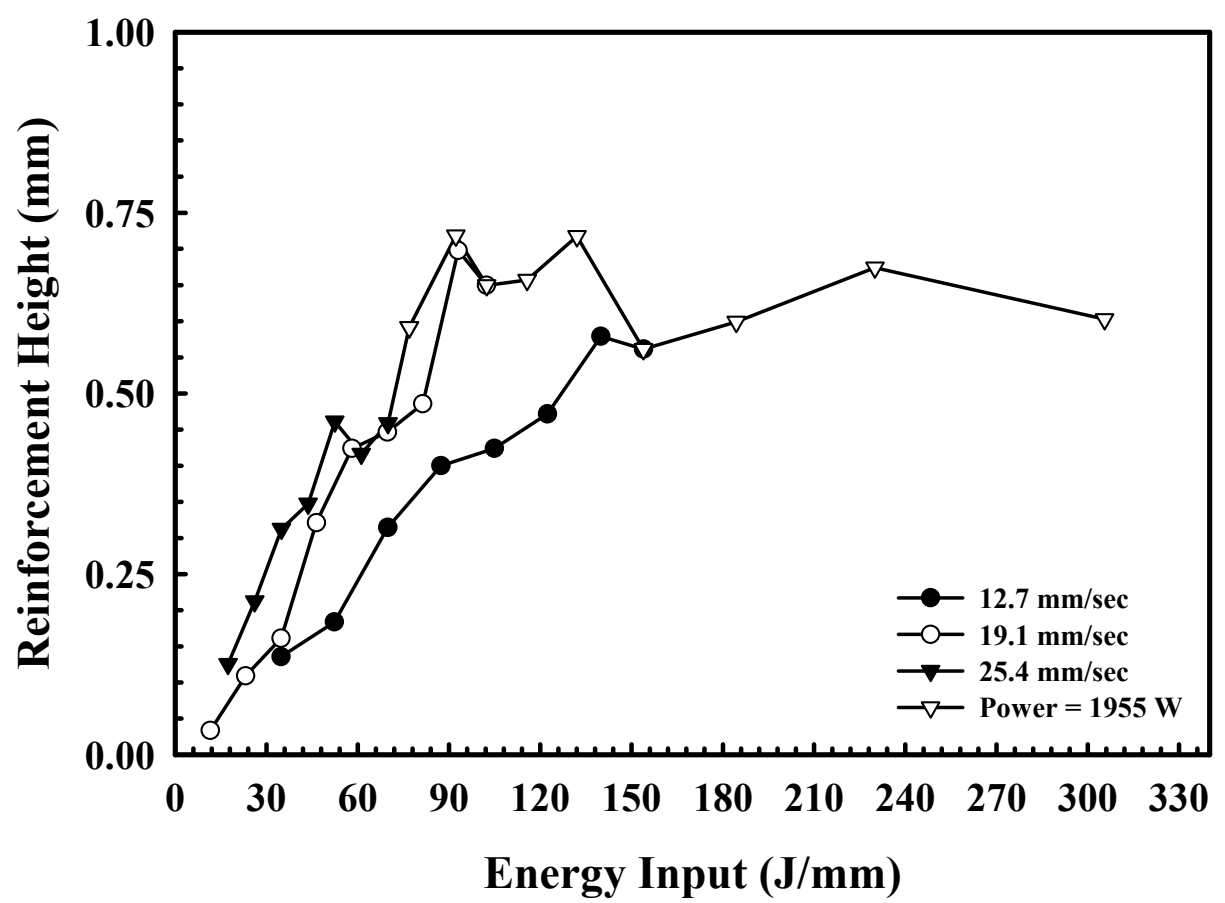

(b)

Figure $47(\mathrm{a} \& \mathrm{~b})$. Plots showing variations in the (a) keyhole width and (b) overfill height for Nitronic 40 welds made on the LLNL welder with changes in the energy input per unit length for the two power variation studies and the travel speed variation study. 
There are some differences in the characteristics of the LLNL and LANL laser systems and in the sample geometry. Both of these differences have been addressed in a previous report. ${ }^{2}$ The material used in the LANL study comes from a different source than that used in the LLNL study described here. A comparison between the chemistries of the two materials is shown in Table 14. In general, the differences in chemistry are rather minor, and both material fall within the desired composition range for this steel. A summary of the measured weld dimensions from the LANL laser weld study is also provided in Table 17.

Results from the power variation study performed on the LLNL laser system at a travel speed of $19.1 \mathrm{~mm} / \mathrm{sec}$ are compared with similar results from the LANL laser system in Figures 48(ad). In these figures, the weld width, depth, aspect ratio, and melted area measurements are shown. Results from the LANL study also include measurements taken on welds made with argon and helium shielding gases. The results from the different shielding gases are indicated on each plot. In general, the results from the two laser systems display similar trends, in which the various weld measurements increase with increasing machine power setting. On the other hand, the LLNL results display lower weld widths and higher aspect ratios and melted areas than the LANL results. The measured weld depths for the two systems are very similar, but the LLNL results do tend to be slightly higher at most power settings. These results can be correlated with the smaller theoretical beam spot size in the LLNL system ( $300 \mu \mathrm{m}$ vs $530 \mu \mathrm{m})$ as compared to the LANL system.

Results from these laser welding studies on Nitronic 40 are also compared with results obtained with another grade of austenitic stainless steel (304L) under similar welding conditions on the LLNL laser system. ${ }^{2}$ The effects of changes in both power input and travel speed on the weld pool shapes and sizes in these two stainless steel systems are compared. Even though both materials are austenitic stainless steels, they display markedly different chemistries, especially in terms of their nickel, manganese, and nitrogen concentrations. In particular, the manganese content of the Nitronic 40 is over four times higher than in the $304 \mathrm{~L}$ stainless steel (9.14 vs. 1.71 wt.\%) and the nitrogen content is nearly three times higher ( 0.23 vs. 0.082$)$. It can therefore be assumed that any differences in behavior between these two stainless steels are attributable to these differences in chemistry.

Comparisons between the resulting weld pool cross sections of these two materials show both similarities and differences. For example, the weld cross sections from both stainless steels display keyhole mode welding characteristics at machine power settings above $500 \mathrm{~W}$. On the other hand, there is a major difference in behavior when it comes to the presence of weld porosity. Whereas the 304L stainless steel welds display significant porosity, the Nitronic 40 welds display little to none. As noted previously, this lack of porosity in the Nitronic 40 welds results from the enhancement of keyhole stability in this weld, most likely due to the high manganese content in the weld.

The weld cross section dimensions, including the weld width, depth, aspect ratio, and melted area, are plotted as a function of power input for travel speeds of $12.7 \mathrm{~mm} / \mathrm{sec}$ and $19.1 \mathrm{~mm} / \mathrm{sec}$ in Figures 49(a-d) for each stainless steel. Comparisons between the weld widths and depths for the two materials show differing behaviors. In general, the widths of the $304 \mathrm{~L}$ stainless steel welds display higher values than those achieved by the Nitronic 40 welds and increase at higher rates with increasing power than the Nitronic 40 welds, which display nearly constant widths at higher powers. On the other hand, the Nitronic 40 welds display higher depths than the $304 \mathrm{~L}$ welds across the range of power inputs. In fact, the depths of the Nitronic 40 welds made at a 
UCRL-TR-222245

Table 17. Summary of measurements made on Nitronic 40 weld samples using the LANL welding system at a travel speed of $19.1 \mathrm{~mm} / \mathrm{sec}$.

\begin{tabular}{|c|c|c|c|c|c|}
\hline$\frac{\text { Power* }}{\text { (Watts) }}$ & $\frac{\text { Weld Width }}{(\mathrm{mm})}$ & $\frac{\text { Weld Depth }}{(\mathrm{mm})}$ & $\frac{\text { Aspect Ratio }}{\text { (Depth/Width) }}$ & $\frac{\text { Reinforcement }}{\text { Height (mm) }}$ & $\frac{\text { Melted Area }}{\left(\mathrm{mm}^{2}\right)}$ \\
\hline \multicolumn{6}{|c|}{ Helium Shielding Gas } \\
\hline 250 & 0.578 & 0.138 & 0.239 & ---- & 0.057 \\
\hline 500 & 1.210 & 1.004 & 0.829 & 0.029 & 0.603 \\
\hline 750 & 1.406 & 1.924 & 1.368 & 0.150 & 1.337 \\
\hline 1000 & 1.484 & 2.663 & 1.795 & 0.210 & 2.078 \\
\hline 1250 & 1.489 & 2.933 & 1.969 & 0.227 & 2.653 \\
\hline 1500 & 1.383 & 2.950 & 2.133 & 0.089 & 2.805 \\
\hline \multicolumn{6}{|c|}{ Argon Shielding Gas } \\
\hline 750 & 1.340 & 2.001 & 1.493 & 0.037 & 1.355 \\
\hline 1000 & 1.363 & 2.427 & 1.781 & 0.095 & 2.016 \\
\hline 1250 & 1.455 & 2.945 & 2.024 & 0.069 & 2.421 \\
\hline
\end{tabular}

* Machine setting values. 


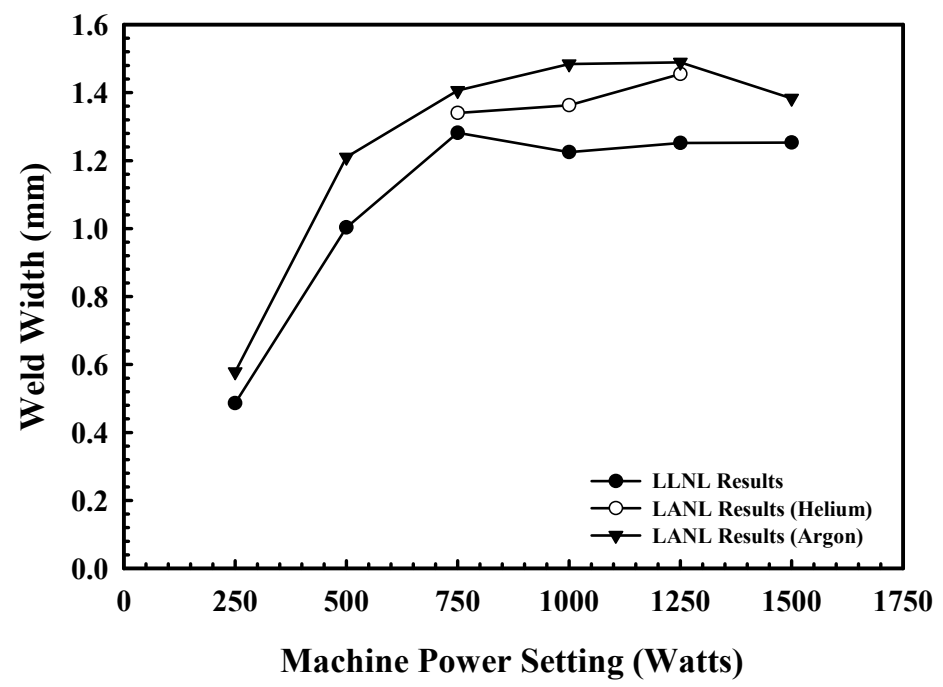

(a)

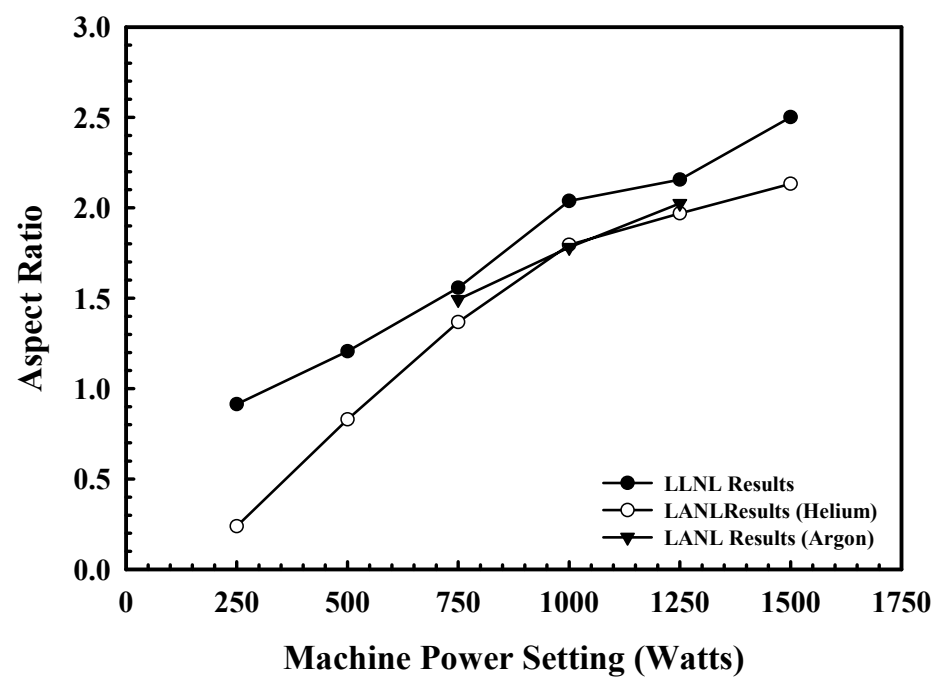

(c)

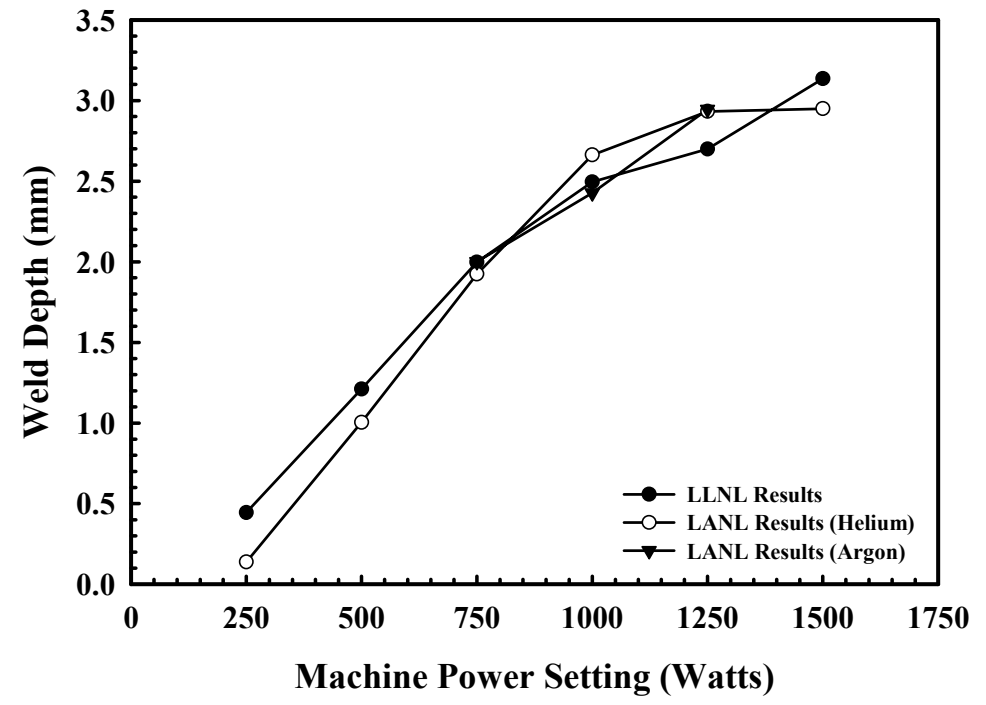

(b)

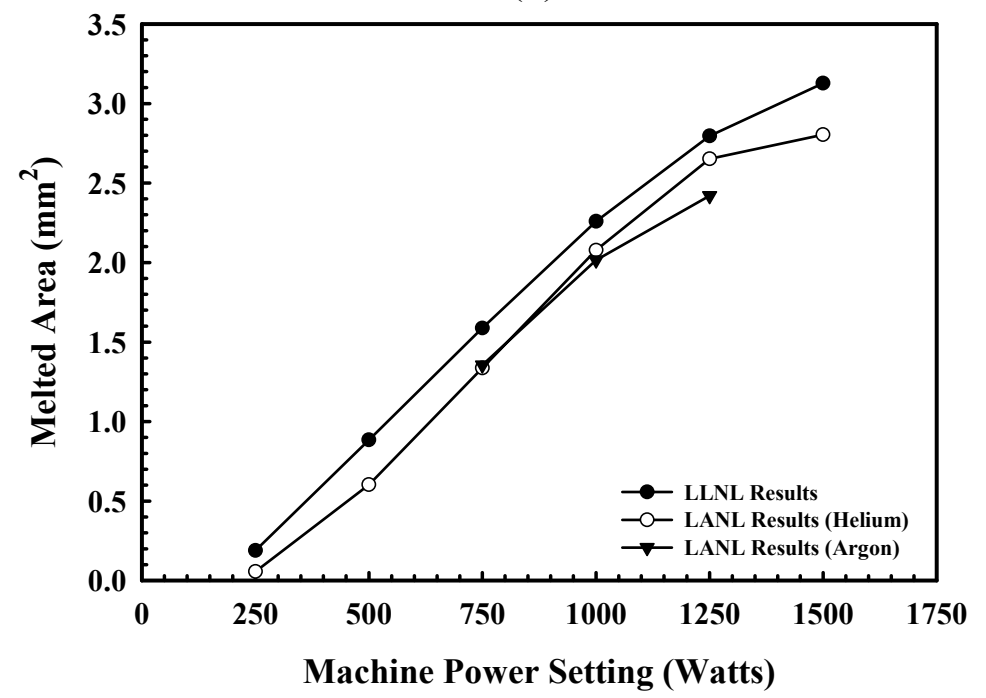

(d)

Figure 48(a-d). Comparison between (a) weld width, (b) depth, (c) aspect ratio, and (d) melted area with changes in the machine power settings at a travel speed of $19.1 \mathrm{~mm} / \mathrm{sec}$ for laser welds made on Nitronic 40 using both the LLNL and LANL laser systems. 


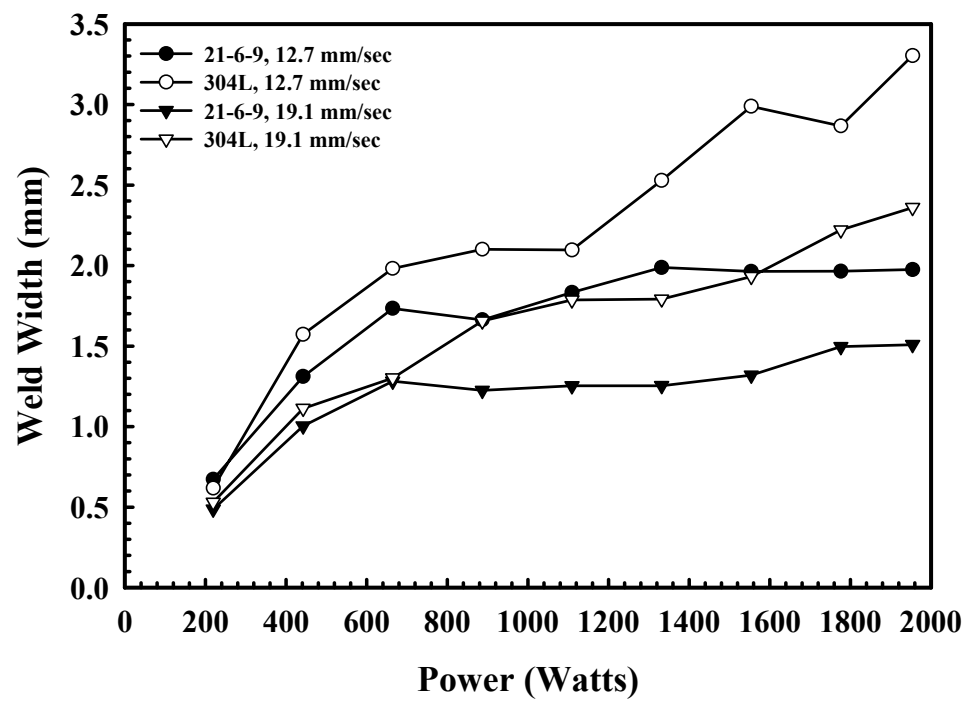

(a)

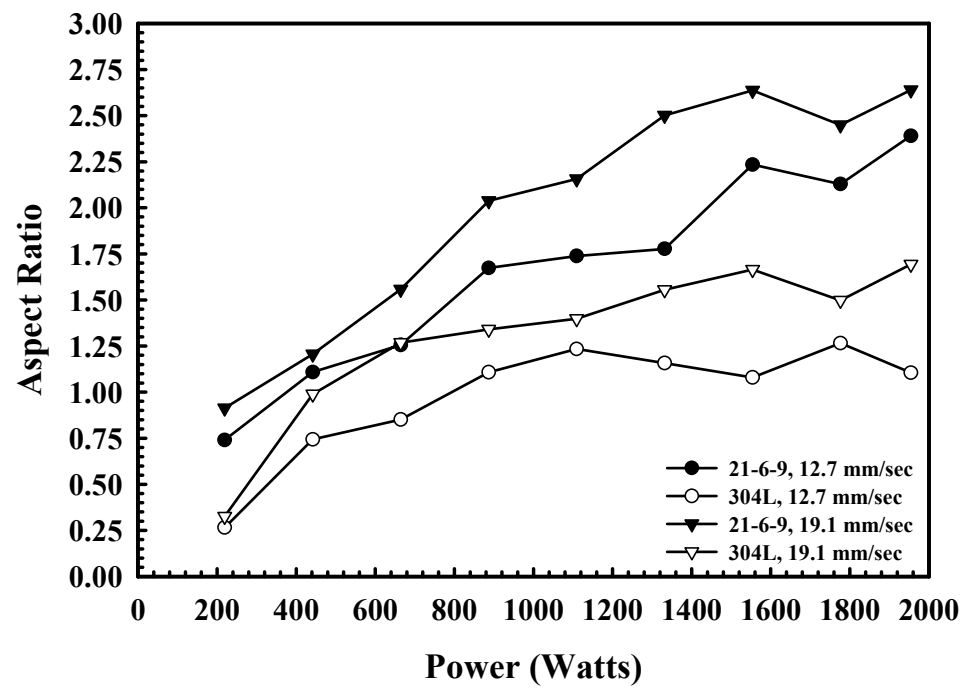

(c)

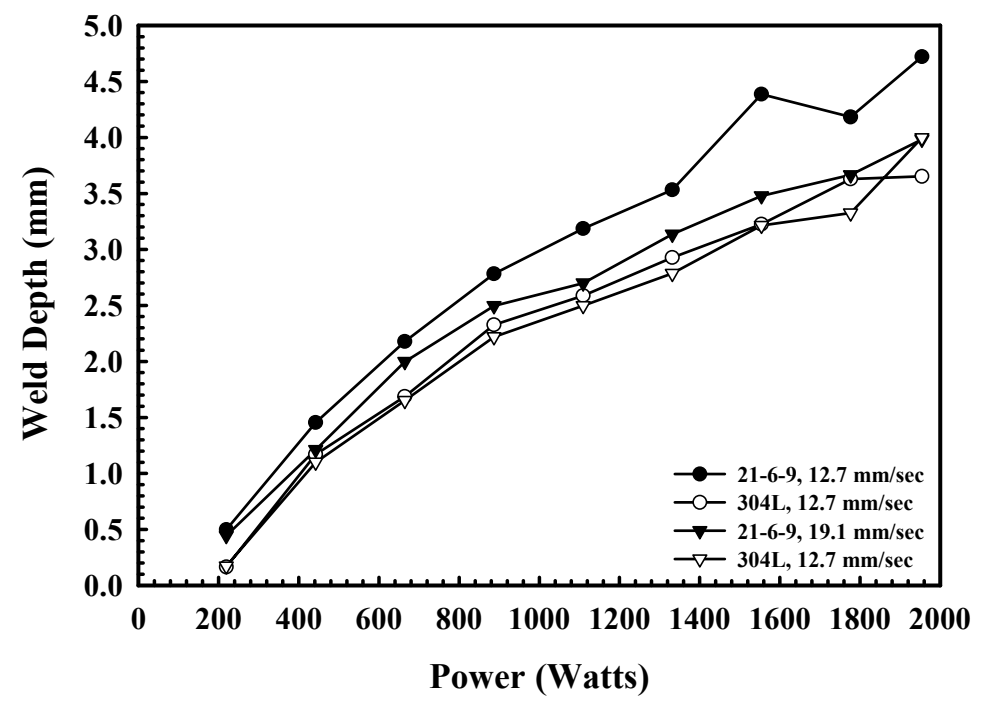

(b)

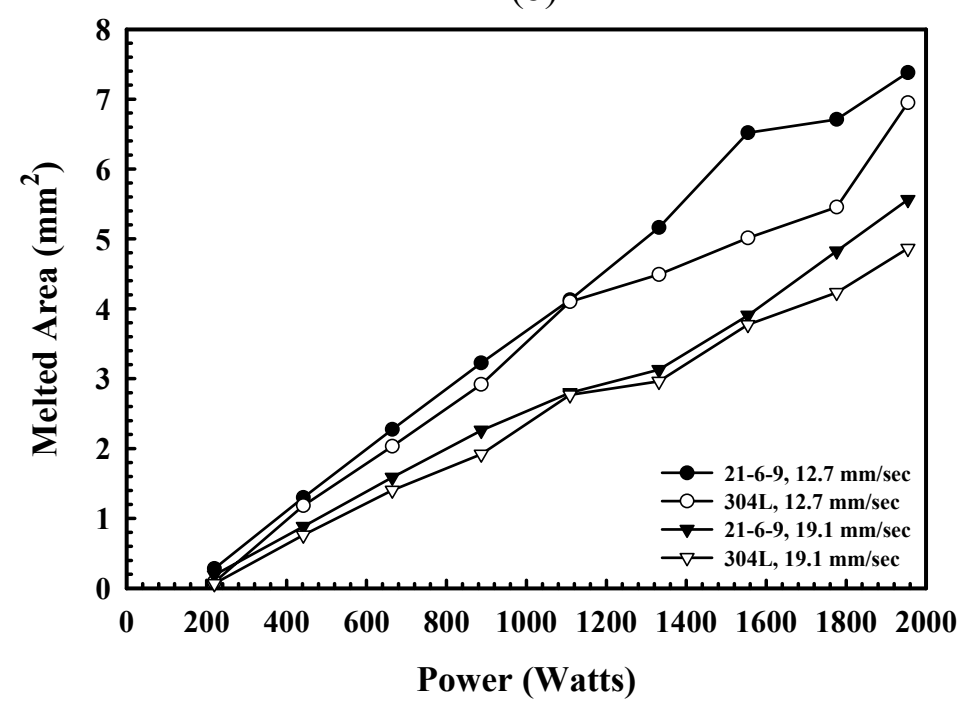

(d)

Figure 49(a-d). Comparison between (a) weld width, (b) depth, (c) aspect ratio, and (d) melted area with changes in weld power at travel speeds of $12.7 \mathrm{~mm} / \mathrm{sec}$ and $19.1 \mathrm{~mm} / \mathrm{sec}$ for Nitronic 40 and 304L laser welds made on the LLNL laser system. 
travel speed of $19.1 \mathrm{~mm} / \mathrm{sec}$ exceed those measured in the 304L welds at a travel speed of 12.7 $\mathrm{mm} / \mathrm{sec}$. Unlike the differing trends observed in the weld widths, the measured weld depths for each material display similar trends over the range of power inputs. Based on these two sets of measurements, the resulting aspect ratios display significantly higher values for the Nitronic 40 welds over the range of power inputs, illustrating the deep and narrow shaped laser welds formed in this material. In addition to the weld width and depth comparisons, the melted areas measured in the two stainless steels are plotted in Figure 49(d) as a function of the power input. In contrast to the results for the weld widths and depths, the melted areas for the two stainless steels are similar when compared at the same power input and travel speed.

Comparisons between the measured keyhole widths and reinforcement heights as a function of power variation for these two stainless steels are shown in Figures 50(a\&b), respectively. In general, the keyhole widths of the Nitronic 40 welds are larger than those observed in the 304L welds. This difference in keyhole widths is a result of the differences observed in the general weld shape. For example, in the Nitronic 40 welds, the side walls of the weld cross sections are rather straight, displaying little difference between the width of the top surface and that in the middle portion of the keyhole. On the other hand, the 304L welds display a more finger-like protrusion of the keyhole from a semi-hemispherical shaped top portion in the weld crosssection. As a result, the keyhole widths in the 304L stainless steel are narrower than the width measured at the top surface of the weld. A comparison of the measured reinforcement heights as a function of power input for these two stainless steels is shown in Figure 50(b). In this case, the Nitronic 40 welds display consistently higher reinforcement heights than the 304L stainless steels and little variation between the two travel speeds. On the other hand, the 304L laser welds display a good deal of scatter over the range of power inputs.

Similar behavior as that observed in the power variation studies discussed above is also present in the comparison between the weld dimensions of these two materials with variations in travel speed at a constant power input of $1980 \mathrm{~W}$. Figures 51(a-d) display comparisons between measured weld widths, depths, aspect ratios, and melted area as a function of travel speed for the Nitronic 40 and 304L stainless steels. In general, the same trends observed in Figures 49(a-d) as a function of power input are observed in these figures as a function of travel speed, albeit in a direction opposite that observed with the input power. For example, the 304L welds display larger weld widths and smaller depths than the Nitronic 40 welds. As a result, the Nitronic 40 welds display much higher aspect ratios than the 304L laser welds. Once again, though, the melted areas for the two sets of stainless steel welds display little difference in magnitude at equivalent power and travel speed and similar trends over the range of travel speeds.

Comparisons between the measured weld keyhole widths and the reinforcement heights as a function of travel speed at a constant power input of $1980 \mathrm{~W}$ for the Nitronic 40 and 304L stainless steel laser welds are shown in Figures 52(a\&b), respectively. As with the relationships shown in the plot comparing these values with changes in power input, the keyhole width for the Nitronic 40 welds display higher keyhole widths than the 304L laser welds over a wide range of travel speeds. These higher keyhole widths for the Nitronic 40 welds are extensions of the basic weld pool shape, much like that discussed earlier. In the case of the reinforcement heights, shown in Figure 52(b), the values measured on the Nitronic 40 welds show similar values across the range of travel speeds and tend to be higher than those for the 304L laser welds.

The above studies of the effects of variations in power and travel speed are combined into plots showing the effects of changes in the energy input per unit length on the primary weld measurements for both stainless steels. These plots are shown in Figures 53(a-d). In the weld 


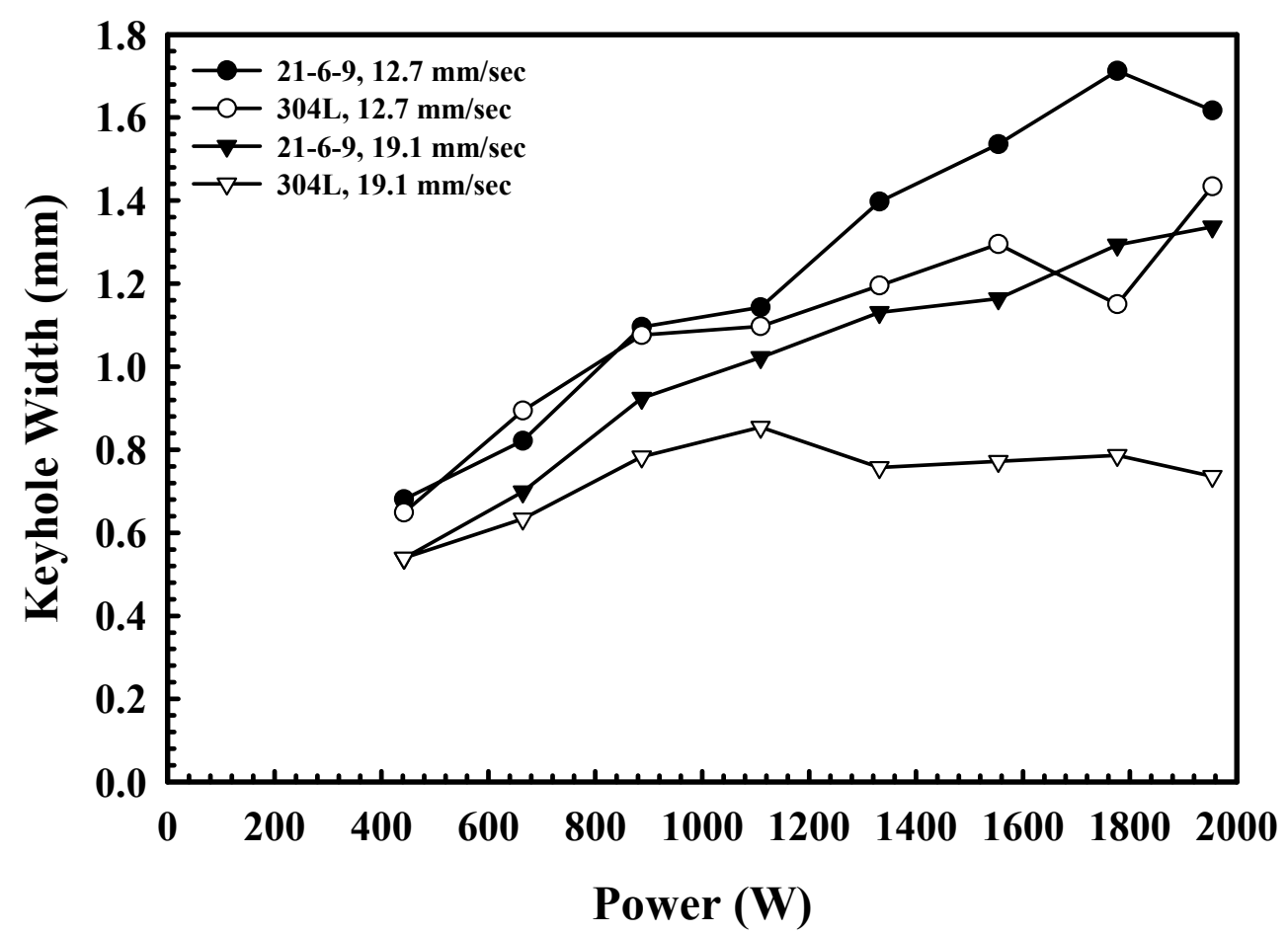

(a)

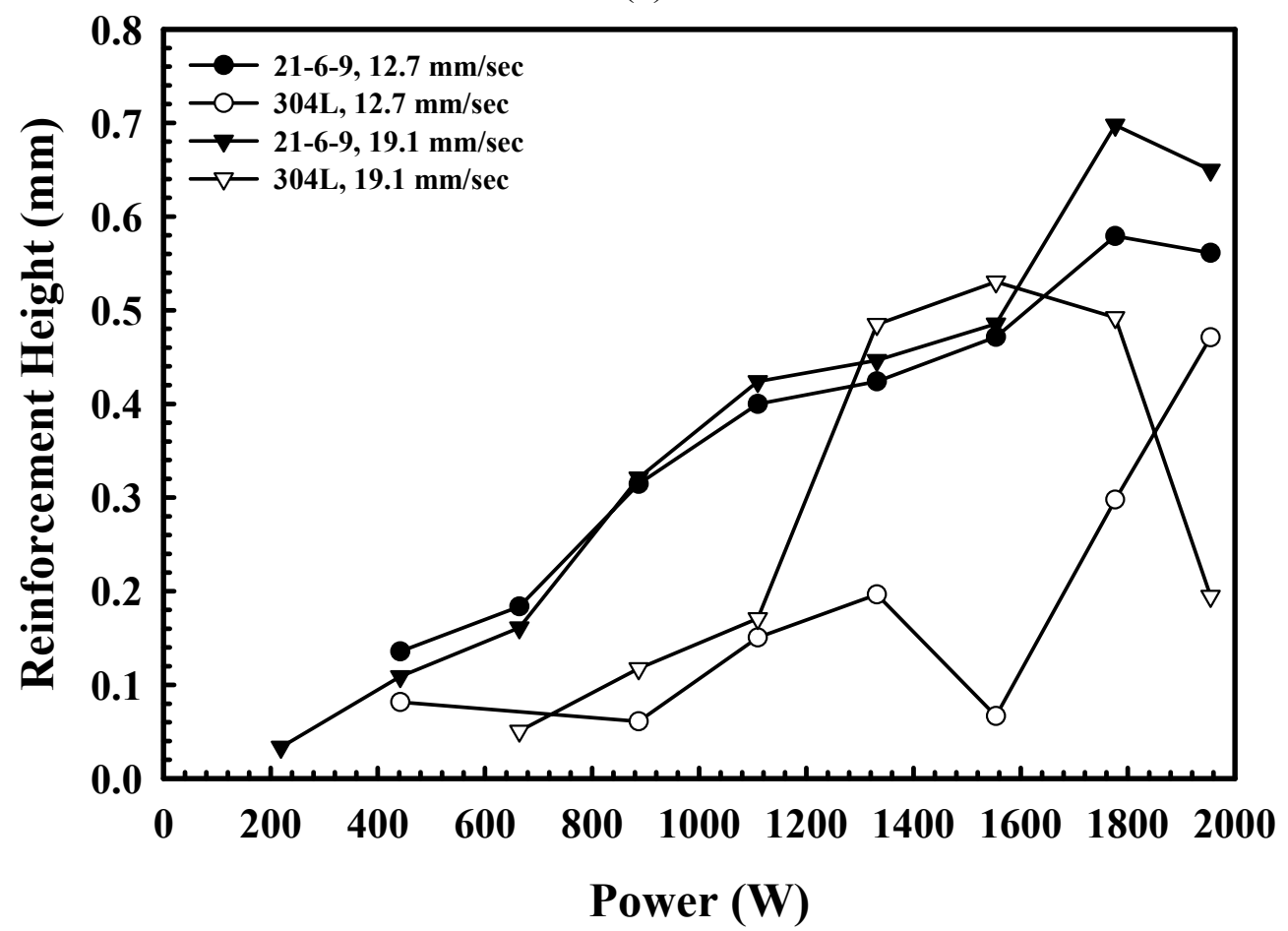

(b)

Figure 50(a\&b). Plots showing variations in the (a) keyhole width and (b) overfill height with changes in weld power at travel speeds of $12.7 \mathrm{~mm} / \mathrm{sec}$ and $19.1 \mathrm{~mm} / \mathrm{sec}$ for Nitronic 40 and 304L laser welds made on the LLNL laser system. 


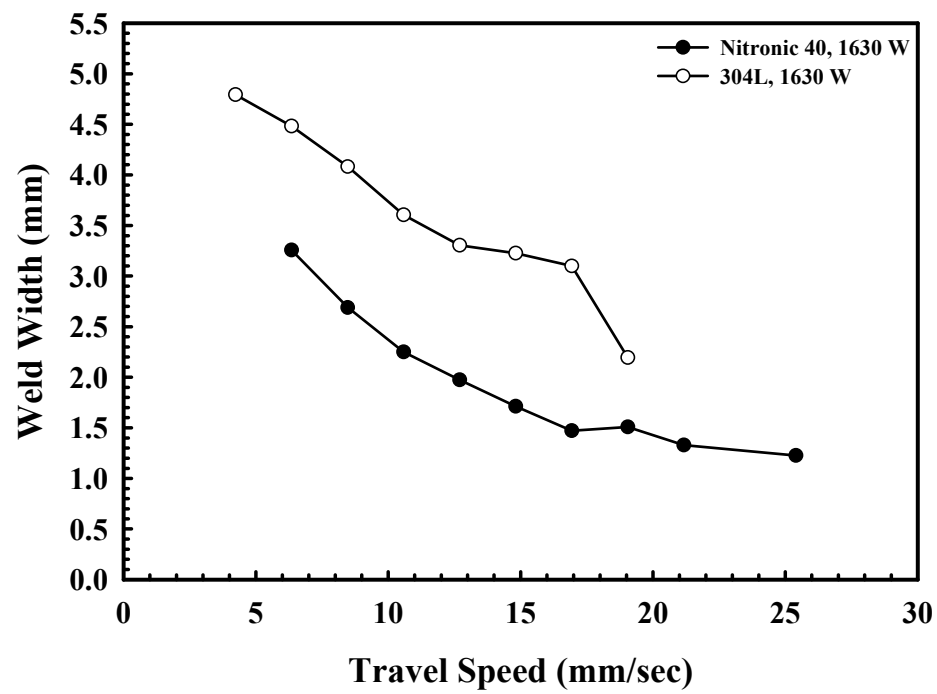

(a)

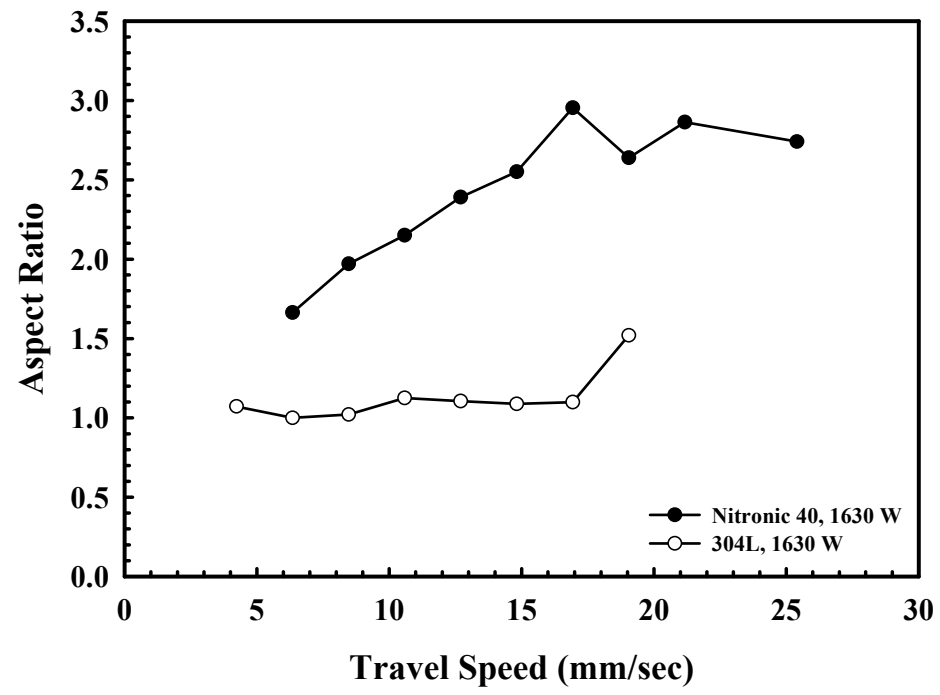

(c)

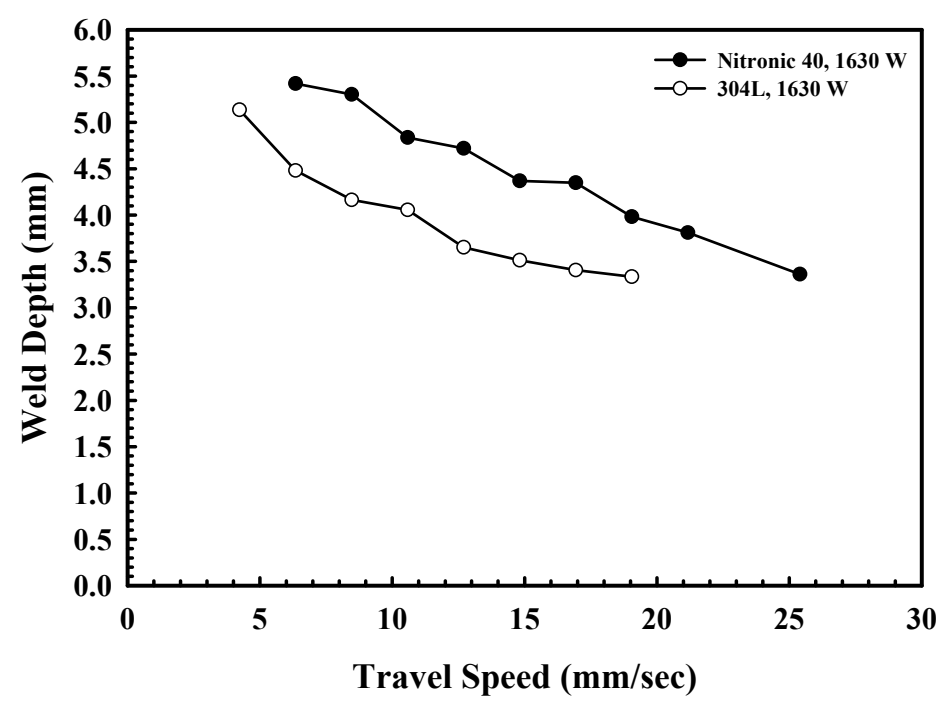

(b)

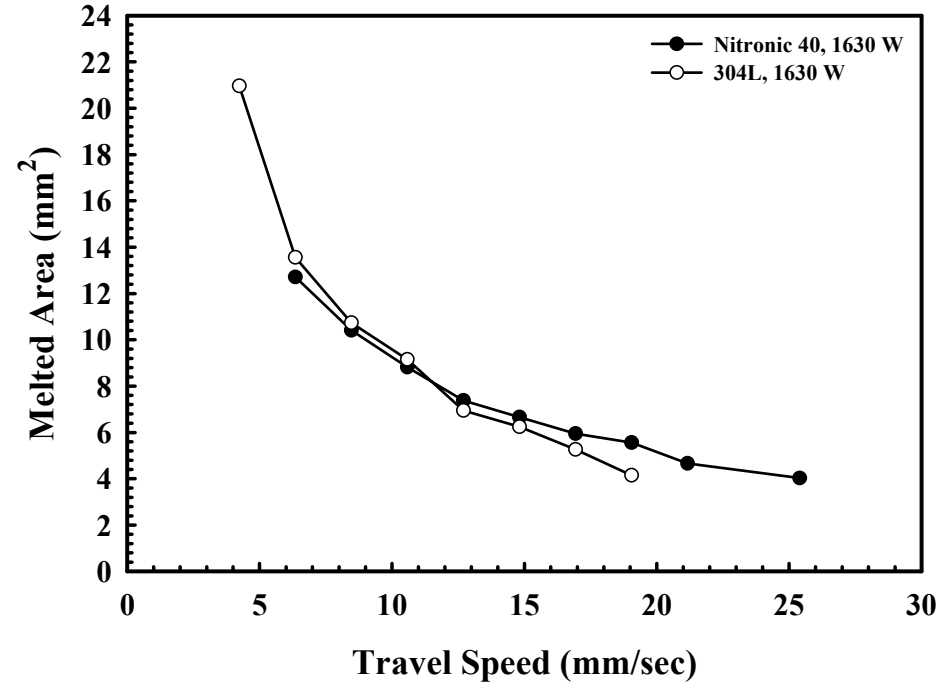

(d)

Figure 51(a-d). Comparison between (a) weld width, (b) depth, (c) aspect ratio, and (d) melted area with changes in travel speed at an input power of $1980 \mathrm{~W}$ for Nitronic 40 and 304L laser welds made on the LLNL laser system. 


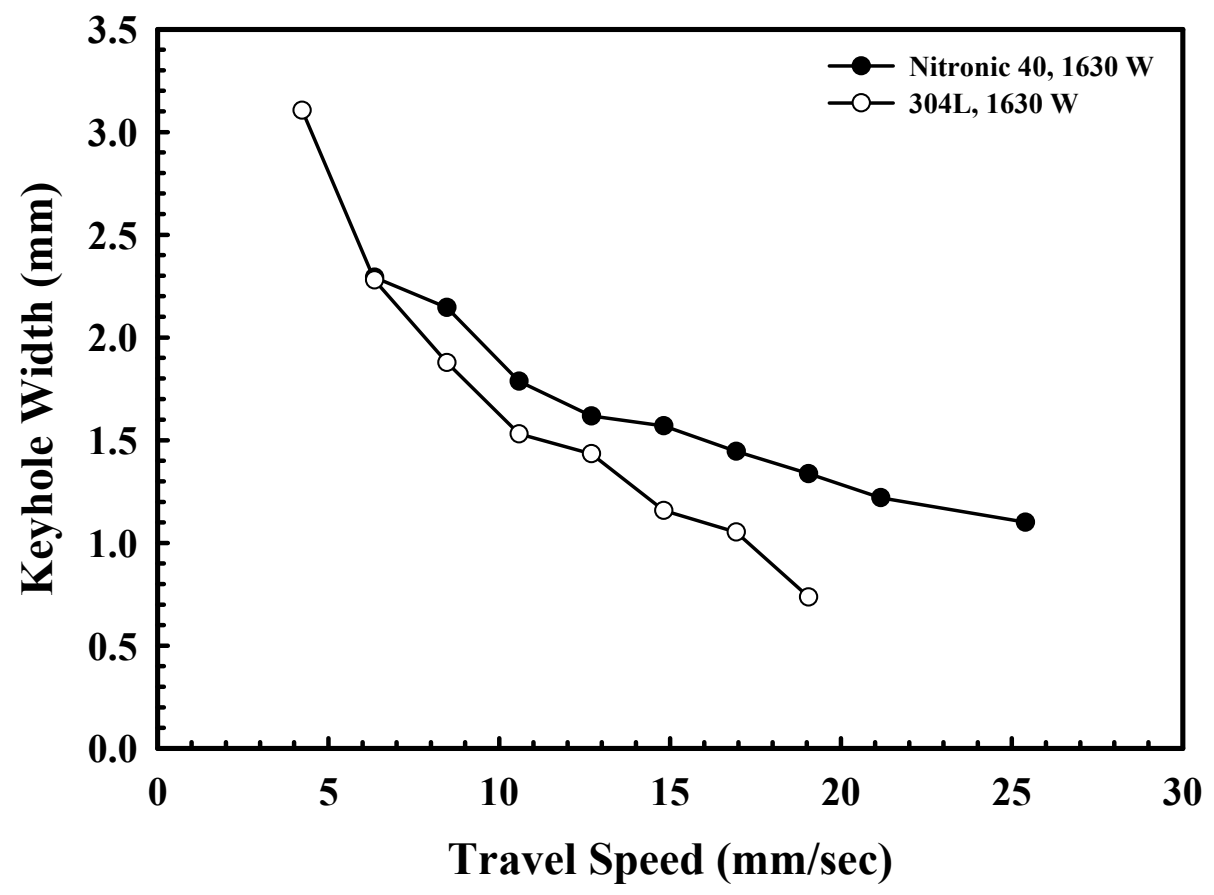

(a)

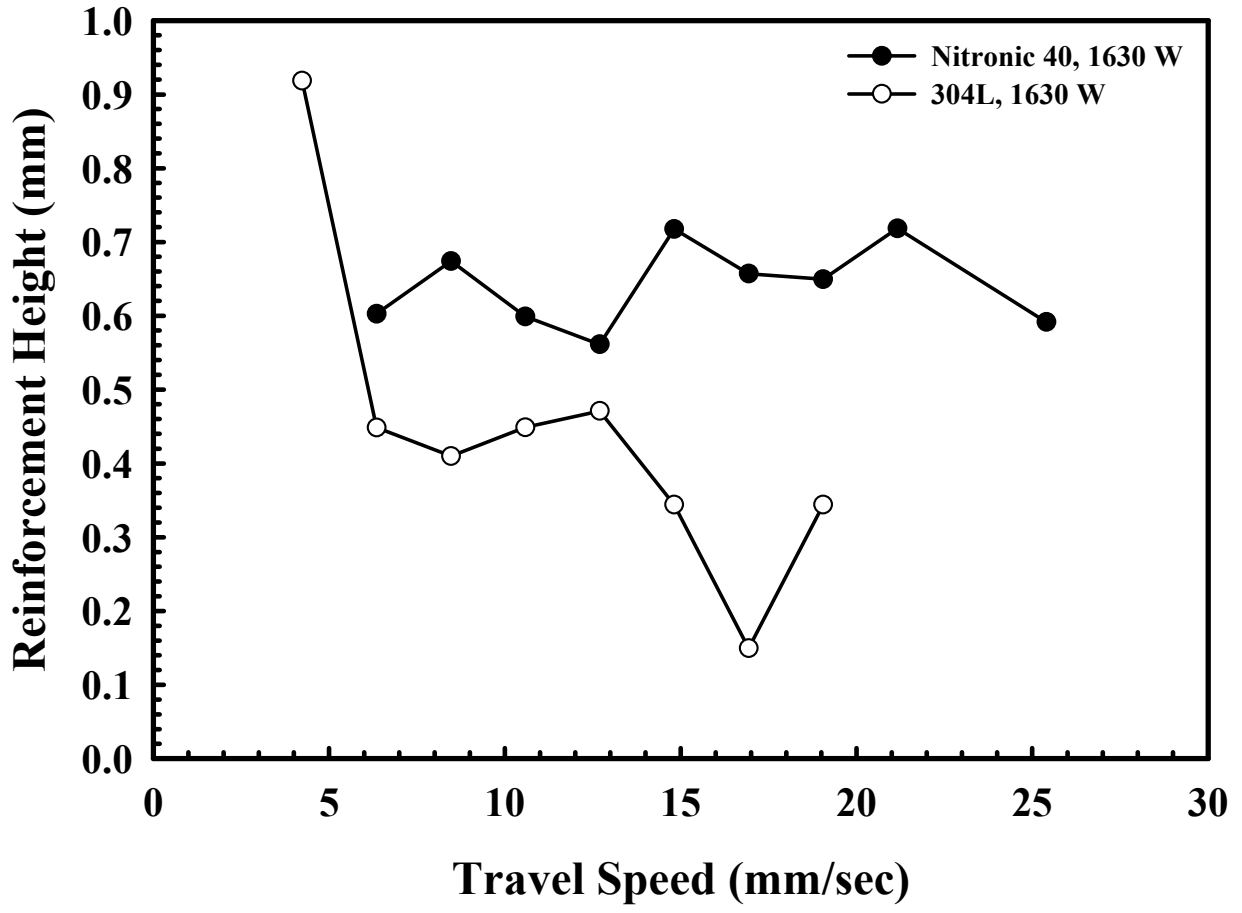

(b)

Figure 52(a\&b). Plots showing variations in the (a) keyhole width and (b) overfill height with changes in travel speed of at a weld power of $1980 \mathrm{~W}$ for Nitronic 40 and 304L laser welds made on the LLNL laser system. 

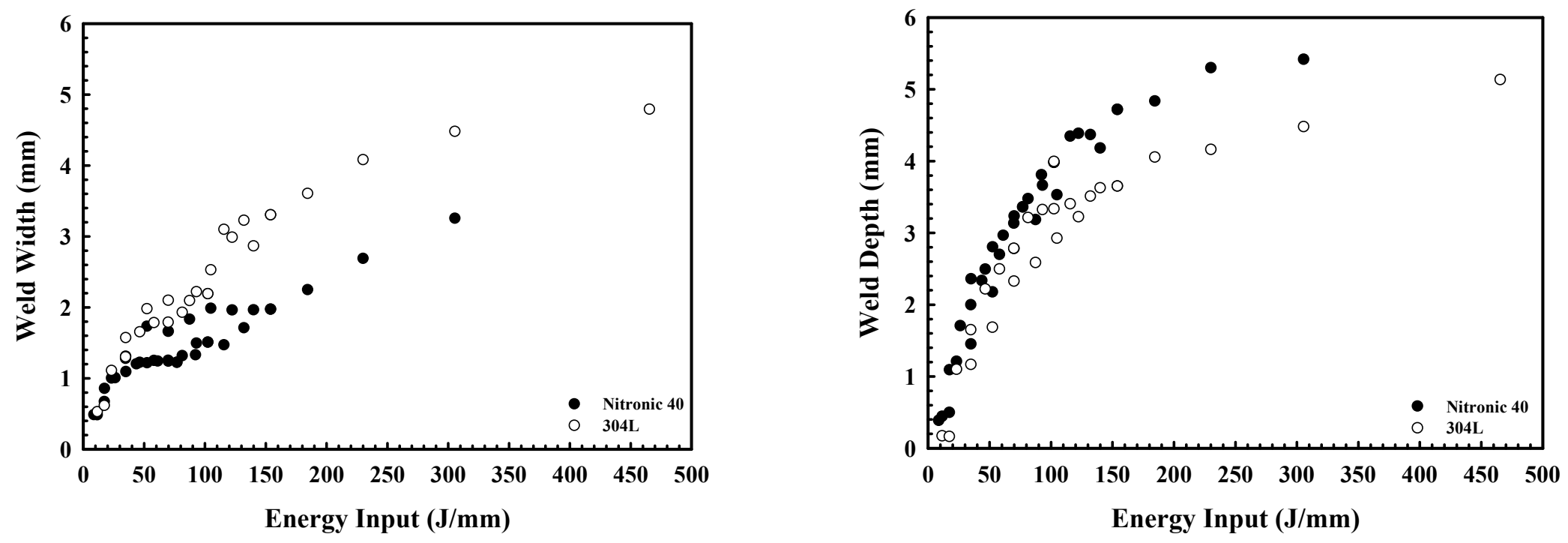

(a)

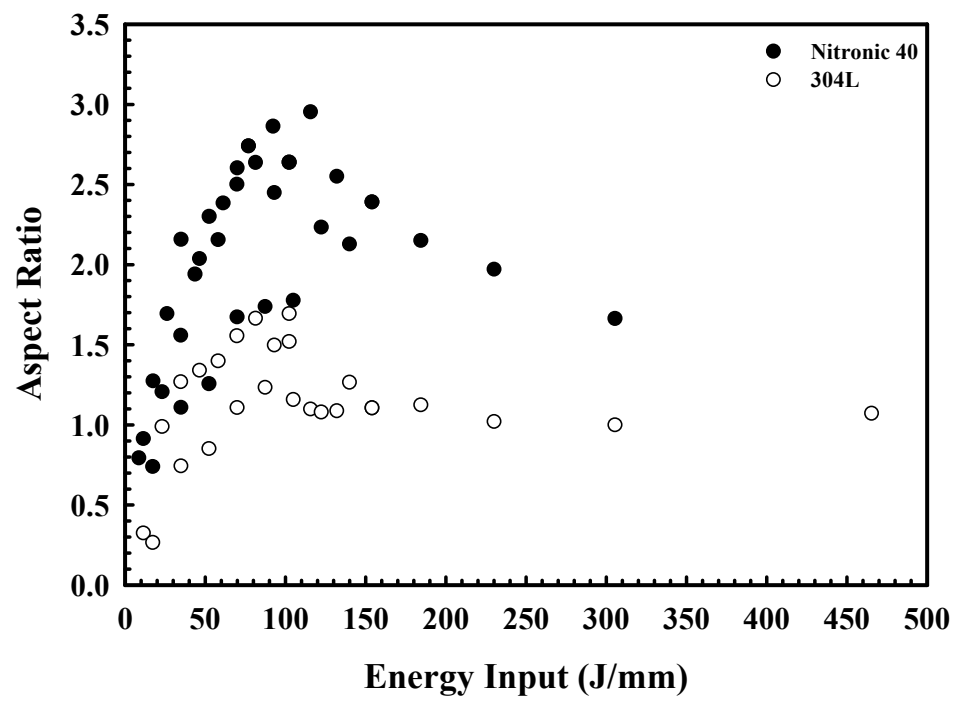

(c)

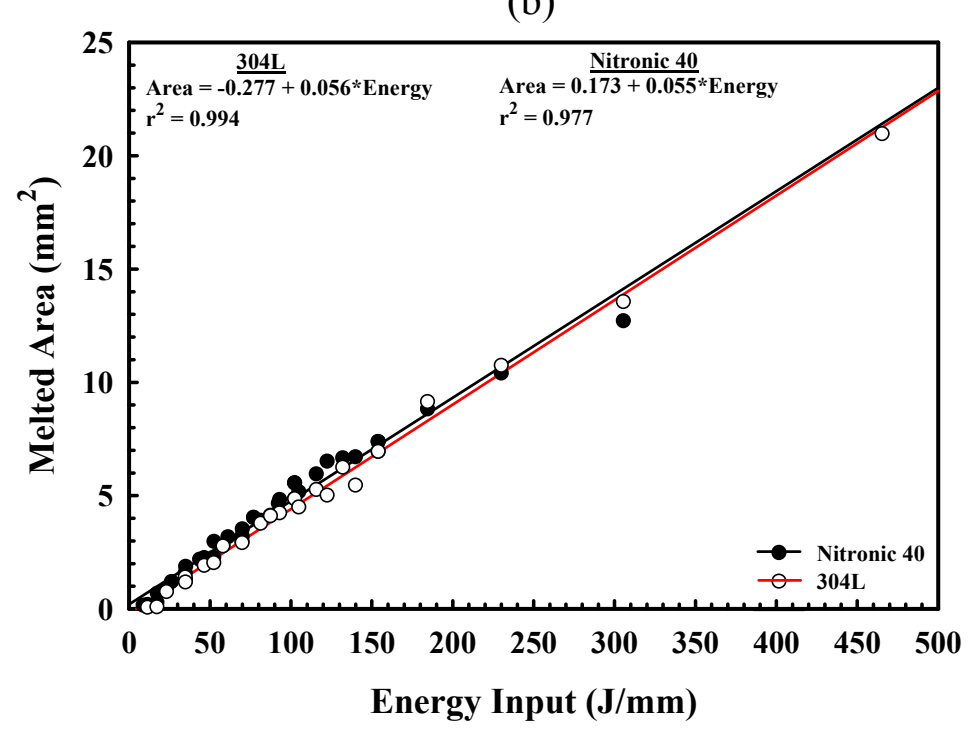

(d)

Figure 53(a-d). Comparison between (a) weld width, (b) depth, (c) aspect ratio, and (d) melted area as a function of energy input for Nitronic 40 and 304L laser welds made on the LLNL laser system. 
UCRL-TR-222245

width and depth plots in Figures 53(a) and 35(b), the previously discussed trends are observed in each plot, namely that the 304L laser welds display larger weld widths and that the Nitronic 40 welds display greater weld depths over the range of energy inputs per unit length. When converted into the aspect ratio in Figure 53(c), the values for the Nitronic 40 welds display higher values than the 304L welds over the range of energy inputs. On the other hand, the aspect ratios for the Nitronic 40 welds display a peak value at an energy input per unit length of approximately $75 \mathrm{~J} / \mathrm{mm}$. A similar maximum is also noted in the 304L laser welds at nearly the same energy input per unit length. As the energy input is further increased, the aspect ratios decrease in value, but still remain higher than the 304L laser welds. When the melted areas of the Nitronic 40 and 304L laser welds are plotted together as a function of the energy input in Figure 53(d), the differences noted between the two materials in the previous plots disappears. As shown in this plot, the melted areas from the two materials fall along basically the same linear trend, with only a minimal difference noted in the slopes of the two linear regressions shown ( 0.056 for $304 \mathrm{~L}$ vs. 0.055 for the Nitronic 40). Based on these various comparisons, it can therefore be determined that in the laser welds made on the Nitronic 40 and 304L stainless steels, the same amount of material is melted but the resulting weld shapes are different.

\subsection{General Findings and Concluding Remarks}

A series of autogenous bead-on-plate laser welds have been made on $12.7 \mathrm{~mm}$ thick Nitronic 40 stainless steel samples using a Rofin Sinar DY-022 CW Nd:YAG laser welder. The effects of variations in the machine power setting and travel speed on the resulting weld pool cross sections have been examined. Measurements of the weld width, depth, and melted area have been made on each weld cross section. Comparisons with results taken from other equivalent laser systems and from laser welds made on 304L stainless steel using this same laser system have also been made. A summary of the general findings of this study are given below:

- In the weld cross sections studied here, a keyhole welding mode is observed at machine power settings of $500 \mathrm{~W}$ and greater for all of the travel speeds considered. At higher travel speeds, the resulting weld pool shapes are similar to those typically observed in electron beam welds. The resulting weld pool cross sections also exhibit a much higher reinforcement height than that observed in the laser welding of previous material systems.

- Little to no weld porosity is observed in any of the weld cross sections analyzed here. This lack of observed porosity is believed to result from the stabilization of the keyhole by the large manganese additions to the base metal.

- Increases in the laser power and decreases in travel speed result in increasing weld widths, depths, and melted areas of the weld cross sections for all travel speeds studies. A maximum weld depth of penetration of nearly $5.5 \mathrm{~mm}$ is obtained at the slowest travel speed and highest machine power setting.

- Weld aspect ratios on the order of 2.7 are obtained at the highest power settings and fastest travel speeds. Slower travel speeds at the maximum power input result in aspect ratios approaching values of 1.6 because of rapidly increasing weld widths. Direct comparison of the results from the power variation and travel speed variation studies can be made by using energy input per unit length (Power/Travel Speed) as a measure of the input power. These comparisons show that a maximum weld aspect 
UCRL-TR-222245

ratio is obtained at energy inputs of approximately $75 \mathrm{~J} / \mathrm{mm}$. At higher energy inputs, which are obtained in this study by slowing the travel speed, the aspect ratios decrease.

- Comparisons are made between the laser welds made on the LLNL laser system and an equivalent system at LANL on Nitronic 40 weld samples. The results show that the welds made using the LLNL system produce narrower and deeper welds with a higher melted area than those produced using the LANL system.

- The measurements made on Nitronic 40 laser welds are compared with those made on 304L laser welds using the LLNL laser system under equivalent welding conditions. Based on this comparison, the Nitronic 40 welds are narrower, deeper, and exhibit a higher aspect ratio than the 304L laser welds. On the other hand, the Nitronic 40 and 304L laser welds display nearly equivalent melted areas under similar welding conditions. When the two sets of weld pool measurements are examined as a function of energy input per unit length, the same trends are observed. 
UCRL-TR-222245

\section{Ti-6Al-4V LASER WELDS}

\subsection{Summary}

A series of autogenous partial penetration laser welds were made on Ti-6Al-4V samples using a Rofin Sinar DY-022 Diode-Pumped Continuous Wave (CW) Nd:YAG laser welder at Lawrence Livermore National Laboratory (LLNL). The goal of these experiments was to characterize weld geometries as a function of welding power, focus setting, and travel speed, for both $300 \mu \mathrm{m}$ and $400 \mu \mathrm{m}$ diameter fibers. The results show that high depth-to-width or aspect ratio welds were produced with weld penetrations up to $5 \mathrm{~mm}$ at a power level of $1830 \mathrm{~W}$ delivered to the part using a sharply focused beam and a travel speed of $8.5 \mathrm{~mm} / \mathrm{sec}$. Varying levels of porosity were observed in the welds made under the variety of conditions tested here, but no attempts were made to reduce the porosity in this study.

\subsection{Experimental Summary}

Laser welds were made using the LLNL CW Nd:YAG laser to look at different laser welding variables. In total, three series of autogenous bead-on-plate laser welds were made, each $50 \mathrm{~mm}$ in length, on $12.7 \mathrm{~mm}$ thick x $152.4 \mathrm{~mm}$ long $\mathrm{x} 76.2 \mathrm{~mm}$ wide Ti-6Al-4V samples. In the first series, welds were made over a range of output powers between $350 \mathrm{~W}$ and $1950 \mathrm{~W}$ at travel speeds of $12.7 \mathrm{~mm} / \mathrm{sec}$ and $16.9 \mathrm{~mm} / \mathrm{sec}$ at the sharp focus position. The second series of weld tests was used to examine the effect of changes in focus setting on the resulting weld depth and width at output powers ranging from $160 \mathrm{~W}$ to $1980 \mathrm{~W}$. A final series of weld tests were performed to compare the performance of the $300 \mu \mathrm{m}$ and $400 \mu \mathrm{m}$ diameter fibers at machine settings between $725 \mathrm{~W}$ and $1830 \mathrm{~W}$ and travel speeds between $20 \mathrm{in} / \mathrm{min}$ and $50 \mathrm{in} / \mathrm{min}$ at the sharp focus setting.

Upon the completion of these studies, the weld samples were cross sectioned and metallographically prepared to measure the fusion zone geometry. Etching of the samples was performed using Krolls etchant to reveal the microstructural details. Metallography was performed at LLNL and Anamet Testing Laboratory, Hayward, CA. The color photo micrographs were prepared by LLNL and the black and white photo micrographs were prepared by Anamet Testing Laboratory, Hayward, California. The depth of penetration and the width of the welds were measured using a Nikon Measure Scope Model 10 microscope at 20X magnification on a stage with digital readout. These series of tests were primarily to characterize the weld bead profiles at different power levels and travel speeds. Most prepared samples exhibited some degree of sub surface porosity. No surface porosity was noted on any of the weld samples.

The Ti-6Al-4V samples were taken from different material sources. In the first series of weld tests, samples were removed from a $146.1 \mathrm{~mm}$ diameter titanium bar stock along an orientation perpendicular to the extrusion direction. The titanium bar was manufactured to Specification MIL-T-9047G Condition A with the following chemical composition: Ti-Bal, Al$6.09 \%, \mathrm{~V}-4.02 \%, \mathrm{C}-0.010 \%, \mathrm{H}-0.0022 \%, \mathrm{Fe}-0.25 \%, \mathrm{~N}-0.0070 \%, \mathrm{O}-0.117 \%$. For the second and third series of weld tests, the samples are obtained from a Ti-6Al-4V plate, manufactured to the specifications listed in AMS 4905. The typical chemical composition for this material is as follows: Ti-Bal., Al-5.5\% to $6.75 \%, \mathrm{~V}-3.5 \%$ to $4.5 \%$, C-0.08\% max., H- $0.015 \%$ max., Fe- $0.25 \%$ max., N-0.05\% max., O- $0.2 \%$ max. 
UCRL-TR-222245

\subsection{Results}

\subsubsection{Effects of Power Variations}

In the first series of tests, welds were made using a range of power settings between 352 Wand $1950 \mathrm{~W}$ at travel speeds of $16.9 \mathrm{~mm} / \mathrm{sec}$ and $12.7 \mathrm{~mm} / \mathrm{sec}$ with the laser beam at sharp focus at the surface of the weld plate. As an overview, selected micrographs are included in the following section to provide a more general overview of the changes in weld cross section appearance with changes in power setting levels.

Figures 54(a-d) display cross sections of welds made at several power setting levels ranging from $352 \mathrm{~W}$ to $1400 \mathrm{~W}$. At the lowest power setting level (352 W) shown in Figure 54(a), the resulting weld pool cross section displays a shape indicative of conduction mode laser welding, with a shallow concave shaped penetration pattern. With increasing power, the weld pool cross section takes on a shape consistent with a keyhole mode of welding. The transition from the conduction to the keyhole mode appears to occur near the $450 \mathrm{~W}$ power setting level, since the cross section obtained at this power setting displays the characteristic shape of a keyhole weld. Further increases in the power setting result in deeper and wider welds and do not affect the mode of welding, which remains as a keyhole mode with increases in power. At these higher powers, though, porosity is observed in the weld cross sections.

Figures 55(a-d) display cross sections of welds made at power setting levels between $783 \mathrm{~W}$ and $1950 \mathrm{~W}$ and a travel speed of $12.7 \mathrm{~mm} / \mathrm{sec}$. In this case, the power setting levels are high enough that all of the welds display a shape consistent with keyhole mode laser welding. With this slower travel speed, though, it is apparent that the width of the lower portion of the weld, typically characterized as the keyhole width, are larger than those observed at a travel speed of $16.9 \mathrm{~mm} / \mathrm{sec}$, giving the weld a less pronounced keyhole shape. Several of the weld cross sections made at this travel speed also display porosity.

Measurements of the depth, width, and aspect ratio for each weld are listed in Table 18, and Figures 56(a) through 56(c) display plots comparing these measurements with the corresponding power settings. In general, the measured weld depths and widths increase with increasing power for both travel speeds. For the welds made at a travel speed of $16.9 \mathrm{~mm} / \mathrm{sec}$, a sharp increase in weld depth is observed at a power setting of $450 \mathrm{~W}$, corresponding to the transition from conduction mode to keyhole mode laser welding. With further increases in the power setting, both the weld depth and width continue to increase. Similar behavior is observed in the welds produced at a travel speed of $12.7 \mathrm{~mm} / \mathrm{sec}$. Because of the slower travel speed, though, the resulting weld widths and depths are higher than those observed at the same power settings at a travel speed of $16.9 \mathrm{~mm} / \mathrm{sec}$.

The aspect ratios of the welds, which are the depth/width ratios based on the measurements included in Table 18, are also calculated. Over the range of lower power settings at a travel speed of $16.9 \mathrm{~mm} / \mathrm{sec}$, it is evident that the aspect ratio of the weld cross sections increases with increasing power, with the pronounced increase occurring between settings of $352 \mathrm{~W}$ and $455 \mathrm{~W}$. The aspect ratio, though, does not exceed a value of 1.0 over this range of power settings for the welds made at both $16.9 \mathrm{~mm} / \mathrm{sec}$ and $12.7 \mathrm{~mm} / \mathrm{sec}$. An aspect ratio of this magnitude is an indication that the weld width and depth are nearly equal. 
UCRL-TR-222245

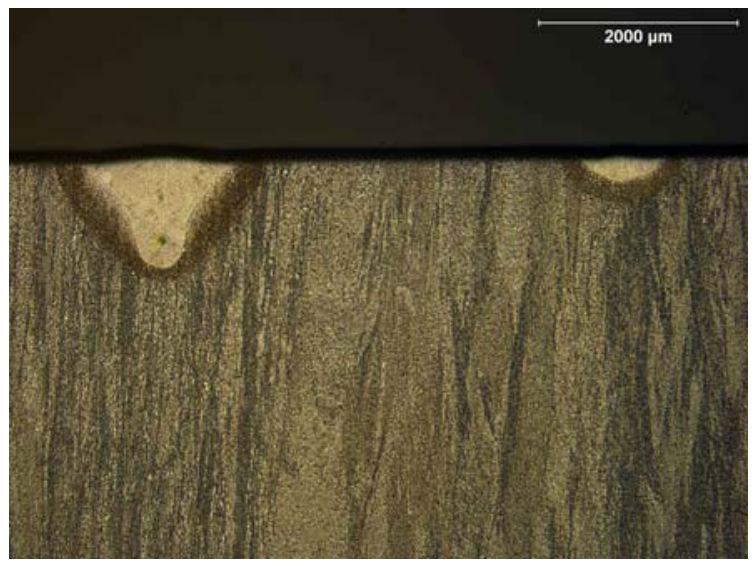

(a)

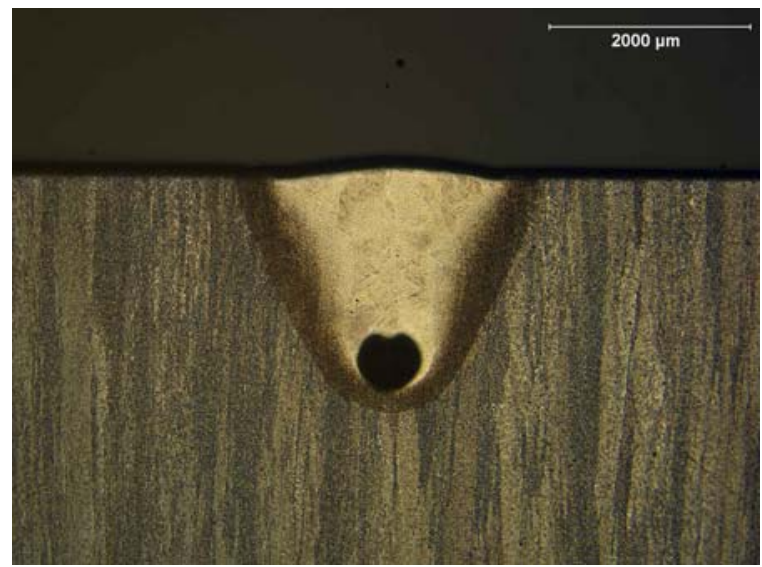

(c)

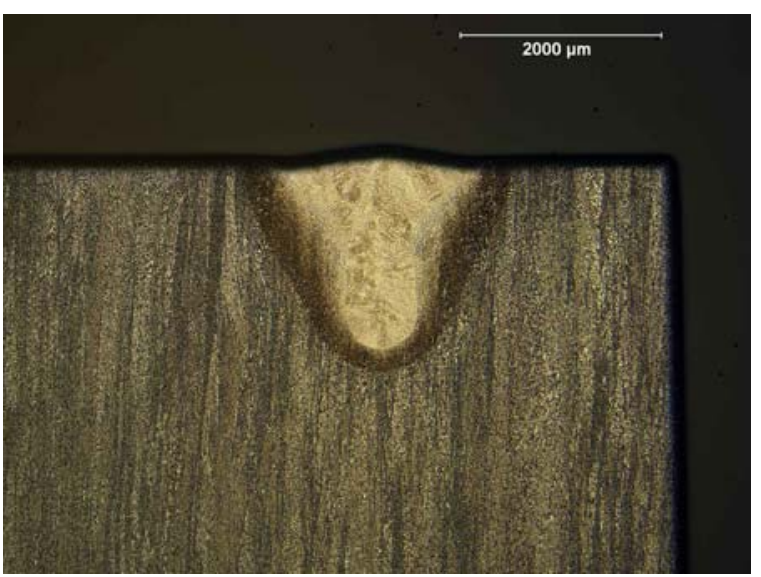

(b)

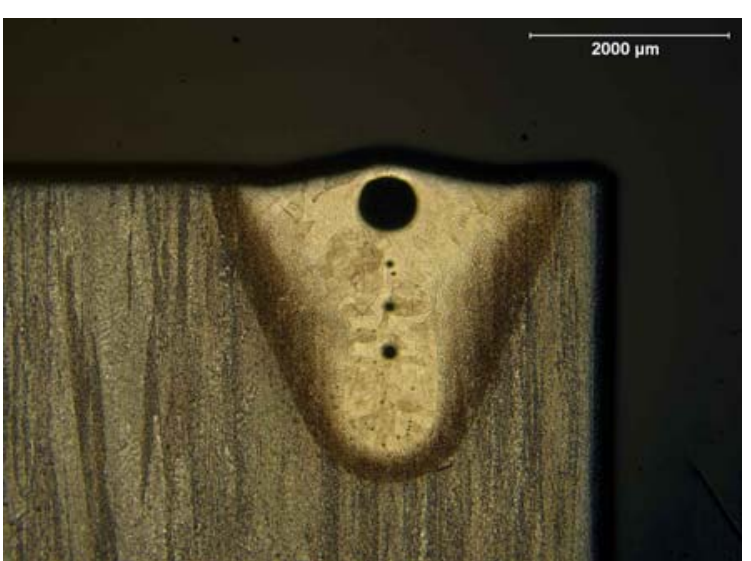

(d)

Figure 54(a-d). Micrographs showing the Ti-6Al-4V weld cross sections produced on the LLNL welder at power levels of (a) $450 \mathrm{~W}$ and $352 \mathrm{~W}$, (b) $720 \mathrm{~W}$, (c) $1100 \mathrm{~W}$, and (d) $1400 \mathrm{~W}$ and a travel speed of $16.9 \mathrm{~mm} / \mathrm{sec}$ at sharp focus. 
UCRL-TR-222245

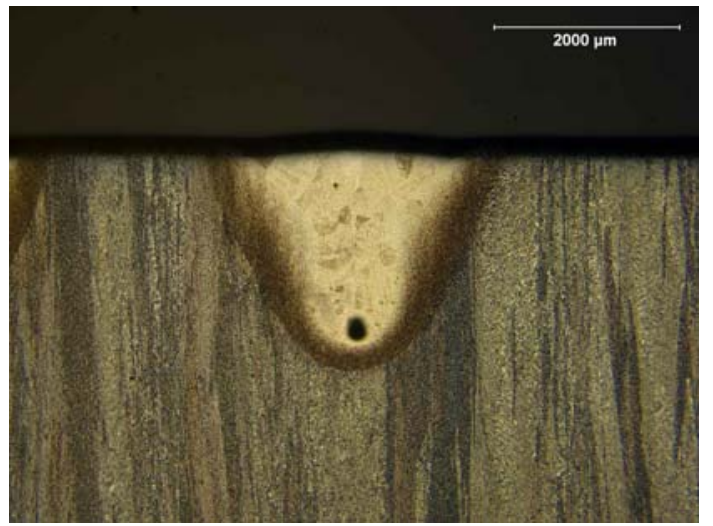

(a)

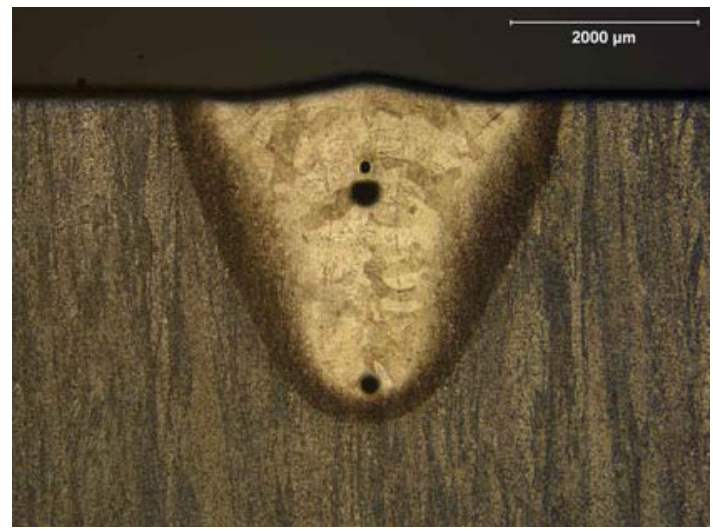

(c)

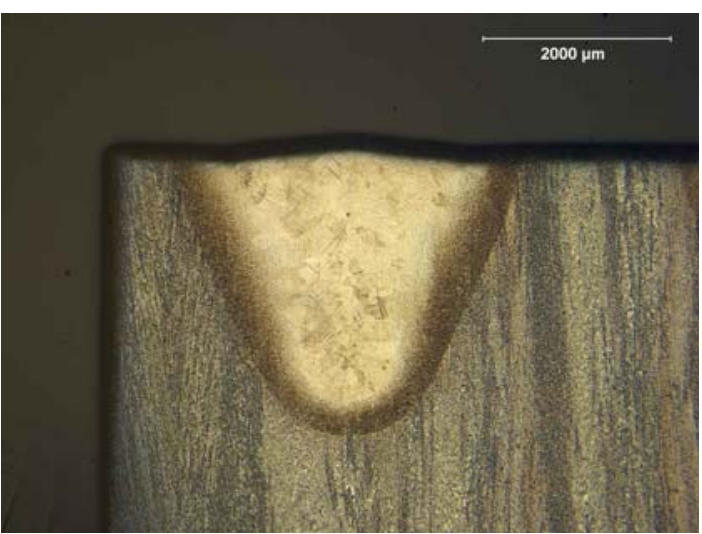

(b)

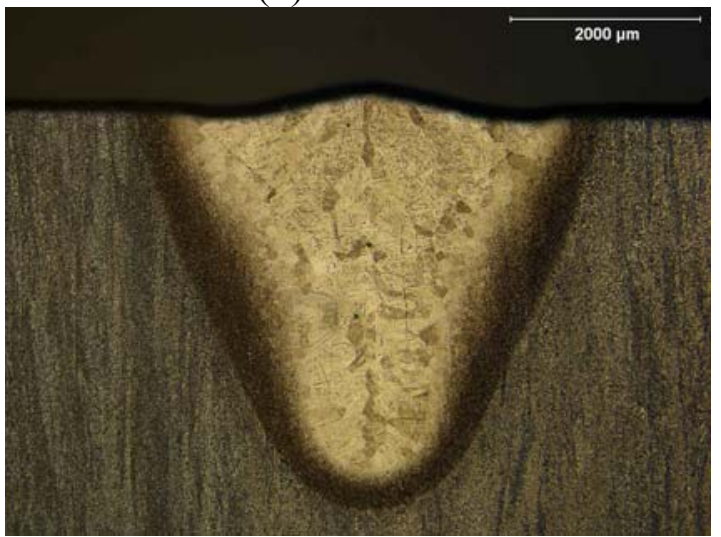

(d)

Figure 55(a-d). Micrographs showing the Ti-6Al-4V weld cross sections produced by the LLNL welder at power levels of (a) $783 \mathrm{~W}$, (b) $1055 \mathrm{~W}$, (c) $1400 \mathrm{~W}$, and (d) $1950 \mathrm{~W}$ and a travel speed of $12.7 \mathrm{~mm} / \mathrm{sec}$ at sharp focus. 
Table 18. Summary of depth, width, and aspect ratio measurements for Ti-6Al-4V welds made using the LLNL welder over a range of powers and travel speeds of $16.9 \mathrm{~mm} / \mathrm{sec}$ and 12.7 $\mathrm{mm} / \mathrm{sec}$.

\begin{tabular}{|c|c|c|c|c|c|c|}
\cline { 2 - 7 } \multicolumn{1}{c|}{} & \multicolumn{5}{c|}{$\mathbf{1 6 . 9} \mathbf{~ m m} / \mathbf{s e c}$} \\
\hline $\begin{array}{c}\text { Power Delivered to } \\
\text { part (Watts) }\end{array}$ & $\begin{array}{c}\text { Depth } \\
(\mathbf{m m})\end{array}$ & $\begin{array}{c}\text { Width } \\
\mathbf{( m m})\end{array}$ & $\begin{array}{c}\text { Aspect } \\
\text { Ratio }\end{array}$ & $\begin{array}{c}\text { Depth } \\
\text { (mm) }\end{array}$ & $\begin{array}{c}\text { Width } \\
\text { (mm) }\end{array}$ & $\begin{array}{c}\text { Aspect } \\
\text { Ratio }\end{array}$ \\
\hline 352 & 0.279 & 0.914 & 0.306 & & & \\
\hline 450 & 1.168 & 1.575 & 0.742 & & & \\
\hline 522 & 1.397 & 1.727 & 0.809 & & & \\
\hline 615 & 1.623 & 1.854 & 0.877 & & & \\
\hline 720 & 1.930 & 2.108 & 0.916 & & & \\
\hline 783 & 2.057 & 2.184 & 0.942 & 2.286 & 2.515 & 0.909 \\
\hline 875 & 2.210 & 2.337 & 0.946 & & & \\
\hline 980 & 2.464 & 2.464 & 1.000 & & & \\
\hline 1055 & 2.540 & 2.642 & 0.962 & 2.794 & 3.023 & 0.924 \\
\hline 1234 & 2.692 & 2.743 & 0.981 & & & \\
\hline 1400 & 3.023 & 2.896 & 1.044 & 3.353 & 3.531 & 0.950 \\
\hline 1950 & & & & 3.912 & 4.039 & 0.969 \\
\hline
\end{tabular}


UCRL-TR-222245
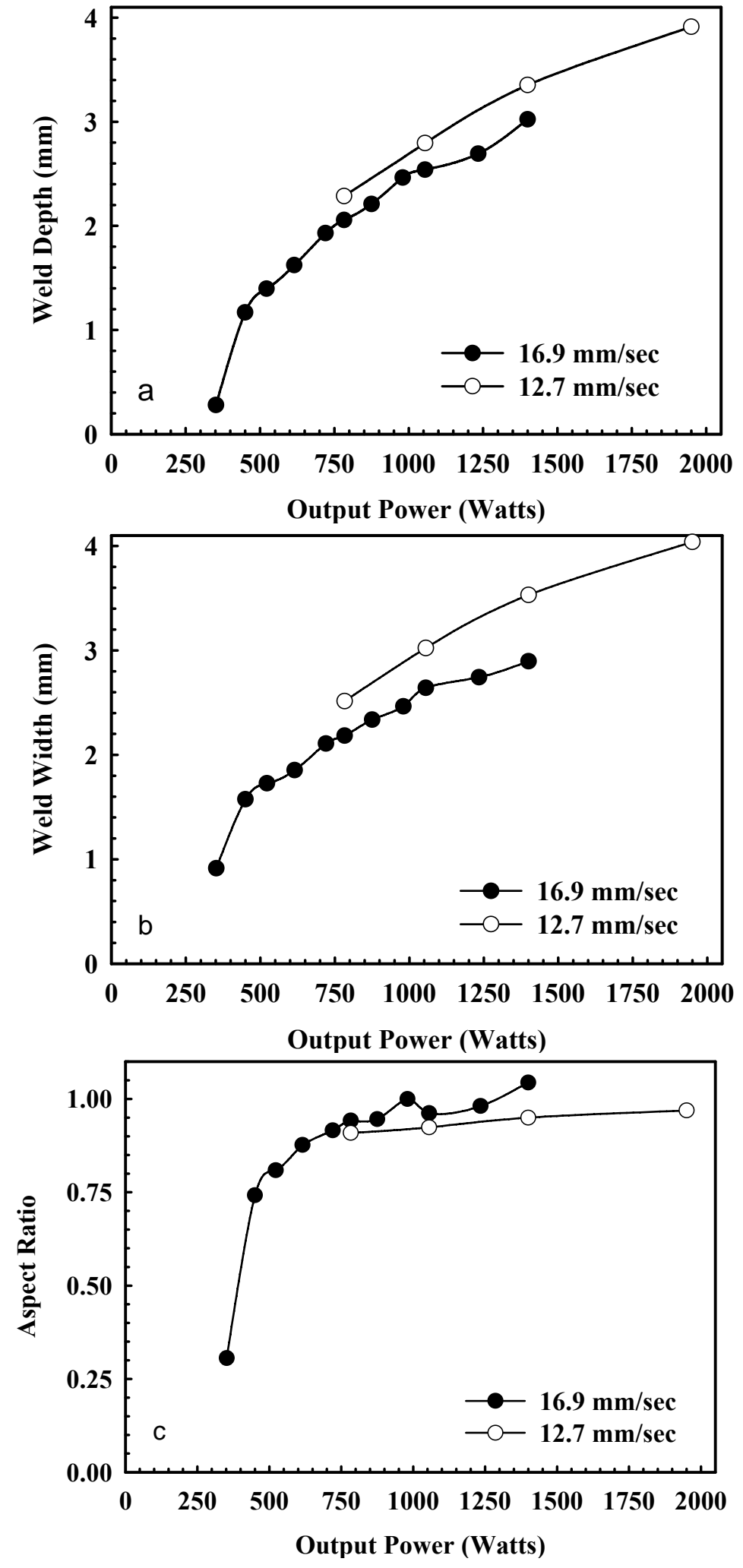

Figure 56(a-c). Plots comparing the measured (a) depth, (b) width, and (c) aspect ratios for Ti$6 \mathrm{Al}-4 \mathrm{~V}$ welds made on the LLNL welder across a range of output powers at travel speeds of 12.7 $\mathrm{mm} / \mathrm{sec}$ and $16.9 \mathrm{~mm} / \mathrm{sec}$. 


\subsubsection{Effects of changes in Focus Position}

While the welds discussed in the preceding sections were made at the sharp focus position, a second series of tests was performed to examine the effect of focus position on the resulting weld dimensions. The tests were performed at power setting levels between $160 \mathrm{~W}$ and $1950 \mathrm{~W}$ and a travel speed of $12.7 \mathrm{~mm} / \mathrm{sec}$. At each power level, focus position was changed from locations approximately $2.54 \mathrm{~mm}$ above the sharp focus position, as determined by the laser focus monitor, to locations which are $2.54 \mathrm{~mm}$ below the sharp position. As an overview, selected micrographs are included in the following section to provide a more general overview of the changes in weld cross section appearance with changes in focus position at selected power setting levels.

Changes in focus position can result in significant changes in the appearance of the weld pool cross section, especially at low powers. These changes can be significant enough to change the dominant welding mode from keyhole to conduction. An example of this transition with changes in focus position is shown in Figures 57(a) through 57(d) for a power setting of $500 \mathrm{~W}$. It is evident in these figures that the welding mode changes from conduction to keyhole at focus positions between $2.54 \mathrm{~mm}$ and $1.27 \mathrm{~mm}$ above the sharp focus position. A similar transition is observed at locations between $1.27 \mathrm{~mm}$ and $2.54 \mathrm{~mm}$ below the sharp focus position. This change in the welding mode is indicative of a decrease in the power density of the beam below the conduction/keyhole transition with increasing distances from the sharp focus position.

At higher power settings, the effects of changes in focus position become less pronounced. Figures 58(a) through 58(d) display weld cross sections made at select positions between 2.54 $\mathrm{mm}$ above and $2.54 \mathrm{~mm}$ below the location of sharp focus for a power setting of $1400 \mathrm{~W}$ and a travel speed of $12.7 \mathrm{~mm} / \mathrm{sec}$. All welds are in the keyhole mode, and there is a noticeable increase in the weld depth between the weld cross sections shown in Figures 58(a) and 58(b), corresponding to a change in focus position from $2.54 \mathrm{~mm}$ above to $1.27 \mathrm{~mm}$ above the sharp focus position. Less of a change is observed in Figures 58(c) and 58(d) at focus positions located below the sharp focus position.

The measured depth and width of the welds made across this range of focus positions at power settings between $160 \mathrm{~W}$ and $1950 \mathrm{~W}$ and a travel speed of $12.7 \mathrm{~mm} / \mathrm{sec}$ are listed in Table 19. Plots illustrating the changes in these weld dimensions with changes in focus are shown in Figures 59 and 60. At each power setting, the welds show deeper penetration at both the sharp focus position and at focus positions located below the surface of the part. This trend appears to hold when there is no change in the welding mode, i.e. all welds are either conduction or keyhole type welds. However, when there is a change in the welding mode, such as that observed at 450 $\mathrm{W}$, there is a different observed trend. In particular, the welds made at locations near the sharp focus position display similar weld depths, while those made at locations further above and below the sharp focus position, the weld depth markedly decreases. The effects of focus settings on the weld width are less pronounced, even at a power setting of $450 \mathrm{~W}$, where the variation in width is less severe than that observed in the plot of weld depths in Figure 59.

Based on these measurements, the aspect ratio was determined for each weld. Table 20 provides a summary of the aspect ratios measured on each weld across the range of power settings and focus positions surveyed here. Figure 61 provides a plot of the change in aspect ratios for each power setting across the range of focus settings. This figure basically shows that at power settings of $720 \mathrm{~W}$ and above, where the keyhole welding mode dominates, the aspect ratios tend to display similar values, approaching 1.0, across the range of focus settings. 


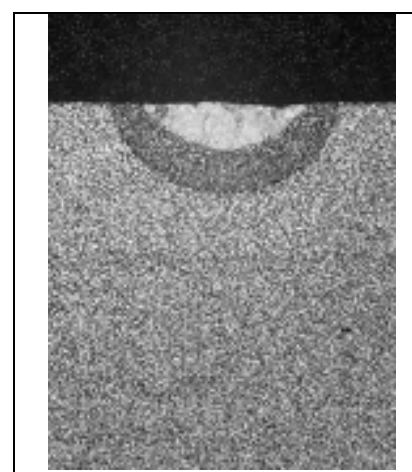

(a)

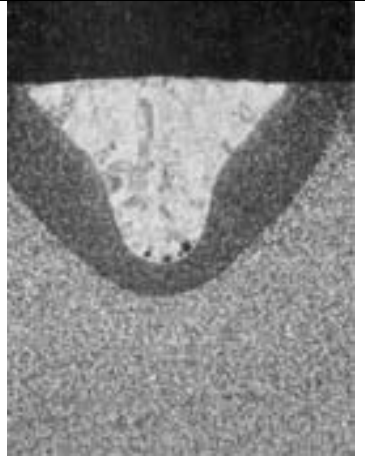

(b)

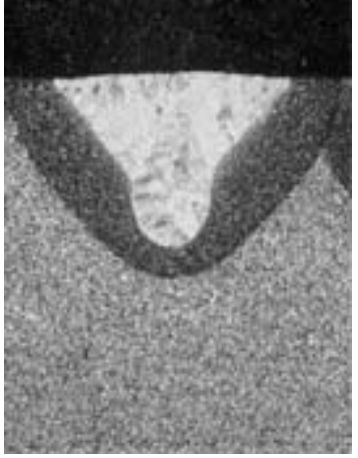

(c)

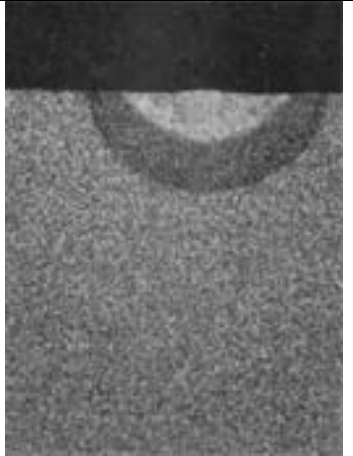

(d)

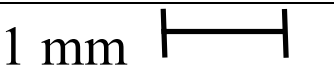

Figure 57(a-d). Cross sections of Ti-6Al-4V welds made on the LLNL welder at $500 \mathrm{~W}$, a travel speed of $12.7 \mathrm{~mm} / \mathrm{sec}$ and (a) $2.54 \mathrm{~mm}$ above, (b) $1.27 \mathrm{~mm}$ above, (c) $1.27 \mathrm{~mm}$ below, and 2.54 $\mathrm{mm}$ below the sharp focus position.

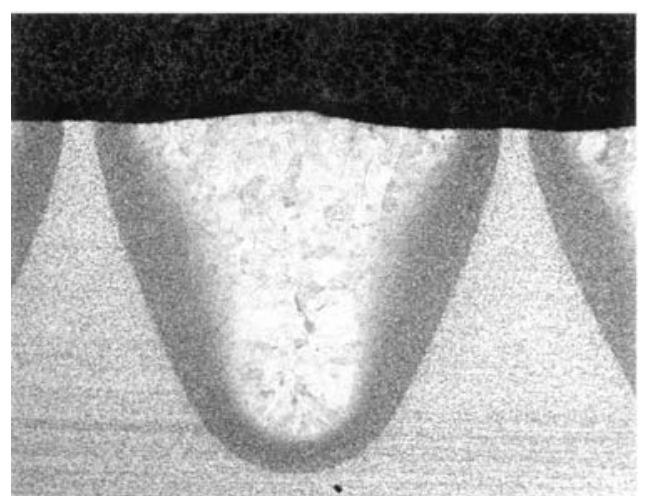

(a)

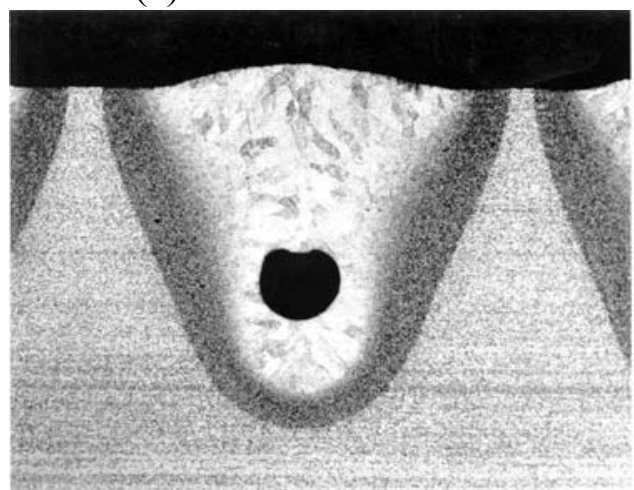

(c)

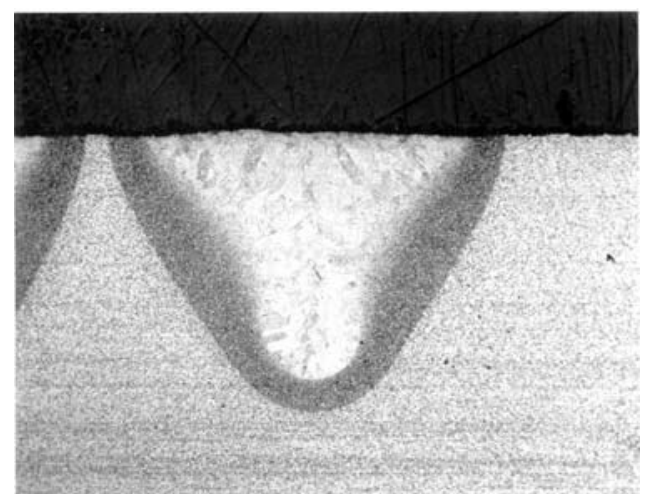

(b)

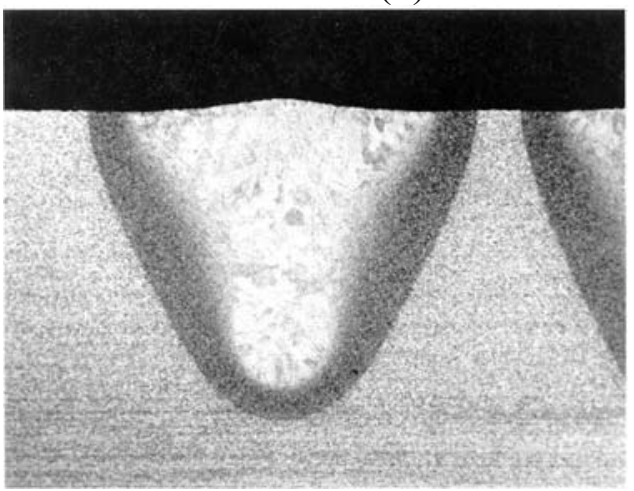

(d)

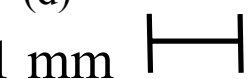

Figure 58(a-d). Cross sections of Ti-6Al-4V welds made on the LLNL welder at $1400 \mathrm{~W}$, a travel speed of $12.7 \mathrm{~mm} / \mathrm{sec}$ and (a) $2.54 \mathrm{~mm}$ above, (b) $1.27 \mathrm{~mm}$ above, (c) $1.27 \mathrm{~mm}$ below, and $2.54 \mathrm{~mm}$ below the sharp focus position. 
Table 19. Summary of depth and width measurements for Ti-6Al-4V welds made on the LLNL welder at different focus positions at a travel speed of $12.7 \mathrm{~mm} / \mathrm{sec}$.

\begin{tabular}{|c|c|c|c|c|c|c|c|c|c|c|c|c|c|c|c|c|}
\hline \multirow{3}{*}{$\begin{array}{c}\text { Focus } \\
\text { Position } \\
(\mathbf{m m})\end{array}$} & \multicolumn{16}{|c|}{ Power Delivered to Part } \\
\hline & \multicolumn{2}{|c|}{$160 \mathrm{~W}$} & \multicolumn{2}{|c|}{$450 \mathrm{~W}$} & \multicolumn{2}{|c|}{$720 \mathrm{~W}$} & \multicolumn{2}{|c|}{$980 \mathrm{~W}$} & \multicolumn{2}{|c|}{$1230 \mathrm{~W}$} & \multicolumn{2}{|c|}{$1480 \mathrm{~W}$} & \multicolumn{2}{|c|}{$1750 \mathrm{~W}$} & \multicolumn{2}{|c|}{$1950 \mathrm{~W}$} \\
\hline & $\begin{array}{c}\text { Depth } \\
(\mathrm{mm})\end{array}$ & $\begin{array}{c}\text { Width } \\
\text { (mm) }\end{array}$ & $\begin{array}{c}\text { Depth } \\
(\mathrm{mm})\end{array}$ & $\begin{array}{l}\text { Width } \\
\text { (mm) }\end{array}$ & $\begin{array}{c}\text { Depth } \\
(\mathrm{mm})\end{array}$ & $\begin{array}{l}\text { Width } \\
\text { (mm) }\end{array}$ & $\begin{array}{c}\text { Depth } \\
(\mathrm{mm})\end{array}$ & $\begin{array}{l}\text { Width } \\
\text { (mm) }\end{array}$ & $\begin{array}{c}\text { Depth } \\
(\mathrm{mm})\end{array}$ & $\begin{array}{c}\text { Width } \\
\text { (mm) }\end{array}$ & $\begin{array}{c}\text { Depth } \\
(\mathrm{mm})\end{array}$ & $\begin{array}{c}\text { Width } \\
\text { (mm) }\end{array}$ & $\begin{array}{l}\text { Depth } \\
\text { (mm) }\end{array}$ & $\begin{array}{l}\text { Width } \\
\text { (mm) }\end{array}$ & $\begin{array}{c}\text { Depth } \\
(\mathrm{mm})\end{array}$ & $\begin{array}{l}\text { Width } \\
\text { (mm) }\end{array}$ \\
\hline 2.54 & 0.152 & 0.686 & 0.381 & 1.245 & 1.778 & 2.311 & 2.464 & 3.073 & 2.845 & 3.785 & 3.251 & 4.166 & 3.632 & 4.140 & 3.861 & 4.420 \\
\hline 1.91 & 0.152 & 0.660 & 0.737 & 1.676 & 1.981 & 2.616 & 2.743 & 3.404 & 3.302 & 4.039 & 3.609 & 4.699 & 4.089 & 4.902 & 4.318 & 5.004 \\
\hline 1.27 & 0.178 & 0.686 & 1.321 & 2.007 & 2.184 & 2.642 & 2.845 & 3.378 & 3.404 & 4.013 & 3.861 & 4.470 & 4.343 & 4.674 & 4.521 & 4.978 \\
\hline 0.64 & 0.178 & 0.660 & 1.549 & 1.981 & 2.311 & 2.616 & 2.997 & 3.251 & 3.581 & 3.708 & 4.039 & 4.216 & 4.496 & 4.674 & 4.648 & 4.902 \\
\hline 0 & 0.178 & 0.660 & 1.575 & 2.083 & 2.388 & 2.489 & 2.921 & 3.226 & 3.607 & 3.708 & 4.191 & 4.140 & 4.674 & 4.420 & 4.699 & 4.699 \\
\hline-0.64 & 0.178 & 0.635 & 1.549 & 2.057 & 2.362 & 2.743 & 2.896 & 3.378 & 3.708 & 3.835 & 4.140 & 4.394 & 4.597 & 4.623 & 4.572 & 4.496 \\
\hline-1.27 & 0.178 & 0.686 & 1.321 & 1.956 & 2.210 & 2.667 & 2.718 & 3.277 & 3.429 & 3.759 & 4.089 & 4.140 & 4.674 & 4.623 & 4.648 & 4.293 \\
\hline-1.91 & 0.152 & 0.686 & 0.914 & 1.753 & 2.057 & 2.464 & 2.616 & 3.150 & 3.480 & 3.658 & 4.089 & 4.089 & 4.597 & 4.674 & 4.724 & 4.674 \\
\hline-2.54 & 0.152 & 0.711 & 0.381 & 1.321 & 1.829 & 2.413 & 2.388 & 3.073 & 3.251 & 3.581 & 3.912 & 4.013 & 4.318 & 4.445 & 4.674 & 4.724 \\
\hline
\end{tabular}




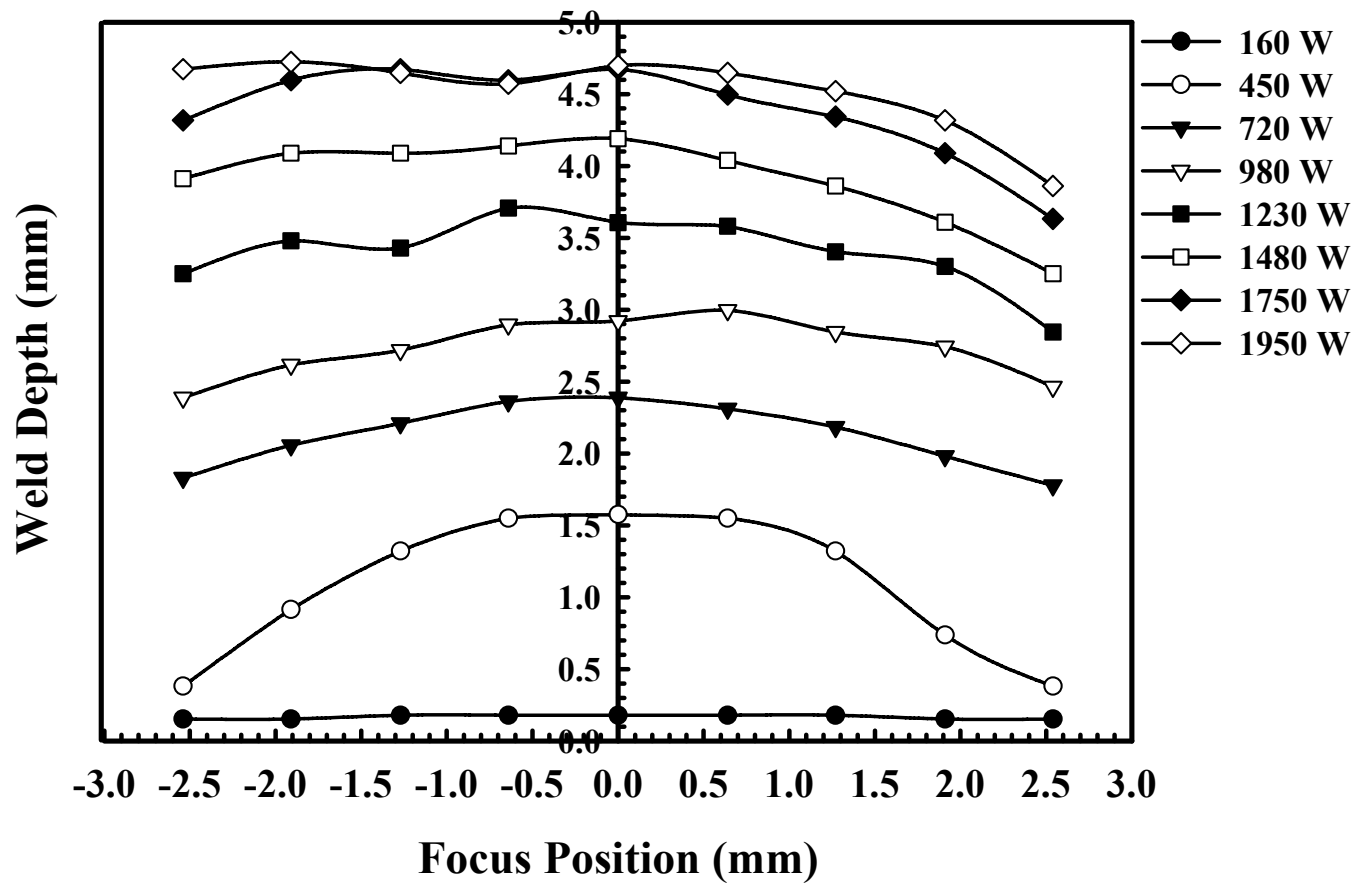

Figure 59. Plot comparing the measured Ti-6Al-4V weld depths as a function of focus position for beams produced on the LLNL welder over a range of input powers at a travel speed of 12.7 $\mathrm{mm} / \mathrm{sec}$.

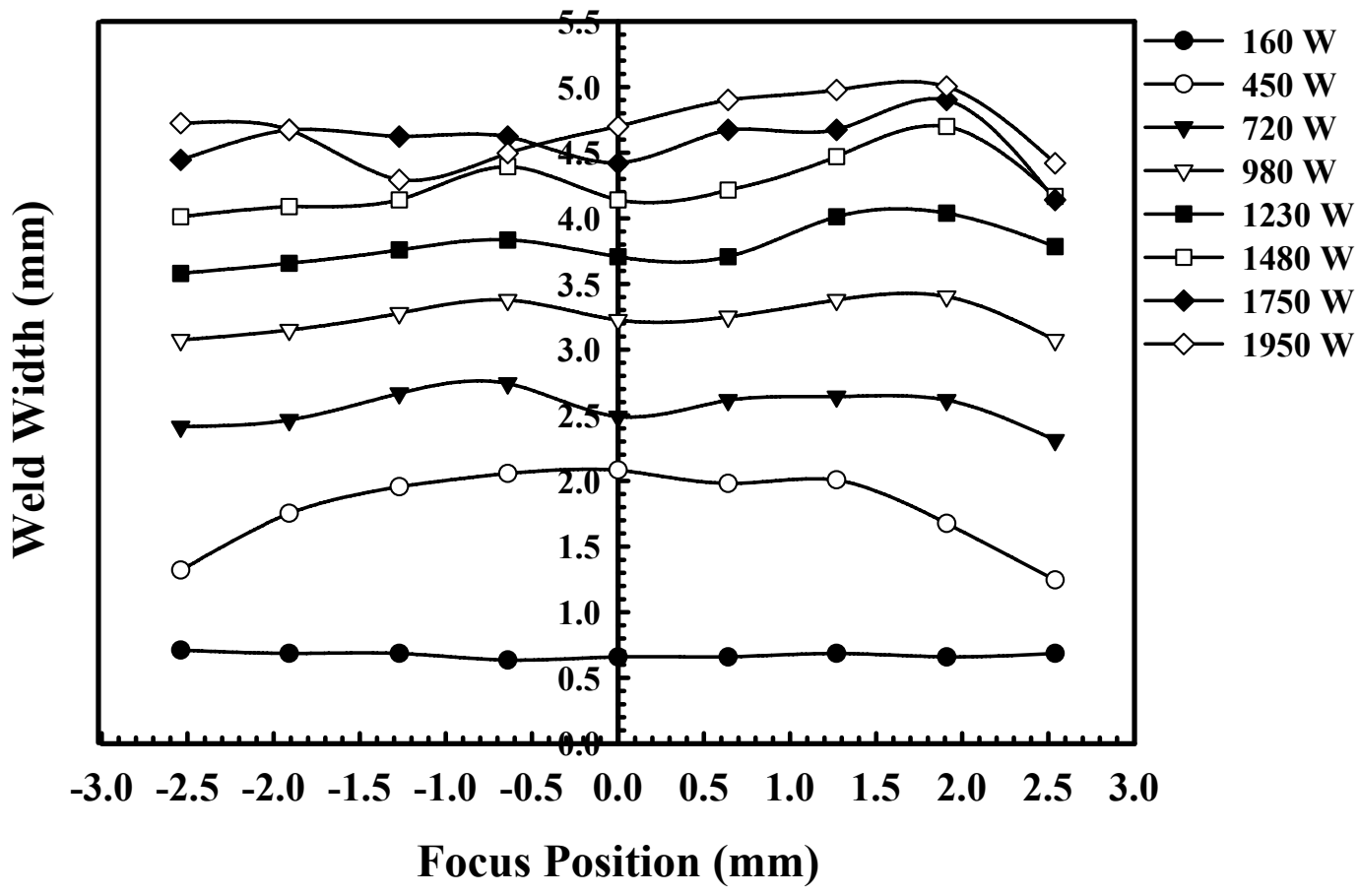

Figure 60. Plot comparing the measured Ti-6Al-4V weld widths as a function of focus position for beams produced on the LLNL welder over a range of output powers at a travel speed of 12.7 $\mathrm{mm} / \mathrm{sec}$. 
UCRL-TR-222245

Table 20. Summary of aspect ratio measurements for Ti-6Al-4V welds made at different focus positions on the LLNL welder at a travel speed of $12.7 \mathrm{~mm} / \mathrm{sec}$.

\begin{tabular}{|c|c|c|c|c|c|c|c|c|}
\hline $\begin{array}{c}\text { Focus } \\
\text { Position } \\
(\mathbf{m m})\end{array}$ & \multicolumn{10}{|c|}{ Aspect Ratio } \\
\cline { 2 - 9 } & $\mathbf{1 6 0 ~ W}$ & $\mathbf{4 5 0} \mathbf{~ W}$ & $\mathbf{7 2 0} \mathbf{~ W}$ & $\mathbf{9 8 0} \mathbf{~ W}$ & $\mathbf{1 2 3 0} \mathbf{~ W}$ & $\mathbf{1 4 8 0} \mathbf{~ W}$ & $\mathbf{1 7 5 0} \mathbf{~ W}$ & $\mathbf{1 9 5 0} \mathbf{~ W}$ \\
\hline 2.54 & 0.222 & 0.306 & 0.769 & 0.802 & 0.752 & 0.780 & 0.877 & 0.874 \\
\hline 1.91 & 0.230 & 0.440 & 0.757 & 0.806 & 0.818 & 0.768 & 0.834 & 0.863 \\
\hline 1.27 & 0.259 & 0.658 & 0.827 & 0.842 & 0.848 & 0.834 & 0.929 & 0.907 \\
\hline 0.64 & 0.270 & 0.782 & 0.883 & 0.922 & 0.966 & 0.958 & 0.962 & 0.948 \\
\hline 0 & 0.270 & 0.756 & 0.959 & 0.905 & 0.973 & 1.012 & 1.057 & 1.000 \\
\hline-0.64 & 0.280 & 0.753 & 0.861 & 0.857 & 0.967 & 0.942 & 0.994 & 1.017 \\
\hline-1.27 & 0.259 & 0.675 & 0.829 & 0.829 & 0.912 & 0.988 & 1.011 & 1.083 \\
\hline-1.91 & 0.222 & 0.521 & 0.835 & 0.830 & 0.951 & 1.000 & 0.984 & 1.011 \\
\hline-2.54 & 0.214 & 0.288 & 0.758 & 0.777 & 0.908 & 0.975 & 0.971 & 0.989 \\
\hline
\end{tabular}

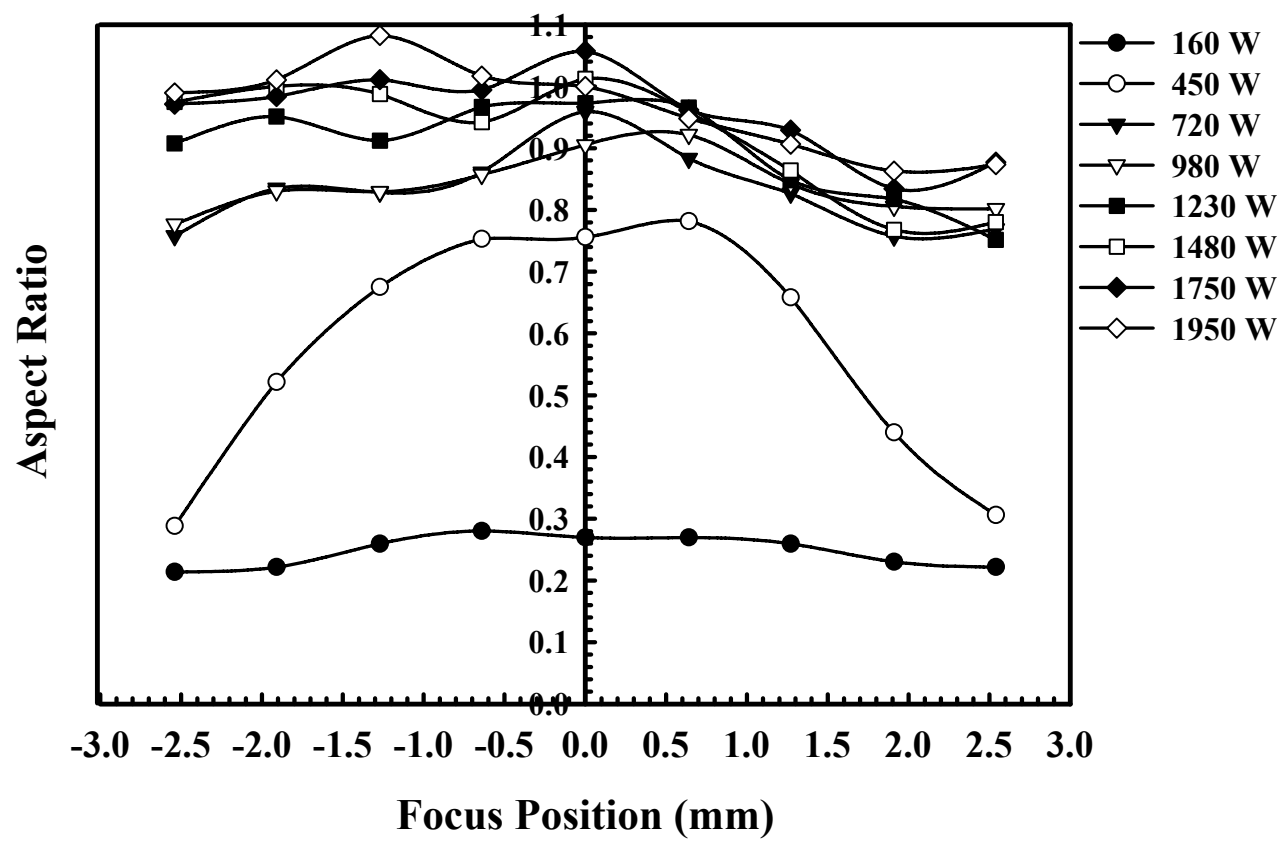

Figure 61. Plot comparing the Ti-6Al-4V weld aspect ratios as a function of focus position for beams produced on the LLNL welder over a range of output powers at a travel speed of 12.7 $\mathrm{mm} / \mathrm{sec}$. 
UCRL-TR-222245

\subsubsection{Comparison between $300 \mu \mathrm{m}$ and $400 \mu \mathrm{m}$ diameter fiber optic cables}

In addition to the other parameters which can be varied during welding, such as the focus position, travel speed, and power setting, there is also an option to change the diameter of the fiber optic cables which deliver laser from the power supply to the work station. The user has the option of using either a $300 \mu \mathrm{m}$ or a $400 \mu \mathrm{m}$ diameter fiber optic cable. Using the focus monitor, the differences in the characteristics of the beams produced with these different diameter fiber optic cables can be determined. A comparison between typical sharply focused beams produced using these two fibers shows a difference in the beam radius produced under the two conditions. When using the $300 \mu \mathrm{m}$ diameter fiber, the beam radius measured using the focus monitor is $145 \mu \mathrm{m}$, which corresponds to a beam diameter of $290 \mu \mathrm{m}$, nearly equivalent to the $300 \mu \mathrm{m}$ fiber diameter. In the case of the $400 \mu \mathrm{m}$ diameter fiber, the measured beam radius is $195 \mu \mathrm{m}$, corresponding to a beam diameter of $390 \mu \mathrm{m}$.

A series of welds were then made using both the $300 \mu \mathrm{m}$ diameter and the $400 \mu \mathrm{m}$ diameter fibers at sharp focus over a range of travel speeds between $8.5 \mathrm{~mm} / \mathrm{sec}$ and $21.2 \mathrm{~mm} / \mathrm{sec}$ and power levels between $725 \mathrm{~W}$ and $1830 \mathrm{~W}$. Figures 62(a-d) and 63(a-d) display typical weld cross sections produced using these two fibers at power settings of 800 Watts and 2000 Watts and travel speeds of $8.5 \mathrm{~mm} / \mathrm{sec}$ and $21.2 \mathrm{~mm} / \mathrm{sec}$. In general, the weld profiles produced with each fiber are similar.

Table 21 summarizes the measurements of depth, width, and aspect ratio for welds made using both the $300 \mu \mathrm{m}$ and $400 \mu \mathrm{m}$ diameter fiber optic cables. Figures 64 and 65 compare the weld depth, width, and aspect ratios for the welds made using both fiber optic cables at travel speeds of $8.5 \mathrm{~mm} / \mathrm{sec}$ and $21.2 \mathrm{~mm} / \mathrm{sec}$, respectively. In general, there is little difference between the measured weld depths and widths produced by both fibers, especially at the higher travel speed $(21.2 \mathrm{~mm} / \mathrm{sec})$, shown in Figure 65 . At the slower travel speed $(8.5 \mathrm{~mm} / \mathrm{sec})$ and lower powers, it appears that the welds produced by the $400 \mu \mathrm{m}$ diameter fiber are shallower and wider than those produced by the $300 \mu \mathrm{m}$ diameter fiber, resulting in a lower aspect ratio for the welds produced using the larger diameter fiber. At higher powers, though, the welds produced using this larger diameter fiber are narrower and slightly deeper. The aspect ratios of the welds produced by the $400 \mu \mathrm{m}$ diameter fiber at these higher powers thus exceed those produced by the $300 \mu \mathrm{m}$ diameter fiber at both travel speeds.

\subsection{General Findings and Conclusions}

A series of autogenous laser welds have been made on $12.7 \mathrm{~mm}$ thick Ti-6Al-4V samples using a Rofin Sinar DY-022 CW Nd:YAG laser welding machine. The effects of variations in power levels, travel speeds, beam delivery fiber diameter, and beam focus position on the resulting weld size and shape were documented. The performance of the laser system was analyzed using a newly installed focus diagnostic tool. This tool was used to verify the position of sharp focus for each of the welds made here and to measure the power density distribution of the beams. A summary of the general findings of this study is given below: 
UCRL-TR-222245

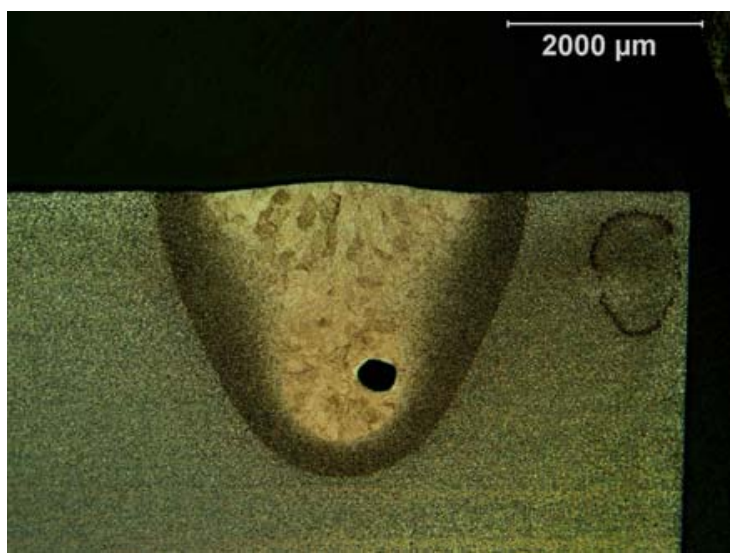

(a)

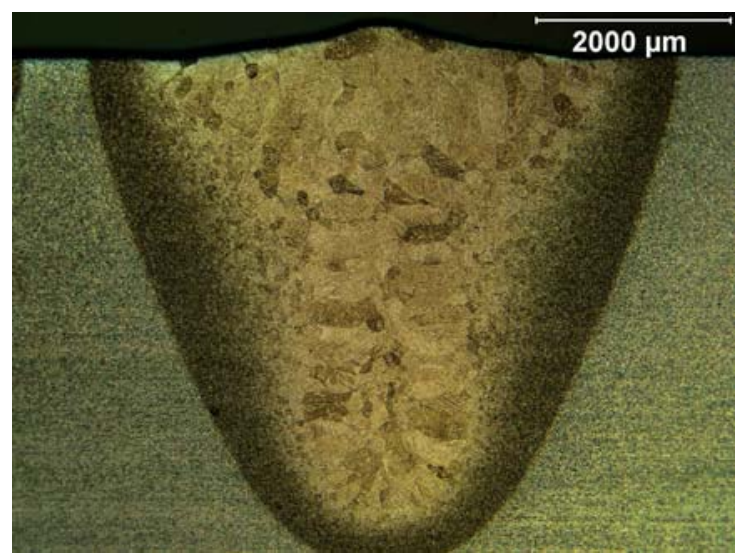

(c)

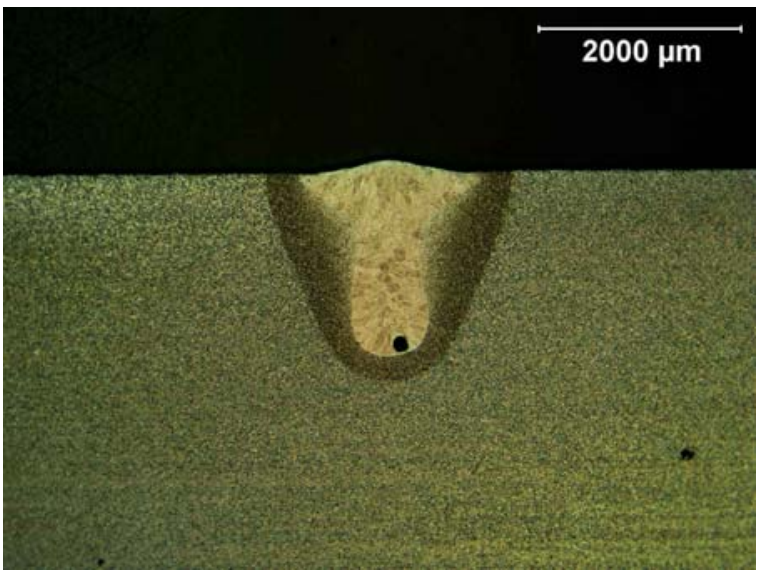

(b)

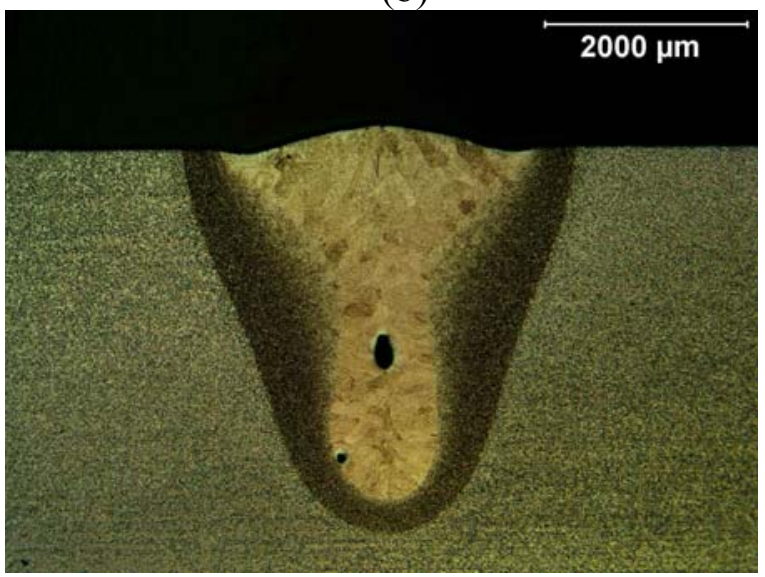

(d)

Figure 62(a-d). Comparison of the cross sections of Ti-6Al-4V welds made on the LLNL welder using the $300 \mu \mathrm{m}$ diameter fiber optic cable at travel speeds of (a\&b) $8.5 \mathrm{~mm} / \mathrm{sec}$ and (c\&d) 21.2 $\mathrm{mm} / \mathrm{sec}$ and powers of $800 \mathrm{~W}$ and $2000 \mathrm{~W}$, respectively. 
UCRL-TR-222245

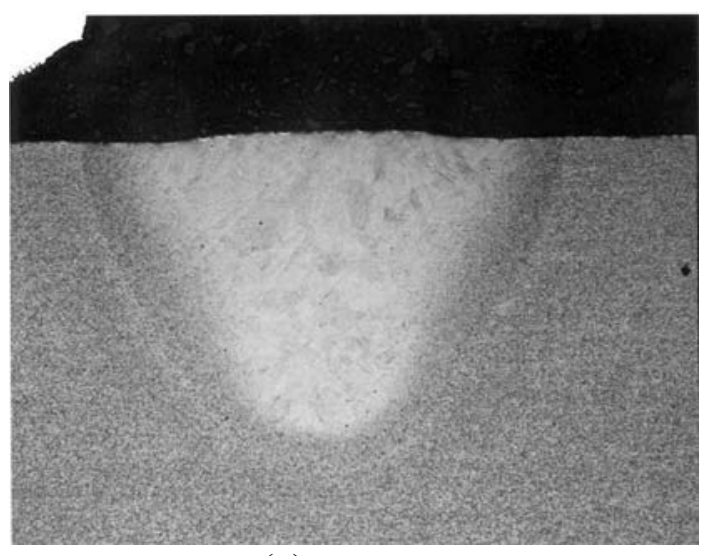

(a)

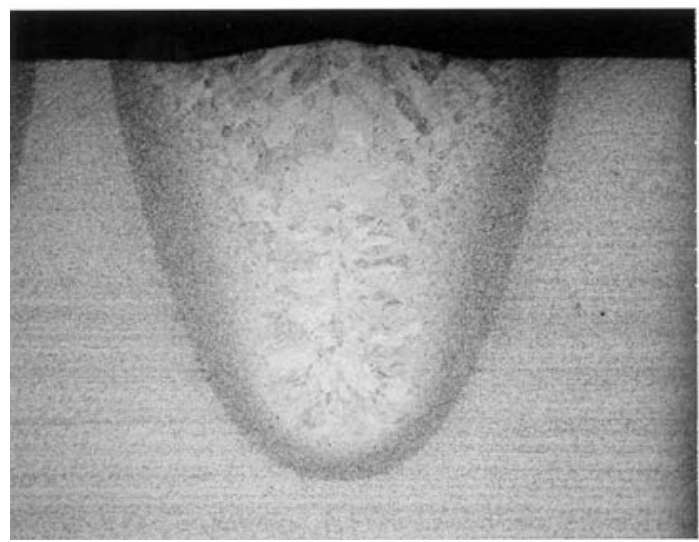

(c)

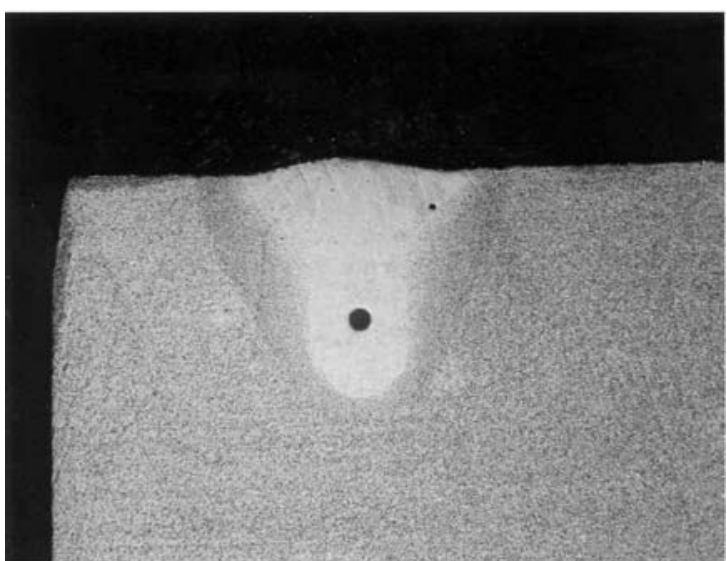

(b)

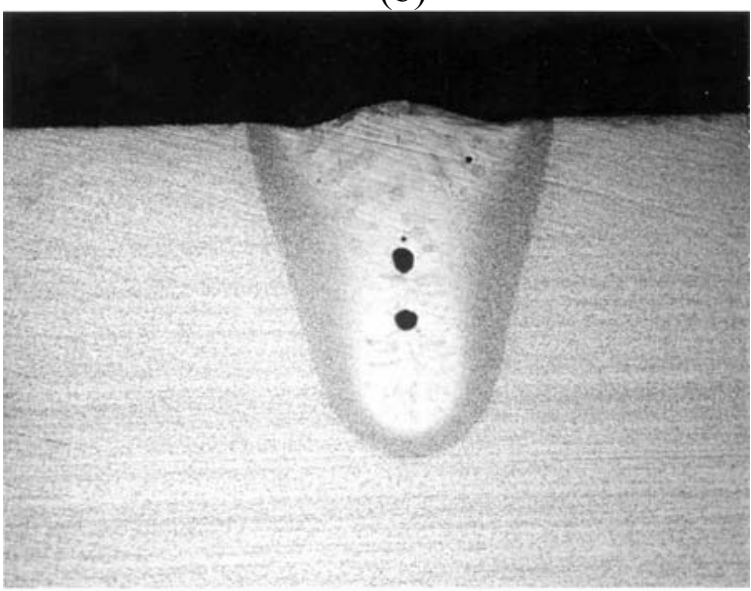

(d)

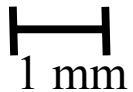

Figure 63(a-d). Comparison of the cross sections of Ti-6Al-4V welds made on the LLNL welder using the $400 \mu \mathrm{m}$ diameter fiber optic cable at travel speeds of (a\&b) $8.5 \mathrm{~mm} / \mathrm{sec}$ and (c\&d) 21.2 $\mathrm{mm} / \mathrm{sec}$ and powers of $800 \mathrm{~W}$ and $2000 \mathrm{~W}$, respectively. 
Table 21. Summary of depth, width, and aspect ratio measurements for Ti-6Al-4V welds made on the LLNL welder at varying power levels and travel speeds with $300 \mu \mathrm{m}$ and $400 \mu \mathrm{m}$ diameter fiber optic cables.

\begin{tabular}{|c|c|c|c|c|c|c|c|c|c|c|c|c|}
\hline \multirow[b]{3}{*}{$\begin{array}{l}\text { Output Power } \\
\text { (Watts) }\end{array}$} & \multicolumn{12}{|c|}{ Travel Speed } \\
\hline & \multicolumn{3}{|c|}{$8.5 \mathrm{~mm} / \mathrm{sec}$} & \multicolumn{3}{|c|}{$12.7 \mathrm{~mm} / \mathrm{sec}$} & \multicolumn{3}{|c|}{$16.9 \mathrm{~mm} / \mathrm{sec}$} & \multicolumn{3}{|c|}{$21.2 \mathrm{~mm} / \mathrm{sec}$} \\
\hline & $\begin{array}{l}\text { Depth } \\
(\mathbf{m m})\end{array}$ & $\begin{array}{l}\text { Width } \\
\text { (mm) }\end{array}$ & $\begin{array}{c}\text { Aspect } \\
\text { Ratio }\end{array}$ & $\begin{array}{l}\text { Depth } \\
(\mathbf{m m})\end{array}$ & $\begin{array}{l}\text { Width } \\
\text { (mm) }\end{array}$ & $\begin{array}{c}\text { Aspect } \\
\text { Ratio }\end{array}$ & $\begin{array}{l}\text { Depth } \\
\text { (mm) }\end{array}$ & $\begin{array}{l}\text { Width } \\
\text { (mm) }\end{array}$ & $\begin{array}{l}\text { Aspect } \\
\text { Ratio }\end{array}$ & $\begin{array}{l}\text { Depth } \\
(\mathbf{m m})\end{array}$ & $\begin{array}{l}\text { Width } \\
\text { (mm) }\end{array}$ & $\begin{array}{c}\text { Aspect } \\
\text { Ratio }\end{array}$ \\
\hline \multicolumn{13}{|c|}{$300 \mu \mathrm{m}$ Diameter Fiber } \\
\hline 725 & 2.642 & 2.718 & 0.97 & 2.337 & 2.261 & 1.03 & 2.032 & 2.032 & 1.00 & 1.778 & 1.778 & 1.00 \\
\hline 1090 & 3.581 & 3.734 & 0.96 & 2.972 & 2.946 & 1.01 & 2.819 & 2.591 & 1.09 & 2.616 & 2.362 & 1.11 \\
\hline 1470 & 4.242 & 4.242 & 1.00 & 3.734 & 3.404 & 1.10 & 3.353 & 3.048 & 1.10 & 3.124 & 2.718 & 1.15 \\
\hline 1830 & 5.029 & 4.902 & 1.03 & 4.318 & 4.013 & 1.08 & 4.013 & 3.429 & 1.17 & 3.785 & 3.150 & 1.20 \\
\hline \multicolumn{13}{|c|}{$400 \mu \mathrm{m}$ Diameter Fiber } \\
\hline 725 & 2.286 & 2.997 & 0.763 & 2.184 & 2.413 & 0.905 & 1.956 & 2.108 & 0.928 & 1.854 & 1.880 & 0.986 \\
\hline 1090 & 3.505 & 3.632 & 0.965 & 3.099 & 2.819 & 1.099 & 2.794 & 2.464 & 1.134 & 2.642 & 2.286 & 1.156 \\
\hline 1470 & 4.445 & 3.861 & 1.151 & 3.912 & 3.251 & 1.203 & 3.531 & 2.819 & 1.252 & 3.251 & 2.464 & 1.320 \\
\hline 1830 & 5.131 & 4.750 & 1.080 & 4.496 & 3.810 & 1.180 & 4.013 & 3.429 & 1.170 & 3.810 & 2.946 & 1.293 \\
\hline
\end{tabular}


UCRL-TR-222245
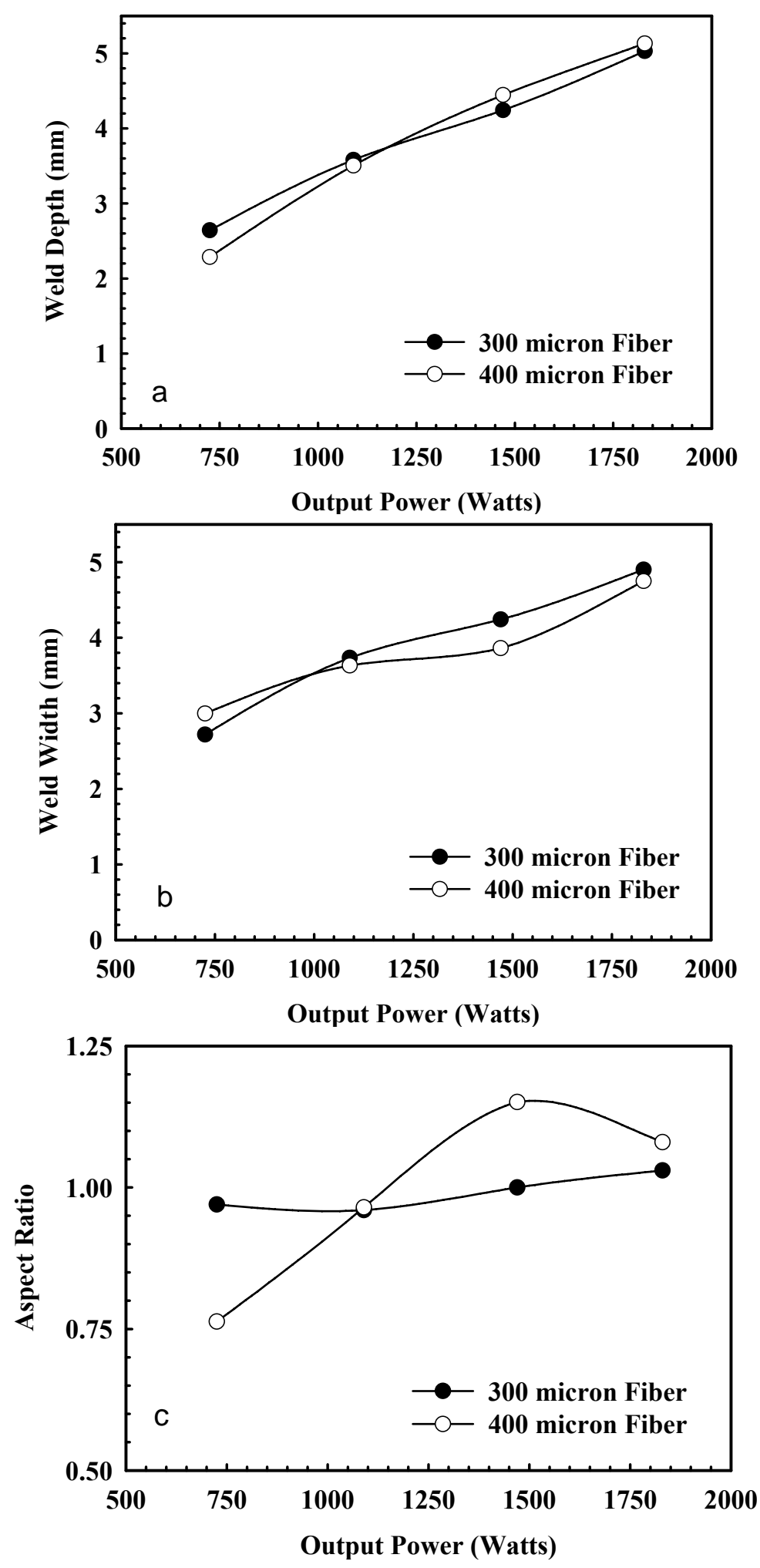

Figure 64(a-c). Plots comparing the measured (a) depth, (b) width, and (c) aspect ratios for Ti$6 \mathrm{Al}-4 \mathrm{~V}$ welds made on the LLNL welder across a range of output powers using the $300 \mu \mathrm{m}$ and $400 \mu \mathrm{m}$ diameter fiber optic cables at a travel speed of $8.5 \mathrm{~mm} / \mathrm{sec}$. 
UCRL-TR-222245
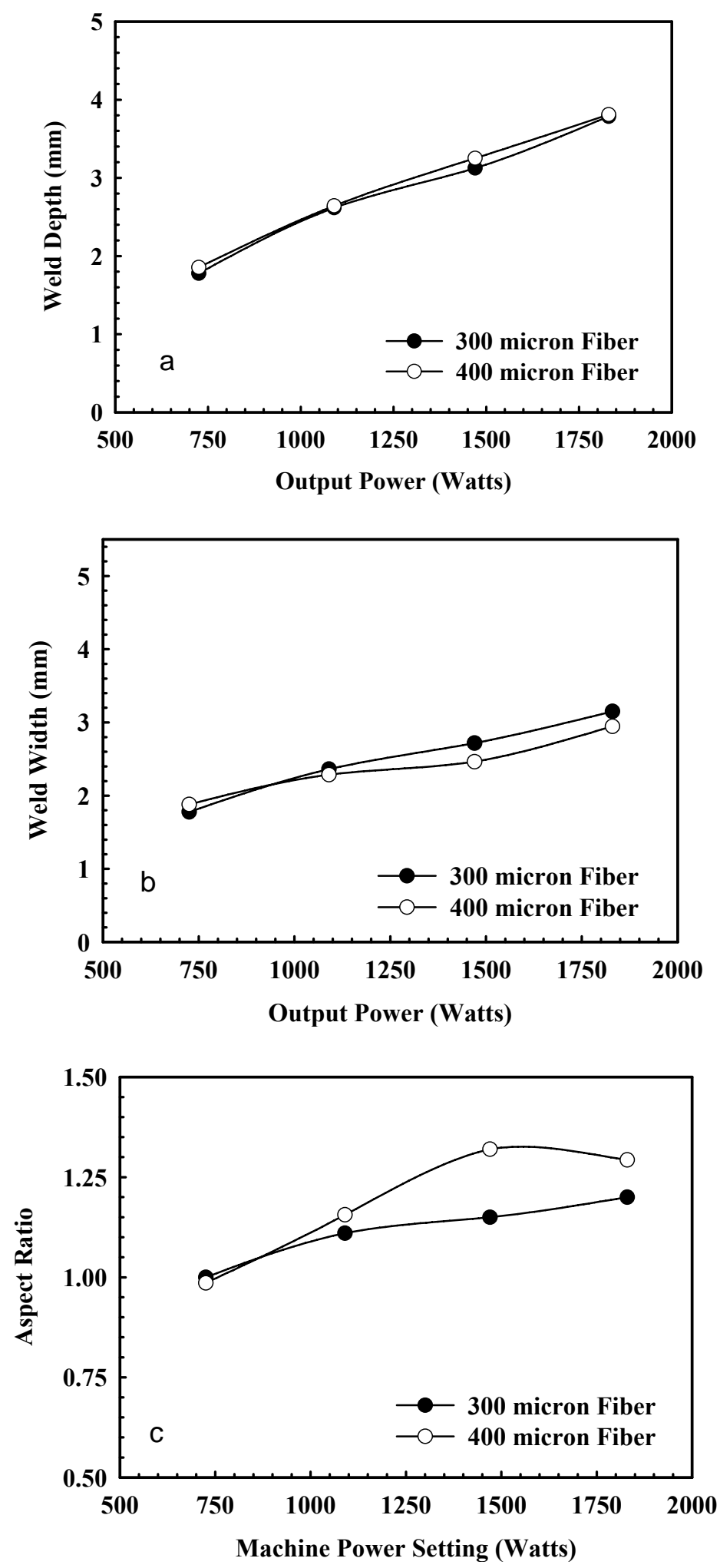

Figure 65(a-c). Plots comparing the measured (a) depth, (b) width, and (c) aspect ratios for Ti$6 \mathrm{Al}-4 \mathrm{~V}$ welds made on the LLNL welder across a range of output powers using the $300 \mu \mathrm{m}$ and $400 \mu \mathrm{m}$ diameter fiber optic cables at a travel speed of $21.2 \mathrm{~mm} / \mathrm{sec}$. 
- The maximum weld penetration achieved in Ti-6Al-4V was $5.1 \mathrm{~mm}$ at a power level of $1830 \mathrm{~W}$ delivered to the part and a travel speed of $8.5 \mathrm{~mm} / \mathrm{sec}$ using the $400 \mu \mathrm{m}$ diameter fiber optic. Aspect ratios of the resulting welds were on the order of 1.0 when welding in the keyhole mode, which occurred for most welds with powers in excess of $500 \mathrm{~W}$. Porosity was present in many samples on welds at both low and high powers with varying travel speeds, however, no attempts were made to reduce porosity in this study.

- Using the power meter, the laser power delivered to the part was measured as a function of machine setting. The power losses in the system were determined to be $10.65 \%$ on average with a standard deviation of $1.19 \%$. The $300 \mu \mathrm{m}$ and $400 \mu \mathrm{m}$ fibers showed essentially the same losses.

- Using the focus monitor, it was found that the sharp focus position moved closer to the laser optics, by as much as $2.7 \mathrm{~mm}$, as beam power increased. With this dramatic of a change, it is important to use the focus monitor to establish focus to set the optical focus before each series of welds, at the power that will be used. Changing the power will require reestablishing the focus position.

- The beam diameters and power densities of $300 \mu \mathrm{m}$ diameter and $400 \mu \mathrm{m}$ diameter fibers were measured using the diagnostic as a function of laser power. The focus diagnostic confirmed that sharp focused beams were approximately the same diameter as the fibers for the optical system used in this study. Average power densities were shown to be less for the $400 \mu \mathrm{m}$ fiber as expected, but both fibers had similar peak power densities. The peak power density increased with laser power, achieving nearly $40 \mathrm{~kW} / \mathrm{mm}^{2}$ at the 2.2 $\mathrm{kW}$ laser machine setting. These power densities are similar to that produced by electron beams.

- Changes in the focus position of $\pm 1.2 \mathrm{~mm}$ did not significantly change the weld size and shape when welding in the keyhole mode for the optical system used in this study (160 $\mathrm{mm}$ lens, $160 \mathrm{~mm}$ collimator). However, at powers below $500 \mathrm{~W}$, close to the conduction to keyhole transition, $\mathrm{a} \pm 1 \mathrm{~mm}$ change in focus can have a significant effect on the weld size and shape.

- Welds produced by the $300 \mu \mathrm{m}$ diameter and $400 \mu \mathrm{m}$ diameter fibers were compared. The results showed that slightly deeper and narrower welds were made using the $300 \mu \mathrm{m}$ fiber at low powers, but that trend changes at higher powers where the $400 \mu \mathrm{m}$ diameter fiber displayed slightly deeper and narrower welds. The transition in behavior occurs at approximately $1000 \mathrm{~W}$. 
UCRL-TR-222245

\section{FUTURE WORK}

Further work is required in order to improve the quality of the laser welds made using the LLNL laser welding system. In particular, future work will be directed at developing weld parameters, including power input, travel speed, and focus condition, for joining components of varying thicknesses and joint geometries. This future work will involve all of the materials systems described above and concentrate primarily on removing the unwanted porosity from these deep penetration keyhole welds.

More focused work will also be pursued in an attempt to better understand the mechanisms responsible for the lack of porosity in the Nitronic 40 laser welds. Porosity is typically observed in high power and deep penetration continuous wave laser welds and has been linked to the collapse of the unstable keyhole during welding. The complexity involved in the dynamic behavior and stability of the keyhole requires a thorough approach to characterizing the laser welding parameters responsible for the formation of porosity in deep penetration welds.

These future efforts will concentrate first on understanding the stability of the laser plume, which exists above the weld pool surface during laser welding and consists of both ionized shielding gas and evaporated metal from the weld pool. High-speed photography may aid in understanding laser/plasma interactions and their effects on keyhole stability. Therefore, an examination of the stability of the laser plume using high-speed cameras and thermal imaging will be performed in order to monitor the laser plume for instabilities and to attempt to correlate these instabilities with porosity formation in the weld pool. Using these tools, a study of the Nitronic 40 laser welds can be undertaken using this material as a model system for better understanding the mechanisms governing keyhole stability.

The interaction between the laser beam, shielding gas, and metal surface, all of which act in concert to form the laser plume, will also be studied. One area requiring further study involves the absorption of the laser beam by the plasma phase in the laser plume, thus decreasing the laser energy available to weld the material. It therefore becomes necessary to attempt to either remove this laser plume from above the weld pool or to decrease its size. There are several areas that contribute to the size of the laser plume that will receive attention:

- The first of these areas involves the effects of shielding gas choices and enhanced plume extraction techniques. This work will involve primarily efforts to remove as much of the plasma as possible from above the melt surface. Variations in the shielding gas, primarily investigating the use of helium, will be attempted, as will changes in the direction, flow rate, and nozzle geometry of the shielding gas.

- Effects of changes in the laser focus condition will also be examined using advanced laser focus diagnostics. The current results show only the effects of the laser focus on the surface of the sample. Changes in the focus position with respect to the sample surface, either below or above, may have a positive or negative impact on the presence of weld porosity.

- Finally, changes in the offset angle in the laser with respect to the sample surface will be investigated. Currently, the laser head is positioned in a direction normal to the sample surface. Changes in this orientation may also positively or negatively impact the condition of the laser plume and the resulting presence or absence of porosity in the weld pool. 